\title{
Educational choice and labour market information
}

Citation for published version (APA):

Borghans, A. H. (1993). Educational choice and labour market information. [Doctoral Thesis, Maastricht University]. ROA. https://doi.org/10.26481/dis.19930917ab

Document status and date:

Published: 01/01/1993

DOI:

10.26481/dis.19930917ab

Document Version:

Publisher's PDF, also known as Version of record

\section{Please check the document version of this publication:}

- A submitted manuscript is the version of the article upon submission and before peer-review. There can be important differences between the submitted version and the official published version of record.

People interested in the research are advised to contact the author for the final version of the publication, or visit the DOI to the publisher's website.

- The final author version and the galley proof are versions of the publication after peer review.

- The final published version features the final layout of the paper including the volume, issue and page numbers.

Link to publication

\footnotetext{
General rights rights.

- You may freely distribute the URL identifying the publication in the public portal. please follow below link for the End User Agreement:

www.umlib.nl/taverne-license

Take down policy

If you believe that this document breaches copyright please contact us at:

repository@maastrichtuniversity.nl

providing details and we will investigate your claim.
}

Copyright and moral rights for the publications made accessible in the public portal are retained by the authors and/or other copyright owners and it is a condition of accessing publications that users recognise and abide by the legal requirements associated with these

- Users may download and print one copy of any publication from the public portal for the purpose of private study or research.

- You may not further distribute the material or use it for any profit-making activity or commercial gain

If the publication is distributed under the terms of Article $25 \mathrm{fa}$ of the Dutch Copyright Act, indicated by the "Taverne" license above, 
Educational Choice and Labour Market Information 
Educational Choice and Labour Market Information 


\title{
Educational Choice and Labour Market Information
}

\author{
PROEFSCHRIFT
}

ter verkrijging van de graad van doctor aan de Rijksuniversiteit Limburg te Mastricht, op gezag van de Rector Magnificus, Prof.mr. M.J. Cohen, volgens het besluit van het College van Dekanen, in het openbaar te verdedigen op vrijdag 17 september 1993 om 16.00 uur

door

Alexander Hubertus Borghans 
Promotores: $\quad$ Prof.dr. J.A.M. Heijke

Prof.dr. F.C. Palm

Beoordelingscommissie: Prof.dr. J.A.H. Maks (voorzitter)

Prof.dr. J. Hartog (Universiteit van Amsterdam)

Dr. A. de Grip

CIP-GEGEVENS KONINKLIJKE BIBLIOTHEEK, DEN HAAG

Borghans, Lex

Educational choice and labour market information /

Lex Borghans ; [ill.: José Borghans]. - Maastricht :

Researchcentrum voor Onderwijs en Arbeidsmarkt. - III.

Proefschrift Maastricht. - Met lit. opg., reg.

ISBN 90-5321-106-3 geb.

Trefw.: onderwijs en arbeidsmarkt ; Nederland. 
CRITO I would.

SOCRATES And what of the monarch's art? In ruling over all that comes under its rule, what does it produce? Perhaps you are not quite ready with the answer.

CRITO I am not indeed, Socrates.

SOCRATES Nor were we, Crito; yet so much you know, that if this is really the one we are seeking, it must be beneficial.

CRITO Certainly.

SOCRATES Then surely it must purvey something good?

CRITO Necessarily, Socrates.

SOCRATES And you know we agreed with each other, Clenias and 1, that nothing can be good but some sort of knowledge.

Crito Yes, so you told me.

SOCRATES And it was found that all affects in general that you may ascribe to statesmanship - and a great many of them there must be, presumably, if the citizens are to be made wealthy and free and immune from fraction - all these things were neither bad nor good, while this art must make us wise and impart knowledge, if it really was to be the one which benefited us and made us happy.

CRITO True: so at all events you agreed then, by your account of the discussion.

Plato, Euhydemus (292 A-C). In: Plato in Twelve Volumes II, translated by W.R.M. Lamb, Cambridge (Mass.), 1977. 
On submitting this thesis I would like to thank the following people for their contributions. First of all, I thank my promotors professor Hans Heijke and professor Franz Palm. Hans Heijke supervised the project by discussing the results intensively with me and by creating a stimulating environment. In the final stage, Franz Palm made me dot the i's and cross the t's with his critical remarks. Willy Spanjers, Geert Woltjer, Andries de Grip, and Paul Ghijsen provided useful comments. Moniek Mols edited the text and Jose Borghans assisted in drawing the graphs and printing the manuscript. 


\section{CONTENTS}

1 INTRODUCTION

1.1 Plan of the Study

1.2 Conventions

\section{MISMATCH}

2 MISMATCH AND EQUILIBRIUM

3 THE BASIC LABOUR MARKET MODEL

3.1 The Market

3.2 Enrolment 22

$\begin{array}{ll}3.3 & \text { Equilibrium and Regret } \\ & 25\end{array}$

4 EVIDENCE ON MISMATCH 29

4.1 The Problem of Choosing and Regret 30

4.2 The Role of the Labour Market in the Educational Choice 33

4.3 Compartmentalisation of the Labour Market 36

4.4 Fluctuations on the Labour Market 39

4.5 Conclusions 42

5 THE PROVISION OF INFORMATION AS AN ECONOMIC POLICY INSTRUMENT

5.1 Tinbergen's Economic Policy 45

5.2 Lucas's Critique 47

5.3 The Neo-Liberal View on Economic Policy 48

5.4 Conclusions 51

\section{INFORMATION}

6 EXPECTATIONS IN THE HISTORY OF ECONOMICS

6.1 The Cobweb Model 57

6.2 Critique on the Cobweb Theory 64

6.3 Direct Measurement of Expectations 66

6.4 Rational expectations 67

6.5 Expectations in Educational Choice 73

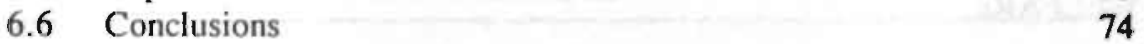

7 A STOCHASTIC CHARACTER OF PREDICTION ERRORS 77

7.1 The Prediction Error $\quad 78$

7.2 States of the World $\quad 80$

$\begin{array}{lll}7.3 & \text { Errors in Forecasts } & 86\end{array}$

7.4 Information versus Interpretation Errors 91

$\begin{array}{ll}7.5 \text { Conclusions } & 96\end{array}$

8 COBWEB VERSUS RATIONAL EXPECTATIONS:

THE JUNIOR SECONDARY TECHNICAL EDUCATION 99

8.1 An Empirical Specification 99

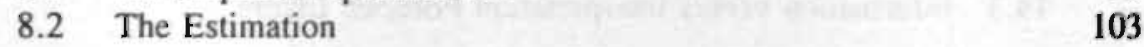


8.4 Implications $\quad 112$

8.5 Conclusions 115

9 VARIABILITY AND PREDICTABILITY

9.1 Lucas's Critique

9.2 Rational Expectations

9.3 The Cobweb Theorem: Interpretation I 12!

9.4 The Cobweb Theorem: Interpretation 2 123

9.5 Econometric Implications 125

9.6 Expectations Manipulating Policies 128

9.7 The Provision of Public Information 132

$\begin{array}{lll}9.8 \text { Conclusions } & 135\end{array}$

10 THE UNDERESTIMATION OF CHANGE 137

10.1 The US Lawyers 138

$\begin{array}{ll}10.2 & \text { Rational Expectations } \\ 139\end{array}$

10.3 Errors in Predictions 143

10.4 A Combined Model 145

10.5 Endogenous Market Reactions 147

10.6 Conclusions 149

11 THE COBWEB THEOREM: A RATIONAL INTERPRETATION 151

11.1 The Equilibrium Concept of Wages 152

11.2 Implications 155

$\begin{array}{ll}11.3 \text { Conclusions } & 159\end{array}$

12 THE MARKET FOR PRIMARY SCHOOL TEACHERS 161

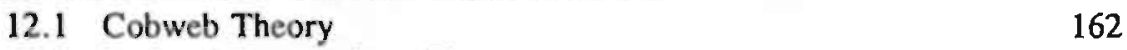

12.2 Rational Expectations Theory 163

$\begin{array}{ll}12.3 & \text { Predictability and Variability } 163\end{array}$

12.4 The Market for Primary School Teachers 165

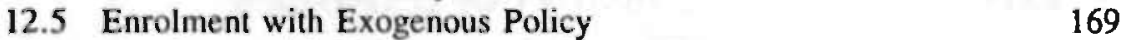

12.6 Enrolment with Endogenous Policy 173

$\begin{array}{ll}12.7 & \text { Implications } \\ 177\end{array}$

$\begin{array}{ll}12.8 \text { Conclusions } & 180\end{array}$

\section{WELFARE}

13 THE MEASUREMENT OF WELFARE

13.1 General Equilibrium Analysis 186

$\begin{array}{ll}\text { 13.2 Partial Equilibrium Analysis } & 187\end{array}$

$\begin{array}{ll}\text { 13.3 The Supply and Demand Curve } & 188\end{array}$

13.4 The Problem of Second Best 189

13.5 Surplus as a Measure of Welfare 191

14 THE VALUE OF INFORMATION 195

$\begin{array}{lll}14.1 & \text { Stabilisation } & 197\end{array}$

14.2 The Value of Predictions: Stabilisation and Allocation 202

14.3 Information versus Interpretation Forecast Errors 205 
14.4 Two Empirical Examples

14.5 The Provision of information 214

$\begin{array}{ll}14.6 \text { Conclusions } & 218\end{array}$

15 THE CASE OF DISPERSED PREDICTIONS 219

$\begin{array}{ll}15.1 & \text { An Example with Dispersed Predictions } \\ 15.219\end{array}$

15.2 General and Individual Predictions 221

15.3 Individual Predictions 223

15.4 The Use of Information 227

15.5 Welfare Effects of Additional Labour Market Information 232

15.6 The Example Reconsidered 236

15.7 Overvaluation of the Public Prediction 238

$\begin{array}{ll}15.8 \text { Conclusions } & 241\end{array}$

Appendix 15.A 242

Appendix 15.B 243

16 CONCLUSIONS 247

$\begin{array}{ll}16.1 & \text { Implications for Economic Theory } \\ & 248\end{array}$

16.2 Implications for Manpower Forecasting 251

16.3 Future Research 253

LITERATURE

AUTHOR INDEX

SUBJECT INDEX $\quad$ XXV

SAMENVATTING $\quad x x i x$

CURRICULUM VITAE XxxV 
For a long time, at least since the Second World War, governments have tried to control education in order to turn it into an instrument of economic policy. ${ }^{1}$ Education is seen as an important investment, both on the individual and social level, with long-term consequences for up to 40 years, the length of a working career. As a result of this aim an extensive literature appeared on 'educational planning' or 'manpower forecasting'. 2 Typically, these studies attempt, on the one hand, to forecast or calculate future needs or requirements for educated labour, and on the other hand, to forecast future supplies of the same type of educated labour. The need for educated labour is derived from the demands for labour at the market, or from a policy target, for example a certain level of economic growth. The comparison of supply and needs gives an indication of the surpluses or shortages for certain types of educated labour. These indications about the future labour market can be used for policies which aim at improving the match between supply and demand for labour, or at achieving the policy target.

Mostly, however, this literature only deals with the question how to forecast the future labour market situation, while little attention is paid to the question how to use these forecasts. In an OECD report, Soumelis (1983, pp. 34-35) states 'that educational planning efforts in the analysis of the education-labour relationship will be particulary directed towards [...] increasing and managing the information flow from the labour market to the potential students to facilitate their educational decisions, leaving to the labour market the allocative function to balance up demand and supply'. ${ }^{3}$ In the same report Tinbergen and Psacharopoulos (1983, p. 309) add that 'precisely because education processes take considerable time, it is possibje to warn both potential suppliers and potential demanders of some type of labour ahead of time of possible discrepancies giving them time to take measures in favour of equalising supply and demand. Information of this type already exists; secondary school leavers are provided with information about the demand for alternative third level jobs open to them. This will have an impact especially on those whose endowment with intellect or other capabilities makes them hesitant about exactly what job to aim at.'

Also in Dutch policy the idea that students have to be guided towards jobs according to the labour market situation plays an important role.

3 Soumelis also mentions curriculum changes as an important area for educational planning. 
The Socio-Economic Council (SER, 1986, pp. 10-11) states that "by involving labour market information in the planning it can be achieved that the correcting developments which now occur with a delay by means of the educational choices of students in relation to employment forecasts, will occur at an earlier stage and will therefore occur with more effect'. ${ }^{4}$ The Temporary Advisory Board Education-Labour Market agrees with this and adds that in her opinion it is important to involve also labour market developments and perspectives in educational and occupational guidance'. These thoughts about the need for manpower forecasts imply that students themselves are not capable of adequately anticipating the future labour market situation at the moment they have to make their educational choices, and therefore they may benefit from the judgements of experts. This gap between the foresight of students and professional forecasters makes it possible to improve the functioning of the labour market without direct intervention in the economic process, as for example in entry barriers and tuition policies.

As a result of this policy view in the Netherlands, the Research Centre for Education and the Labour Market (ROA) started to provide data and forecasts about the labour market for an automated system for study and occupational choice. ${ }^{6}$ The largest and best developed information service of this type is provided by the Bureau of Labor Statistics (BLS) of the United States Department of Labor. After the second world war BLS started to collect detailed information about the labour market. Initially, this information was used to inform veterans about their possibilities on the labour market. Later, this policy was extended to anyone who wanted to embark on a study. The information was only descriptive. From 1962, however, BLS started to make forecasts. These forecasts are published in among others the biannual Occupational Outlook Handbook. ${ }^{7}$ This book includes job descriptions and expected prospects of many occupations, and is designed to help people make educational and vocational decisions. ${ }^{8}$

4 'Door het betrekken van arbeidsmarktgegevens bij de planning kan bereikt worden dat de corrigerende ontwikkelingen die zich nu vertraagd voordoen door middel van de schoolkeuze van leerlingen in relatie met werkgelegenheidsprognoses, in een eerder stadium en dus met meer resultaat kunnen optreden."

5 Tijdelijke Adviescommissie Onderwijs-Arbeidsmarki (1990, p. 24). "Naar haar oordeel is het van belang in de studie- en beroepskeuzevoorlichting ook arbeidsmarktontwikkelingen en perspectieven te betrekken.

6. See e.g. De Grip, Heijke, and Dekker (1989).

7 See e.g. BLS (1984).

8 In many other countries also labour market forecasts at detailed level are made, but mostly these are only used for policy making, and not to assist students' educational choice. E.g. in the United Kingdom the Institute for Employment Research (IER) publishes the Review of the Economy and Employment (Wilson et al., 1991) and in Germany the Institut furr 
The eminent metaphor to describe the ignorance of students with respect to changes in the labour market situation is the cobweb-model. In this model, it is assumed that students base their enrolment decisions on current wages instead of anticipating the labour-market situation at the moment they enter the market. Suppose there is a surplus of students entering the market for a particular type of educated labour. As a consequence, wages will fall, resulting in decreasing enrolment, because new students base their decisions on current wages, which are low. This leads to a shortage on the market at the moment these students finish their schooling and consequently wages will rise again. This mechanism shows that the behaviour of inexperienced students may lead to matching problems and that the best way to overcome these problems is to inform students adequately about their real prospects.

Not only from practical policy but also from theoretical economic studies, the relevance of providing labour market information to assist students in their educational choices has been noted. Based on a study of Hayek's view of the economic order as a system of communication Pikkemaat (1969, thesis 5) states that 'the most important condition for preserving employment as labour productivity increases is a lasting correct match between the composition of demand and the composition of supply on all markets. For that, information is required which is increasingly detailed and centralised, also with regard to the individual preferences of families. This last issue will result in government getting involved in market research, in a more integrated way than is currently being carried out by industrial enterprises and the like." Furthermore, one of Freeman's (1971, p. 229) eight policy implications for education and manpower policy is that "the existence of lengthy disequilibriums under incomplete adjustments directs attention to the value of manpower forecasts in the labour market. Since career decisions result from a rational consideration of alternatives, students are likely to react favourably to a comprehensive, high quality set of forecasts.' Freeman's suggestion is that the informational problems students are faced with, will be reduced by means of a set of high quality forecasts. Such forecasts counteract the disequilibria on the labour market and are

Arbeidsmarkt- und Berufsforschung (IAB) makes forecasts concerning the labour market (IAB, 1990).

9 'De voornaamste voorwaarde voor het behoud van de werkgelegenheid bij toenemende arbeidsproductiviteit is een blijvend juiste afstemming op elkaar van de samenstelling van de vraag en de samenstelling van het aanbod op alle markten. Daartoe is steeds meer gedetailleerde en gecentraliseerde informatie nodig, ook betreffende de individuele preferenties van de gezinshuishoudingen. Dit laatste zal er toe leiden, dat de overheid zich met marktonderzoek gaat bernoeien, en we! op een meer integrale wijze dan nu geschiedt door industriële ondernemingen en dergelijke." 
favourable to students.

The aim of this study is to investigate this intuitive relation between the provision of public labour market forecasts, educational choice, and functioning of the labour market, especially the effects on the stability of the market and welfare effects of such a policy. There is some literature concerning topics which are closely connected. Freeman (1971, 1989), Zarkin (1983, 1985), Siow (1984) and Connelly (1989) investigate students' expectation formation with respect to labour market conditions. Freebairn (1976), Freebairn and Withers (1979) and Antonovitz and Roe (1986) try to measure the value of information. Finally, Smyth (1973) and Turnovsky (1978) are devoted to the stabilisation effects of public forecasts.

The theory developed in these publications is, however, to some extent naive where the problem of public forecasts is concerned. On the one hand, by assuming that students take the current labour market situation into account, instead of anticipate the future situation, students are too easily regarded as naive. The cobweb behaviour is simply assumed and not explained. The only alternative put forward in the literature is the assumption of rational expectations in which the need for public forecasts is denied. On the other hand, just as students' expectation formations, public forecasts will never be perfect, and will always be subject to a large amount of uncertainty. The studies mentioned above ignore this problem by simply assuming that the public forecasts are perfect, or at least by assuming that students will treat those forecasts as totally reliable. In view of the great difficulties manpower forecasting is confronted with in practice, these assumptions trivialise the question too much.

This facet of errors in forecasting is particulary important for the field of labour market expectations of students. Rosen (1987, p. 179) compares investments in human capital with other investments in for example buildings or production capacity and concludes that "there is an important difference between the two. Business investment activities in the private sector are placed in hands of a relatively small cadre of highly trained and highly skilled professionals. These people continually obtain market feedback on the wisdom of their judgements and repeatedly revise and revalue their decisions as new information comes available. Education decisions, on the other hand, are squarely in the hands of young people and their parents. They are usually made at early stages of life, before the acquisition of significant practical experience, and do not continually occur.' An attempt to give a theoretical basis for the effects of the provision of public labour market forecasts, at least 
has to grasp the sense of this type of uncertainty, which hampers the educational choice of students.

The significance of this study is that it attempts to reconsider economic theory on expectations and information, departing from the practical experience of labour market forecasting. The problems connected with the labour market forecast activities of the Research Centre for Education and the Labour Market have greatly influenced the contents of this study. ${ }^{10}$ It appears that the existing theory is not always adequate to describe these practical experiences and intuitive notions about expectations, prediction errors and information. Therefore, these theories will be reinterpreted and new theoretical concepts will be added in order to create a framework to deal with the questions about the effects of the providing public forecasts.

At the practical level the concepts developed in this study may contribute to a foundation of certain common practices in manpower forecasting and the provision of labour market information, while furthermore it may provide a framework for the development of new methods for producing and providing public information.

These new concepts may not only be useful at a practical, but also at a theoretical level. The field of educational choice is only a marginal area for economic theory, but, as mentioned before, it provides an example to economic theory in general, which is far more extreme in certain aspects than the usual examples. This is most clearly the case for the role of uncertainty in educational choice. Therefore, the results of this study may sharpen the thoughts about information and expectations in mainstream economic fields, such as monetary policy and savings behaviour. Decision makers at, for example, a financial market will be much more experienced than students, making less obvious errors than students do. Furthermore, these professionals will in general behave much more in agreement with each other and with economic theory. Errors in their expectations will therefore appear as being unavoidable. For many students the choice of education is very difficult. The decision may have far-reaching consequences, and it is often not possible for students to cope adequately with the complexity of the labour market. This aspect of uncertainty, which is typical for educational choice, and which, as a consequence, enables more specialised forecasters, to contribute towards improving students' expectations, is the main subject of this study. 


\subsection{Plan of the Study}

The usual approach to model expectations in an uncertain situation is to start with a model of the economic relationships. The economic reality is thought to be at hand. Within the framework of such model people's expectations are described, and therefore in such model these expectations are by assumption correct, i.e. consistent with the model, oi are formulated ad hoc, i.e. the expectations are not related to the economic variable that has to be predicted. From this point of view there necessarily is a fixed relation between the expectation and observable economic data. Such a fixed expectation formation scheme contradicts, however, the everyday experience that forecasting requires power of thought (not simply calculations) and that always at least some doubt is felt about the correctness of the forecast. Although due to the sophisticated mathematical modelling it may be difficult to recognise, the current approach to expectations is always based on some postulated a priori knowledge of the agents about the economic system, or views people's behaviour as an effect of the circumstances. In both cases the essence of forecasting is lost. A forecast is an attempt to say what is to happen in the future. The first approach makes this attempt to a triviality, in which the forecast is enclosed in the available data, while in the second approach expectations are disconnected from the future.

In contrast with this usual approach, this study takes the possibility of people to make forecasts as a starting point, without reference to the 'real model' which generates the economic data. Although forecasts of a certain variable are always directed towards the realisation of this variable, the quality of this forecast may differ between people, indicating differences in individual capabilities to forecast.

This study consists of three main parts. In the first part, Mismatch, some basic concepts, mismatch and equilibrium (chapter 2), and a basic labour market model (chapter 3) are introduced. Since a direct reference to the 'real model' or 'data generating proces' disappears, it makes no sense to compare expectations to this real model, but it requires as a benchmark the realisations. Therefore, the meaning of a correct expectation changes from 'consistent with the model' to 'corresponding to the actual realisation", i.e. correct expectations are expectations that are fulfilled. Equilibrium is defined, in a Hayekian way, as a situation in which all expectations are correct in this sense and therefore in equilibrium not one student regrets his educational choice at the time he participates in the labour market. Deviations from equilibrium are called mismatch. The policy to provide public labour market information aims at reducing these mismatches. The equilibrium serves as the bench-mark 
or target for this policy. Furthermore, in chapter 4 some empirical evidence on the magnitude of the mismatch problem due to educational choices is given. In chapter 5 the possibilities to incorporate the provision of public labour market information in the different theoretical views on economic policy are discussed. It is shown that the usual way to make economic models, departing from the 'true model' eliminates the possibility to fruitfully investigate this information policy. Although also in the neo-liberal view on economic policy this information instrument in not found, it seems to fit well into this, less formalised, thought.

The second part, Information, focuses on expectation formation. Based on an investigation into the history of expectation formation in economic thought, in chapter 6 , it is shown that due to the formalisation of economic theory, especially due to Haavelmo's conception of the economy as a stochastic process, the representation of economic reality as something which is available was developed, which inevitably led to the development of rational expectations.

In chapter 7 the stochastic characteristics of a forecast as such are described. It is shown that a forecast error fits into the common conception of uncertainty as due to uncertainty regarding states of the world, but that forecast errors can also be interpreted as being caused by the difficulties of students to predict future events in a context in which the true model is not at hand. Due to errors students make in forecasting there is a trade off between the shortcomings of naive, abstract expectations, and their errors in specific expectations, based on real economic insights. The recognition of errors in forecasts undermines the theoretical supriority of rational expectations.

In chapter 8 an empirical study of the Dutch junior secondary technical education shows that the rational expectation hypothesis indeed does not dominate the much less sophisticated cobweb theory. Furthermore, it indicates the extent of the mismatch problem on this market.

In chapter 9 both rational expectations and cobweb theory are interpreted in the framework of the errors in forecasts model of chapter 7. The optimal way of forming expectations depends on the variability and the predictability of the economic variable which has to be forcasted. If a variable has a low variability and is difficult for students to predict, the optimal prediction comes close to a naive, abstract expectation. In such a case the rational expectation hypothesis will be easily rejected. In contrast to the students' situation, in professional markets a variable with a high variability forecasted by capable experts 
will not differ very much systematically from the rational expectations hypothesis. The usual tests will not easily reject the rational expectations hypothesis in this case. Based on the model it is investigated to what extent policy can manipulate expectations and, which is the main aim of this study, what are the possibilities for policy to improve prediction and thereby the match between education and the labour market.

Theil (1958) observed that people tend to underestimate changes. Rational expectations theory is not able to explain this phenomenon. In chapter 10 it is shown that the errors in forecasts model developed in chapter 7 and 9 is able to explain the underestimation of changes and based on this difference it is possible to distinguish econometrically the model developed in this study from the rational expectations model.

The occurence of prediction errors causes disequilibrium situations. Such disequilibria make it more difficult to predict future labour market situations. In chapter 11 the interdependency between the errors in forecasts and disequilibria is investigated. This interdependency explains the cycles which typify the cobweb model.

In chapter 12 the theoretical concepts of this study are used to analyse the market for primary school teachers. This is a typical example of a market in the Netherlands with many mismatch problems. The investigations show that these mismatches are largely caused by unexpected policy changes.

In the third part, Welfare, the welfare consequences of the errors in forecasts model of chapter 9 are taken into account. In chapter 14 , the basic model is studied. Naive, ignorant behaviour of students places some of the welfare costs of prediction errors on employers, compared to more active anticipatory behaviour. An improvement of students' predictions, therefore, can be confronted with two opposite effects. The prediction improves, and therefore the costs of prediction errors decrease, but at the same time students become more active, due to a change in the trade off between abstract and specific expectations, which causes a shift of the costs from employers to students. Furthermore, in chapter 15 attention is paid to dispersed predictions. One of the effects of the presence of dispersed predictions may be that the provision of public information destabilises the market under certain circumstances. However, as long as students correctly estimate the reliability of the public prediction welfare improves. The positive effects of public information induce besides improvements of the market at aggregate level, individual gains due to improved allocation. It is therefore not sufficient to base evaluations of the effects of forecasts solely on 
aggregate effects. In this part too, these cases are illustrated by some empirical examples.

Finally, in chapter 16 conclusions and implications regarding economic theory and the practice of manpower forecasting and the provision of labour market information are presented.

\subsection{Conventions}

Throughout this study some (notational) conventions are adopted. For the sake of clearness the most important conventions are listed below:

$w$ is the general indication for the wage. There are two relevant moments of time: (1) the moment at which the student enters the labour market and is confronted with the labour market situation, and $(0)$ the moment, in advance of this, at which he has to make his educational choice, which decision he will base on a prediction of the labour market situation at moment (1).

$w^{-d}$ is the current wage at the moment of choice (0).

$w^{\exp }$ is an expectation of the wage at the moment the student will enter the market (1), made at the moment of choice (0), available to the student.

$w^{\text {pre }}$ is an expectation similar to $w^{\exp }$, which is actually used by the student.

$w^{\text {rea }}$ the wage at the moment the student enters the market (1).

$w^{e q}$ the equilibrium wage at the moment he enters the market (1).

$\Delta w=w^{\text {pre }}-w^{e q}$

$\Delta \bar{w}=w^{\text {pre }}-w^{\text {rea }}$

Throughout this study all students are assumed to evaluate the quality of an expectation with an MSE loss function. Qualifications like 'the best prediction' or 'the optimal prediction' therefore also refer to the MSE loss function, with $\operatorname{MSE}(\Delta \bar{w})=E\left\{\Delta \bar{w}^{2}\right\}$.

All expectations, variances, and covariances are unconditional, if not explicitly indicated with the conditioning sign $\mid$.

$F()$ denotes a probability density function

A denotes an estimate

denotes a new value of a variable after the provision of public information 
$\equiv$ denotes 'almost sure', i.e. $a \equiv b$ means $\operatorname{Pro} b\{a=b\}=1$. 


MISMATCH 

The fundamental idea behind the provision of public labour market forecasts is that this enables students to better anticipate future developments on the labour market and therefore to make more appropriate educational choices. The aim to improve educational choices implies a point of reference at which all students make 'optimal" choices, $i . e$. the choice they actually made is equal to the choice that is ex post optimal, given their possibilities. On a market with a well functioning price mechanism this individual optimality also implies collective optimality. Such an optimality of the market is, however, not assumed. The structure of the demand side of the market is taken as given. Optimality in this framework therefore only refers to a situation in which students made the decisions which could not have been improved by them, while the functioning of the market as a whole is not taken into account.

Educational decisions typically have a strong impact which lasts for a very long period of time, in which many unexpected things can take place. Therefore, it is not unlikely that students make decisions which they regret once they experience the consequences. Such a situation of regret is called a mismatch: a choice which would not have been made given the realisations. In this respect it is important to note that mismatch is limited in two ways. Mismatch only occurs in a situation in which ex post an alternative appears to exist. Firstly, this alternative must be preferred to the choice actually made. Secondly, this alternative must have been feasible. This second condition depends on the scope of the analysis. In a lot of literature the education of workers is taken as given, which implies that in such a framework education can not generate any mismatch. In this study education is of course not taken as given, but the functioning of the demand side of the labour market is. Another example of such a restriction, which is imposed in this study, is a complication regarding employment opportunities. In this study employment opportunities are described as the probability to get a job. The question of regret therefore refers to regret given the probability to get a job and not given the individual realisation of this, i.e. being employed or unemployed. The assumption is made that educational decisions merely determine employment probabilities. The realisation of such a probability is therefore not treated as a consequence of the educational decision.

In the literature about labour economics the word mismatch is mostly used in a narrow meaning, only referring to frictional or structural 
unemployment.' 'The identification of the presence of the frictionalistructural unemployment rate should be based on the coexistence, at the aggregate level, of both unemployment and vacancies, even when aggregate labour demand equals labour supply' (Padoa Schioppa, 1991b, p. 17). Although frequently used, this concept is not very useful for two reasons.

Firstly, the restriction of mismatch to unemployment is rather arbitrary and misleading, since it does not include people who, forced by the labour market situation, accepted a job which they do not like or for which the wages are too low. ${ }^{2}$ The central question concerning this problem is whether they would have made other decisions with respect to their schooling and careers if they had known in advance the labour market situation they are faced with now. People may be willing to accept the risk of unemployment if this is compensated for by other advantages.

Furthermore, the fact that mismatch sometimes leads to (involuntary) unemployment instead of other types of market adjustment is hard to explain by economic theory. Most theories of unemployment do indeed explain the existence of unemployment as a trade off between unemployment and possible gains, such as union power, better search possibilities, or decreased income risk. Therefore, the reduction of the mismatch concept to unemployment is strange and in the welfare judgements at least these possible gains, which are an essential part of the theory itself, should also be taken into account.

Secondly, the unemployment/vacancy concept of mismatch implicitly uses a benchmark, which is in fact meaningless. The statement that the coincidental eccurrence of a certain number of vacancies for e.g. computer specialists and the unemployment of an identical number of taxi-drivers implies a mismatch, suggests that these taxi-drivers had been able and would have wanted to become computer specialists if they had known the circumstances in advance. Not accepting this critique is like claiming a mismatch in resources in a country with a shortage of oil and an abundance of water.

The term 'mismatch' implies that (i) the current situation is not optimal, i.e. an improvement would have been possible at the moment of choice, and (ii) this non-optimality is due to the match, in this case the match

1 See e.g. Layard, Nickell, and Jackman (1991) and Padoa Schioppa (1991a).

2 Klaassen and Heijke (1977, p. 118), therefore conclude "that discrepancies or tensions on the labour market exist to a far higher degree than is indicated by unemployment or open demand figures'. 
between student and education and afterwards between student and occupation.

In this study, mismatch is interpreted as a divergence between a decision actually taken, based on uncertain expectations of relevant economic variables, and a decision that would have been taken if the actor had known these variables with certainty. This leads to a definition of mismatch which is referred to by Padoa Schioppa (199lb, p. 2) as 'short-run shocks'. The term short-run is, however, misleading. IIt suggests that, firstly, the information which was not known at the moment the decision was made, will be known soon after, and secondly, that problems disappear as soon as this information is revealed. This view is inadequate since the only thing that wil! become known to the actors after a while is that a wrong decision has been made, given the current developments. These developments themselves are, however, partly generated by these wrong decisions. Other decisions would have caused other developments. Therefore, the situation of regret itself does not reveal an alternative in which no regret would occur.

Furthermore, the thought that mismatch problems will disappear as soon as the relevant information is revealed, disregards the fact that former decisions might not be reversible and that changes are not once-only, but will continually occur, or at least might continually occur. These two components of uncertainty and continual changes play a crucial role in the cobweb theory, which is discussed in chapter 11. The more revisable a decision, the less the mismatch problem will occur. In the most extreme case, in which the decision is completely revisable, in fact no decision has been made.

Suppose, for example that the demand for electricians increases, which has not been anticipated. As a consequence the wages for electricians rise. A student who decided some years ago to study to be a pipefitter instead of an electrician, might, faced with these developments, regret his decision. Given the present wages he would have preferred to be an electrician. This regret does, however, not imply that he decides to revise his educational choice and take up a course for electricians. The costs of such a revision may be too high. Furthermore, the regret does not imply that if everybody would have made a decision based on the current situation, no mismatch would have been introduced. The present wages might be too high, leading to a surplus of electricians. The change in enrolment decisions may, furthermore, also affect the supply of other occupations. The observation of a mismatch does, therefore, not indicate which situation would have been optimal. 
The definition of mismatch as a situation in which (wrong) decisions are made, due to the fact that some relevant information was not known with certainty at the moment the choice was made, suggests as a benchmark the imaginary situation in which all decisions are the same as those which would have been made, based on correct information known with certainty. This benchmark is called equilibrium, according to Hayek (1937, pp. 39-41), who explains his definition as: 'We may' merely mean that these plans are mutually compatible and that there is consequently a conceivable set of external events which will allow all people to carry out their plans and not cause any disappointments. [...] It appears that the concept of equilibrium merely means that the foresight of the different members of the society is in a special sense correct. It must be correct in the sense that every person's plan is based on the expectation of just those actions of other people which those other people intend to perform, and that all these plans are based on the expectation of the same set of external facts, so that under certain conditions nobody will have any reason to change his plans. Correct foresight is then not, as it has sometimes been understood, a precondition which must exist in order that equilibrium may be arrived at. It is rather the defining characteristic of a state of equilibrium.'

The choice of a full information equilibrium as a benchmark excludes from the analyses certain 'non-optimalities' which are referred to in the literature as 'structural' or 'disequilibrium'. There are three reasons why a certain situation may be viewed as a mismatch without reference to information problems, as above. Firstly, the 'mechanics' of the economic system may lead to situations which are non-optinal (e.g. exogenous fixed prices). In this view economic relations are treated as independent from human behaviour. In the economic model additional restrictions are added to the choices of people, which are neither technical restrictions, nor restrictions which are chosen by them. It is Lucas, who most clearly opposes this type of reasoning. In his conversation with Klamer (1984, p. 45) he states: 'I just don't get the sense that their theory is being driven by an attempt to get at, or model, some specific kind of human behaviour. They're trying to explain other economists" words, but they're not thinking about human decisionmaking. That's why the key actors are always some external force in their models, like at price that just won't change. Why won't it change?" Mainiy in this respect Lucas's thought stems from Austrian sources. Hayek (1937, p. 50, note 2) already makes a distinction between 'the verstehende social science' and 'the behaviourist approach'.

Secondly, situations may occur in which the optimal situation can not be 
reached, due to inadequate contracts, e.g. in the principal-agent problem (Hellwig, 1989), and in models of dynamic inconsistency of government behaviour (Blanchard and Fisher, 1989). These models focus on the difficulties of coordination. Since contracts do not play a role in the study of the effects of providing information, this problem of nonbinding contracts does not seem to be crucial.

A third reason for not accepting the exclusively information-based definition of mismatch and equilibrium, is the situation in which the information-based equilibrium is regarded as undesirable. This point is fundamental in studies concerning poverty and income distribution, but also in studies about labour market performance these types of arguments often play an implicit role. Bentolila and Dolado (1991, pp. 183-184) argue that the 'willingness to look for work in other regions than their own', is 'a source of mismatch from the labour supply side [...] and there is a role for policy in speeding up the process'. This third objection against the equilibrium-benchmark of this study is in general very relevant, and perhaps not sufficiently accepted by economists. The provision of public information as a policy instrument has, however, in its very nature an aim which can not go beyond the equalisation of actual behaviour and behaviour desired by individuals. The information purpose of this instrument justifies the use of the equilibrium-benchmark.

The study of the provision of public labour market information requires the possibility that students do not make the best possible forecast, and that others, the professional forecasters, are able to improve these forecasts. In the case of educational choice it seems reasonable to assume that students can make errors in their predictions. These errors can result in a situation in which there is an alternative decision which is preferred to the decision actually made, and which is also feasible. In this framework it is assumed that every forecast is theoretically feasible. Mostly, however, in economic models the assumption is made that an ex ante optimal prediction exists, i.e. it is impossible to make a prediction which is better than this optimal prediction. This usual assumption restricts the feasibility set. The introduction of forecast possibilities as a restriction in the choice, is consequently mostly accompanied by the assumption that agents do indeed use this optimal prediction. In this view, discrepancies between forecasts and realisation do not lead to mismatch, because a better alternative forecast was not feasible at the moment of choice. Therefore, situations which are nonequilibrium in the framework sketched above, become equilibrium from this point of view. The crucial difference in point of view is the 
existence of an optimal forecast. This issue is discussed in chapter 7. 
In this chapter a model is presented which serves as a basis for the rest of this study. Furthermore, the concepts introduced in the previous chapter will be illustrated by this model.

The model presented here is a single market model. The market is cleared by wages and there is a one-to-one relation between education and work. The consequences of both assumptions will be discussed further on in this study.

\subsection{The Market}

The model presented in this section describes a segment of the labour market. For the sake of simplicity the following two assumptions are made.

Firstly, every worker on the market earns the same wage in a certain period $t$. This wage is called the realised wage, $w^{\text {rea }}$. Thus, the wage does not depend on the workers characteristics. The only relevant factor is the presence of the worker in this labour market segment.

Secondly, it is assumed that only the wages in the first period are relevant for the decision made by students. This assumption can be interpreted in different ways. The whole working period might be seen as one period. In that case it is likely that the working period for different generations overlap. Unless different cohorts are no substitutes the wages in this case are determined by the decisions of future generations. Siow (1984) shows that in the case of identical workers, perfect substitution between generations and rational expectations, only the first year's wages are relevant for workers' choices. New entrants make decisions, such that the utility of entering the market equals the utility of not entering the market, and this equality will hold for all workers. The assumptions to obtain this result are, however, very strong. The second interpretation of the first period assumption is that future wages are completely determined by the first year's wages. It might, for example, be the case that the wage development is completely determined institutionally once the starting salary is given, perhaps converging to a salary independent of the labour market situation. In such a case the pay-off of a correct match is concentrated in the beginning of the career. The choice between these interpretations becomes relevant only in empirical studies. The theoretical results apply to both interpretations.

In general, the market characteristics of the occupation in one specific segment of the labour market are subject to change. The wages and the 
probability to get a job, but also the contents of the job, and the working conditions, may change. In this basic model the assumption is made, however, that all market characteristics except for the wages are constant. Thus, the wages are the only flexible factor on the demand side, and therefore the variation in the wages has to equalise, given the other characteristics of the job, supply and demand. Otherwise: rationing should take place and a change in the ratio of supply and demand would lead to changes in the probability to get a job.

The following three equations describe the market:

(3.1) $S_{1}=S_{0}$

(3.2) $D=C_{D}+\beta_{D} w^{\text {rea }}$

in which $\beta_{D}<0$

(3.3) $S_{1}=D$

The supply on the market $\left(S_{1}\right)$ is completely determined by the enrolment decision $\left(S_{0}\right)$. Once somebody has chosen for a certain education, his supply at the related segment at the labour market is fixed. Revision is assumed not to be possible. The enrolment decision itself is the subject of the next section of this chapter.

Demand ( $D$, equation (3.2)) is a linear function of the realised wage. (3.3) is the market clearing condition. Substituting (3.1) and (3.2) in this market clearing condition provides an expression for this realised wage:

$$
w^{\text {rea }}=\frac{S_{0}-C_{D}}{\beta_{D}}
$$

\subsection{Enrolment}

Since labour supply is assumed to be totally inflexible given the type of education, the enrolment decision is the crucial decision on the supply side. This decision will depend on a person's characteristics (preferences and capacities) and on the predicted situation on the market. Since the assumption is made that wages are the only varying characteristic of the market the optimal decision of a student $i$ depends, given his own preferences and capacities, only on the wage. This is the wage at the moment the student will enter the labour market $\left(w^{\text {rea }}\right)$, and not the current wage (denoted by $w^{-d}$ ). Therefore, this wage is not known to the students, and they have to base their decision on their prediction of the future wage $\left(w_{i}^{\text {pre }}\right)$. The enrolment decision depends on a comparison of the predicted wage with an exogenous reservation wage $\left(w_{i}^{\text {res }}\right)$ : 


$$
\begin{cases}s_{i}=0 & \text { if } w_{i}^{\text {pre }} \leq w_{i}^{\text {res }} \\ s_{i}=1 & \text { if } w_{i}^{\text {pre }}>w_{i}^{\text {res }}\end{cases}
$$

in which $s_{i}$ denotes the individual enrolment decision which is 1 if student $i$ enters and is 0 if he does not enter a certain education. In this chapter the predicted wage is treated as exogenous. Therefore, the model is still static. In later chapters the relation between the predicted wage and the labour market situation will be modelled explicitly, introducing dynamics into the model.

Based on the individual decisions it is possible to define the total enrolment as:

$$
S_{0}=\sum_{i} s_{i}
$$

This total enrolment depends on the distribution of the individual reservation wages and the distribution of individual predictions of the wage. The distribution of individual reservation wages does not depend on the wage and is therefore a constant. Furthermore, the distribution of the predicted wages is assumed to be independent on the distribution of the reservation wages. The supply function can therefore be defined as the enrolment in the notional case every student predicts wage $w$ :

$$
\text { (3.7) } S_{0}(w)=\sum_{i} s_{i}(w)
$$

This supply function is assumed to be linear: ${ }^{1}$

$$
\text { (3.8) } S_{0}(w)=C_{s}+\beta_{s} w
$$

This specific form for the supply function is in fact an implicit definition of the distribution of the reservation wages.

In general, the predicted wage will not be equal for every student. In the literature it is mostly (implicitly) assumed that this prediction is unique. In this study this convention is sometimes - in cases where the dispersion of predictions is not relevant - adopted. In such case the general prediction is denoted as $w^{\text {pre }}$ for every student $i$. If the

1 The linearity of the supply and demand curve serves two ends. Firstly, it makes it easier to derive analytical results. Secondly, non-linearities introduce some relationships which are not directly relevant for the purposes of this study. These effects of non-linearities are discussed in chapter 14. 
dispersion is explicitly taken into account it is, however, also useful to distinguish a general prediction. This general prediction is denoted by $G$ and implicitly defined as:

(3.9) $G: S_{0}=S_{0}(G)$

i.e. $G$ is the predicted wage which if every student made this prediction, would result in the same supply as actually results from the dispersed predictions. Due to the linearity of the supply and demand curve this general prediction is equal to the average individual prediction.

Based on this general prediction, the individual prediction can be split up into two components.

$$
\text { (3.10) } w_{i}^{\text {pre }}=G+I_{i}
$$

In which $I_{i}$ is the individual component, i.e. the difference between the individual prediction and the general prediction.

A combination of the market model (3.1)-(3.3) and the enrolment model provides the complete description of the basic model. This model is illustrated in figure 3.1. In this figure the supply and demand functions are depicted. The supply does not depend on the realised wage, but on the predicted wages. The predicted wages are distributed over the wage-space, i.e. the vertical axis. By definition the general prediction $G$ determines the actual enrolment or supply. Once students have made their educational decision their choice is irreversible, and their supply at this segment of the labour market is completely inelastic. This inelastic supply curve after the enrolment decision is depicted by $S_{1}$. 
FIGURE 3.1: THE BASIC MODEL OF A SEGMENT OF THE LABOUR MARKET.

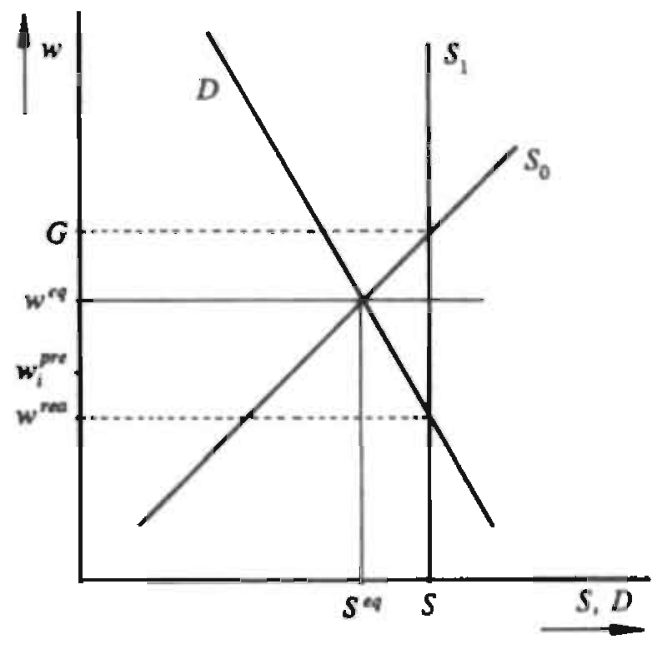

\subsection{Equilibrium and Regret}

Based on this partial labour market model it is possible to illustrate the concepts equilibrium and regret, introduced in the previous chapter.

In general, the predicted wages do not equal the realised wage. A student regrets his decision if he would have taken another decision if he had known the realised wage with certainty before the decision had to be made, i.e. if

$$
\text { (3.11) } s_{i}\left(w_{i}^{\text {pre }}\right) \neq s_{i}\left(w^{\text {rea }}\right)
$$

Equilibrium is defined as a situation in which no student regrets his decision: ${ }^{2}$

$$
s_{j}\left(w_{i}^{\text {pre }}\right)=s_{i}\left(w^{\text {rea }}\right) \quad \forall i
$$

In that case total supply equals $S_{0}\left(w^{\text {rea }}\right)=C_{s}+\beta_{s} w^{\text {rea }}$. Substituting this into the market model (3.1)-(3.3) gives the equilibrium wage:

2 As stated in chapter 2, mostly equilibrium is defined as a situation in which no student wants to change his position, given his past decisions. In such a definition regret has no role. In the present model such an equilibrium equals the realisation. 
(3.13) $w^{\text {eq }}:=w^{\text {rea }}=\frac{C_{D}-C_{S}}{\beta_{S}-\beta_{D}}$

If the equilibrium condition (3.12) does not hold, the realised wage will in general not equal the equilibrium wage:

(3.14) $w^{\text {rea }}=\frac{C_{S}-C_{D}+\beta_{S} G}{\beta_{D}}$

and because $C_{S}-C_{D}=w^{e q}\left(\beta_{D}-\beta_{S}\right)$ (equation (3.13))

$$
w^{\text {rea }}=w^{e q}-\frac{\beta_{S}}{-\beta_{D}}\left(G-w^{e q}\right)
$$

This equation shows that an underestimation by the general prediction of the equilibrium wage leads to an excess realised wage and $v . v$. if students' expectations are too high, too many enter the market, which leads to wages below the equilibrium level.

FIGURE 3.2: THE SIX POSSIBLE SITLATIONS REgARDING REGRET, GIVEN REALISED AND EQUILIBRIUM WAGE.

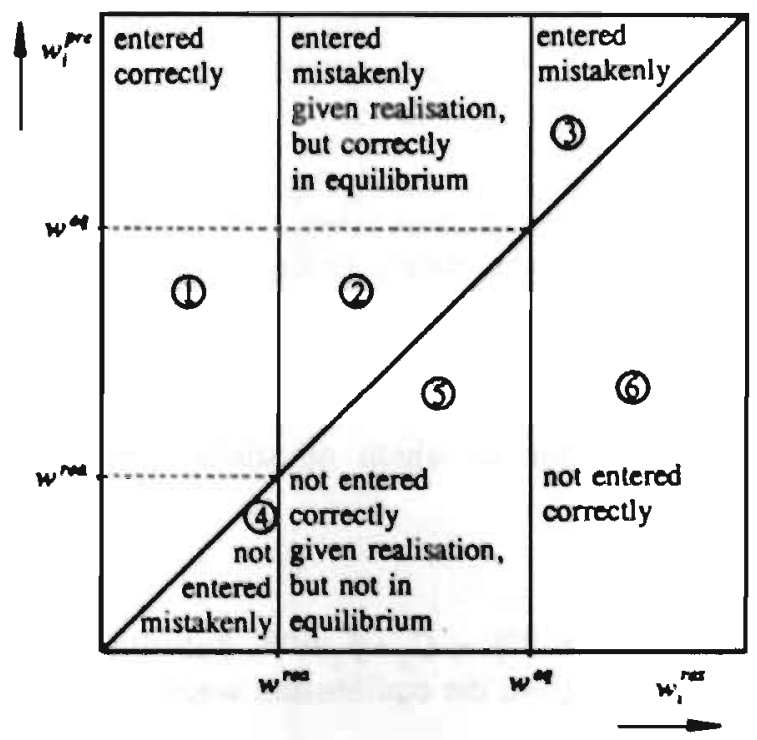


The relation between the realised wage and predictions only depends on the general prediction. It may be the case that the general prediction equals the realised wage, and therefore also equals the equilibrium wage, but this situation does not imply an equilibrium, since some students whose predictions were too high may have entered mistakenly, while others whose predictions were too low did not enter, but also regret their decision. If the realised wage equals the equilibrium wage in such a situation, on aggregate level the supply appears to be optimal, but on individual level welfare losses occur due to wrong decisions.

Figure 3.2 gives the possible combinations of the reservation wage $\left(w_{i}^{\text {res }}\right)$ and the predicted wage $\left(w_{i}^{\text {pre }}\right)$. The figure shows, given the equilibrium wage and the realised wage, the six possible positions a student can find himself in. In the case depicted in the figure $\boldsymbol{w}^{\text {rea }} \leq \boldsymbol{w}^{\text {eq }}$. The reverse situation may, however, also occur. On the diagonal line students are indifferent about their choice: $w_{i}^{\text {pre }}=w_{i}^{\text {res }}$.

FIGURE 3.3: A SITUATION OF EQUILIBRIUM.

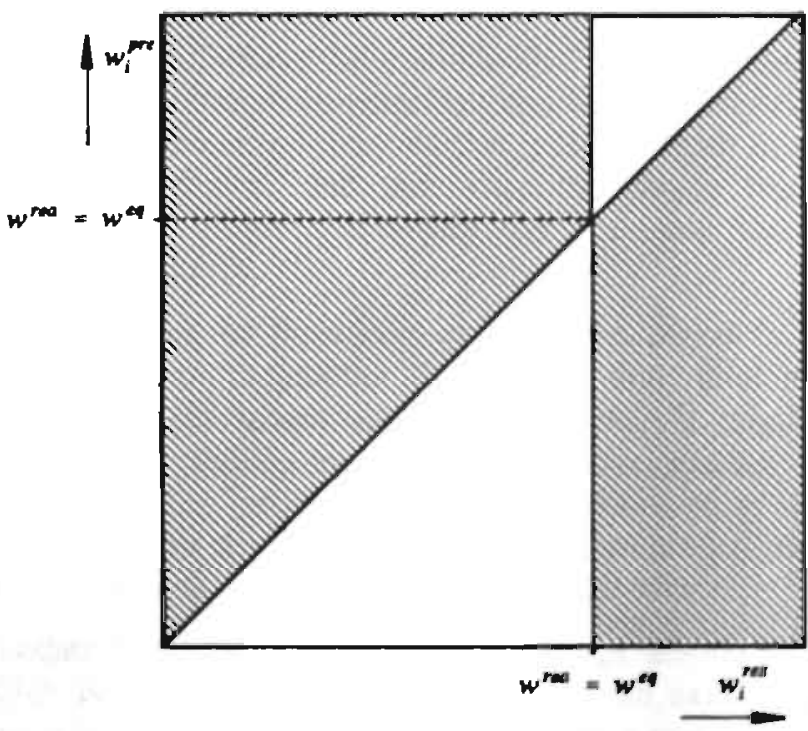

Above this line students decide to enter the market, since their predictions exceed their reservation wages. Below the line they decide not to enter. The prediction may be wrong, however. Students with a reservation wage below the realised wage, optimally, should have entered the market. Therefore, group (1), above the diagonal, entered 
correctly, while group (2) did not enter by mistake.For students with reservation wages above the realised wage the opposite is the case. They, optimally, should not have entered the market. Therefore, students above the diagonal (group (2) and (3)) mistakenly entered, while those below the line (group (5) and (6)) correctly did not enter. If, however, every student would have behaved optimally, the realised wage would have been equal to the equilibrium wage. Therefore, students in group (2) entered by mistake, but their decision would have been correct in case of an equilibrium situation. Group (5) did not enter correctly, but their behaviour would not have been optimal in the equilibrium situation. When every student makes the right decision the realised wage will equal the equilibrium wage. Figure 3.3 shows the combinations of reservation wages and predictions the equilibrium situation allows for. Predictions need not to be correct, but should lie in the shaded segments. 
The previous two chapters gave a conceptual description of mismatch. Mismatch is defined as a situation in which, based on predictions, decisions are made which would not have been made if, instead of these predictions, the realisation had been know with certainty. Recognising this theoretical concept does, however, not imply that it is significant for the relation between education and the labour market. Of course it will be true that students make wrong decisions, but the significance of the mismatch problem depends on the number of students making wrong decisions and on the effects these wrong decisions have. In this chapter some empirical evidence is presented to indicate the magnitude of the mismatch due to educational decisions in the Netherlands.

There is no straightforward measure for labour market mismatch. Every way to measure mismatch presupposes a theoretical framework, and throws light on different aspects of the mismatch problem. For that reason several indicators will be presented in this chapter which all indicate only one aspect of mismatch in educational choices, but which together provide some evidence on the extent of the mismatch problem in, mainly, the Dutch situation.

These indicators have been subdivided into four categories. In the first category (section 4.1) students' choices are observed rather directly. The mismatch concept implies that it is a difficult process for students to make their choice, and that after the choice has been made some students will discover that they did not make the right choice: they regret their choice.

A shortcoming of the direct evidence on regret is that it is not clear whether these difficulties in choice and this regret are due to uncertainties in labour market conditions. It might be the case that students are indifferent regarding labour market conditions. In the second category (section 4.2) some results of other studies are presented which measure the responsiveness of students in their educational choice to the labour market situation of a certain education.

Another important aspect of the concept mismatch is that the choice which is made is a relevant choice to some extent, i.e. by choosing for one education rather than for another some future possibilities are opened, while others are closed. In the third category (section 4.3) evidence is given on the compartmentalisation of the labour market. This indicates whether the educational choice is a real choice with consequences for the labour market possibilities of the students.

Finally, in the fourth category (section 4.4) it is examined whether 
anticipation of labour market conditions is a relevant activity. It is shown that the fluctuations on the labour market are of such a magnitude that it makes anticipation worthwhile.

\subsection{The Problem of Choosing and Regret}

As stated in the introduction of this chapter, the mismatch concept implies that students make mistakes, i.e. they make choices which they regret later, since they acquire information or insight which was not available at the moment the choice had to be made. The significance of the mismatch concept implies that students indeed experience a lack of information at the moment of choice, and that a considerable number of them will regret the decision afterwards. In this section some evidence from survey data is presented on both aspects.

In Weerdenburg $(1985,1987)$ the results are presented of a survey among students at the senior general secondary education and the preuniversity education concerning their educational choice and the role of educational guidance and information in this decision.

TABLE 4.1: THE IMPORTANCE OF SEVERAL. ASPECTS WTTH REGARD TO THE CHOICE OF EDUCATION.'

\begin{tabular}{l|ccc}
\hline & important & neutral & unimportant \\
\hline contents of study & $95 \%$ & $5 \%$ & $1 \%$ \\
entry requirements & $90 \%$ & $9 \%$ & $2 \%$ \\
labour market aspects & $83 \%$ & $16 \%$ & $1 \%$ \\
$\begin{array}{l}\text { possibilities for } \\
\text { specialisation }\end{array}$ & $74 \%$ & $19 \%$ & $8 \%$ \\
difficulty & & & \\
cost & $64 \%$ & $22 \%$ & $14 \%$ \\
\hline
\end{tabular}

Table 4.1 provides the results of the question what aspects students regard as important with respect to their educational choice. Although the contents of the study is the most important aspect, the labour market aspects of the choice are also regarded as important by $83 \%$ of the students. Only $1 \%$ answered that labour market aspects are unimportant to them.

For the relevance of the mismatch concept it is not only relevant that 
students regard labour market aspects as important, but also that they indicate that the amount of information they already acquired does not satisfy their needs. This is indicated in figure 4.2 . In this survey $43 \%$ of the students indicated that they did not have enough information with respect to labour market aspects. This percentage is much lower than the $83 \%$ who said that labour market aspects were important to them. This is, however, completely in accordance with the labour market model in chapter 3 . Since the reservation wages of the individual students are not all the same, some of them are in a situation in which a more accurate prediction of the future labour market situation is not relevant to them, since their choice does not depend on this situation. For that reason, Freeman (1971, pp. 223-226) distinguishes between marginal and non-marginal students. For marginal students the reservation wages are near the predicted realised wages, and therefore information on the exact value of the realised wages is important to them.

TABLE 4.2: THE NEED FOR MORE INFORMATION. ${ }^{2}$

\begin{tabular}{l|cc}
\hline \hline & enough & not enough \\
\hline contents of study & $59 \%$ & $41 \%$ \\
entry requirements & $84 \%$ & $16 \%$ \\
labour market aspects & $57 \%$ & $43 \%$ \\
possibilities for & $32 \%$ & $68 \%$ \\
specialisation & & \\
difficulty & $47 \%$ & $53 \%$ \\
cost & $38 \%$ & $62 \%$ \\
\hline
\end{tabular}

Educational guidance and information can be split up into general and detailed sources. General information for example consists of meetings with a student counsellor or an occupational test. Detailed information is information about the contents of a study, the entry requirements and labour market prospects. Table 4.3 shows that this detailed information is used more often and appreciated much more than general information. This indicates that the problem students have in choosing is not mainly caused by questions about their own preferences and abilities, but much more by lack of information concerning detailed consequences of the educational choice. 
TABLE 4.3: THE USE AND APPRECIATION OF GENERAL VERSUS DETAILED GUIDANCE AND INFORMATION. ${ }^{3}$

\begin{tabular}{l|cc}
\hline & general & detailed \\
\hline use & $61 \%$ & $70 \%$ \\
appreciation & $37 \%$ & $67 \%$ \\
\hline
\end{tabular}

The results in these tables indicate that the future labour market is indeed relevant for students' choices. Furthermore, the figures indicate that students experience a lack of information, mainly on a detailed level, which hampers their educational choice..

A second piece of evidence on mismatch in this section concirns regret. Since students experience a lack of information at the moment they make their choices some of them will make the 'wrong' choice. This wrong choice is the mismatch, introduced in chapter 2 . The most direct way to measure mismatch is to count the number of students who regret their choice afterwards. Table 4.4 provides the results of ten Dutch surveys with respect to this question. In these surveys students are asked whether they choose the same study again.

As far as the surveys allow, a distinction is made between regret with respect to the study, and regret with respect to the specialisation subject of the study. In total, the percentage of students who regret their choice, specialisation or study, varies from $20 \%$ to $57 \%$. $11 \%$ to $53 \%$ regret their study. The percentages in the table are very high, indicating a large group of people who made the wrong choice, given the knowledge they have afterwards. These high numbers of mismatch are, however, not only due to labour market uncertainty, but might also be caused by uncertainty about the contents of the study, or about individual preferences. 
TABLE 4.4: THE FRACTION OF STUDENTS WHO REGRET THEIR MAIN SUBECT OR. THEIR STUDY AFTERWARDS, ACCORDING TO SOME DUTCH SURVEYS. ${ }^{4}$

\begin{tabular}{|c|c|c|c|c|c|}
\hline & & $\mathrm{N}$ & $\begin{array}{l}\text { regret } \\
\text { total }\end{array}$ & $\begin{array}{l}\text { regret } \\
\text { subject }\end{array}$ & $\begin{array}{l}\text { regret } \\
\text { study }\end{array}$ \\
\hline 1 & $\begin{array}{l}\text { junior general secondary } \\
\text { education }\end{array}$ & ) & $53 \%$ & $12 \%$ & $4 ! \%$ \\
\hline 2 & $\begin{array}{l}\text { senior general secondary } \\
\text { education }\end{array}$ & 593 & $57 \%$ & $20 \%$ & $37 \%$ \\
\hline 3 & pre-university education & & $46 \%$ & $12 \%$ & $34 \%$ \\
\hline 4 & $\begin{array}{l}\text { junior secondary technical } \\
\text { education }\end{array}$ & 157 & $20 \%$ & & \\
\hline 5 & $\begin{array}{l}\text { senior secondary technical } \\
\text { education }\end{array}$ & 470 & & & $13 \%$ \\
\hline 6 & art (higher vocational education) & 943 & $30 \%$ & $19 \%$ & $11 \%$ \\
\hline 7 & economics (university) & 1840 & $46 \%$ & $29 \%$ & $17 \%$ \\
\hline 8 & $\begin{array}{l}\text { agricultural engineering } \\
\text { (university) }^{s}\end{array}$ & 1899 & & $46 \%$ & \\
\hline 9 & physics (university) & 1038 & & & $16 \%$ \\
\hline 10 & health sciences (university) & 135 & $34 \%$ & $9 \%$ & $25 \%$ \\
\hline 11 & languages (university) & 714 & $39 \%$ & $9 \%$ & $30 \%$ \\
\hline 12 & total Dutch population & 526 & & & $53 \%$ \\
\hline
\end{tabular}

\subsection{The Role of the Labour Market in the Educational Choice}

In the previous section it was shown that a large number of students regret their educational choice afterwards, indicating a rather large amount of mismatch. As noted earlier, this mismatch is not necessarily due to uncertainty with respect to labour market conditions. Table 4.1 showed, however, that $83 \%$ of the students regard labour market aspects as important. This section gives further evidence on the relation between labour market conditions and educational choice. It contains the results of some studies on students' responsiveness to changing labour

4 Translation of types of education according to Ministerie van Onderwijs en Wetenschappen (1989). Sources: 1, 2 and 3 from Pater (1987), p. 34; 4 from Stijnen and Wieling (1988), p. 43; 5 from MTS-Roermond (1986), p. 4; 6 from Haanstra, Koppen and Oostwoud Wijdenes (1987), p 119; 7 from Wilbrink (1989), pp. 25, 27; 8 from NILIMPW (1989), p. 67; 9 from Maurice (1991), p. 19; 10 from Kramer and Schreurs (1988), p. 27; 11 from Dostwoud Wijdenes (1990), p. 69; 12 from SMO (1988).

5 The question in this survey is not completely comparable to others because the regret is explicitly related to the career. 
market conditions. The relation between choice and labour market condition is measured by the elasticity. If a study itself did not provide elasticities, it has been calculated for the most recent year in the study. All results in this section concern higher education, simply because these are the only studies of this kind.

TABLE 4.5: ESTIMATES OF THE ELASTICITY OF SUPPLY FOR HIGHER EDUCATION IN RESPONSE TO WAGES.

\begin{tabular}{l|ll}
\hline Study & Sample & Supply \\
\hline Psacharopoulos (1973) & US, time series & 0.45 to 2.18 \\
Tinbergen (1974) & countries & 0.54 to 2.64 \\
Willes and Rosen (1979) & US, individuals & 2.00 \\
Pissarides (1979) & UK, time series & 1.12 to 1.31 \\
Dolpin (1981) & UK, time series & 0.70 \\
Leffler and Lindsay (1981) & US, time series & 0.54 \\
& physicians & \\
Mattila (1982) & UK, time series & 0.86 to 1.39 \\
Freeman and Hansen (1982) & US, time series & 1.82 \\
Fiorito and Dauffenbach (1982) & US, time series & 0.53 \\
Kodde (1985) & NL, individuals & 1.39 to 1.99 \\
Huijsman et al (1986) & NL, time series & 0.34 \\
Paulsen and Pogue (1988) & US, time series & 0.95 \\
Stapleton (1989) & US, time series & \\
& adaptive expect. & 1.23 to 1.25 \\
& rational expect. & 1.13 to 1.80 \\
Whitfield and Wilson (1991) & UK, individuals & 1.30 \\
\hline
\end{tabular}

Tables 4.5 and 4.6 provide measurements of the elasticity of supply in response to wages. A similar survey is provided by Freeman (1986, 1987). Some studies distinguish several measurements of the elasticity. In that case the tables provide the range of their estimations. In accordance with Freeman's results these tables show that the elasticity varies roughly between 0.5 and 2.0 . 
TABLE 4.6 ESTIMATES OF THE ELASTICITY OF SUPPLY AND DEMAND FOR HIGHER EDUCATION IN RESPONSE TO WAGES. ALL SAMPLES ARE TIME SERIES.

\begin{tabular}{l|lll}
\hline \hline Study & Sample & Supply & Demand \\
\hline Freeman (1971) & US, engineers & 3.0 & -10.0 \\
Freeman (1975a) & US, lawyers & 2.25 & -10.0 \\
Freeman (1975b) & US, physics & 1.05 to & -7.14 to \\
& & 3.64 & -3.85 \\
Scott (1979) & US, Ph.D. economists & 0.89 & -4.38 \\
Hansen et al (1980) & US, Ph.D. economists & 0.73 & -0.087 to \\
& & & -0.015 \\
Huffman and Orazem & US, agricultural economists & 0.43 to & -0.65 to \\
(1985) & & 0.48 & -0.59 \\
\hline
\end{tabular}

Table 4.6 also provides results for the elasticity of demand in response to wages. This elasticity varies much more, from -10.0 to -0.015 . These estimates are probably relatively poor. It is remarkable that the estimates below -1.0 are obtained from a regression relating wages to demand, while the estimates above -1.0 are obtained from a regression relating demand to wages. This might indicate a large bias due to errors in variables.

Most studies relate educational choice to wages. Only a few studies take unemployment into account, while the relation with other possible labour market variables, such as job level and working conditions are not investigated in literature. Table 4.7 provides the results of two studies which take into account the probability to get a job. The variation between these two studies is rather large.

TABLE 4.7: ESTIMATES OF THE ELASTICITY OF SUPPLY AND DEMAND FOR HIGHER EDUCATION IN RESPONSE TO THE PROBABILITY TO GET A JOB.

\begin{tabular}{l|lll}
\hline \hline Study & Sample & Supply & Demand \\
\hline Freeman (1980) & US, time series & 0.29 & -1.28 \\
Kodde (1985) & NL, individuals & 2.33 & \\
\hline
\end{tabular}

Although the elasticities in the studies presented in this section vary, which may also be caused by variations in sample, they all indicate that both wages and the probability to get a job influence the choice of students significantly. It may be concluded therefore that labour market conditions indeed play a role in the choice and that uncertainty with 
respect to these variables causes mismatch.

\subsection{Compartmentalisation of the Labour Market}

In this section the question is investigated whether the educational choice is a crucial decision in the sense that by making the choice for one direction, other possibilities are excluded. This is an important question because if the educational choice has no real consequences for the occupational possibilities, this choice is not relevant to mismatch on the labour market.

In this section two indicators are provided which measure the compartmentalisation of the labour market. Firstly, the extent to which (academic) students with different educational background, end up in different occupations is presented. Secondly, a measure of compartmentalisation based on the duration of vacancies is presented.

Students with different educational backgrounds will in general get different occupations, but the relation between education and occupation is of course not a purely one-to-one relation. Based on data on the occupation of people with a certain (university) background it is possible to measure the similarity in the occupations. In this study data are used from the Dutch census and the Dutch Labour Market Censuses (AKT), about the distribution of twelve types of university studies over different occupations. If $f_{i k}=A_{i k} / A_{i}$ is the fraction students in occupation $k$ of education $i$, than this similarity can be measured by the cosine-measure: ${ }^{?}$

(4.1) $\operatorname{Sim}(i, j)=\frac{\sum_{k} f_{i k} f_{j k}}{\sqrt{\sum_{k} f_{i k}^{2} \sum_{k} f_{j k}^{2}}}$

The similarity equals 1 if $i=i i$ and the similarity equals 0 if $f_{i j}=0$ if $f_{i j} \neq 0$ and $v . v$.

Borghans (1992a) measures these similarities, corrected for observed similarities between occupations. This measure provides a matrix with similarities between studies. Table 4.8 provides for 7 years the average similarity for the 144 cases, weighted with the distribution of people over the studies. 
TABLE 4.8: AVERAGE SIMILARITY

BETWEEN 12 ACADEMIC STUDIES IN THE NETHERLANDS. ${ }^{8}$

\begin{tabular}{c|c}
\hline \hline year & average similarity \\
\hline 1947 & 0.20 \\
1960 & 0.15 \\
1971 & 0.21 \\
1979 & 0.21 \\
1981 & 0.21 \\
1983 & 0.28 \\
1985 & 0.26 \\
\hline
\end{tabular}

The results indicate that indeed the market for university trained students is segmentated although the separation is not complete and the similarity has increased in recent years. The similarities are averages. For particular studies the similarity with other types of education may differ from this. Medicine, pharmacology, languages, and theology have very low similarities with other studies, while management science, economics, and law have high average similarities. The segmentation indicated by these calculations tends to be too low. The academic studies are clustered in twelve groups, and also the occupations are clustered. It may be the case that students with different studies fulfil completely different jobs, which are nevertheless clustered in one class of occupations. The results of these calculations depend very much on the specific clustering used.

Another way to measure the compartmentalisation of the labour market is by use of data on the duration of vacancies. The moment in which a vacancy arises does not generally coincide with the moment a student becomes available to the labour market. Therefore, if every vacancy gets filled by a new entrant at the labour market an employer has to wait on average

(4.2) $T_{v}=\frac{1}{F_{S}}$

for the next entrant, in which $T_{v}$ is the average duration of a vacancy and $F_{S}$ is the flow of people starting to search for a job. The

8 See Borghans (1992a), p. 17. Data from the Dutch censused 1947, 1960, and 1971 and the Dutch Labour Force Censuses 1979, 1981, 1983, and 1985. 
compartmentalisation of the market makes, however, that not every student satisfies the employers' needs. The more compartments on the market $(M)$, the longer the employer has to wait on average for an appropriate candidate.

$$
\text { (4.3) } T_{v}=\frac{M}{F_{s}}
$$

This formula allows to estimate $M$. In case of unemployment, or a stock of people already searching for a job, there also is a probability that one of the unemployed is available directly for the vacancy. By assuming the same compartmentalisation $M$ for the stock of searchers $(S)$, the probability of not finding a candidate directly among the searchers is $\exp \left(-\frac{1}{M} S\right)$. Therefore, the average duration of a vacancy becomes:

(4.4) $T_{v}=\frac{M}{F_{S}} e^{-\frac{1}{M} s}$

FIGURE 4.1: 5 YEARS MOVING AVERAGE ESTIMATION OF NUMBER OF COMPARTMENTS $M$ ON THE DUTCH LABOUR MARKET, WITH THE $95 \%$ CONFIDENCE INTERVAL. ${ }^{9}$

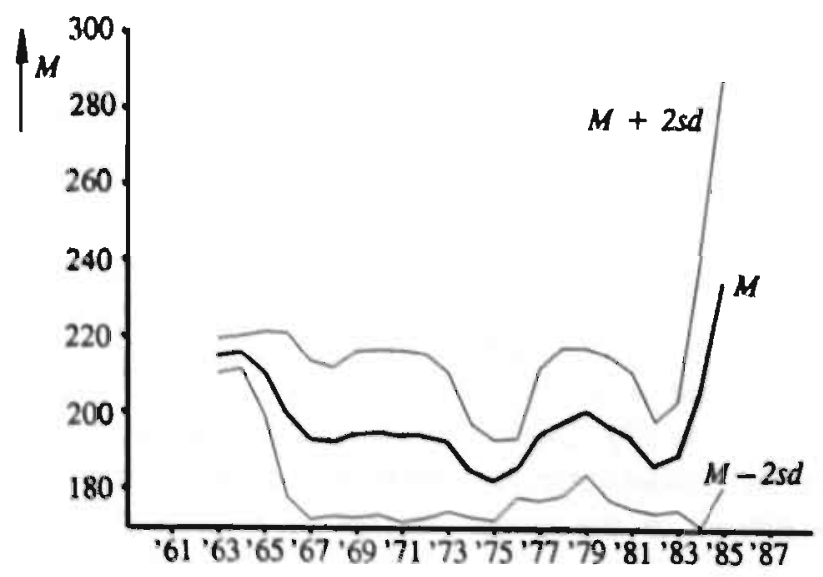

In recent economic literature (e.g. Blanchard and Diamond (1989), Jackman, Layard, and Pissarides (1989) and Van Ours (1991)), the relation between job-searchers and vacancies is usually modelled as a 
matching production function. The main difference with (4.4) is, apart from the functional form, the role of the flows in the model. In a search model a large flow of matchings is seen as a high productivity of the matching function, while in (4.4) a high flow of new searchers indicates large possibilities for employers to find an appropriate employee within a short time-period.

Figure 4.1 shows the results of the estimation of this equation for a moving time-period of 5 years. An estimation over the whole period results in $M=210(s d=7.45)$. Through time the compartmentalisation first decreases slightly, but later increases again. This increase is, however, not significant. It should be noted that (4.4) explains all variation in the vacancy duration as a result of the compartmentalisation. Therefore $M$ may also contain other influences, so $M$ should be interpreted as a representative number of compartments. In job search models (Blanchard and Diamond (1989), Jackman, Layard, and Pissarides (1989) and Borghans (1992b)) only an increase in the matching inefficiency is found in this period. From a job search model point of view this increase indicates a decreased search intensity at the market. The results of the analysis in this section may on the other hand be interpreted as increased selectivity with employers. The large amount of unemployed and other job searchers reduces the average duration of vacancies which makes it profitable for employers to be more selective.

\subsection{Fluctuations on the Labour Market}

In the previous sections evidence has been presented on the difficulty of educational choice, the large numbers of students who regret their choice, the influence of labour market conditions on the choice and the cruciality of the educational choice. In this final section on evidence for mismatch, figures are presented which indicate the extent of fluctuations of labour market variables. Large fluctuations make it necessary for students to anticipate the future labour market at the moment they enter the market. Basing the choice on the current instead of the future situation creates, due to the large fluctuations, a large mismatch.

In this section two examples are given. The first, about the market for teachers, indicates fluctuations in the demand for teachers, and in the second, about lower technical education, fluctuations in relative wages and the probability to get a job are indicated.

In table 4.9 results are presented about the market for primary school teachers. The demand for new teachers is split up into three 
components. ${ }^{10}$ The first component is the replacement demand, while the second and the third refer to expansion demand. Replacement demand is demand for new teachers due to the departure of others, who create a vacancy. Expansion demand is demand due to new places. The extension demand is again split up into a demographic component and a policy component. The demographic component is constructed by imposing the student/teacher ratio from year $t$ upon the change in the number of children at primary school between year $t$ and year $t+1$. This figure indicates the demand for teachers that would be created due to a growth in the number of children, under the assumption that the average class size does not change. The remaining part of the extension demand is called the policy component, because it is caused by (intended or unintended) changes in the student/teacher ratio. Table 4.9 gives the variability of these components, which is, e.g. for the replacement demand, defined as:

$$
\sigma_{\text {Repl }}^{2}=\frac{1}{T} \sum_{t}\left(\frac{\operatorname{Repl}_{t}-\operatorname{Repl}_{t-1}}{D_{t}}\right)^{2}
$$

in which Repl, represents the replacement demand, and $D$, the total demand at $t$.

TABLE 4.9: VARIABILITY OF THE THREE COMPONENTS OF THE DEMAND FOR TEACHERS FOR 1950-1980 AND SUB-PERIODS.

\begin{tabular}{l|ccc}
\hline & $' 50-' 60$ & $770-' 80$ & $' 50-' 80$ \\
\hline replacement demand & 0.006 & 0.080 & 0.042 \\
demographic comp. & 0.032 & 0.005 & 0.017 \\
policy componemt & 0.006 & 0.027 & 0.057 \\
\hline
\end{tabular}

The table shows that while the variability of the demographic component decreased, the variability of the replacement demand and the policy component increased over time. Assuming independency of the thrce components results in a total variability of 0.116 , which is comparable to a yearly shift of $34 \%$ in the demand.

Table 4.10 provides similar figures for the variability of wages and the probability to get a job for technicians. Two sectors, building industry and metal industry are distinguished, which are compared with the food and catering industry. 
Measured over the whole period the variability of these wages and probabilities to get a job are much lower than the variability of the demand for teachers, although e.g. the variability of the wages in the building industry is comparable to a $3 \%$ shift in the wages yearly. The main cause for this is most likely the fact that these wages and probabilities to get a job refer to the whole stock of workers and not only to starting employees.

TABLE 4.10: VARIABILTY OF WAGES AND THE PROBABILTTY TO GET A JOB FOR THE DUTCH BUILDING INDUSTRY AND THE METAL INDUSTRY COMPARED TO FOOD AND. CATERING INDUSTRY', FOR THE PERIOD 1951-1985."

\begin{tabular}{l|cc}
\hline \hline & wages & prob. to get a job \\
\hline building industry & 0.000929 & 0.000702 \\
metal industry & 0.000328 & 0.000128 \\
\hline
\end{tabular}

FIGURE 4.2: VARIABILITY OF THE WAGES BASED ON AN 11 YEAR MOVING AVERAGE.

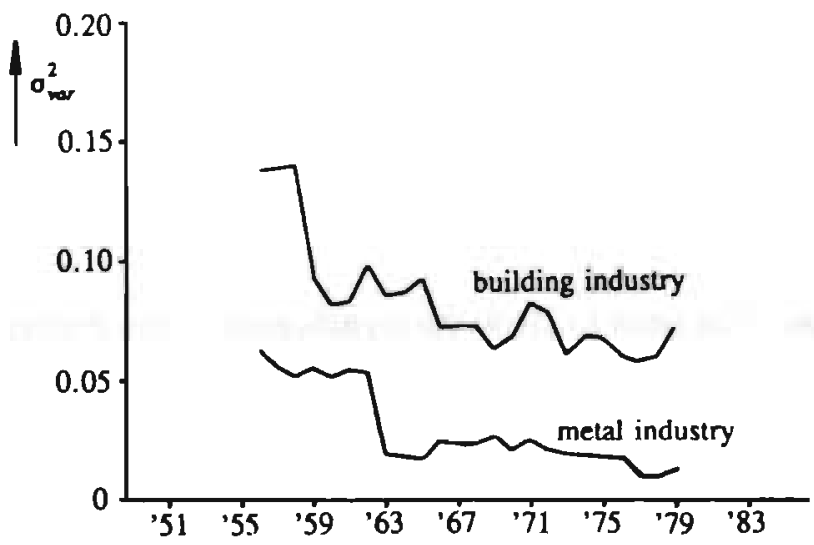

The variability of these labour market variables remained far from constant during the years. Figures 4.2 and 4.3 show the development of the variabilities, based on an 11 year moving average. They clearly show that, while the variability of the wages decreased slightly, the variability of the probability to get a job increased dramatically from the 
end of the seventies. Both empirical examples show that the labour market conditions do not remain constant. Together with the evidence in earlier sections of this chapter, which show that students face problems in correctly anticipating the future labour market, the extent of these changes indicates a possible large mismatch due to these wrong anticipations.

FIGURE 4.3: VARIABIL.ITY OF THE PROBABILITY TO GET A JOB BASED ON AN 11 YEAR MOVING AVERAGE.

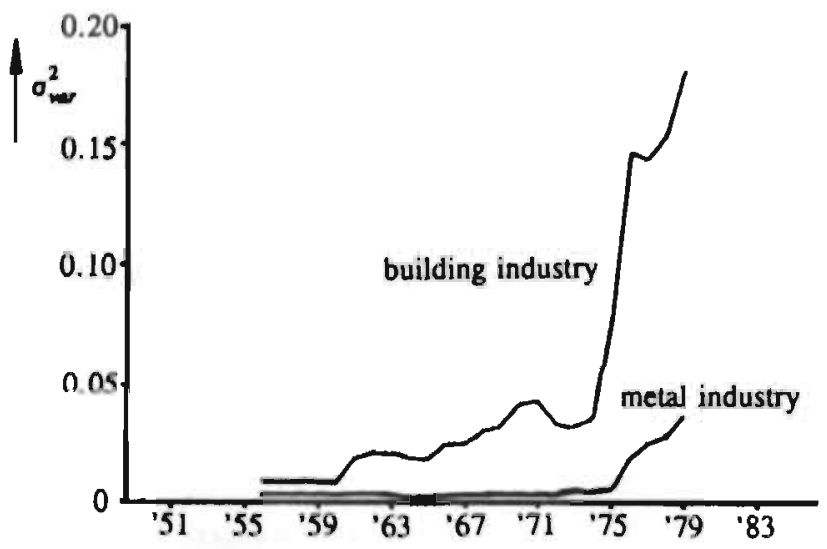

\subsection{Conclusions}

The aim of this chapter has been to show the significance of the concept 'mismatch' for the Dutch labour market. It is, however, not passible to find one single figure that can prove this relevance. Therefore, in this chapter different kinds of empirical evidence have been given which together indicate the importance of an improved match between education and the labour market.

In section 4.1 it is shown that students would like to get additional (labour market) information and that afterwards many students regret their choice. Section 4.2 gives an overview of the elasticities of supply. These indicate that at least a group of marginal students is affected in their educational choice by changing labour market prospects. In section 4.3 some evidence has been given regarding the compartmentalisation of the Dutch labour market. It is shown that the educational choice influences the labour market possibilities of students. Finally, in section 4.4 it is shown that changes on the labour market are large enough to 
make some anticipation necessarily. It does not suffice to base the educational choice on the current labour market situation. 



\section{THE PROVISION OF INFORMATION AS AN ECONOMIC POLICY INSTRUMENT}

As stated in the introduction, the provision of labour market forecasts to students is an economic policy instrument which may improve the allocation of educated workers and may stabilise wages. Although both improved allocation and stabilisation are generally accepted aims of economic policy, most textbooks on public economics do not mention the provision of information as an instrument.

This chapter gives a short sketch of the theory of economic policy, as an orientation for the provision of information as an economic policy instrument. Although the views on economic policy described in this chapter mainly stem from macro-economic theory, the basic thoughts in these theories seem to be influential in all economic research.

\subsection{Tinbergen's Economic Policy}

The most influential view on economic policy has been described by Tinbergen (1952, 1956). Based on his early experiences with econometrics he develops a theory for government influence on the economic process.

Tinbergen distinguishes three types of economic policy, quantitative policy, qualitative policy and reform. Quantitative policy "consists mainly in the adaption of the economy to the continuous changes in data that threaten to upset its equilibrium' (1956, p. 48). Qualitative policy refers to 'problems in which the structure of the economy is changed' (1956, p. 149). Reforms are defined 'as changes in the more fundamental features of social organization: those affecting spiritual aspects of society and essential relations between individuals' (1956, p. 186).

The provision of labour market information clearly belongs to the category of quantitative policy. Tinbergen (1952, p. 4) presents a scheme for such economic policy:

(i) the fixation of a collective preference indicator;

(ii) the deduction, from this indicator, of the targets of economic policy generally;

(iii) the choice of "adequate" instruments, qualitative and quantitative; (iv) the determination of the quantitative values of the instrument variables, as far as such instruments are chosen and

(v) the formulation of the connections between (a) the relation between targets and quantitative variables on the one hand and $(b)$ the structure of the economy studied on the other hand.' 
It is, however, not easy to put the provision of labour market information in this framework. Tinbergen regards, according to Lucas $(1976$, p. 21), the structure of the economy as a difference equation

(5.1) $y_{s+1}=f\left(y_{p}, x_{r}, e_{t}\right)$

in which $y_{t}$ is a vector of state variables, $x_{t}$ a vector of exogrenous forcing variables, and $\epsilon$, a vector of independent, identically distributed random shocks. The art of economic policy according to Tinbergen is to find an adequate description of $f$, and, based on this to calculate the appropriate vaiues of $x_{t}$ to obtain the preferred value of $y_{t+1}$.

Tinbergen's theory of economic policy is based on two fundamental points. Firstly, he assumes that it is possible for the policy maker to know $f$. Although Tinbergen pays much attention to the problems of finding the exact form of the model of the structure of the economy, he believes, according to e.g. Haavelmo (1944), that after sulficient investigations $f$ will be approximately known, making the economic policy possible.

Secondly, Tinbergen assumes the system of the economy to be closed and fixed. The model will, of course, contain equations about the people's behaviour, but Tinbergen believes this behaviour is sufficiently predictable and can therefore also be described in a mathematical equation. Expectations may for example play a role in the model, but these expectations are, according to Tinbergen, functions of data in the model and can therefore also be described by mathematical equations.

For studying the effects of the provision of labour market information on the functioning of the economic system this view on economic policy is not very useful. Firstly, the assumption that the policy maker knows the model $f$ trivialises the problem of the possibility of mistakes in public forecasts. Secondly, the mechanistic form of the economic system does not make clear what the use of additional information would be in the system. Since people's reactions are given, there are no opportunities, for influencing these reactions. In connection to this, Tinbergen's model devolves all responsibilities to the government. While the government has the task to adjust its behaviour to the economic targets, other people are assumned simply to react in a mechanistic way to the circumstances. A main point of providing information to students is, however, that on the one hand students, need assistance and expert information to make their choice, but on the other hand students are eventually responsible for their own educational choice. 


\subsection{Lucas's Critique}

The econometric program of Tinbergen and Haavelmo led to great optimism regarding the possibilities of economic policy. The results were, to some extent, disappointing. It appeared to be very difficult to find appropriate descriptions for the model $f$. In 1976 Lucas published a critique on the econometric program in which he stated that it was not the problem of finding the appropriate form for $f$ which caused the disappointing results. In his view there is a more fundamental problem, which is the assumed mechanistic behaviour.

According to economic theory people will optimally react to their circumstances, and therefore a reaction function which is optimal under one type of government behaviour may not be optimal once this government behaviour has changed. Therefore people may change their reaction function if the government adopts a new policy. Lucas therefore states that the right formulation of the economic policy theory is based on policy rules and not on incidental values of the exogenous forcing variables. In his alternative specification:

$$
y_{t+1}=f_{\theta}\left(y_{t}, x_{t}(\theta), \epsilon_{t}\right)
$$

the policy rule $\theta$ determines the values of the forcing variables $\left(x_{r}(\theta)\right)$, but might also influences the structure of the model $f_{\theta}$, since reaction functions will adjust to the new policy.

Lucas explicitly takes into account people's autonomous behaviour in his model of 'democratic decision making' (Lucas ,1976, p. 42). In his model the description of the economic system $f_{\theta}$ remains, however, known by the policy maker. Furthermore, his interpretation of the optimising behaviour of the people is based on rational expectations, which assume that the 'true model' also is known to the people. Based on his democratic principle he not only assumes that people act in accordance with their aims, but also that everybody has the same (perfect) capabilities to do this.

It will be clear that also Lucas's variant of the theory of economic policy is not useful for the study of the concept provision of labour market information. On the one hand his economic system is (in principle) knowable to the government, thereby excluding main errors in public forecasts, while on the other hand everybody is assumed to have this perfect insight, making the provision of information from experts to laymen redundant. 


\subsection{The Neo-Liberal View on Economic Policy}

One of the fundamental properties of Tinbergen's model of economic policy is that the model of the economic system is (in principle) knowable by the policy maker. Lucas added to this model the property that not only the government, but also the economic agents know this true model. This extension is very often seen as too strong and unrealistic, but the question is whether this assumption, departing from the Tinbergen's model, can be avoided. According to Lucas (1976, p. 25) "we have to attribute to individuals some view of the behaviour of the future values of variables of concern to them'. If this attributed view of the individual agents is inconsistent with the true model of the economic system, the agents are assumed in the model to behave in a way which is a priori not optimal for them. The assumption that everybody is equally capable to analyse the market is for Lucas (1976, p. 42) essential for 'democratic decision making'. For the study of the effects of providing labour market information the assumption that everybody perfectly analyses the economic situation will, however, not be fruitful. It excludes the possibility of an incorrect public forecast and it excludes in advance possible gains from information from experts to laymen.

In the neo-liberal economic thought (e.g. the Austrian school and the Freiburg school) two themes, closely connected to this problem, play an important role. Firstly, for example Von Mises and Kirzner stress the role of errors in the economy. Secondly, especially Hayek has discussed the problems related to the fact that knowledge in the economy is not known by one single person.

Kirzner (i978) remarks that 'economists have traditionally been concerned with issues related to efficiency. Inefficient action occurs when one places oneself in a position which one views as less desirable than an equally available alternative state of affairs. Inefficiency can therefore not be thought of except as the result of an error, a mistake, an incorrect and wrong move' (pp. 57-58). But, he continues, 'at the same time, however, as he directs his energies toward the obviation of error, the contemporary economist is frequently to be found pursuing his analysis on the assumption that men do not, and will not, ever fall into error' (p. 58).

In the neo-liberal economic thought the possibility of errors is fundamental. "The market is a process. The state of the market is continually changing. The market process is characterized by profits and losses as the judgements made by entrepreneurs turn out to be correct 
or incorrect' (Littlechild, 1990, p. 52). In this continually changing economy it is unavoidable to make errors, but some people turn out to be better in judging the market than others, and therefore these experts become entrepreneurs. In this thought the capabilities in analysing the economy might differ between persons and therefore Lucas's democratic principle does not hold.

Hayek (1945, p. 519) raises the question 'what is the problem we wish to solve when we try to construct a rational economic order? On certain familiar assumptions the answer is simply enough. If we possess all the relevant information, if we can start out from a given system of preferences and if we command complete knowledge of available means, the problem which remains is purely one of logic'.' 'This, however, is emphatically not the economic problem which society faces. And the economic calculus which we have developed to solve this logical problem, though an important step toward the solution of the economic problem of society, does not yet provide an answer to it. The reason for this is that the "data" from which the economic calculus starts are never for the whole society "given" to a single mind which could work out the implications, and can never be so given.'

From this point of view it seems possible to improve individual decisions by transferring information from experts to laymen. Hayek, however, rejects this. 'It may be admitted that, so far as scientific knowledge is concerned, a body of suitable chosen experts may be in the best position to command all the best knowledge available - though this is of course merely shifting the difficulty to the problem of selecting the experts' (Hayek, 1945, p. 521). This rejection is, however, most likely not based on economic but on political motives, which are always largely interwoven in neo-liberal thought. The argument that finding an expert is equally difficult as analysing the problem is not very convincing. Hayek's rejection of expert influence on individual decisions is probably inspired by his fear for 'the dangers that the then visible collectivist tendencies created for personal freedom' (Hayek, 1990 , p. 439).

The Freiburg school has more confidence in the government. Also based on the possibilities of errors in the economic process Röpke stresses the role the government has in improving the economy. The policy influence should, however, not eliminate the flexibility of the economic system. 'Regarding the fluctuations in the conditions of the economy and in the resulting economic activity, it is necessary to give 
priority to permanent adjustment and balancing. This is, however, only possible, if the economic system is as flexible as possible in all its parts' (Röpke, 1949, pp. 272-273). ${ }^{2} \mathrm{He}$ compares the economic system to a bicycle. It may be necessary for the government to steer, but if the government fixes the handlebars, the bike will fall (Röpke, 1949, p. 273).

Although Röpke does not refer directly to public forecasts, this policy instrument seems to fit perfectly in his thought. By providing information the government influences the economic process. But since information leaves the decisions to the individual agents, the flexibility of the system is not affected.

According to Röpke (1949, p. 190) some specific problems occur in the relation between education and the labour market, which need special attention. 'A similar problematic exception in the price-making process is to be found on the labour market, where the law of prices may be used in a similar way as on the goods markets. While the elasticity of demand for labour differs for every part of the business cycle and will decrease sharply during a depression, the elasticity of the supply is, at least for the qualified occupations, really low, since human labour force in case of a lack of economic capacity can not be "stored" for a long time, and also because in the short term due to long terms of education and the strong inflexibility can only be extended within a very limited range. This low elasticity of supply may be increased by all kinds of social political measures, for example by unemployment benefits, which increase the "storability", by improvement of the employment services etc. The longer the period of education, the longer the delay in adjusting the supply to the market situation, and the more difficult it will become. For this the academic labour market is a good example, where in every single occupation surpluses and shortages alternate very easily, and therefore the advice of a wise uncle for his nephew, to study the subject which at the moment faces the largest surpluses, becomes understandable, - an advise, which remains wise, as long as there are not too many uncles and nephews of this kind. ${ }^{3}$

2 'Angesichts der Schwankungen in den Wirtschaftsbedingungen und der daraus sich ergebenden Schwankungen der Beschâftigung ist die Notwendigkeit der stündigen Ampassung und Ausgleichung an die. Spitze zus stellen. Das ist aber nur mőglich, wenn der Wirtschaftsapparat in allen seinen Teilen mōglichst beweglich ist. .

3 'Einen solchen problematischen Sonderfall der Preisbildung stellt im aflgemeinen auch der Arbeirsmark dar, auf den die Preisgesetze in gleicher Weise angewandt werden kōnnen wie auf die Warenmărkte. Während die Elastizităı der Nachfrage nach Arbeitskcrătten in den eiruelnen Kunjunkturphasen verschieden ist und in der Depression außerordentlich tief sinkt, ist die Elastizităt des Angebots, zum mindesten für die qualifizierten Berufe, recht 


\subsection{Conclusions}

This chapter started from the observation that most textbooks on public economics do not mention the provision of information as an instrument of economic policy. It is shown that this ignorance might be caused by the current views on economic policy.

In Tinbergen's $(1952,1956)$ view - which is the most influential - the economic system can be described by some quantitative relationships. These relationships are assumed to be known by the government and therefore it can control the system. People's expectations are a part of the description of the system. Economic policy therefore may influence expectations indirectly by changing the economic control variables, but does not change the mechanisms themselves. In Tinbergen's model the government takes all the responsibilities for the optimal control of the economy. People's behaviour only serves as a relationship which has to be taken into account.

Lucas (1976) showed that in order to make economically sense the expectation formation schemes in Tinbergen's model must depend on the economic system as such. While according to Tinbergen only the government controls the economic relationships, Lucas's democratic principle states that all agents will have optimising behaviour. Since Lucas also departs from a knowable economic system, this does, however, not lead to the need for public information. Because people act optimally within this knowable economic system their expectations are a priori optimal.

The neo-liberal view on economic policy does not depart from a knowable economic system. Instead they describe the economy as continually changing, in which it is unavoidable to make errors in forecasts. Since some people are better in judging the market than others, in this theory there may be possibilities to let experts provide information to laymen. For the Austrian school, however, personal

gering, da die menschliche Arbeidskraft bei mangelnden Vermögensreserven nícht lange "gelagert", aber auch auf kürzere Fristen wegen der lăngeren Ausbildungszeit und der starken Unbeweglichkeit nur in geringen Grenzen vermehrt werden kann. Diese geringe Elastizităt des Angebots kann durch allerlei sozialpolitische Maßnahmen erhōht werden, so durch die Arbeidslosenunterstützung, die die "Lagerungsfähigkeit" erhöht, durch Verbesserung der Arbeitsvermittlung u.a. Je lănger die Ausbildungsperiode ist, um so mehr verzögert sich die Anpassung des Angebots an die Marktlage, um so schwieriger wird sie zugleich. Dafür ist der akademische Arbeitsmarkt ein gutes Beispiel, wo in den einzelnen Berufen leicht Überfullung und Unterbesetzung miteinander abwechseln, so das der Rat eines weisen Onkels an seinen Neffen verständlich wird, das im Augenblick am meisten überlaufene Fach zu studieren, - ein Rat, der Weise bleibt, so lange es nicht zu viele solcher Onkel und Neffen gibt." 
liberty is a very important political issue, which makes the provision of public information unacceptable. For the Freiburg school these political motives are less important. Therefore, although they do not refer directly to public forecasts, this policy instrument seems to fit perfectly in their thought. 


INFORMATION 

Expectations play an important role in the study of the effects of providing public labour market information. The concept of expectations has, of course, been recognised important in economics for a long time, at least since the beginning of this century. The meaning of this concept is part of an economic theory and with the changes in the economic thought, the meaning of the concept 'expectations' has also changed. While the first part of this study was devoted to mismatch, in this second part on information, an interpretation will be given of the fact that students make prediction errors. This interpretation makes it possible to derive how information can be used to improve students" predictions and thus to decrease mismatch. In this chapter the history of 'expectations' in economic thought is discussed. This historical framework aims to show how the concept of expectations depends on the more general economic thought, which may clarify the crucial relationship between the way of economic thought and the meaning of this specific concept.

\subsection{The Cobweb Model}

In 1930 Ricci, Tinbergen, and Schultz published studies containing the first explicit models of a theory on expectations, which has since become known as the 'cobweb theorem'. The name orginates from Kaldor (1934). The cobweb theory has been the first explicit economic theory about expectations formation. The well-known cobweb mechanism is clearly explained by figure 6.1 which is an illustration of Schultz (1930).

The figure shows a demand curve DD' and a supply curve SS'. Their intersection is the equilibrium point, but suppose that initially supply has been very low, and therefore the price was very high $(a)$. The essential cobweb assumption is that suppliers base their investment decision on this price. They are not able to anticipate perfectly the price as a function of their behaviour, but simply assume that the current price will prevail in the future. This leads to a too large supply (b), and therefore prices fall very sharply $(c)$. These low prices cause the supply to be very low and therefore prices will go up again. The mechanism produces a cycle in prices and quantities, shown in part B and $\mathrm{C}$ of the figure. 
in the supply curve to be distinguished from fluctuations in the demand curve.

Moore (1929) invented an alternative approach to identify these relations. His assumption is that changes in prices and quantities through time are not caused by shifts in the supply and demand curve, but are caused by deviations from the equilibrium. Since suppliers have to make their supply decisions in advance they may make errors which cause fluctuations in the supply. These fluctuations make it possible to identify the demand curve, in which no errors occur. If in addition the assumption is made that suppliers base their decision on the price at the moment their decision has to be made, also the relation between prices and supply can be identified.

Thus, Moore discovered that the cobweb model made it possible to identify a model which had seemed to be unmeasurable. Ricci $(1930, \mathrm{p}$. 653) describes Moore's method: 'With respect to the supply curve, Moore uses a brilliant tool. Since the price in one year affects the production in next year, he pulls down the column of prices one row, and calculates the supply curve with the same data, which already served to determine the demand curve. ${ }^{5}$

The cobweb theory, therefore, provided a theory of expectations which included the idea that people could make prediction errors and made it possible to estimate the supply and demand curve. A fundamental issue in the theory is the assumption that people expect the current price to prevail in the next years.

In the static Walrasian model, equilibrium prices reflect the total availability and utility of goods in a society, indicating their 'subjective' value. It is therefore sufficient for people to be price taker, i.e. to compare their own subjective utility with the prices. Kaldor $(1934$, p. 123) illustrates this view by defining "perfect knowledge" as "all the relevant prices quoted in all markets are known to all individuals' (italics added). In a dynamic context, however, this leads to the paradox of the general equilibrium model. 'It so happens that the general equilibrium comes about, on the one hand by consumers and companies, maximising their utility, and profit respectively, while on the other hand supply and demand for every good are equal. The latter condition determines the prices. Prices are, however, for consumers and

5 'In bezug auf die Angebotskurve verwender Moore ein brillantes Hilfmittel. Da der Preis eines Jahres auf die Produktion des folgenden Jahres einwirkt, rūckt er die K.olonne der Preise um eine Zeile nach unten, und berechnet mit den gleichen Daten, die schon zur Bestimmung der Nachfragekurve gedient haben, die Angebotskurve." 
companies constant parameters. ${ }^{16}$

The (classic) idea that the price of a good reflects its value, and that this value can be thought of as a property of the good is still dominant in the economic thought of the thirties. Of course, prices may deviate slightly from the value but in the long run they tend to the equilibrium or normal price. 'The normal price is that price at which the market price would tend to settle over a period of time long enough to bring quantities demanded (by purchasers) and quantities produced into an equilibrium' (Ezekiel, 1938, p. 261).

Hicks (1935, p. 29) cites Pareto who defined 'the economic equilibrium is the state which preserves eternal, if there is no change of the conditions in which it is observed'. " Equilibrium of prices was equivalent to constant prices. Hicks remarks that in order to extend this static equilibrium concept to a dynamic equilibrium concept the condition must be added that people correctly forecast all changes that will occui. Morgenstern (1935, p. 344) thinks that such perfect forecasts will be impossible. People should take all future relationships into account. 'There is aiways an ininite chain of mutually suspected reactions and responses to be taken into account. This chain can never be broken off by an act of knowledge, but always by an arbitrary act, by a decision. ${ }^{8}$ But on the other hand he concludes that 'besides the assumption of perfect, unlimited foresight, [...] also the assumption that there is no foresight at all has to be excluded' (p. 345). "It may therefore be maintained, that a somehow positive degree of "knowing" about future relations, i.e. a with more or less probability provided assumption about the future, indispensable for economic practice. This is for example expressed in the fact that individuals refrain from a purchase which is possible today, because experience showed them, that these prices will not change until tomorrow, or the day after tomorrow, etc. Would it be impossible for them to make such assumptions, but also to make any assumption, then every suspicion about tomorrow's

6. Lange (1935), p. 359. 'Das allgemeine wirtschaftliche Gleichgewichi kommt nămlich dadurch zustande, daß einerseits die Konsumenten und die Unternehmer ihren Nutzen, bzw. ihren Profit maximalisieren, wăhrend andererseits das Angebot und die Nachfrage für jedes Gut gleich sind. Durch die letztere Bedingung werden die Preise bestimmt. Die Preise sind aber für die Konsumenten und für die Unternehmer konstante Parameter."

7 'L'equilibre économique est l'état qui se maintiendrait indéfinement s'il $n$ ' $y$ avait aucun changement dans les conditions dans lesquelles on l'observe.'

8 'Immer liegt eine unendliche Kette von wechselseitig vermuteten Reaktionen und Gegenreaktionen vor. Diese Kette kann niemals durch einen Akt der Erkenntnis, sondern immer nur durch einen Willkūrakt, durch einen Entschluß abgebrochen werden.'

9 'Neben der Annahme der vōlligen, unbeschränkten Voraussicht scheidet. aber auch [...] die. Annahme aus, es bestūnde überhaupt keine Voraussicht.' 
prices would be equally probable' (p. 345). ${ }^{10}$

People are, atcording to this theory, not able to forecast perfectly what is going to happen in the future, what would be necessary for dynamic equilibrium, but they may use the past and present as an orientation. Pcople interpret these data. The cobweb theory assumes that people interpret the current price in the same way as economists do. The current price reveals the relation of supply and demand, which is likely to persist.

The economists of the cobweb theory are very well aware of the paradox which is generated by this assumed behaviour. Mostly they stress that the cobweb assumption should not be taken too strictly. It is not necessarily the case that people do not anticipate future developments, but the opposite assumption that anticipations are perfect is even more unrealistic. "It is the supposition of this paper, rather, that estimates of conditions for future dates are wrapped in a thicker and thicker mist of uncertainty the more remote the date in question' (Hart, 1937 a, p. 69). Furthermore, 'entrepreneurs' estimates for the future are to be regarded as uncertain. [...], but the entrepreneur will not have perfect confidence in his guess' (Hart, 1937b, p. 285). This means that although people, e.g. in the cobweb theory, make errors in forecasting the future, it is not thought that they do not realise that they make such errors.

Tinbergen (1931, pp. 171-172) gives the clearest exposition of this problem of dynamics. 'While in static schemes only quantities appear of which the numerical values are assumed to be known to all subjects all quantities which will exists in future have the same value there as in the past - , in dynamics the fundamental situation appears, that certain future quantities are not known and therefore the subjects can only calculate with expectations, which they have with respect to these quantities."II is, however, not possible to state with certainty how

10 'Es kann also festgehalten werden, daß irgendein positiver Grad von "Wissen" um zukūnftiges Verhalten, d. h. eine mit mehr oder minder Wahrscheinlichkeit ausgestattete Annahme über die Zukunft für das Wirtschaften unentbehrlich ist. Dies drückt sich z. $\mathbf{B}$. auch darin aus, daß die Individuen heute durchführbare Käufe unterlassen, weil ihnen die Erfahrung gezeigt hat, dal sich die Preise bis morgen oder übermorgen usw. nicht verändern. Würden sie derartigen Annahmen nicht machen können, sondern überhaupt keine haben, so wăre jede Vermutung über die morgigen Preise gleich wahrscheinlich."

11 'Während in statischen Schema immer nur Größen vorkommen, deren numerischer Wert bei allen Subjekten als bekannt vorausgesetzt wird - alle Größen, die in der Zukunf bestehen werden, haben da eben denselben Wert wie in der Vergangenheit - , kommt in der Dynamik prizipiell der Umstand dazu, daß̧ bestimmte zukünftige Größen nicht bekannt sind und die Subjekte deshalb nur mit der Erwartung, die bezüglich des Umfangs dieser Größen haben rechnen kōnnen.' 
people will form these expectations. "These "expectations" show an important distinction opposite to the "real" quantities. They may, also in the case of full information, be different for individual subjects.' ${ }^{12}$ Tinbergen assumes that people who have to form the expectations understand economic relationships and use these in their expectation formation. He assumes ' $[\ldots]$, that the expectations are "reasonable", i.e. agree with the economic relationships. ${ }^{13}$ 14 This reasonability does according to Tinbergen not imply that expectations simply become a given quantity: 'This last assumption does, however, not contradict the fundamental property just posed'. ${ }^{15}$

According to Tinbergen only in some very specific situations the replacement of an expectation in the theory by a given quantity may be possible. 'In certain cases - and these will temporarily be the most successful in the analysis - the "expectations" might be replaced by economic deduction, by certain constants or real quantities. In relation to e.g. an expectation with respect to a quantity which is a "random variable", the reasonable expectation will be the mathematical expectation and therefore also a given constant. ${ }^{16}$ Most economic variables, however, can not be viewed upon as stochastic variables. Tinbergen's examples, mostly about uncertainty with respect to the weather conditions, are according to him only exceptions.

These specific examples bring Keuzenkamp (1989, p. 4) to the conclusion that Tinbergen 'explicitly uses rational expectations, but it disappeared under the dust of history'. Tinbergen's equalisation of the reasonable expectation with the mathematical expectations, however, only concerns random variables. Morgan (1987) shows that economists before Haavelmo (1944) reject the probability approach to economics. Tinbergen does not, as is typical for rational expectations, view all economic variables as random variables.

In his papers about reasonable expectations, Tinbergen $(1931,1933)$

12 "Die "Erwartungen" weisen gegenüber den "wirklichen" Größen einen wichtigen Unterschied auf. Sie können nămlich auch bei vollkommener Information, für einzelne Subjekte verschieden sein."

13 " $\ldots]$, daß die Erwartungen "vernünftig" sind, d. h. mit den wirtschaftilichen Zusammenhängen übereinstimmen.'

14 Tinbergen (1933) introduces the word 'reasonable' for 'vernünftig'.

15 'Die letzte Annahme widerspricht überigens nicht der soeben angegebenen essenziellen eigenschaft der Erwartungen."

16 'In bestimmten Fällen - und das werden vorläufig wohl die meist erfolgreichen bei der Analyse sein - kann man die "Erwartungen" durch wirtschaftsteoretische Deduktion, durch bestimmte Konstanten oder reelle Größen ersetzen. handelt er sich z. B. um eine Erwartung bexüglich einer Grôße, welche eine "zufallige Variable" ist, so ist die vernünftige Erwartung die mathematische and also eine bestimmte Konstante.' 
unfolds the tension in economic modelling of expectations between, on the one hand, the fact that people do have insight in the functioning of the economy, but on the other hand, the fact that despite this insight people make forecast errors. The economic reality is too complex and ambiguous to make possible an unequivocal interpretation. Cobweb theory incorporates the erroneous expectation behaviour of people, but at the cost of the notion that people have insight in some very general economic principles. In his subsequent work Tinbergen sticks to his choice for naive expectation schemes, apparently because he considers the erroneous character of expectations to be more relevant for practical research than people's insight in economic relationships.

\subsection{Critique on the Cobweb Theory}

From two different sources the cobweb theory was criticised. Firstly, there are some theoretical problems with this theory, and secondly, empirical research raised some doubts about the validity of the cobweb theory.

The theoretical problem the cobweb theory is posed to is the fact that its dynamic mechanism does not necessarily lead to convergence. Tinbergen (1930) already showed that, depending on the parameters of the model, price and quantity fluctuations may increase. Figure 6.2 gives his illustration of both a divergent (2a) and a convergent (2b) process.

FIGURE 6.2: ILLUSTRATION OF DIVERGENT (2a) AND CONVERGENT (2b) COBWEB PROCESS FROM TINBERGEN (1930, P. 671).

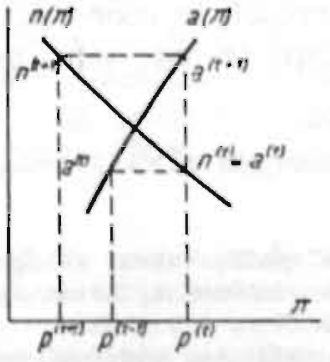

Ahl., ?

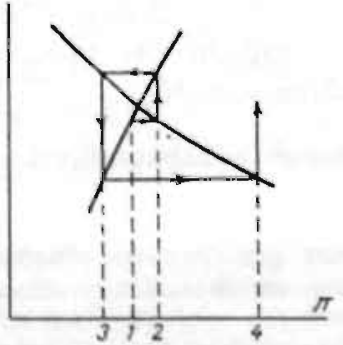

Abb. 2 a

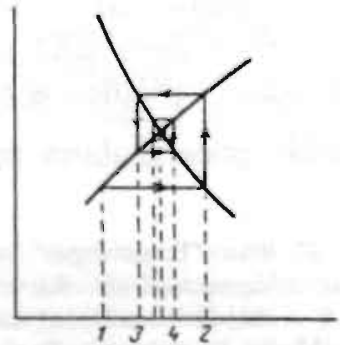

Abb. 2 b

Initially, this observation has been interpreted as a discovery concerning the 'economic reality'. 'Since the classic economists it has been undisputed that the exchange economy of which the equilibrium has been distorted, will establish a new equilibrium, if no further changes in 
the data take place $[\ldots]$. But now, more recent authors, namely Ricci, Schultz, Tinbergen, and Rosenstein-Rodan showed that these automatic adjustments of the market price to the equilibrium price [...] is not at all as obvious as they wished since the classics' (Lange, 1935, p. 358). ${ }^{17}$

Kaldor $(1934$, p. 122) is the first to understand the problem of this possibility. If a theory predicts infinite fluctuations, there is no problem in reality, but there is simply something wrong with the theory. "The assumptions of static theory are, therefore, nothing else than the conditions necessary to make equilibrium "determinate": the conditions under which we can give a scientifically precise description of the actual course of economic phenomena. Once these assumptions have been specified and have gained general acceptance as the limits within which deductive speculation must proceed, any new elements subsequently discovered which play a rôle in shaping the course of events are likely to be put down as "causes of indeterminateness" since the human mind finds it easier to alter the conclusions arrived at within an accepted framework, than to alter the framework itself. Whenever, therefore, new causes of "indeterminateness" are said to be detected this is merely another way of saying that a new set of determining forces has been found: forces whose behaviour and manner had not hitherto been reducible to uniformities and whose influence must therefore also be assumed absent if the existing body of generalisation is to be regarded as valid.'

The accepted assumptions, which lead to the indeterminateness of the theory are:

'5. All independent variables remain constant through time.

6. All individuals expect the prices actually ruling to remain in force permanently: no price-changes are anticipated' (p. 123).

Kaldor concludes that if the cobweb theory predicts divergent fluctuations of prices, something must be wrong with the theory. He gives a list of possible corrections, related to the velocity of adjustment. His final possibility is that "in any actual situation, the presence of some foresight may always be expected. The existence of foresight, however incomplete, will always change the situation in favour of stability so

17 'Seit den klassischen Nationalökonomen galt es als unumstritten, dah die Verkehrswirtschaft, deren Gleichgewicht gestört ist, sich wieder von selbst in ein neues Gleichgewicht einspielt, falls keine weitere Datenănderungen stattfinden [...]. Nun hahen aber neuere Autoren, namentlich Ricci, Schultz, Tinbergen und Rosenstein-Rodan, gezeigt, dafi diese automatische Anpassung des Marktpreises an den Gleichgewichtspreis [...] keineswegs so selbstverständlich ist, wie man es seit den Klassikern wahr haben wollte." 
long as the expectations of price-changes are in the right direction, $[\ldots]^{\prime}$ (p. 136).

Also Buchanan (1939, pp. 80-81) brings in these theoretical objections. 'The cobweb theorem has been offered as a formal statement of a certain combination of conditions under which the displacement of equilibrium does not set in motion a chain of events leading to a new equilibrium of an enduring sort. If our analysis is valid, we have shown that neither perpetual fluctuation at a given amplitude nor expanding fluctuation is theoretically possible if the supply curve is a competitive curve such as most writers apparently had in mind in their exposition of the doctrine.' In many papers that followed this observation, attempts were made to save the cobweb theory. Leontief (1934) for example shows that in case of non-linear supply and demand curves, local unstable processes may turn out to be globally stable.

The second source of critique against the cobweb theory comes from empirical arguments. Coase and Fowler (1935, p. 159n) observed that the length of the waves measured in the pig-cycle did not correspond to the cobweb theory. "To have shown that farmers react immediately to changes in the profitability of pig-breeding is, however, a serious objection to the attempt to explain the pig-cycle by an appeal to the "cobweb-theorem." For if farmers react immediately, then on the assumption of that theorem one would get a two-year not a four-year cycle'. While a wave of four years was observed, the theory would predict a two years length. Cohen and Barker (1935) tried to refute this analysis by some additional hypotheses about the farmers behaviour with respect to the number of gilts kept for replacement purposes and the number of old sows culled off, but Coase and Fowler (1937, p. 55) again show the inconsistency of the theory: 'In fact, however, such explanation as they attempted in their Reply involved certain important modifications of the theory previously held and was not based on any analysis of the way farmers had behaved but was purely hypothetical'.

\subsection{Direci Measlirement of Expectations}

The introduction of the cobweb theory, and also the Keynesian theory showed to economists the importance of expectations in economic analysis. An alternative way to investigate expectations and to test the theory is by direct measurement of expectations. To this end surveys were started to ask entrepreneurs about their price and inflation expectations. Examples of such studies are Klein (1954), Modigliani and Sauerlender (1955), Haavelmo (1958), and Katona (1958). The dispersed answers to the expectation question are aggregated to one 
single market expectation. The findings of these surveys did in general not confirm the cobweb hypothesis that people expect the current price to persist.

This rejection is, however, accompanied by a very remarkable observation. Theil $(1958$, p. 126), who gives a very broad overview on the forecast literature states that, "the obvious conclusion is that the entrepreneurs consistently underestimated the actual changes in their variables'. Theil, therefore suggests to multiply predicted changes such that the underestimation will disappear. He explains the phenomenon as psychological. "It should perhaps be noted beforehand that the "economic" analysis which follows has, in a sense, a "psychological" competitor. For, if a man predicts large but not very large changes, the public will regard him as a man of imagination; but if he predicts extremely large changes, his audience will replace imagination by phantasy. Thus, there is some kind of social pressure in the direction of the bias which we have observed' (p. 156).

Theil expresses this phenomenon as (using the notation of this study):

$$
w^{\text {pre }}-w^{-d}=\theta\left(w^{\text {rea }}-w^{-d}\right) \quad 0<\theta<1
$$

From this it can be deduced that

$$
\text { VAR }\left\{w^{\text {pre }}-w^{-d}\right\}=\theta^{2} V A R\left\{w^{\text {rea }}-w^{-d}\right\}
$$

i.e. the variance of the prediction, related to the current value $w^{=d}$ of the wages is lower than the variance of the realised wages related to the current wages. Compared to the present wages, the realised wages fluctuate more than the predictions of people. This 'psychological' law has been interpreted by many economists as a partial confirmation of the cobweb theory. People do not use the present prices as predictions, but also do not forecast the change completely. Their expectations are somewhere in-between.

\subsection{Rational Expectations}

The theoretical and empirical observations concerning the cobweb theory led to new theories concerning expectation formation. It was noticed that people have expectations which are more adequate than the cobweb theory assumed. One example of such a theory is extrapolative expectations introduced by Metzler (1941, p. 119). "The dynamic models [...] introduce a somewhat artificial assumption about business expectations. [...] entrepreneurs are assumed to base their expectations of sales in a given period upon sales of the preceding period. It is 
natural to object that expectations of future sales may depend not only upon the past level of sales, but also upon the direction of change of such sales'. Therefore, 'to discuss the role of expectations, I shall make use of a coefficient of expectations $(\eta)$ defined as the ratio between periods $t$ and $t-1$ and the observed change of sales between periods $t-1$ and $t-2$ ':

$$
\text { (6.3) } w^{p r e}=w^{-d}+\eta\left(w^{-d}-w_{-1}^{-d}\right)
$$

The thought behind this expectation formation scheme is that people may improve their expectation by taking into account also the past change of a variable and not only its level. Cagan (1956) introduced adaptive expectations in which the expectation depends on all past observations. In general these expectation schemes can be formulated as:

$$
w^{\text {pre }}=f\left(\ldots, w_{-2}^{-d}, w_{-1}^{-d}, w^{-d}\right)
$$

It is also possible to extend the formula by elements other than past wages. In general, the prediction is a function of all data known to the forecaster. This general specification leaves open a great deal of possible expectation formation schemes which leads to the question which scheme should be selected. This problem could not be solved empirically, because it appeared even impossible to identify the parameters of simple forms of (6.4) in a simple one-market model.

In order to restrict the large amount of possible expectation formation schemes some theoretical restrictions are proposed. Enthoven and Arrow (1956), Arrow and Nerlove (1958), and Arrow and Hurwicz (1958) restrict the possible expectation formations to those which lead to a stable equilibrium. Kaldor's (1934) critique that a theory which predicts indeterminateness of the equilibrium should be interpreted as a defect theory is used to select between possible and impossible expectation schemes.

The idea introduced by Muth (1960) to solve the selection problem is to assume that people use the optimal ${ }^{18}$ expectation scheme. Nerlove and Wage (1964) proved that adaptive expectations are optimal in the usual cobweb model. Implicitly in the proof of Nerlove and Wage is an assumption about the stochastic process which determines the development of the equilibrium wages (p. 208). In fact all selection criteria for expectation formations schemes relate the optimal or

18 To make possible the use of 'optimality' (implicitly) a loss function has to be introduced. See section 7.1. 
possible expectation schemes to the properties of the economic reality, assumed in their model. Thus, expectations are optimal if they adjust as good as possible to the nature of the economic stochastic, or data generating process.

This seems to be a trivial statement, but it certainly is not. The approach to view the economy as a stochastic process has for a long time not been common practice among economists. The description of the developments in an economy as a stochastic process has been introduced by Haavelmo (1944), inspired by Slutzky (1937). Morgan (1987) shows that the general opinion among economists before the revolution of Haavelmo was that probability was not useful in economics. Ezekiel (1928, p. 223) writes that the results obtained by statistical determination of the relations are not fundamental "laws of nature" in the same sense as is the law of gravity. They are measures of the way that particular groups of men, in the aggregate, have reacted to specific economic conditions during a specified period in the past. If the study is elaborate enough, it may reveal the way in which the reaction has been changing during the period considered, and the direction and rate of change. But it does not tell how long the same reaction will continue to prevail, what new causes may arise to change the responses, or what the relations would be in the new situation. The theories of mathematical probability do not apply.' Economic relations are largely based upon individual preferences and decisions, and these individual characteristics can not be described, according to Ezekiel, by a data generating process. Some regularities may be found in the data, but this provides no certainty about the persistence of the regularity. People may change their mind and alter their preferences.

Robbins (1935, p. 107) also raises questions about the possibilities to use probability concepts in economics. 'Ought we not to wish to be in a position to give numerical values to the sales of valuation, to establish quantitative laws of demand or supply? [...] No doubt such knowledge would be useful. But a moment's reflection should make it plain that we are here entering upon a field of investigation where there is no reason to suppose that uniformities are to be discovered. The "causes" which bring it about that the ultimate valuations prevailing at any moment are what they are, are heterogenous in nature: there is no ground for supposing that the resultant effects should exhibit significant uniformity over time and space."

Besides this problem of the non-uniformity of economic relations, economists opposed to probability concepts because it is unclear what may be the source of the probabilities. In empirical work it is of course 
necessary to allow for some randomness, but these probabilities in the economic relations were ascribed to measurement errors (Frisch, 1934) or incompleteness of the model (Working, 1925). The probabilities do not arise at the theoretical but only at the practical empirical level. In the theoretical economic relations there is little reason to assume randomness. Economic decision rules are optimal according to the neoclassical theory, so can not be subject to chance. The only exceptions in which probability is accepted are examples like the weather condition in Tinbergen (1931). For a farmer the amount of rain next year is a stochastic variable.

Haavelmo (1944, p. iii) remarks that 'so far, the common procedure has been, first to construct an economic theory involving exact functional relationships, then to compare this theory with some actual measurements, and, finally, "to judge" whether the correspondence is "good" or "bad"'. He continues that "it has been considered legitimate to use some of the tools developed in statistical theory without accepting the very foundation upon which statistical theory is built. For no tool developed in the theory of statistics has any meaning - except, perhaps, for descriptive purposes - without being referred to some stochastic scheme.'

Haavelmo is of course right in his observation that statistic theory can only be used for stochastic models, but then he states: 'The reluctance among economists to accept probability models as a basis for economic research has, it seems, been founded upon a very narrow concept of probability and random variables. Probability schemes, it is held, apply only to such phenomena as lottery drawings, or, at best, to those series of observations where each abservation may be considered as an independent drawing from one and the same "population"'. He continues with an explanation why it is not necessary to assume that observations are independent. The reason some economists did not accept probability theory is, however, not that they thought the observations should be independent draws from one population, but that they thought that this population does not exist. In their view it is not possible to assume that future events are drawn from the same population as past events.

Opponents of probability theory in economics are confronted with the dilemma that it is only possible to make empirical inferences based on some stochastic model, but their theory does not allow for stochastic elements. Haavelmo (p. iv) states that 'in fact, if we consider actual economic research - even that carried on by people who oppose the use of probability schemes - we find that it rests, ultimately, upon 
some, perhaps very vague, notion of probability and random variables'. Although they reject it, implicitly every empirical economic study needs some stochastic notion. Therefore, mostly measurement errors are introduced.

As a result of Haavelmo's ideas it became more and more common practice not to ascribe all randomness to measurement errors, but to assume the economic reality itself to be subject to probabilities. The economic theory itself, however, did not change drastically. It is still assumed that people make optimal decisions. Human behaviour, therefore, can not be the source of the randomness, and therefore the economic system is considered to be subject to exogenous random shocks. The source of these shocks is not clear. The weather is still the archetype, but the concept is replaced to all economic variables, also to those for which it is difficult to think what the meaning is of exogenous random shocks.

Accepting a model of the economy which is a stochastic process makes it possible to fit expectations in these analyses. Based on the optimality idea of expectations, Muth (1961) introduced the concept of rational expectations. The observation of Nerlove and Wage (1964) that adaptive expectations are optimally given a certain stochastic process of the real world, led to the observation that the optimal expectation scheme is in fact a function of the stochastic process of the real world. Given this stochastic process the optimal expectation or rational expectation equals:

$$
w^{r e}=E\left\{w^{r e a} \mid I_{t-d}\right\}
$$

in which $I_{t-d}$ denotes all data available at the moment the expectation has to be formed. "The hypothesis can be rephrased a little more precisely as follows: that expectations of firms (or, more generally, the subjective probability distribution of outcomes) tend to be distributed, for the same information set, about the prediction of the theory (or the "objective" probability distributions of outcomes)' (Muth, p. 316). ${ }^{19}$ In rational expectations all economic events are treated as realisations of random variables with a simultaneous probability density function. This density function is known to the economic agents and therefore the realisation of one variable makes it possible to improve the forecast of other (future) variables by making the marginal density function

19 This definition of the rational expectation is the most precise. The rational expectation predicts a probability distribution, not a single outcome. In (6.5) the expectation is 'described' by the mean, what is sufficient only for certain loss functions (e.g. an MSE loss function). See section 7.1. 
conditional on this realisation. Therefore, at the moment $t-d$ a part of $w^{\text {rea }}$ is predictable using the information set $I_{t-d}$, and a part is not predictable. This unpredictable part is the prediction error.

A remarkable feature of rational expectations was that although it assumes optimal behaviour of the agents, it seemed to be able to explain Theil's underestimation of changes. By construction, $w^{\text {re }}=E\left[w^{\text {rea }} \mid I_{t-d}\right\}$ is not correlated with the prediction error $\Delta \bar{w}$. Therefore,

$$
\begin{aligned}
\operatorname{VAR}\left(w^{r e a}-w^{-d}\right) & =\operatorname{VAR}\left\{w^{r e}+\Delta \bar{w}-w^{-d}\right\} \\
& =\operatorname{VAR}\left\{w^{r e}-w^{-d}\right\}+\operatorname{VAR}\{\Delta w] \\
& >\operatorname{VAR}\left(w^{r e}-w^{-d}\right]
\end{aligned}
$$

Rational expectations thus also explain that the realisation of a variable is more fluctuative than the prediction, which was noticed by Theil (equation (6.2)). Although Muth (1961) suggested that rational expectations did explain the underestimation phenomenon, this is not the case since the formulation of the underestimation of changes in (6.1) implies the prediction error:

$$
\Delta \bar{w}=\left(\frac{1}{\theta}+1\right) w^{\text {pre }}-\left(\frac{1}{\theta}+1\right) w^{-d}
$$

Since $w^{\text {pre }}$ and $w^{-d}$ are both known at $t-d$, they are an element of $I_{t-d}$, and thus it is possible to predict $\Delta \bar{w}$ based on information in $I_{t-d}$, which is impossible in rational expectations by definition. Bossons and Modigliani (1966) pointed to this inconsistency, but their observation did not play an important role in the discussion about rational expectations. ${ }^{20}$

Tinbergen, as mentioned before, recognised the large tension in the economic modelling between, on the one hand, the notion that people use economic principles to anticipate the future developments, and on the other hand, the notion that these developments are so complex that nobody will ever make perfect anticipations. The formalisation of economic theory, together with the enormous influence of econometrics caused, however, the theory on expectations to evolve from cobweb theory into rational expectations. The insight of cobweb theory that people make errors in their forecasts, was modelled in a rather ad hoc way. This aspect was lost in the rigor of the further developments of the theory, leaving the theory with a more consistent framework in which, 
however, all uncertainty is reduced to external shocks. ${ }^{21}$

\subsection{Expectations in Educational Choice}

Studies about students' expectations in educational choice are confronted with the same dilemma between the consistency of rational expectations and the usefulness of the cobweb model. The first study about expectations formation of students with respect to their educational choice, was carried out by Freeman (1971). This study contains both the results of a survey and a theoretical expectation scheme. Freeman uses the cobweb model to model the expectation behaviour of students. He does, however, not give any fundamental reasons why he prefers the cobweb model, and even refers to Muth (1961) as a theoretical preferable model. But, 'if expected salaries can, as a first approximation, be taken as functions of current salaries only, the traditional cobweb analysis is obtained' (Freeman, 1975a, p. 174).

The choice of the cobweb assumption is clarified in Freeman (1975b, p. 31). 'The cobweb relation, obtained by substituting the salary equation into the basic supply equation, highlights the endogenous fluctuations that characterize the market.' By assuming the cobweb expectation formation Freeman introduces errors in the expectations of students, which according to him is a realistic and necessary property of the model. For Freeman it is more important that students make mistakes, than to know exactly which mistakes they make.

The cobweb specification in educational choice has been criticised with similar arguments as described in the previous sections. Zarkin (1983, pp. 94-95) compares a cobweb and a rational expectations model about the educational choice of teachers. 'A myopic cobweb model fits the: data only marginally worse. This paper demonstrates that we may be led to incorrectly accept a cobweb model of occupational choice if we look solely at the fit of the model. Because of its autoregressive specification, a cobweb model should fit most data well, regardless of the true underlying structure. This same feature makes it difficult in other contexts to distinguish a world in which agents are myopic from one in which they pursue a forward-looking, rational expectations mechanism.' Therefore, he concludes that the comparison of both

2! In game theory agents can play mixed strategies. In such a case one player generates the randomness for the other players and v.v. The crucial property of such a model that for every agent ail relevant uncertainty is external to him remains, however. Fundamental exceptions to this, in which uncertainty is really internal, are theories in which the: players play with a 'trembling hand' (See Selten, 1975). 
models must be based on theoretical grounds. 'In investigating the dynamic properties of the two models, we find that a cobweb model implies a long, oscillatory adjustment path in response to a future anticipated baby boom.' These long oscillations are unprobable and therefore the cobweb model must be rejected.

Siow (1984) also uses rational expectations. 'The benefits of the integration include: [...] (iv) An alternative to the cobweb model for forecasting the supply of new entrants into an occupation is developed' (p. 632). Siow views the use of rational expectations as an evident improvement of the model of Freeman. The systematic errors which students make in the cobweb model are regarded as unrealistic and therefore replaced by a model in which all prediction errors have external causes. Freeman on the other hand accepts the disputable assumption of the cobweb behaviour, but uses it to incorporate errors of the students in his model.

It is highly remarkable that in the context of educational choice the cobweb model, which has been abolished in more theoretical fields kept its lure. ${ }^{22}$ It would be too easy to explain the popularity of the cobweb model in this context as a lack of theoretical notion in practical research. It rather seems to be the case that with the formalisation of rational expectations, the theory lost some aspects about the way students form expectations, which are important for studies about educational choice. Implicit in the cobweb view is the notion that due to the complexity of the labour market, students will make errors in their predictions. Cobweb theory incorporates such errors while rational expectations does not. Although cobweb theory is rather ad hoc, for them, the cobweb model simply provides a better metaphor to describe their thoughts about the functioning of the match between education and the labour market. The aim of this second part of the study, on information, is to model prediction errors in a more general way, but in such a way that the possibility of errors in the forecasts, due to the difficulty for students to forecast, is preserved.

\subsection{Conclusions}

The rise of empirical research in the thirties made it necessary for: economists to incorporate expectations in their model. Of course, it was recognised that expectations may be incorrect. The cobweb theory incorporated this possibility and was able to explain Hanau's pig cycle. Empirical research and formalisation led to the fall of the cobweb 
theory, which got replaced by various alternative expectation formation schemes. This ultimately led to the concept of rational expectations in which the possibility that agents make errors in forecasting disappeared.

For a long time economists opposed against the introduction of stochastic elements in the theory, which appeared to conflict with the economic principle of optimising behaviour. Haavelmo introduced the idea that the economic process is a stochastic process. In rational expectations these stochastic elements are incorperated, but because of this economic principle and the assumption of a given data generating process these must necessarily be external random shocks. 



\section{A STOCHASTIC MODEL OF PREDICTION ERRORS}

In the first part of this study some theoretical notions and empirical evidence concerning the provision of public labour market information were given. The two central issues were, firstly, that students base their educational decisions on predictions which may not equal the realisations, and secondly, that the extent of this difference between realisation and prediction may be influenced by providing additional labour market information. In the model of chapter 3 the prediction and the equilibrium wages are treated as given constants.

For the study of the effects of providing information it is necessary to extend the model of chapter 3 . Firstly, there is a relation between the prediction and the realisation which has to be modelled. The essence of a prediction is that it is intended to equal the realisation, and therefore the prediction can not be treated independently from this realisation. Secondly, information generally influences the prediction. The prediction can therefore not be exogenously, but at least depends on this information.

In the previous chapter it was shown that the formalisation of expectation theory and the attempts to make the theory consistent, led to rational expectations, in which predictions are by definition the best possible. Every prediction error is caused by external random shocks, while it is not possible for students themselves to make errors in forming an expectation. The theory therefore lost the characteristic that making a forecast in the real world is a difficult process.

In this chapter an attempt is made to model expectation formation in a way which both serves the theoretical request for consistency and the realistic every day experience of the difficulty to make an adequate forecast. The relation between prediction and realisation is modelled stochasticly. In section 7.2 and 7.3 two different approaches to the stochastic character of the prediction error are considered: the states of the world view and the errors in forecasts view. In section 7.4 it is shown that as soon as errors in forecasts are allowed for, there arises a trade off between information and interpretation errors. Information errors represent the type of uncertainty used in rational expectations. Interpretation errors represent the difficulties students (and professional forecasters) have in the act of forecasting. 


\subsection{The Prediction Error}

A prediction is mostly defined in dictionaries as 'a statement about what is (likely) to happen in the future'. 'For economic analysis, the interpretation of the word 'statement' is important. Since economics deals with people's intentions it is important to stress that such a statement aims at being right. A prediction is therefore 'an attempt to say what is (likely) to happen in the future'. However, as will be shown in later chapters, many economic theories neglect this attempt aspect. Some theories simply assume that the attempt will always be successful, while in other theories the expectation formation is modelled conpletely independent of its aim, the realisation.

For the study of student behaviour it is important not to neglect possible mistakes in predicting the future. It may be useful to assume that professional forecasters in e.g. financial markets, make perfect predictions, but it is very unrealistic to assume that students have this capability of perfect forecasting. The evidence in chapter 4 already made clear that students do not forecast perfectly. On the other hand, it is necessary to assume that students aim at correct forecasts. A forecast that does not aim at its realisation is simply not a forecast.

In general, the prediction of some future economic variable, e.g. future wages, will not equal its realisation. The difference between these two, i.e. the prediction error, $\Delta \bar{w}=w^{\text {pre }}-w^{\text {rea }}{ }^{2}$ may take different values. The reason prediction errors are made is that the student does not know beforehand what value $\Delta \bar{w}$ will have.

To model this uncertainty the prediction error $\Delta \bar{w}$ is interpreted as a stochastic variable, with a marginal probability density function $F_{i}\left(\Delta \bar{w}_{i}\right)$. Since this random variable models the uncertainty of an individual student, the marginal density function may differ for every student $i$. In this section, the prediction error of one particular student is considered and therefore the index $i$ is omitted. As noted above, the prediction of the wage aims at its realisation. To operationalise this concept a loss function is needed. A loss function assigns to every value of $\Delta \bar{w}-0$ a positive loss associated with this error. If $\Delta \bar{w} \equiv 0$ the loss should be 0 . In this study we use the mean square error (MSE) as the loss function for students.

See e.g. Fowler's Concise English Dictionary, 1989.

2 The bar in $\Delta \bar{w}$ indicates that the prediction $w^{m e}$ is compared to the realisation $\mathbf{w}^{\text {wn }} . \Delta \mathbf{w}$ without a bar will be used for comparisons with the equilibrium wage. Thus. $\Delta w=w^{m w}-w^{e q}$. 


\section{(7.1) $\operatorname{MSE}(\Delta \bar{w})=E\left\{\Delta \bar{w}^{2}\right\}$}

The use of the mean square error as a loss function makes it sufficient to describe errors with their mean and variance. ${ }^{3}$ The student who has to make a prediction aims at minimising the loss. In the best case $\Delta \bar{w} \equiv 0$. Since the random variable $\Delta \bar{w}$ models the uncertainty of the student with respect to the prediction it can not be the case that a nonidentical transformation of the prediction $f_{\theta}\left(w^{\text {pror }}\right)$ exists, with $\operatorname{MSE}\left(f_{\theta}\left(w^{\text {pre }}\right)-w^{\text {rea }}\right)$ lower than $M S E(\Delta \bar{w})$. $\theta$ represents a variable parameter of the transformation. If such a transformation existed the student would be able to improve his prediction without any further information or insight into the situation. This implies that the MSE of such a transformation should be minimal for $f_{\theta}\left(w^{\text {pre }}\right)=w^{\text {pre }}$. This property makes it possible to put a restriction on the distribution of $\Delta \bar{w}$.

The $M S E$ of such a transformation equals:

$$
\begin{aligned}
& M S E\left(f_{\theta}\left(w^{\text {pre }}\right)-w^{\text {rea }}\right) \\
& =E\left\{\left(f_{\theta}\left(w^{\text {pre }}\right)-w^{\text {rea }}\right)^{2}\right\} \\
& =E\left\{\left(w^{\text {pre }}-w^{\text {rea }}+\left(f_{\theta}\left(w^{\text {pre }}\right)-w^{\text {pre }}\right)\right)^{2}\right\} \\
& =E\left\{\Delta \bar{w}^{2}+2 \Delta \bar{w}\left(f_{\theta}\left(w^{\text {pre }}\right)-w^{\text {pre }}\right)+\left(f_{\theta}\left(w^{\text {pre }}\right)-w^{\text {pre }}\right)^{2}\right\} \\
& =M S E(\Delta \bar{w})+2 E\left\{\Delta \bar{w}\left(f_{\theta}\left(w^{\text {pre }}\right)-w^{\text {pre }}\right)+\left(f_{\theta}\left(w^{\text {pre }}\right)-w^{\text {pre }}\right)^{2}\right.
\end{aligned}
$$

Minimising the MSE with respect to $\theta$ gives:

$$
\frac{\mathrm{d} M S E\left(f_{\theta}\left(w^{\text {pre }}\right)-w^{\text {reg }}\right)}{\mathrm{d} \theta}=2 E\{\Delta \bar{w}\} \frac{\partial f_{\theta}\left(w^{\text {pro }}\right)}{\partial \theta}+2\left(f_{\theta}\left(w^{\text {pro }}\right)-w^{\text {pre }}\right) \frac{\partial f_{\theta}\left(w^{m+r}\right)}{\partial \theta}=0
$$

which implies that

$$
f_{\theta}\left(w^{\text {pre }}\right)=w^{\text {pre }}-E\{\Delta \bar{w}\}
$$

Therefore, to have $f_{\theta}\left(w^{\text {pre }}\right)=w^{\text {pre }}$ the assumption must be made that

3 Based on the model of chapter 3 the exact loss function for a student who decides to enter the market is $\operatorname{Loss}_{i}=\operatorname{Max}\left(0, w_{i} \mathrm{mb}-w^{\mathrm{rem}}\right)$. This implies that if the student has a probability distribution as expectation about the realised wages, it is optimal to base the supply decision on the expected value of this distribution. For the comparison of two forecasts, the higher moments of the distribution may matter. The use of the MSE is an approximation in which the assumption is made that students do not use moments other than the second (the variance) and that the class of distributions is such that for two distributions $\boldsymbol{P}_{1}$ and $\boldsymbol{P}_{2}$, Loss $\left(\boldsymbol{P}_{1}\right)<\operatorname{Loss}\left(\boldsymbol{P}_{2}\right)$ if $\boldsymbol{\sigma}^{2}\left(\boldsymbol{P}_{1}\right)<\sigma^{2}\left(\boldsymbol{P}_{2}\right)$. For many reasonable classes of distribution functions this second assumption holds exactly, while the first assumption is met for the normal distribution. 


\section{(7.5) $\boldsymbol{E}\langle\Delta \bar{w}\}=0$}

This assumption (7.5), within the framework of the Mean Square Error loss function, can be regarded as the definition of a prediction of $w^{\text {rea }}{ }^{4}$ A priori it is impossible to decide that it is more likely that a prediction will be an underestimation or an overestimation. This does not exclude, however, that somebody else may make a prediction of the students' prediction error $\Delta \bar{w}^{p r e}$. Again, by definition of a prediction $\boldsymbol{E}\left\langle\Delta \bar{w}^{\text {pre }}-\Delta \bar{w}\right\}=0$, but this does not imply that $\Delta \bar{w}^{\text {pre }}=0$.

If a student receives such a prediction of his own prediction error and recognises it as such, this will be valuable for him, since this additional information enables him to improve his initial prediction. Mostly, this additional information does not take the form of a prediction of the prediction error, but of an alternative prediction of the realised wage. Such a prediction gives the student equal opportunities to improve his own prediction. This possibility is an essential point in this study.

\subsection{States of the World}

In the previous section the prediction error has been introduced as a random variable. The essence of prediction errors is that the person who makes the error does not know its value. Therefore the assumption is made that although the realisation of the prediction error mostly differs from 0 , the expectation of the prediction error, $E\langle\Delta \boldsymbol{W}\}$, equals 0 .

The reason for modelling the prediction error stochasticly has to do with the fact that, from the viewpoint of the student, it is not possible to correct this error. It does, however, not explain the source of such prediction errors. There are two basic models of the sources of prediction errors in economics, which are discussed in this and the next section. In this section the states of the world model is discussed, while section 7.3 is devoted to the errors in forecasts model.

This states of the world model is the most widely used model of prediction errors in economics. ${ }^{5}$ Its basic point is that at the moment some decision has to be made, the (future) consequences are not known with certainty. There are different states of the world which can not be excluded beforehand. Table 7.1 gives an example. In this example a

4 Benassy (1991) generates results about the suboptimality of rational expectations by neglecting this definition. Therefore, his results have to be interpreted as that it may sometimes be better if people do not maximise their utility function, which is generally true in the case of market failure.

5 See e.g. Arrow (1951) and Debreu (1959). 
student has to make a choice between two schools. At school $A$ he will get some specialised knowledge, while at school $B$ he will be more generally educated. The question the student is faced with is whether the labour market for the specialised knowledge will be good or bad at the moment he finishes his school. Therefore, two scenarios are distinguished, state 1 in which the market is indeed good and his earnings measured in utility are 100, while with the more general education he only gets 50 . On the other hand the situation may be bad, as in state 2 , in which case the earnings with school $\boldsymbol{A}$ fall to 0 while with school $B$ the earnings remain 50 .

TABLE 7.1: CONSEQUENCES OF SEVERAL CHOICES IN DIFFERENT STATES.

\begin{tabular}{l|rr}
\hline decision & state 1 & state 2 \\
\hline school $A$ & 100 & 0 \\
schoo! B & 50 & 50 \\
\hline
\end{tabular}

In a states of the world model it is crucial that all the information given in table 7.1 is known with certainty. If for example the payments in the different states of the world themselves are uncertain, the model has to be extended with additional states of the world which incorporate this uncertainty. This model is very powerful. It is able to include every form of uncertainty. Therefore, the only uncertainty in the model is, by definition, the fact that it is not known beforehand which state of the world will occur.

It is clear that $A$ would be chosen in state 1 and $B$ would be chosen in state 2 . In both states the cost of a wrong decision (based on a false belief) are 50. This student's problem is, that he does not know which state of the world wil! occur. To solve this decision problem it is assumed that the student has some subjective probabilities about which state will occur. ${ }^{6}$ In table 7.2 such subjective probabilities are given.

Based on this probability distribution it is possible to calculate the expected value $(E V)$ for both alternatives. The expected value of an alternative $j$ is equal to the weighted gains in the possible states of the world. 
(7.6) $E V^{j}=E\left\{U^{j}\right\}=\sum_{k} p_{k}^{j} U_{k}^{j}$

in which $p_{k}$ is the probability of a certain state of the world, and $U_{k}^{j}$ is the gain with choice $j$ in state $k$.

TABLE 7.2: A SUBJECTIVE PROBABILITY

DISTRIBUTION.

\begin{tabular}{l|rr}
\hline decision & state 1 & state 2 \\
\hline $\begin{array}{l}\text { subjective } \\
\text { probability }\end{array}$ & 0.80 & 0.20 \\
school $A$ & 100 & 0 \\
school B & 50 & 50 \\
\hline
\end{tabular}

In this example

$$
\begin{aligned}
& E V^{A}=0.8 \times 100+0.2 \times 0=80 \\
& E V^{B}=0.8 \times 50+0.2 \times 50=50
\end{aligned}
$$

The states of the world model asserts that, without further information, the agent chooses the alternative with the maximum expected utility, so he chooses school $A$. More in general, the choice $J \in\{A, B\}$ is such that

$$
\text { (7.7) } E V^{J}=\operatorname{MAX} E V^{j}
$$

An interesting question in this model is what the welfare costs of not having perfect information are, or stated inversely, what the value of perfect information is. These costs of uncertainty $(W)$ depend on the contents of the information. For a given state it can be defined as the value of the decision made by the student, minus the value of the optimal decision in that state.

(7.8) $W_{k}=U_{k}^{J}-\underset{j}{\operatorname{MAX}} U_{k}^{j} \leq 0$

By definition these costs are always less than or equal to zero. In the example

$$
\begin{aligned}
& \boldsymbol{W}_{1}=100-100=0 \\
& \boldsymbol{W}_{2}=0-50=-50
\end{aligned}
$$

If the student receives perfect information, which tells him state 1 will 
be the case, his gain is zero, because his decision does not change due to the extra information. If, however, the perfect information tells him state 2 will be the case his gain is 50 , because now he can anticipate this state by changing his decision from school $A$ to $B$.

The state the information will predict, however, is not known beforehand, so a student has to calculate the expected value of perfect information, which can be calculated by again weighting the welfare effects with the subjective probability distribution.

$$
W(p)=E\{W\}=\sum_{k} p_{k} W_{k}
$$

In the example this negative welfare effect due to imperfect information equals $0.2 \times-50=-10$.

A problem in this theory of uncertainty is that the calculation of the value of information is only correct if the subjective probability distribution is correct. A probability distribution that is correct, i.e. which corresponds to the 'real' probability distribution is called an objective probability distribution.

The assumption of a subjective probability distribution asserts that students regard the future world as stochastic. They mentally assign probability values to the different states of the world they distinguish. The assumption of the existence of an objective probability distribution is stronger. It states that the real world is not only viewed upon as stochastic, but really is stochastic. Many theories assume, furthermore, that the subjective probabilities equal the objective probabilities. Students do, in their view, face uncertainty, and they do make errors due to this uncertainty, but the real source of these errors is the stochastic character of the world. Keynes (1937) calls this type of uncertainty (mathematica!) risk, which he compares to gambling roulette: The probability distribution is known with certainty, but the realisation depends on chance. In rational expectations theory this assumption, that objective probability distribution equals the subjective probability distribution is essential. To operationalise this thought the objective probability distribution is furthermore assumed to equal the probability distribution generated by the economic model in question. The strength of this assumption can be illustrated by the fact that even in a casino there are people willing to play, although roulette is one of the best examples of a situation with a knowable objective probability distribution. The only possible explanation for this fact in the states of the world theories is that these people have some curious utility 


\section{function.}

Thus, a subjective probability function which assigns a too high probability to the one, and a too low probability to the other state, will have two effects. The student will put 100 much emphasis on the consequences in the first state (because he has overestimated the probability this will occur), and he will underestimate the value of extra information, because he underestimates the probability that there will be a deviation from his expectations. The subjective probability distribution serves in this context both as a statement about the probability of the two states, and implicitly as a statement about the quality of this information. Students do not, according to the model, realise that their expectations may be incorrect. In a situation in which it is assumed that the subjective probabilities equal the objective probabilities, this is no problem because students are always right by definition. If it is allowed that the subjective probabilities differ from the objective probability, a discrepancy arises between the complete confidence students have in their (stochastic) forecast ${ }_{n}$ and the differences between subjective and objective probabilities, which are assumed to exist.

A way to overcome this problem is by using Bayesian statistics.? Suppose that in the example the objective probability distribution is $(0.7,0.3)$, i.e. the economic environment is such that with $70 \%$ chance state 1 will occur, while state 2 has a $30 \%$ probability. Initially, however, this objective probability function is not known to the student. To model this uncertainty the assumption is made that conform Bayesian statistics, for the student the value of $p_{1}$, the probability of state 1 , is itself a stochast. To operationalise the model, furthermore the assumption is made that they assign a priori equal probabilities to every value of $p_{1}$ (see figure $7: 1,(a)$ ). This stochastic variable of $p_{1}$ represents student's knowledge about $p_{1}$. After 1 year the world provides the students with one realisation of the state of the world. This information enables the students to update their prior probabilities $P_{t-1}$ according to Bayes' rule to posterior probabilities $P_{i}$ :

$$
\text { (7.10) } P_{t}\left(p_{1}\right)=P_{t-1}\left(p_{1} \mid \text { state }\right)=\frac{P_{t-1}\left(\text { state }_{t} \mid p_{1}\right) \cdot P_{t-1}\left(p_{1}\right)}{\left.\int_{p_{1}} P_{t-1}\left(\text { state } p_{t}\right) \cdot p_{1}\right) \cdot P_{t-1}\left(p_{1}\right) \mathrm{d} p_{1}}
$$

Graph $(b)$ in figure 7.1. gives the prior distribution after one year, based on a computer simulation. For every year a realisation of the 
objective distribution has been drawn. In this year the state of the world was 1 and therefore the prior probability of high values of $p_{1}$ has risen. Graph $(c)$ gives the simulated prior after 10 years, while $(d)$ gives the situation after 100 years.

FIGURE 7.1: THE PRIOR DISTRIBUTION OF $p_{1}$ AFTER $(a)$ $0,(b) 1,(c) 10$, AND (d) 100 YEAR(s).

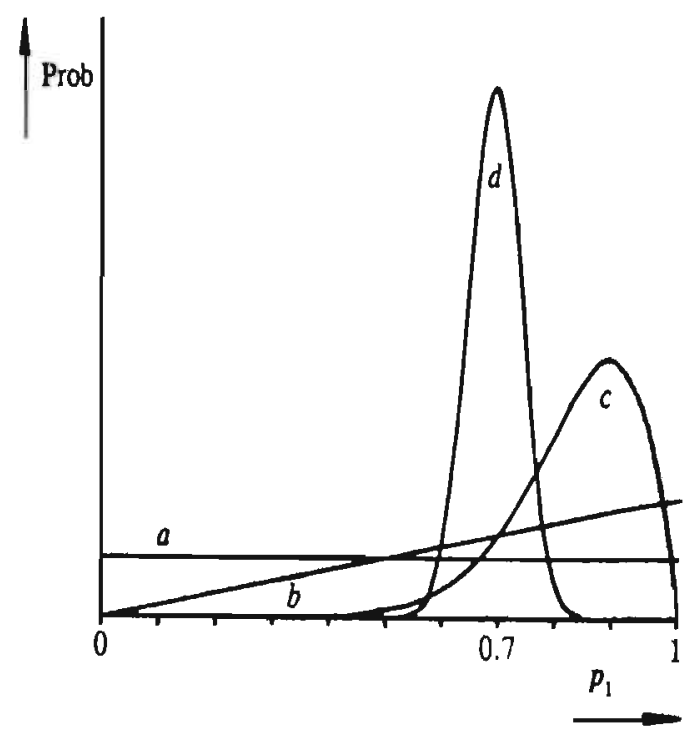

This Bayesian approach to model the uncertainty with respect to the objective probabilities is very disputable. In fact this Bayesian extension does not solve the problem but moves the fundamental problem to an additional level. In this extension not the objective probability is given anymore, but instead the prior distribution, which is an objective probability distribution of probabilities, is given. The fundamental problems of the approach have already been observed by Knight (1921), Keynes (1937), and Shackle (1949). The main issue is that this model always presumes certain prior knowledge, without clarifying why the agent obtained this knowledge, and why he did not obtain additional knowledge. This fundamental problem is usually masked by the presupposition of a clear relation between past events and future probabilities. It is a frequentistic approach. The only information about the probabilities of the states of the world are the realisations in the past. This requires that (i) the situation in the past was evidently completely identical to the future situation, and (ii) there are no other possibilities to say anything about future events than what is enclosed in 
past events. Shackle (1949) stressed that every future event is to some extent unique. Relating such a future event to past experience is not an undisputable calculus, but is based on a human assessment about the nature of the future event. The forecaster uses experience as an indicator for the future. There is, however, no rule which tells which indicator is the best. Furthermore, there may be other things than data on the past, which are informative about a future situation. The forecaster may have some argumentation or opinion about the future. ${ }^{8}$ This may also influence his forecast, although there is no precise relation between the past and this forecast.

It is difficult to show the shortcomings of the states of the world model. It can model every type of uncertainty (even uncertainty regarding people's own knowledge as in Bayesian learning models). The agent who has to model his uncertain situation in this framework, however, never knows whether he has chosen the right specification: for every situation there is a states of the world representation, but there is not one representation for every situation.

In the example used in this section only two states of the world are distinguished. In general, it can be assumed that there is a continuum of states of the world. Of course only those states have to be taken into account which are relevant for the decision that has to be made. Suppose for example that a student's decision only depends on the wages, as in chapter 3 , then all states of the world can be described by the wage that prevails in that state. The objective probability distribution is a distribution of those wages. With an MSE loss function decisions based on this probability distribution only depend on the mean of the distribution, while for a comparison of the quality of the forecast the variance is sufficient. The probability distribution therefore can be summarised by the mean and the variance. If such a forecast $\left(w^{r e}\right)$ is based on the objective probability distribution, the prediction error $e^{r e}=w^{r e}-w^{r e}$ is unpredictable at the moment the prediction is made, and therefore the realisation can be viewed upon as equal to the prediction plus an unforcastable innovation: $w^{\text {rea }}=w^{r e}+e^{r e}$.

\subsection{Errors in Forecasts}

The states of the world view on expectation formation asserts that people recognise that the future world is stochastic to some extent. Therefore, they base their decisions on the probability distribution of

8 Berger (1989) calls this hermeneutics: people's decisions depend on their interpretation of the world. 
these future events. The model therefore requires a priori knowledge concerning the states of the world and their probabilities. To avoid this problem, if these probabilities are not known to them with certainty, the construction is extended one stage by the introduction of prior probabilities of these objective probability distributions. The difficulty of this approach is, however, that it should still be a priori clear to every person how to infer probabilities from past data. In the construction of a probability function, the decision has to be made which past events are similar to the future event, and to what extent. Furthermore, argumentations and theoretical thoughts may be also viewed upon as 'data' for the construction of the probability function.

The problematic character of these decisions becomes most clear in a situation in which no extended set of data about the past exists. Suppose a new study 'environmental sciences' is introduced. A student considers to take this course. His only concern is the total enrolment. He argues that due to the fact that the study has not existed until now, environmentalists will be scarce, and therefore the prospects at the moment are much better than they will be after four years, at the moment all these students enter the market. On the other hand it may also be possible that the total supply will only be a drop in the ocean, due to the growing demands for this discipline. He may decide to compare his arguments with the experiences of other studies which started recently. He could use the frequency of oversupply in those cases as an indication of the probability that this will happen again, but then he wonders whether all these situations are comparable. Some studies were started due to growing labour market demand as in the case of environmental science, while others were not.

In judging the probability of oversupply, both theoretical and empirical arguments may be used. The theoretical arguments may differ from person to person and it will in general be impossible to foresee who is going to use which argument. The use of theoretical concepts is not simply a function of some characteristics of the person. The same is, however, true for empirical arguments. Although the data may be public domain, the decision which cases to compare the future situation with, and how to design this comparison is a personal judgement. The data itself does not provide a method which way of inference is the best. ${ }^{9}$

9 Many authors have stressed the problems with the states of the world view on uncertainty. Knight (1921), Keynes (1937), Shackle (1949), Ellsberg (1961), Runde (1990), and Davidson (1991) distinguish between risk and uncertainty. Fuhrer (1987) uses the term 'model uncertainty'. 
Because expectations depend on personal judgements, in many cases they will differ from person to person. Such an interpersonal dispersion will in general be low in professional situations. In such a situation forecasts are made by people who join a comparable theoretical background, and who communicate a great deal about the topic. Both aspects make the opinions converge. This does not alter the fact that the forecasts may contain mistakes.

In cases where people make forecast statements which do not include probabilities, but simply foretell that something is going to happen as if it was certain, it is clear that forecast errors will be made. These errors are very easy to detect. If the predicted event does not occur, the forecast is false. If predictions are formulated as probability events, such an evaluation is not. so easy. If an event which was predicted with a high probability does not occur, the forecast may be wrong, or the less probable event may have happened by chance. Although it is not possible to detect errors with certainty, there is no reason to assume that probabilities can not be incorrect.

The difference between the two views on prediction errors can be illustrated by their relation to a hypothetical optimal prediction. Imagine some prediction to be optimal in the sense that at the moment the prediction is made it is not possible to make an alternative prediction which adds extra information. The states of the world view then asserts that the prediction actually made equals this optimal prediction, but that the realisation will differ from this optimal prediction due to unforecastable events in the future, i.e. due to the fact that the realisation of some random variables is not known at that moment. The error made here is an information error. The errors in forecasts view asserts that the optimal prediction may equal the realisation, but the prediction actually made differs from this optimal prediction due to the fact that students are not able to make such a perfect forecast. The error in this forecast is an interpretation error.

Subjective probabilities are examples of incorrect predictions. If the subjective probabilities do not equal the objective probabilities, the forecaster makes an error, although he may not recognise his error, since the realisation may be both explained by the objective and the subjective probability function. The extension to the model in which the probabilities are themselves stochastic does not overcome this problem. The probabilities remain subjective, and therefore possible incorrect, as long as the prior distribution and the link between past events and this prior distribution are not known with certainty. The model with stochastic parameters may be very useful to model learning by doing, 
but it does not solve the problem of possible errors in the forecast.

The possibility of errors in forecasts has to be accepted, but the meaning of prediction requires these interpretation errors to be stochastic. As shown in section 7.2 it makes no sense to preassume some upward or downward bias in the expectation. The expectation of the prediction error, $E\{\Delta \bar{w}\}$, should equal zero, i.e. it can not be known a priori whether an expectation is too low or too high.

Thus, although Bayesian analysis may be very useful to model uncertainty, it is not fully able to exclude errors of a classical type in which the forecast actually made is only an approximation to the optimal forecast. In the states of the world model the prediction error is the difference between the best possible prediction, given a certain set of information, ${ }^{10}$ and the realisation. This best possible forecast given a certain set of information will be called a perfect expectation. The state of the world may deviate from the prediction:

(7.11) $w^{\text {rea }}=w^{\text {pre }}+\varepsilon^{\text {re }}$

$\epsilon^{r e}$ is the information error. Because the prediction is the best possible forecast given the information used, the error term $\epsilon^{r e}$ is independent of the prediction. In this specification, the prediction can be viewed upon as given and uncertainty arises due to a deviation of reality from the best possible prediction. In the errors in forecasts model, however, people make errors because the forecasts deviate from the optimal forecast, which is in an extreme example equal to the realisation:

$$
w^{\text {pre }}=w^{\text {rea }}+e^{\text {pre }}
$$

In this case the error, $e^{\text {pre }}$, which is an interpretation error, is independent of the realisation. Of course, both models are extreme variants. It might be the case that both types of error occur in a forecast. In that case there is, given the set of information used, an unobserved optimal forecast ( $w^{\text {re }}$, in which re stands for rational expectation) such that:

10 Usualiy, this best possible prediction is denoted (within an MSE context) as $w^{\boldsymbol{m}}=\boldsymbol{E}\left(\boldsymbol{w}^{\text {ree }} \mid I_{t-d}\right\}$, i.e. the (rational) prediction equals the conditional expectation of $w^{\text {res }}$ given the information available at the moment of choice. This notation suggests to provide a method to calculate the optimal prediction. To calculate $E / w^{m} \mid I_{z-d}$ it is, however, necessary to know the 'true model', and therefore with this notation it appears as if the 'true model' is at hand. To avoid this suggestion, which has led to a one-sided development of the theory of expectation formation (see chapter 5 and 6 ), the hypothetical optimal prediction is introduced without a constructive definition. 


$$
\left\{\begin{array}{l}
w^{r e a}=w^{r e}+e^{r e} \\
w^{\text {pre }}=w^{r e}+e^{\text {pre }}
\end{array}\right.
$$

The information error $e^{r e}$ and the interpretation error $e^{p r e}$ are independent of $w^{r e}$. In this specification the unobservable hypothetical benchmark $w^{r e}$ is the perfect expectation which contains no errors. The realisation differs from this expectation due to states of the world uncertainty, and the prediction actually used also differs, due to errors in the prediction.

In (7.13) there is, given a certain set of information, an expectation $\left(w^{r e}\right)$ that is optimal. Without extra information this hypothetical perfect expectation can not be improved. This hypothetical expectation is "however, not 'observed' by students. Their prediction ( $w^{\text {pre }}$ ) deviates from the rational expectation. The information error $\left(\epsilon^{r e}\right)$ and the interpretation erroi $\left(e^{p r e}\right)$ are necessarily independent. The variance of the interpretation error represents the capability of a student to forecast. Suppose there are two people, one bad and one good forecaster. By definition, both will make, if they use the same information set, the same information error. It is therefore possible for the good forecaster to predict the interpretation error ( $e^{\text {pre }}$ ) of the bad forecaster. But if this interpretation error is not independent from the information error, it would also be possible for him to predict the information error, which by definition is impossible.

The possibility of interpretation errors is also observed by proponents of rational expectations, which is a typical states of the world model. In rational expectations forecast errors caused by unforecastable exogenous shocks. Muth (1961, p. 321) however states that it is possible that there will be deviations from rationality. 'Certain imperfections and biases in the expectations may also be analyzed with the methods of this paper. Allowing for cross-sectional differences in expectations is a simple matter, because their aggregate effect is negligible as long as the deviation from the rational forecast for an individual firm is not strongly correlated with those of the others."

Sargent and Wallace (1976, p. 180) remark that 'in this regard, it should be noted that the rational expectations hypothesis does not require that people's expectations equal conditional mathematical expectations, only that they equal conditional mathematical expectations plus what may be a very large random term (random with respect to the conditioning information),'

The unproved proposition of Muth, Sargent, and Wallace is that 
interpretation errors do not matter. In the next section it is shown that this proposition is false. The presence of interpretation errors influences the optimal predictions.

\subsection{Information versus Interpretation. Errors}

In section 7.2 a model was presented in which forecast errors occur due to unpredictable events in the future. In section 7.3 it was argued that it is unlikely that this type of forecast errors is the only type that exists. Although it may be difficult to make a clear distinction, forecasts are likely to be incorrect themselves. There is no recipe about the way optimal forecasts should be made, and therefore the act of forecasting is always arbitrary to some extent. In this section it is shown that allowing students' expectation errors to consist not only of information errors, as is done by the states of the world model, but also of interpretation errors, leads to a model of prediction errors in which a trade off between the two errors occurs.

Suppose again that a student has to make a prediction of the future wage on which to base his enrolment decision. There are many different approaches to make such a forecast and there is no reason to choose for one of these methods in advance. One approach is to make an abstract forecast based on global information and simple theoretical links. An example of this would be if a student uses the mean of the past wages as a forecast of the future wage. For such a rough, abstract forecast he uses a limited set of information, and a rather simple theoretical link with the future wage which has to be forecasted. The production of such a forecast depends on certain arbitrary choices, e.g. the decision which past events are seen as comparable to the future event, i.e. which events are selected and which are not. The quality of the forecast will depend on these choices, but the results will be rather robust. The exact design of the abstract forecast does not influence the result very much. The major part of the error of such a forecast stems from its global character: the information error will be large, while the interpretation error will be small.

On the other hand, it may be possible for a student to incorporate more theoretical arguments in his forecast. By using extra theoretical insights it becomes possible to link additional data with the future wage and therefore it becomes possible to make the forecast more specific. In the forecast of the wage, information and insights about the general development of the economy and its consequences for the labour market could be incorporated. To make such a specific forecast, and to use other data than past wages, it is, however, necessary to make choices 
about the exact form of the relationships between the variables. These arbitrary choices about the design of the forecast model will have a large influence on the outcome. The forecast becomes more specific, and thus more informative, but at the same time the probability that interpretation errors are made increases. The information error is relatively small but the interpretation error will be larger. It is therefore not a priori clear that such a specific forecast is better than an abstract forecast.

TABLE 7.3: THE RELATIVE POSITION OF ABSTRACT AND SPECIFIC EXPECTATIONS IN THE ERRORS IN FORECASTS MODEL.

\begin{tabular}{|c|c|c|c|c|}
\hline & $\begin{array}{l}\text { states of the } \\
\text { world }\end{array}$ & abstract & specific & $\begin{array}{l}\text { only errors in } \\
\text { forecasts }\end{array}$ \\
\hline based on: & & $\begin{array}{l}\text { global } \\
\text { information } \\
\text { and few } \\
\text { theory }\end{array}$ & $\begin{array}{l}\text { much, } \\
\text { detailed } \\
\text { information } \\
\text { and specific } \\
\text { theoretical } \\
\text { insights }\end{array}$ & \\
\hline $\begin{array}{l}\text { information } \\
\text { error }\end{array}$ & yes & much & few & no \\
\hline $\begin{array}{l}\text { interpretation } \\
\text { error }\end{array}$ & no & few & much & yes \\
\hline
\end{tabular}

If students are no longer assumed to make perfect forecasts, a range of possible alternative ways of forecasting becomes available to them. They have to choose between the information error of an abstract expectation, and the interpretation error of a specific expectation. It is therefore not sensible to distinguish only one (unobservable) perfect prediction as in equation (7.13), but there will be a continuum of perfect predictions, rankable from a low degree of informativity to a high degree of informativity. In this section the analysis is restricted to two different unobservable perfect predictions, but this can easily be extended to more. Table 7.3 presents the relative position of these two forecasts. An abstract expectation is based on a small information set (e.g. only past wages), but this information can be used for straightforward forecasting. Therefore the information error will be large, but the interpretation error will be small. A specific expectation is based on additional information (e.g. about the general economic developments). Therefore the information error decreases, but to use this information also more insight is needed in the functioning of the 
economy and the labour market. The risk of this specific forecast is that an error is made in the use of this concrete information. An extended model may provide very specific forecasts, but as soon as the specific assumptions do not hold an interpretation error is introduced. In the states of the world view on prediction errors all expectations are regarded as extremes of the abstract expectation. No interpretation error is made, only information errors occur. In the other extreme there might be only errors in forecasts without any states of the world uncertainty. Every error is an interpretation error.

It is remarkable that in table 7.3 the states of the world prediction is nearest to the abstract prediction. Rational expectations, which is a typical states of the world theory "seems to make very strong assumptions about the capabilities of people to forecast, but since it does not allow for interpretation errors it can also be stated that this theory only allows for simple relationships, since only then forecasts can be made without errors. It therefore only applies to abstract models. Let $w_{1}^{r e}$ be a perfect expectation, based on a small information set $I_{1}$ with a high degree of abstraction, and therefore a low degree of informativity, and let $w_{2}^{\text {re }}$ be a more specific perfect expectation, based on a set of information $I_{2}$ which includes $I_{1}$. Equation (7.13) can be extended to:

$$
\begin{aligned}
& \text { (7.14) } w_{2}^{\text {exp }}=w_{2}^{r t}+e_{1}^{\exp }+e_{2}^{\exp } \\
& \text { (7.15) } w_{1}^{\text {exp }}=w_{1}^{r e}+e_{1}^{\text {exp }}
\end{aligned}
$$

$$
w^{r e a}=w_{2}^{r e}+e_{2}^{r e}
$$

$$
w_{2}^{r e}=w_{1}^{r e}+e_{1}^{r e}
$$

in which the error terms have the expected value 0 , and are always independent of the other right hand side variables. Their variances are assumed to exists and are denoted with respectively $\sigma_{\text {rel }}^{2}, \sigma_{r e, i}^{2}, \sigma_{\operatorname{expl}}^{2}$, and $\sigma_{\text {exp } 2}^{2}$. The observed forecasts are denoted by $w_{1}^{\exp }$ and $w_{2}^{\text {eitp }}$. Since in this mode! the student has more than one expectation at his disposal, the superscript exp is used to denote expectations which are alvailable. The forecast actually used is denoted by pre. $w_{1}^{r e}$ is an abstract perfect expectation of the realised wage, but since it is based on less information, it can also be seen as a perfect expectation of the more specific perfect expectation $w_{2}^{\text {re }}$. Both perfect expectations are only observed with an additional error: the interpretation error. By taking the interpretation error of the specific expectation equal to $e_{1}^{\exp }+e_{2}^{\exp }$, with $\epsilon_{2}^{\exp }$ independent of $\varepsilon_{1}^{\exp }$ the assumption is made that it contains at least 
the interpretation error of the abstract perfect expectation $w_{1}^{r e} .^{11}$

Summing up, the assumption is made that all error terms are mutually independent. The information errors are independent by definition of the perfect expectations (since $I_{1} \subset I_{2}$ ). In section 7.3 it is shown that their meaning requires that also interpretation errors are independent of information errors. Finally, above the assumption is made that $\varepsilon_{1}^{\exp }$ is independent of $e_{2}^{\exp }$.

In a rational expectations model the interpretation errors $\boldsymbol{e}_{i}^{\exp }$ equall 0 . In this case the specific model dominates the abstract model, so it is optimal to use the most specific model. The proposition of Muth, Sargent, and Wallace, however, is that this will still be the case if measurement errors are introduced to the model. It is, however, easy to show that it is possible in that case to gain from a combination, $w^{\text {pre }}$, of both expectations:

$$
\begin{aligned}
w^{\text {pre }} & =\lambda w_{1}^{\text {exp }}+(1-\lambda) w_{2}^{\exp } \\
& =\lambda\left(w_{1}^{r e}+\epsilon_{1}^{\exp }\right)+(1-\lambda)\left(w_{2}^{r e}+\epsilon_{1}^{\exp }+\epsilon_{2}^{\exp }\right) \\
& =\lambda\left(w^{\text {rea }}-e_{1}^{r e}-e_{2}^{r e}+\varepsilon_{1}^{\exp }\right)+(1-\lambda)\left(w^{\text {rea }}-\epsilon_{2}^{r e}+\epsilon_{1}^{\exp }+\varepsilon_{2}^{\exp }\right)
\end{aligned}
$$

The prediction error of this combined prediction equals

$$
\text { (7.19) } \begin{aligned}
\Delta \bar{w} & =w^{\text {pre }}-w^{r e a} \\
& =\lambda\left(e_{1}^{\exp }-\varepsilon_{1}^{r e}-\varepsilon_{2}^{r e}\right)+(1-\lambda)\left(\varepsilon_{1}^{\exp }+e_{2}^{\exp }-\varepsilon_{2}^{r e}\right) \\
& =\lambda\left(-\varepsilon_{1}^{r e}\right)+(1-\lambda) \varepsilon_{2}^{\exp }+\varepsilon_{1}^{\exp }-e_{2}^{r e}
\end{aligned}
$$

The combination is optimal for the value of $\lambda$ for which the MSE, $\sigma_{\bar{w}}^{2}$ is minimal. The MSE of the prediction error equals (because of the mutually independency of the error terms):

$$
\sigma_{\bar{w}}^{2}=\lambda^{2} \sigma_{r e l}^{2}+(1-\lambda)^{2} \sigma_{e x p}^{2}+\sigma_{e x p 1}^{2}+\sigma_{r e 2}^{2}
$$

Minimising equation (7.20) with respect to $\lambda$ gives: 


$$
\text { (7.21) } \begin{aligned}
\frac{\mathrm{do}_{\bar{w}}^{2}}{\mathrm{~d} \lambda}= & 2 \lambda\left(\sigma_{e x p l}^{2}+\sigma_{r e l}^{2}+\sigma_{r e 2}^{2}\right)-2(1-\lambda)\left(\sigma_{e x p l}^{2}+\sigma_{e x p 2}^{2}+\sigma_{r e 2}^{2}\right) \\
& -2\left(\sigma_{e x p l}^{2}+\sigma_{r e 2}^{2}\right)+4 \lambda\left(\sigma_{e x p l}^{2}+\sigma_{r e 2}^{2}\right) \\
= & 2 \lambda \sigma_{r e l}^{2}-2(1-\lambda) \sigma_{e x p 2}^{2}=0
\end{aligned}
$$

Thus, the combination is optimal for

(7.22) $\lambda=\frac{\sigma_{e x p 2}^{2}}{\sigma_{r e l}^{2}+\sigma_{e x p 2}^{2}}$

In the model presented here students can use a range of expectations between the abstract and the specific expectation. Somewhere inbetween there is an optimal point in which the total error is minimised. Making the prediction more abstract will increase the information error more than the interpretation error will decrease, while the gain in information error by making the prediction more specific does not compensate the loss due to an increase in the interpretation error. Only the additional expectation errors are relevant for the choice. $\sigma_{\text {exp } 2}^{2}$ is the variance of the error of the specific expectation compared to the abstract expectation. By introducing the specific expectation an additional interpretation error appears. $\sigma_{r e l}^{2}$ is the the variance of the additional information error of the abstract expectation, compared to the specific expectation.

The most specific expectation is optimal only if $\sigma_{\text {exp } 2}^{2}=0$ or $\alpha_{r e 1}^{2}=\infty$. The proposition of Muth, Sargent, and Wallace is therefore not true in this construction. The only exception is the case in which only one expectation exists, or $\sigma_{r e l}^{2}=\infty$, i.e. the more abstract expectation is completely uninformative.

The result (7.22) can be given a Bayesian interpretation (see figure 7.2). $w_{1}^{\exp }$, with $\sigma_{\text {rel }}^{2}$, can be seen as moments of a prior distribution for the realised wage. The optimal prediction is the posterior distribution after inference with $w_{2}^{\exp }$. The variance of this posterior distribution, i.e. the variance of $w^{\text {pre }}$ equals:

$$
\begin{array}{rlrl}
\sigma_{p r e}^{2} & =\lambda^{2} \sigma_{r e 1}^{2}+(1-\lambda)^{2} \sigma_{e x p 2}^{2} & +\sigma_{e x p 1}^{2}+\sigma_{r e 2}^{2} \\
& =\lambda \sigma_{r e 1}^{2} & & +\sigma_{e x p 1}^{2}+\sigma_{r e 2}^{2} \\
& =(1-\lambda) \sigma_{e x p 2}^{2} & & +\sigma_{e x p 1}^{2}+\sigma_{r e 2}^{2}
\end{array}
$$


This Bayesian interpretation of expectation formation differs, however, considerably from the model presented in section 7.2. In the usual model the prior distribution is based on some a priori theoreticall insight in the possible distribution of the parameters, while empirical events provide the model with data for inference. In the model of this section the prior distribution is formed by the frequency of past events, while theoretical insights are viewed upon as data from a distribution centred round the real value of the wages which has to be forecasted.

While in the usual model forecasts improve with new data, the main improvements in this model come from additional theoretical insights. New data, however, may also improve the forecast, because it will improve the prior distribution, which is not without error in the model of this section.

FIGURE 7.2: A BAYESIAN INTERPRETATION OF (7.22).

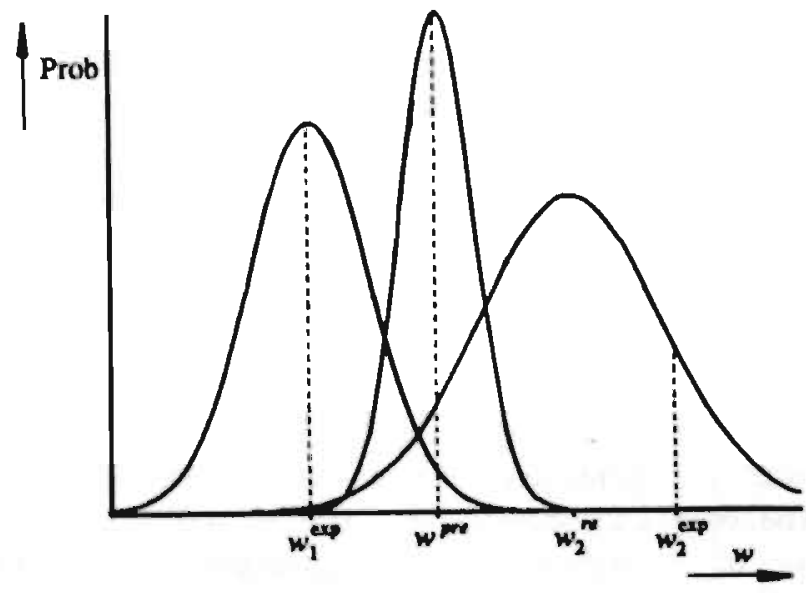

\subsection{Conclusions}

In this chapter it has been shown that it does not sufnce to describe students' uncertainty by the states of the world model. In this model agents have to assign probabilities to the possible states of the world. The assumption that they use the objective probabilities - and therefore only make information errors - ignores the fundamental question how students obtain this knowledge. The introduction of subjective probabilities makes students' expectations deviate from the optimal prediction. The meaning of prediction requires, however, that such 
deviations are random, as described by the errors in forecasts model.

The introduction of such errors in forecasts is not neutral, as assumed by Muth, Sargent, and Wallace. If students deviate from the rational expectation by a random error (the unsystematic error), it may be optimal for them to use a more abstract, simpler model. This trade off between interpretation errors and information errors leads to systematic errors in their expectations. 

The economic literature about educational choice fits in with literature about expectation formation in general. Most studies are based on the cobweb expectation theory, in which students expect the current wage to prevail, while some authors reject this cobweb theory as too naive and use rational expectations. In this chapter these two expectations models are analysed empirically. It is shown, in accordance with many other studies, that the rational expectations model does not dominate the cobweb model. Later, in chapter 9 , it will be shown that, based on the model of chapter 7, the two models can be interpreted as extreme cases in a more general expectation framework. The attention in this chapter is focused on the Dutch junior secondary technical education. ${ }^{1}$ The estimation of the two models, and their comparison, gives a first impression of the expectation formation by these students.

Based on these test and estimation results the yearly mismatch is calculated. As a simple measure for mismatch the number of students who made a wrong decision due to incorrect labour market anticipations is taken. These numbers indicate the possible gains from a public labour market forecast. In the third part of this study the measurement of mismatch is based on welfare economic concepts. Measuring the number of students who experience mismatch, therefore, serves as a first indication.

\subsection{An Empirical Specification}

At the Dutch junior secondary technical schools students start with a general curriculum of one (until 1970) or two (from 1971) years. After this general course they have to choose one of the (two year) vocational specialisations the school offers.

In this analysis, the specialisations are clustered into three groups in order to integrate corresponding segments of the labour market and to avoid problems due to changing classification schemes through time at a lower level of aggregation. These three specialisations are: building industry $(B)$, metal industry $(M)$ and food and catering industry $(F){ }^{2}$

1 In the Netherlands these schools are called LTS (Lower Technical School), or VBO (Voorbereidend Beroepsonderwijs) and ITO (Individual Technical Education).

2 The data consist of figures about the number of students in the first year of specialisation, wages and the probability to get a job for the three segments building industry, metal industry and food and catering industry, from 1949 till 1986. Because of two years lagged 
Figure 8.1 shows the development of the numbers of students choosing for one of these three specialisations. The figure clearly shows that not only the total number of students has changed through time, but also that the distribution among the three specialisations is far from constant.

FIGURE 8.1: THE ENROLMENT THROUGH TIME IN THE THREE SPECIALISATIONS.

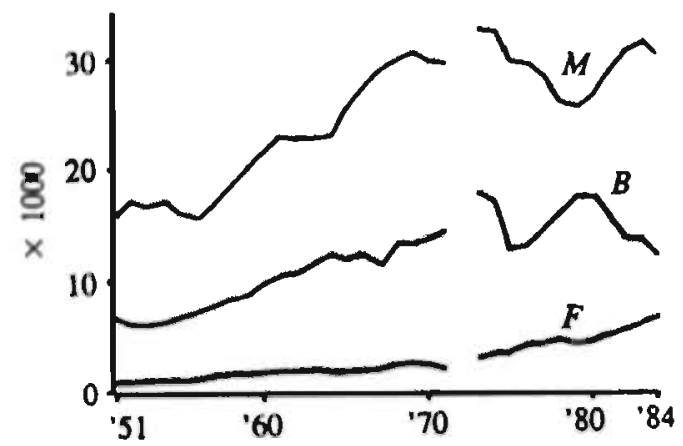

According to the model in chapter 3, these changing choices may, apart from changes in capabilities and the students' preferences, be explained by changes in the situation of the labour market segments that these specialisations give access to. According to the labour market model of chapter 3 it is assumed that students choose a specialisation by taking into account their preferences and the labour market perspectives of vocational specialisations. The distribution of preferences among students is not expected to change quickly, while the labour market situation may change fast.

Because preferences and capabilities are given for one student, they are constants in the choice function of that individual student. The only variables in this individual choice function are related to the labour market situation (according to (3.7)). Restricted by the availability of data, the labour market situation is only represented by the wages and

instruments and because of two years forward-looking expectations, the estimation is restricted to 1951 till 1984. The enrolment in 1972 is missing due to the one year increase of the general curriculum in 1971. In 1971 first-year students had to decide about their specialisation, while the cohort of 1972 had to make this decision after their second year (in 1973). Simultaneousiy the curriculum changed from three into four years so the length of the specialisation period has remained constant.

The figures have been taken from The Statistics of the Junior Secondary Vocational Education, Monthly Bulletin of Socio-Economic Statistics and National Accounts, published by Netherlands Central Bureau of Statistics (CBS). 
the probabilities to get a job in the three specialisations. Because students do not know these figures exactiy, the choice function depends on their expectations of these figures rather than on these figures themselves.

Wages are measured by the total sum of wages in sectors of industry related to a particular specialisation, divided by the number of people working in these sectors. The wages, defined this way, do of course not necessary equal the wages of entrants, nor do they equal the present value of life-cycle-incomes. However, the average wage at the moment of entrance may be viewed as a suitable indicator for the labour market situation the occupation is in.

The probability to get a job is defined by the number of people working in the relevant sectors divided by the sum of this number of people working and the number of unemployed with relevant occupations. These figures also represent a one year situation for the whole occupational group.

On an aggregate level the model of chapter 3 leads to an enrolment function in which the fraction of students choosing a certain specialisation increases as the expected labour market perspectives for that specialisation improve. The better these labour market expectations, the more students will have passed their reservation wage, or probability to get a job. In the theoretical model of chapter 3 this supply equation is assumed to be linear. For empirical purposes such a linear equation has some disadvantages. The form is not very flexible and it may lead to negative supply predictions. To avoid these problems, the choice function is assumed to have the logit-form:

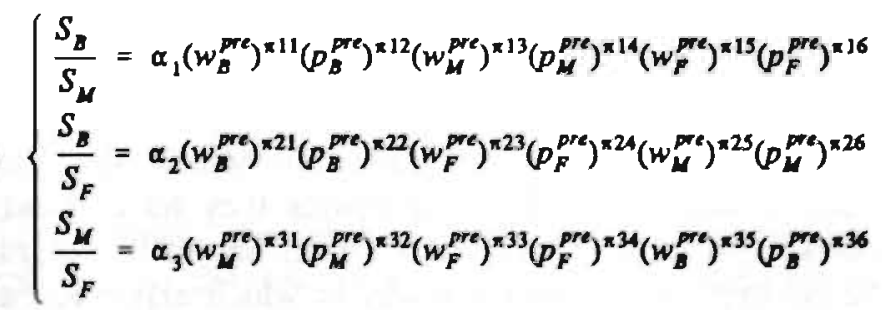

in which $S_{i}$ is the number of students choosing specialisation $i(i=B, M, F), w_{i}^{p r e}$ is the expectation, formed at $t$, of the wage at $t+2$, the moment the student will enter the labour market, related to specialisation $i$, and $p_{i}^{\text {pre }}$, similarly, is the expected probability to get a job at $t+2$, formed at $t$, also for specialisation $i$.

The ratio of e.g. the choice for the building industry and the metal industry specialisation also depends on the wage and probability to get a 
job in the food and catering specialisation. This is relevant because a change in the labour market situation in the food and catering industry may have a different impact on the enrolment in the building industry specialisation and the metal industry specialisation, which may cause a change in the ratio.

By assuming that choices only depend on relative wages and relative probabilities (i.e. by assuming the 'income-effect' to be absent), equation (8.1) can for estimation purposes be reduced to:

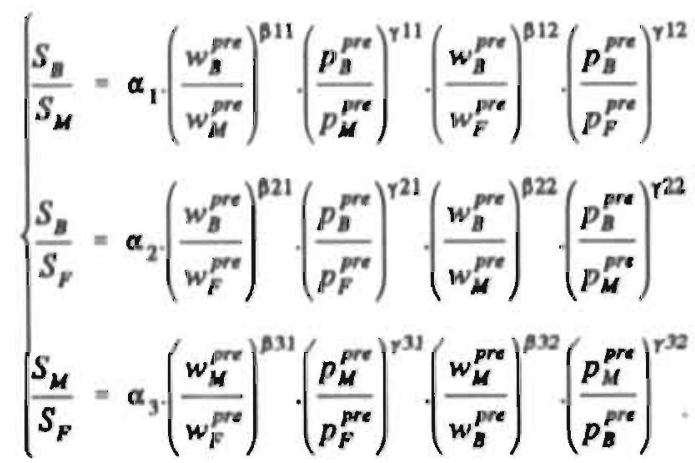

with

$$
\begin{aligned}
& \pi i 1=\beta i+\beta i 2 \\
& \pi i 2=\gamma i 1+\gamma i 2 \\
& \pi i 3=-\beta i 1 \\
& \pi i 4=-\gamma i 1 \\
& \pi i 5=-\beta i 2 \\
& \pi i 6=-\gamma i 2 \quad, i=1,2,3
\end{aligned}
$$

The estimation is based on this model with parameter restrictions, while the results of model (8.1) will be presented, which has a more convenient economic interpretation.

(8.1) provides a model of students' choices in which the choices students make are a function of the expectations they have about the future labour market situation. Finally, this model has to be completed with two alternative hypotheses about the way in which expectations are formed.

In the economic literature, as discussed in chapter 6, with regard to students' choices, two streams of thought can be distinguished. The first stream is the so-called cobweb theory, which assumes students to base their decisions entirely on the present instead of the future labour market situation. In other words, it is assumed that students expect the future situation to be similar to the present situation. Freeman is the 
most well-known propagator of this view.

The second stream is represented by Zarkin (1983) and Siow (1984). In their models, students have rational expectations about the future labour market. The rational expectations theory assumes that students" expectations are the best possible expectations, given the data available at the moment choices have to be made.

These two common theories about expectation formation are estimated. Furtheron it will be shown that these theories can be viewed upon as extremes, so the truth may be somewhere in between.

\subsection{The Estimation}

In order to investigate the use of information, both the cobweb model and the rational expectations model are estimated. The next step is the comparison of both models by an artificial nesting method. It is calculated to what extent one model is able to explain the unexplained part of the other model.

The first model to be estimated is the cobweb model. In the equations (8.2) the expectation variables have to be replaced by present wages, which leads to:

$$
\left\{\begin{array}{l}
\frac{S_{B}}{S_{M}}=\alpha_{1} \cdot\left(\frac{w_{B}^{-d}}{w_{M}^{-d}}\right)^{\beta 11} \cdot\left(\frac{p_{B}^{-d}}{p_{M}^{-d}}\right)^{\gamma 11} \cdot\left(\frac{w_{B}^{-d}}{w_{F}^{-d}}\right)^{\beta 12} \cdot\left(\frac{p_{B}^{-d}}{p_{F}^{-d}}\right)^{\gamma 12} \cdot t^{\delta 1} \\
\frac{S_{B}}{S_{F}}=\alpha_{2} \cdot\left(\frac{w_{B}^{-d}}{w_{F}^{-d}}\right)^{\beta 21} \cdot\left(\frac{p_{B}^{-d}}{p_{F}^{-d}}\right)^{\gamma 21} \cdot\left(\frac{w_{B}^{-d}}{w_{M}^{-d}}\right)^{\beta 22} \cdot\left(\frac{p_{B}^{-d}}{p_{M}^{-d}}\right)^{\gamma 22} t^{\delta 2} \\
\frac{S_{\mu}}{S_{F}}=\alpha_{3} \cdot\left(\frac{w_{M}^{-d}}{w_{F}^{-d}}\right)^{\beta 31} \cdot\left(\frac{p_{M}^{-d}}{p_{F}^{-d}}\right)^{\gamma 31} \cdot\left(\frac{w_{M}^{-d}}{w_{B}^{-d}}\right)^{\beta 32} \cdot\left(\frac{p_{M}^{-d}}{p_{B}^{-d}}\right)^{\gamma 32} t^{\delta 3}
\end{array}\right.
$$

In this model the choices are only influenced by predetermined quantities, so the use of ordinary least squares for the estimation is possible. To get a linear equation the logarithm is taken at both sides of the equations. In this model of three equations, in fact, two equations determine all the parameters of the third one. Due to the use of OLS these parameter restrictions between the three equations are automatically fulfilled. Further, to allow for slow changes in preferences or the schooling system, a (multiplicative) trend variable $(t)$ has been added. 
The second model, with rational expectations, can not be estimated directly by OLS since the expectation variables are not observed directly. Rational expectations will, in general, differ from their future realisations. Rational expectations are only the best possible forecasts at a certain moment $(t)$ of this future realisation $($ at $t+2)$, given the information available at this moment $(t)$. McCallum (1976) has shown, however, that it is possible to use the realisations of the future variables as proxies for expectations of these future variables. These proxies do, in that case, contain an error, which is the unpredictable part of the variable. But if the equation is estimated by use of instrumental variables which are known at the moment of forecasting, the estimation will be consistent. Equations (8.2) can be rewritten, including these proxies, as:

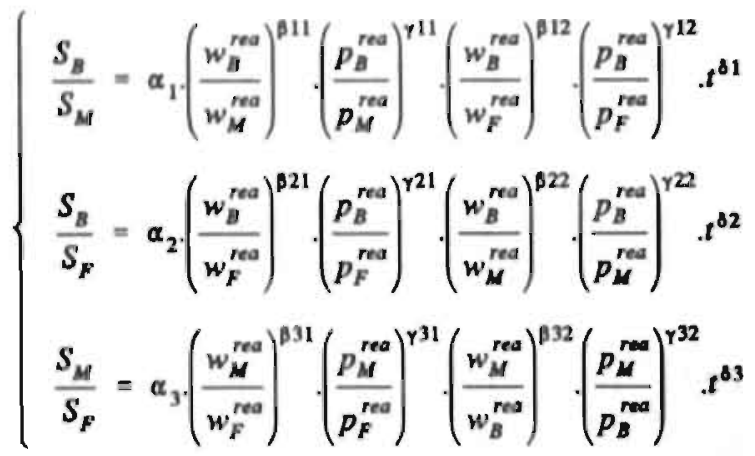

As a rational expectation is by definition the best possible expectation, the difference between this expectation and the realisation $\left(\varepsilon=w^{p r e}-w^{r e a}\right)$ can not be correlated with the expectation. The expectation is known at the moment of choice, and based on the correlation between this expectation and the error term, the error term could be forecasted, and thus the expectation could be improved. Therefore, there has to be a correlation between this error term and the proxy variable (the realisation). Furthermore, since the lag between the moment of choice and the entrance onto the labour market (which is 2 in this case) is more than one year, the error terms will be autocorrelated. Uncertainty in rational expectations, is due to random external shocks. Every year the realisation of some of the stochastic variables becomes known, so if the periods of prediction are overlapping, errors in both forecasts will be affected by the events in the overlapping year. This causes autocorrelation of the error terms.

Thus, the error term in this model is both autocorrelated and correlated with the proxy variables. Using OLS in such a situation would lead to 
an estimation that is biased because of the correlation with the variables and it would be not efficient because of the autocorrelation. Estimation with OLS would be consistent with the assumption of perfect foresight. The expectations are, in that case, assumed to be equal to the realisation of wages and the probability to get a job. A.ccording to the rational expectations theory, they are however only an approximation. Cumby, Huizinga, and Obstfeld (1983) suggest an estimator for such models (a two-step two-stages least squares estimator), which is efficient and unbiased.

The model is estimated with lagged variables as instruments for the endogenous variables that are correlated with the error term and this estimation is carried out twice, a first step assuming no autocorrelation and a second step using autocorrelation estimates taken from the first step. A disadvantage of this procedure is that the parameter restrictions between the three equations will not be fulfilled automatically.

As instruments for the expectations the wage and the probability to get a job at moment $t, t-1$ and $t-2$ have been used. Since these figures are assumed to be known at $t$, they do, by definition of rational expectations, not correlate with the error term, which includes the difference between expectation and realisation. ${ }^{3}$

Finally, a comparison between the two models will be performed. The test is based on a regression of the predictions of both models on the true values of relative choices:

$$
\frac{S_{B}}{S_{M}}=\operatorname{CONST}+\mathrm{M}\left(\frac{\hat{S}_{B}}{\hat{S}_{M}}\right)_{\text {Cobreb }}+(1-\mathrm{M})\left(\frac{\hat{S}_{B}}{\hat{S}_{M}}\right)_{\text {RaEx }}
$$

with

$$
\text { (8.7) } \quad M=\frac{\mu \sigma_{\text {RaiEx }}^{2}}{(1-\mu) \sigma_{\text {Cobweb }}^{2}+\mu \sigma_{\text {RatEx }}^{2}}
$$

(8.6) and (8.7) are based on a artificial nesting procedure (Fisher and McAleer, 1981), in which $\mu$ is the test-statistic for both hypotheses. Because the rational expectations model includes an unobserved

3 Representing the right-hand variables of $(8.5)$ by $X$, the left-hand variable by $y$, the matrix of instruments by $Z$ the estimator of Cumby, Huizinga, and Obstfeld becomes: $\hat{\theta}_{\mathrm{CHO}}=\left(X^{\prime} Z\left(Z^{\prime} \hat{\mathrm{L} Z}\right)^{-1} Z^{\prime} X\right)^{-1} X^{\prime} Z\left(Z^{\prime} \hat{D} Z\right)^{-1} Z^{\prime} y$, in which $\hat{\Omega}$ is the estimated covariance matrix, which has been corrected for the gap in 1972 . 
forecasting error it will show a larger standard error than the cobweb model. (8.7) corrects for this difference. ${ }^{4}$

If the cobweb model is strictly better than the rational expectations model (i.e. the rational expectation predictions equal the cobweb predictions except for some noise not correlated with the real data) $\mu$ will be equal to 1 . The other extreme is $\mu$ equals 0 . In this case the rational expectation model dominates the cobweb model. The absolute $t$ values indicate the additional information of the model, compared with the other model.

\subsection{Estimation Results}

Table 8.1 presents the estimation results of the cobweb model, based on equations (8.1). It contains six "triangles". Each triangle shows the effects of a change in wages or the probability to get a job (vertically) in one of the three sectors (horizontally), leaving all other variables constant. For example, if the probability to get a job in the building industry (first triangle of the second row) increases by $1 \%$, the ratio of students choosing building industry specialisation and students choosing the metal industry specialisation increases by $2.72 \%$ ( $\pi 12$ in (8.1)). Significant effects (The level of significance is $90 \%$, which corresponds to an absolute $t$-value greater than 1.70) are indicated by bold arrows.

All significant effects do have the correct sign. The significant arrows suggest that probabilities to get a job play an important role in choosing for the building industry specialisation, while wages are most important for metal industry and food and catering. The insignificance of the other parameters may be caused by the fact that these effects are rather small, or by the fact that the cobweb assumption about the expectations does not hold.

Since it is difficult to interpret the parameters of table 8.1 , an example of the size of these results is presented in table 8.2. In order to indicate the trend, the predicted choices of 1951 and 1984 have been calculated as if no wages and probability differences occurred. Furthermore, the table presents the predicted choices in 1984, based on actual wages and probability figures, and the changes in this distribution in case of a $1 \%$ change of one of the six labour market variables.

$4 \mu$ is only identified in (8.7) if $\sigma_{\text {common }}^{2} \sigma_{\text {Rum }}^{2}$ are known. Since they are not: known directly, they are replaced by their estimates, which is in fact incorrect because they may be estimates based on an incorrect model. An incorrect model will, however, lead to an overestimation of $\sigma^{2}$, which will lead to a correction of $\mu$ in favour of the false model. 
TABle 8.1: Estimation WITH THE cobWeb Model ( $t$-Values Between BRACKETS).

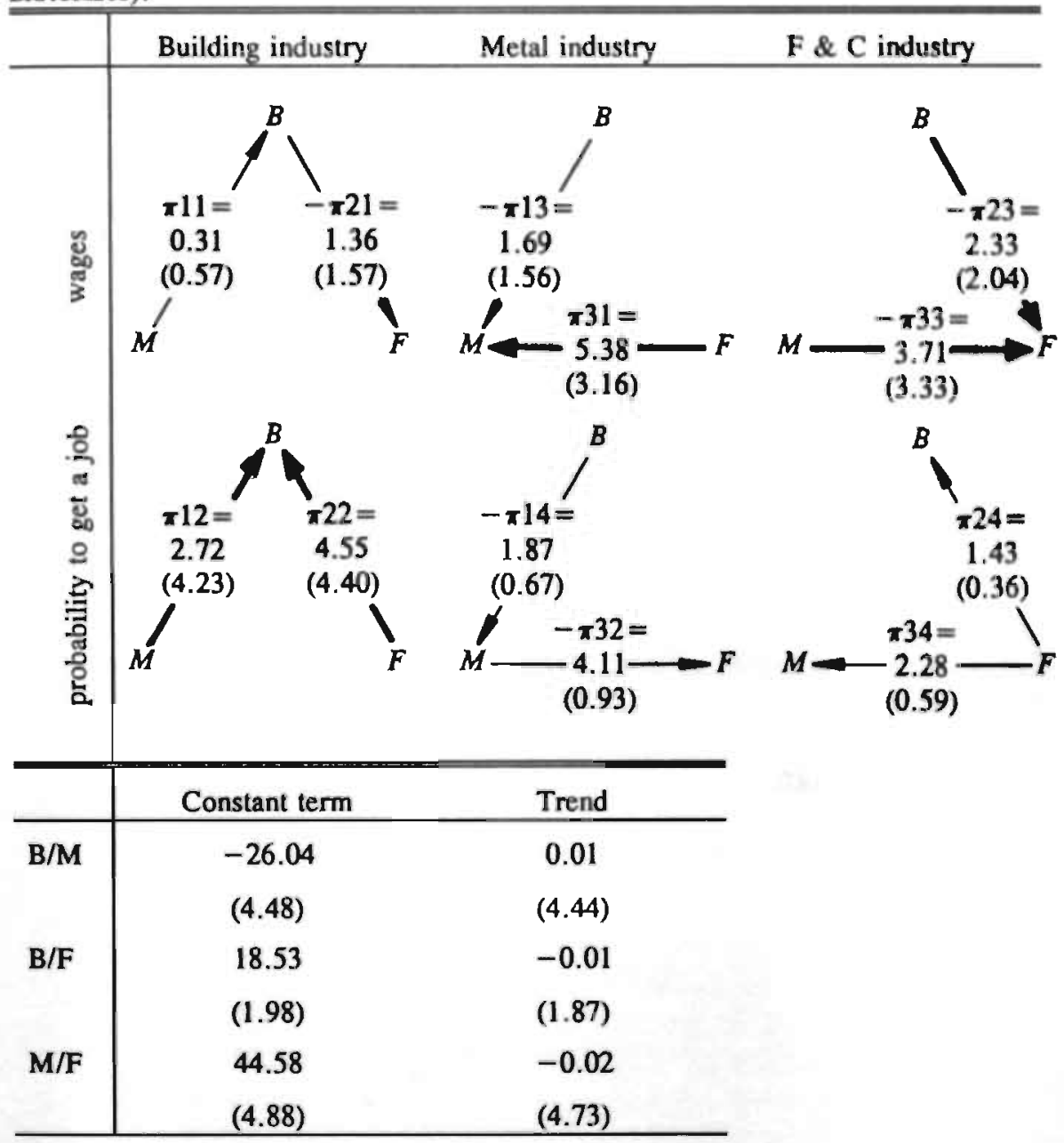

Table 8.2 shows that the growth of the food and catering specialisation is structural. The growth is not only caused by an increase in wages or probabilities to get a job, but from 1951 to 1984 this specialisation grew $300 \%$, even with no differences in wages and probability.

In 1984, the labour market situation caused 4956 students to leave the building industry in favour of mainly the metal specialisation. The elasticities of supply vary in a range according to the results of similar studies. For wages the maximum elasticity is 2.9 in the food and catering industry, while for the probability to get a job the elasticity reaches its maximum of 2.2 in the building industry. 
TABLE 8.2: AN EXAMPLE OF THE ESTIMATION RESULTS OF THE COBWEB MODEL (SIGNIFICANT VARIABLES ARE PRINTED BOLD).

\begin{tabular}{l|rrc}
\hline & Building & Metal & F\&C \\
\hline 1951 (ali wages and prob. equal) & $\mathbf{7 0 7 9}$ & 14628 & 1707 \\
1984 (all wages and prob. equal) & 18286 & 24623 & $\mathbf{5 8 9 1}$ \\
1984 (actual wages and prob.) & 13330 & 29518 & $\mathbf{5 9 5 2}$ \\
change due to 1\% rise of & & & \\
$\quad$ wage B & +2 & -84 & +82 \\
wage M & -79 & +326 & -247 \\
wage F & +73 & -246 & +173 \\
probability B & +293 & -156 & -137 \\
probability M & -247 & -1 & +248 \\
probability F & -46 & +149 & -104 \\
\hline
\end{tabular}

Table 8.3 shows the estimation results of the rational expectations model. Four out of the twelve labour market effects are significant and one of these, the ratio between building and food and catering industry, has the wrong sign. 
TABLE 8.3: ESTIMATION OF THE RATIONAL EXPECTATIONS MODEL ( $\boldsymbol{t}$-VAlUES BETWEEN BRACKETS).

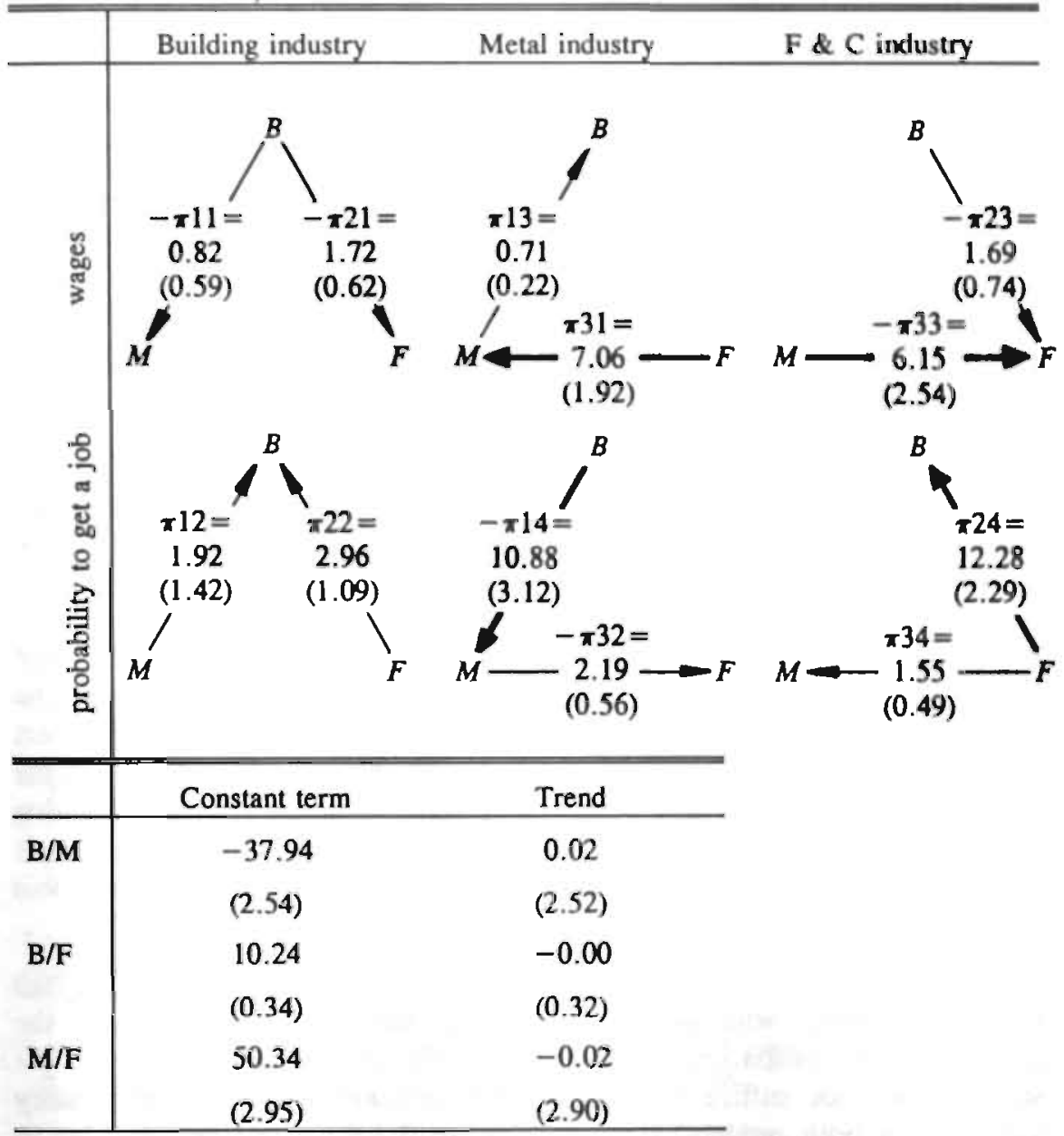

Table 8.4 gives an example of the rational expectations estimation results, similar to table 8.2 . As parameter restrictions in the rational expectations are not fulfilled, the parameters of the third equation, the ratio of the choices for metal industry and food and catering industry, have been taken according to the other two equations. In this model the maximum elasticity of supply with respect to wages is 5.5 again for food and catering, and 2.7 for the probability to get a job in the metal industry. 
TABLE 8.4: AN EXAMPLE OF THE ESTIMATION RESULTS OF THE RATIONAL EXPECTATIONS MODEL (SIGNIFICANT VARIABLES ARE PRINTED BOLD).

\begin{tabular}{l|ccc}
\hline & Building & Metal & F\&C \\
\hline 1951 (all wages and prob. equal) & 5560 & $\mathbf{1 5 7 5 4}$ & $\mathbf{2 1 0 0}$ \\
1984 (all wages and prob. equal) & $\mathbf{1 6 4 8 6}$ & $\mathbf{2 5 0 3 0}$ & $\mathbf{7 2 8 4}$ \\
1984 (actual wages and prob.) & $\mathbf{1 4 7 0 2}$ & $\mathbf{2 8 7 4 3}$ & $\mathbf{5 3 5 5}$ \\
change due to 1\% rise of & & & \\
wage B & -98 & +42 & +56 \\
wage M & +182 & +152 & -334 \\
wage F & -90 & -205 & +295 \\
probability B & +214 & -137 & -80 \\
probability M & $-\mathbf{1 1 5 6}$ & $+\mathbf{7 7 0}$ & +387 \\
probability F & +985 & -687 & $-\mathbf{2 9 8}$ \\
\hline
\end{tabular}

In figure 8.2 and 8.3 the fit of the two models has been indicated. They show the percentage of students in a certain year that did not choose the specialisation predicted by the model. Although due to the different estimation techniques a comparison between the cobweb model and the rational expectations model is not completely justified, it is obvious that the rational expectations model fits less well than the cobweb model. It is, however, not allowed to draw final conclusions from this observation.

In order to get an indication of the influence of both hypotheses, the two extreme models will be compared. Zarkin (1983) mentioned the difficulties of comparing these two models. A comparison of the $R$ square does not suffice because of the correlation of the explanatory variables of both models. However, an artificial nesting test enables to make such a comparison. 
FIGURE 8.2: MISSPECIFICATION OF THE COBWEB MODEL.

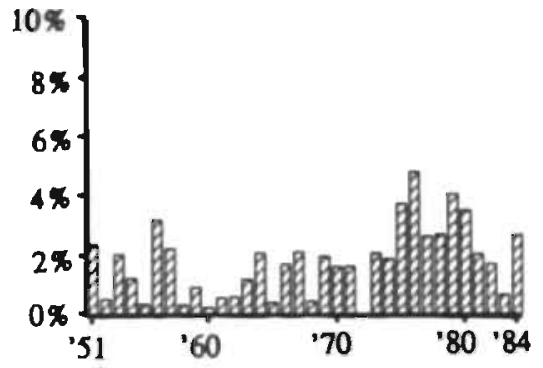

FIGURE 8.3: MISSPECIFICATION OF THE RATIONAL EXPECTATIONS MODEL.

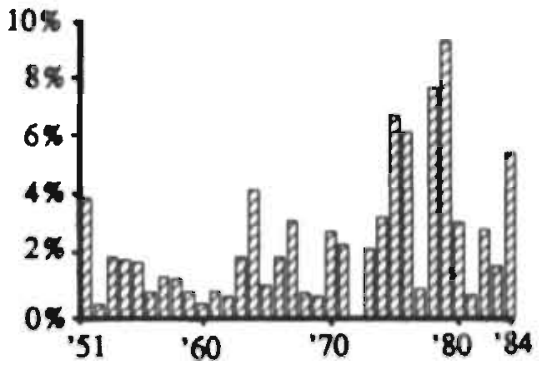

Table 8.5 gives the results of this test between the models. The parameter $\mu$, of equations $(8.6,8.7)$ has been estimated for the three equations of the model. If the predictions of both the cobweb model and the rational expectations model are regressed on the real data, e.g. in the complete model of the building industry versus food and catering, the cobweb predictions get a parameter value $\mu$ of 0.90 and the rational expectation model a $1-\mu$ of 0.10 . If a parameter of this kind gets 1 and therefore the other parameter 0 , the model with the 1-parameter explains at least everything that is explained by the other model. The 0 parameter model may be rather good, but it is completely dominated by the other model.

TABLE 8.5: COMPARISON OF COBWEB AND RATIONAL EXPECTATIONS MODEL ( $\boldsymbol{l}$-VALUE'S BETWEEN BRACKETS).

\begin{tabular}{l|ccc}
\hline & B/M & B/F & M/F \\
\hline$\mu$ & 0.87 & 0.90 & 0.76 \\
$1-\mu$ & $(1.77)$ & $(1.77)$ & $(1.33)$ \\
& 0.13 & 0.10 & 0.24 \\
$\mathrm{C}$ & $(0.27)$ & $(0.19)$ & $(0.41)$ \\
& -0.78 & 1.52 & 2.30 \\
& $(34.00)$ & $(28.57)$ & $(35.89)$ \\
\hline
\end{tabular}

The table shows that in all cases the cobweb model has a higher parameter value than the rational expectations model, which implies that the cobweb model is a better description than the rational expectations model. $1-\mu$ does not significantly differ from 0 , and therefore $\mu$ does 
not significantly differ from 1 . On the other hand, only in two of the three equations $(B / M$ and $B / F)$ does $\mu$ differ significantly from 0 at a $5 \%$ level $\left(t_{26 ; 0.05}=1.70\right)$. These parameter estimates indicate a dominant performance of the cobweb model, although the $t$-tests indicate that the evidence is not very strong. This may be due to the relative short time-series.

An overali conclusion of the analysis of this section might be that in general the cobweb model gives better estimation results, and also that it is better able to predict than the rational expectations model. An important implication of accepting the cobweb hypothesis is that students make systematic errors in their anticipations of the future labour market situation. It seems to be the case that students, indeed, are not very capable to predict the future developments at the labour market. These errors lead to mismatches at the moment they enter the market. In the next section some simulations show the extent of these mismatches.

\subsection{Implications}

In the discussion cobweb versus rational expectations, the latter is becoming, also in the literature about educational choice, increasingly popular. This popularity is mainly based on the theoretical argument that it is not reasonable for students to waste information. In the cobweb model students seem to ignore valuable information. The empirical test in the previous section gives, however, an advantage to the cobweb theory. There exists therefore a gap between the theoretical insight concerning economic behaviour of the rational expectations theory and the empirical evidence of cobweb behaviour. In the next chapter the theoretical aspects of this gap will be taken into account. In this section the implications of the empirical phenomenon is investigated. The extent of the mismatch is indicated by use of the estimation results of section 8.3.

In order to be able to indicate the extent of the problem, a criterion for measurement is needed. In chapter 13 such a criterion is derived from a welfare economic point of view. The criterion used here, which is more straightforward, is the number of students that (according to the estimated supply function) regret their decision at the moment they enter the labour market and the realisation of the labour market situation becomes known to them. Thus mismatch is measured in this section as the number of students that would have chosen another specialisation if they had had full information on future labour market prospects. To measure this mismatch, the predicted enrolment for two (hypothetical) 
situations is calculated. Firstly, the predicted enrolment is based on actual labour market figures, according to the cobweb theory. Secondly, the: enrolment is calculated by replacing the actual labour market figures by the figures at $t+2$. This second enrolment indicates the hypothetical choice of students if they had known the future labour market situation. The difference between the two indicates the mismatch.

Three observations have to be made about this criterion. Firstly, it measures only aggregate, net effects. If one student chooses the metal instead of the building industry, but another student chooses the building instead of the metal industry these effects will not appear in the aggregate supply functions of the previous sections. Secondly, the criterion does not take into account the fact that if everybody had chosen the right specialisation, the labour market situation would have been different. Finally, the criterion gives every mismatch equal weight, while there will be some students who made a wrong decision, who were almost indifferent between the 'right' and the 'wrong' decision, while others' costs of a wrong decision might be rather high. In general, this will lead to an overestimation of small mismatches and an underestimation of large mismatches.

On account of the results of the estimation in the last section, the assumption is made that the cobweb model is the correct model. Thus, students' choices are completely determined by the present labour market situation. The extent of the mismatch is measured, based on the parameter estimations of the cobweb model.

FIGURE 8.4: THE TOTAL MISMATCH.

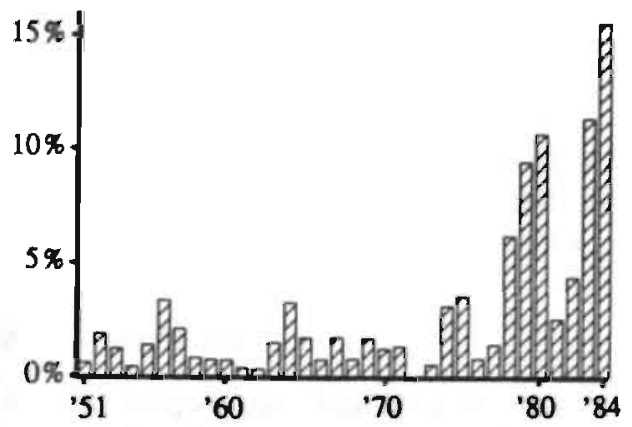

Figure 8.4 shows the fraction of students that made the wrong decision, per year. The number of students making a wrong decision is, especially in recent years, rather high: on average $3 \%$ of all the students 
at the junior secondary technical schools, but the last ten years on average $7 \%$, up to almost $16 \%$ in 1984 . Figures $8.5,8.6$, and 8.7 provide the same data for the three specialisations separately. All the three specialisations show an increase in recent years; in the building industry, however, the change is most radical. In the food and catering specialisation some high percentages of mismatch already occur in the fifties. The extent of the problem is far from equal for the three specialisations. In the building industry the fraction making the 'wrong' decision is $9 \%$ on average and goes up to $49 \%$ in 1980 , while the average in the metal industry is $4 \%$ with a maximum of $22 \%$ in 1984 . The food and catering specialisation also had its maximum in 1984, at $60 \%$, but in this sector high scores already appeared in the fifties, with e.g. $27 \%$ in 1956 . In this sector the average mismatch is $12 \%$.

FIGURE 8.5: MISMATCH IN THE BUILDING INDUSTRY.

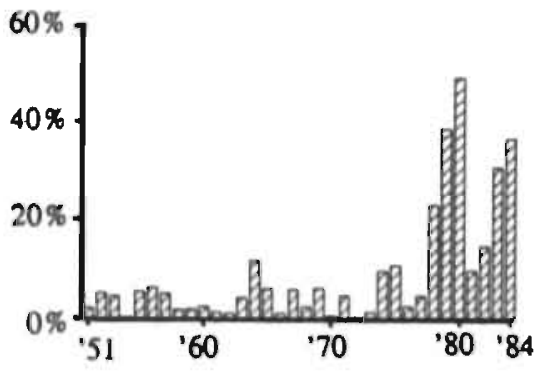

FIGURE 8.7: MISMATCH IN FOOD AND CATERINO.

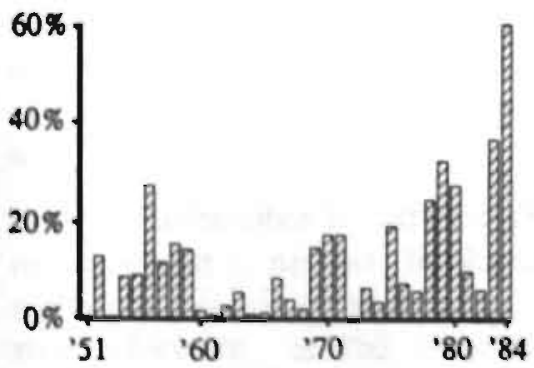

FIGURE 8.6: MISMATCH IN THE METAL INDUSTRY.

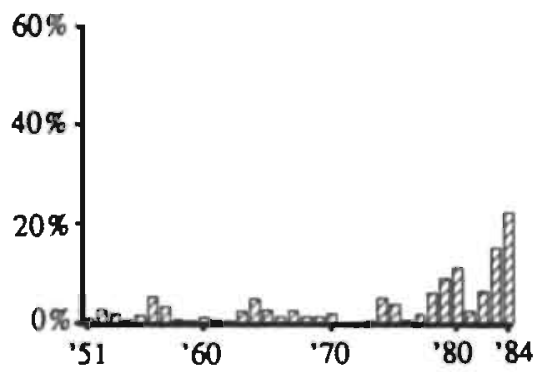

The mismatch fractions indicated in these figures may be seen as an indication for the value of correct information. If correct information was available this fraction of students would have chosen correctly, and thus this amount of students would be better off in that case. Although it 
will not be possible for professional forecasters to predict the future labour market situation perfectly, this value of correct information can be viewed upon as the opportunity costs of not having better predictions.

FIGURE 8.8: VALUE OF INFORMATION ABOUT WAGES.

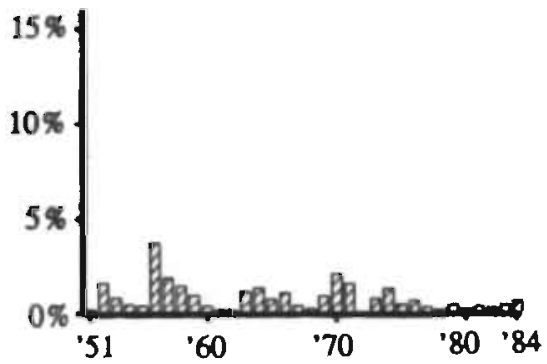

FIGURE 8.9: VALUE OF INFORMATION ABOUT PROBABILITY TO GET A JOB.

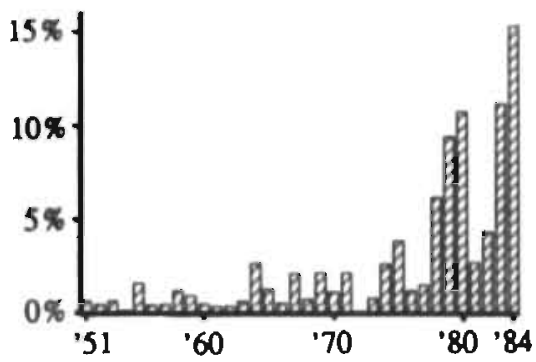

In figure 8.8 and 8.9 this value of information is split up into information about the wages and information about the probability to get a job. The figures lead to two important conclusions. Firstly, the value of information about wages is decreasing while the value of information about probabilities to get a job is increasing. Secondly, while the value of information about wages is only $0.9 \%$ on average before 1972 and $0.4 \%$ after 1972 , the value of information about the probability to get a job is $0.9 \%$ on average before 1972 but $5.7 \%$ after 1972 .

The decrease of the value of information about wages may be explained by the increase of the wage rigidity. If wages do not change much the value of knowing future wages instead of present wages is not big, because present wages will be a good predictor for future wages. But, due to this wage rigidity the fluctuations of the probability to get a job have risen. If wages do not regulate the allocation process, this task will be adopted by the unemployment rate.

\subsection{Conclusions}

In this chapter the choice between specialisations at the junior secondary technical education has been investigated. The cobweb model and rational expectations are compared. The empirical results show a preference for the cobweb model. This provides again empirical evidence for the theoretical model of chapter 7, which explains that systematic forecasts errors may occur. 
Furthermore, it is shown - departing from the cobweb model - that mismatch may be rather large. E.g. in the food and catering sector the estimation of the average number of students who make the wrong choice is $12 \%$. 


\section{VARIABILITY AND PREDICTABILITY}

Uncertainty about future developments on the labour market may be caused by random elements in the external world, and by errors made in the construction of forecasts. In chapter 7 it was therefore argued that prediction errors which are made by students are not only due to uncertainty with respect to different possible states of the world, but that the predictions themselves also contain an error. Based on this, it was shown that not the most informative prediction (i.e. the rational expectation) is optimal, but that there is a trade off between informative, very specific, expectations, and more abstract expectations. The first one will contain a large interpretation error, due to the specific assumptions it is based on, while the latter contains an information error due to its generality.

In chapter 8 some empirical evidence was given, which showed that indeed the rational expectations theory does not dominate the cobweb theory. From a rational expectations point of view this is, as shown in chapter 6 , unacceptable. For this theory it is problematic that students deliberately do not use the optimal prediction. In section 9.1 this vision about optimal behaviour, called the Lucas critique, will be considered. In section 9.2 this optimality criterium is adopted to the rational expectations theory, which fits well into this framework. The usual interpretation of the cobweb behaviour is, as stated before, problematic from the optimality point of view. In section 9.3 the problems which arise in the usual cobweb interpretation will be taken into account. Section 9.4 provides an alternative interpretation which is not liable to Lucas's critique. A simplified version of the model of chapter 7 is used to show that cobweb behaviour may be explained by optimal behaviour of the students. This model is based on two concepts: variability and predictability.

This model has severe implications. In section 9.5 the implications for econometric tests of the rational expectations hypothesis will be considered. Section 9.6 will discuss the implications in the case of a public policy that aims at manipulation of expectations. The model also has important consequences for the theory about the provision of public labour market information. In section 9.7 the predictions model developed in this chapter will again focus on the main subject of this study: how does public information influence the individual expectation formation, and therefore the individual labour market behaviour? 


\subsection{Lucas's Critique}

In section 5.2 the critique of Lucas (1976) on the econometric program of Tinbergen and Haavelmo was discussed. Tinbergen (1952, 1956) viewed the economy as a set of relations which are principally knowable. By estimating these relations the government is able to calculate the consequences of its policies and can choose the optimal policy given its policy target. Part of the economic model $f\left(y_{p} x_{r}, \varepsilon_{t}\right)$ are the decision rules of the agents, which depend among others on their expectations. In Tinbergen's theory of public policy these expectations depend, just as the other economic relations, on other economic variables. This relation between expectations and economic variables is fixed.

It is this fixity of the expectation relation that Lucas (1976, p. 25) opposes to. 'The function $f$ and parameter vector $\theta$ are derived from decision rules (demand and supply functions) of agents in the economy, and these decisions are, theoretically, optimal given the situation in which each agent is placed.' Expectations are, according to Lucas, not simply variables like other economic variables, as the capital stock and the money supply, but should be understood as agents' attempts to grasp their economic environment. If the environment changes, the expectations will also change. In Lucas's case, if the public policy changes, the former reaction may be not optimal anymore, and people may switch to other reaction functions. Expectations about the economic system will depend on the structure of the economic system itself. 'We have to attribute to individuals some view of the behaviour of the future values of variables of concern to them. This view, in conjunction with other factors, determines their optimum decision rules' (p. 25). The fact that expectations are directed towards reality is characteristic of expectations.

Lucas holds on to Tinbergen's assumption about the existence of the true model $f$ (which may be difficult to discover, p. 25). If such a true model $f$ is assumed to exist it becomes inevitable to assume that agents have rational expectations. To obtain a situation in which agents' expectations are not rational, the economic model attributed to them must differ from the model known to the investigator. From the investigator's point of view, the agents therefore will make certain errors by assumption. The investigator knows the true model, he knows the (wrong) model of the agents and can therefore calculate (not merely predict) the prediction errors the agents make. For Lucas such a situation is impossible. It is not clear why the investigator is able to see errors made by the agents which can not be seen, by definition, by the 
agents themselves. If the agents make different forecasts than the investigator, it will, in general, not be possible for him to predict these differences structurally. 'It is perhaps necessary to emphasize that this point of view towards conditional forecasting, due to Knight and, in modern form, to Muth, does not attribute to agents unnatural powers of instantly divining the true structure of policies affecting them. More modestly, it asserts that agents' responses become predictable to outside observers only when there can be some confidence that agents and observers share a common view of the nature of the shocks which must be forecast by both' (p. 41).

If the view of the investigator is a completely knowable model, only with forecast errors due to different states of the world, without any errors in forecasts, this view should also be assumed to be present for the economic agents in the model.

Lucas's criterium for economic modelling is that human behaviour can not be modelled by some arbitrary mathematical rules, but must be such that behaviour can be understood economically. 'Any disequilibrium model, constructed by simply codifying the decision rules which agents have found it useful to use over some previous sample period, without explaining why these rules are used, will be of no use in predicting the consequences of non-trivial policy changes' (Lucas, 1981, pp. 220-221). It may not be the case that the way an agent is assumed to behave is such that someone who considers the model would think that he could have made a better decision if he were in the agent's situation.

Vercelli (1991, p. 139) criticises the fact that Lucas restricts his critique to Tinbergen-type of models, and therefore restricting himself to rational expectations. 'With regard to those models which incorporate elements of disequilibrium, criticism has concentrated on the most commonly used large-scale econometric modeis, since they do not satisfactorily explain why certain rules of decision are adopted by economic agents, and hence they cannot explain or predict structural transformations of the economic system. This is not a new argument; it has been used many times in criticizing prevailing econometric practice. We find it clearly sketched out in the last works of Keynes himself, in particular in his critical review of Tinbergen (1939).

Lucas undoubtedly deserves credit for having managed to reformulate this criticism in a much more precise and rigorous version. But there is still no convincing argument to show why such a defect must necessarily characterize any disequilibrium model. At the theoretical level there is no reason why one should not postulate a disequilibrium 
path as an optimal trajectory for reaching certain results, which would permit the solution of the model to be recalculated after a change in the environment. The conclusions that can be drawn from the so-called "Lucas-critique" are for the moment purely negative with regard to both disequilibrium and equilibrium models. In the future, however, there is no reason to assume a priori that disequilibrium models may not have an equal chance of circumventing this obstacle.'

\subsection{Rational Expectations}

In chapter 7 a model is developed, in which expectations are distinguished with a varying degree of abstraction.

(9.2) $w_{1}^{\text {exp }}=w_{1}^{\text {re }}+\varepsilon_{1}^{\text {exp }}$

(9.3) $w^{\text {rea }}=w_{2}^{\text {re }}+e_{2}^{r e}$

(9.4) $w_{2}^{r e}=w_{1}^{r e}+e_{1}^{r e}$

The rational expectations theory is a special case of this model namely the case in which no errors in predictions occur: $\sigma_{\exp 1}^{2}=0, \quad \sigma_{\exp 2}^{2}=0$. In a rational expectations model all uncertainty is due to the stochastic character of the outside world. Model (9.1)-(9.4) therefore reduces to
(9.5) $w_{2}^{\text {exp }}=w_{2}^{\text {re }}$
(9.7) $w^{r e s}=w_{2}^{r e}+e_{2}^{r e}$
(9.6) $w_{1}^{\exp }=w_{1}^{r e}$
(9.8) $w_{2}^{r e}=w_{1}^{r e}+\epsilon_{1}^{r e}$

Since the hypothetical rational expectations are measured without error (i.e. there is no interpretation error), the best prediction is the most specific one, in which all available information is used. More abstract predictions are dominated by this specific prediction. The information error is minimised without an increase in the interpretation error. The optimal mix between the specific and the abstract expectation therefore equals

$$
\text { (9.9) } \lambda=\frac{\sigma_{\exp 2}^{2}}{\sigma_{r e l}^{2}+\sigma_{e x p 2}^{2}}=\frac{0}{\sigma_{r e !}^{2}+0}=0
$$

From a policy point of view this theory has severe implications. The most usual implications are the so called neutrality properties. If two policies have the same effects on real economic variables, they will also have the same impact on expectations. It is therefore not possible for a government to manipulate the expectations of the agents. For the theory of the effects of providing public information, rationa! expectations also 
has severe implications. If the assumption is made that students make the best possible forecasts, it makes no sense to try to improve these forecasts. The only reason why students make prediction errors is according to rational expectations because of the uncertainty with respect to possible states of the world. It is not a lack of insight in the functioning of the economic process which causes the errors. The only way to improve these predictions is to provide new information (data) about the uncertain states of the world. This is only possible if the public forecaster has data about the labour market, which are not available to the students. Such a situation is called a situation of asymmetric information. Students' predictions will of course always improve as a result of such information, but it is only the availability which causes this effect. From a rational expectations point of view it is not important in what form the information is given. It suffices to make the pure data available to students. All forecasts and conclusions based on the information can be deduced by the students as well as the forecaster.

Rational expectations evidently satisfy Lucas's criterion. The rational expectation equals the solution of the model with respect to this variable, so it is not possible to improve the decisions of the agents in the framework of the model.

In this framework the provision of public information can, as stated before, only be interpreted as the publication of additional relevant data. This implies that the most specific prediction becomes even more specific ( $\sigma_{r e 2}^{2}$ decreases). Since $\lambda=0$, the prediction error of the forecast equals the error of this most specific rational expectation: $\sigma_{p r e}^{2}=\sigma_{r e 2}^{2}$. Starting from an initial prediction error with an MSE $\sigma_{\text {pre }}^{2}$, the provision of information which explains a fraction $\pi$ of this uncertainty leads to a proportional decrease in the prediction error: ${ }^{1}$

(9.10) $\dot{\sigma}_{p r e}^{2}=(1-\pi) \sigma_{p r e}^{2}$

\subsection{The Cobweb Theory: Interpretation 1}

The rational expectations hypothesis fits well in the expectation model (9.1)-(9.4). It is also possible to view the cobweb expectation formation scheme from this point. There are, however, two different ways to do this. These two interpretations have very different implications with respect to possibilities to improve expectations by providing public

1 the ${ }^{*}$ in $\delta_{p e r}^{2}$ denotes the new value of $\sigma_{p r e}^{2}$ after the provision of public information. 
information. The first one of these interpretations, which will be discussed in this section, does, however, not meet Lucas's criterium for economic modelling as discussed in section 9.1. This interpretation is, however, mostly used. In the next section an other interpretation is discussed which is not susceptible to Lucas's critique.

The cobweb theorem states that:

(9.11) $w^{\text {pre }}=w^{-d}$

Usually, this cobweb expectation scheme is interpreted analogously to the rational expectation. Conform (9.5) and (9.7) it can be written:

(9.11) $w^{\text {exp }}=w^{-d}+0$

in which $e^{\text {cobweb }}$ denotes the difference between the realised wage and the wage at the moment the decision has to be made. A problem with this specification is that in general $\boldsymbol{E}\left\{e^{\text {cobweb }}\right\} \neq 0$, and furthermore this specification does not explain why students use this forecast rather than another. But it is argued, that apparently students who have a cobweb behaviour, have the wrong belief that $E\left\langle e^{\text {cobweb }\}}=0\right.$, and that students simply think that the present wage is the best predictor of the future wage. $^{2}$

In the model no errors in making forecasts are introduced $\left(\sigma_{\text {exp }}^{2}=0\right)$, but students are assumed to have a wrong, naive model about the functioning of the labour market. Therefore, the rational expectation model is used, but the objective probabilities are replaced by the subjective probabilities of the naive model used by the students.

This interpretation seems to be analogous to the rational expectations interpretation. In both cases there is a component which is unpredictable. The difference is, however, that in the rational expectations interpretation the unpredictable part is a typical states of the world uncertainty with objective probabilities. In this cobweb interpretation the forecast students make is based on a wrong model. The forecast error included in this prediction therefore not only consists of states of the world uncertainty, but also contains an error in the prediction, or stated differently, their subjective probabilities differ from the objective probabilities. The behaviour of students is interpreted,

2 Of course, in sorne sifuations the cobweb expectation might aqual the rational expectation. Such a situation does, however, not validate the cobweb expectation. The optimality of the expectation is accidental and is no explanation of the cobweb behaviour. Therefore, although rational expectations and cobweb generate the same results, conceptually they remain different. 
however, as if they think their prediction is the best possible (i.e. as if $\sigma_{\text {exp }}^{2}=0$ ). Since there is no interpretation error in this model, there is no reason why the rational expectation is not also available to the students. Furthermore, if $\sigma_{\text {expi }}^{2}$ equals 0 for every expectation $i$, the use of the rational expectation would dominate the cobweb expectation.

This interpretation does, therefore, not satisfy Lucas's criterion. Students are assigned a view of the world which is wrong by assumption, and it would be easy, within the framework of the model, to improve the expectations formed by the students. The model provides no reason as to why students form this cobweb expectation rather than the rational expectation.

The implications for the provision of public labour market information of this cobweb interpretation seem to be the same as those for the rational expectations model. This is, however, a problematic vision. Since the model of students' cobweb expectations does not explain why students use the cobweb expectation rather than some other expectation scheme, the model also does not provide any reason why students would alter their behaviour if additional information is given.

\subsection{The Cobweb Theory: Interpretation 2}

The rational expectations model of section 9.2 assumes that students have perfect insight into the functioning of the labour market. As is shown in chapter 4 this is a very unrealistic assumption. It is evident that students, but also professional economists, are not able to fully grasp the true structure of the world. For the provision of labour market information students' errors are important. Therefore, a model of expectation formation has to contain such errors in forecasts. The first interpretation of the cobweb model provides an expectation scheme which includes errors in forecasts, but the model is unsatisfactory since it does not explain why these errors are made. Therefore, it is liable to Lucas's critique, that models which do not explain human behaviour as optimal behaviour are not. useful. In this section another interpretation of the cobweb behaviour is provided which explains the cobweb behaviour as the optimal reaction to the limited forecast possibilities students have.

This second interpretation is, again, based on the basic model (9.1)-(9.4). In this model students are supposed to have a very specific forecast of the future wage, and a more abstract forecast. The specific forecast is, however, subject to an interpretation error. This interpretation error denotes students disability to forecast the future 
wage. For simplicity the assumption is made that this rational expectation is equal to the realised wage. On the other hand, students have an abstract. expectation. The assumption is made that students use the current wage as this abstract expectation. The idea behind this is that the current. wage gives a rough indication of the level of the future wage. Without further investigation it may be equally probable that the wage will decrease or increase. Of course, this abstract expectation, the current wage, will contain a large information error, compared to the specific expectation, but will in general also contain an interpretation error, because $\boldsymbol{E}\left\{w^{-d i}-w^{r e a}\right\} \neq 0$, although this interpretation error will be much smaller. In order to simplify this error is put equal to 0 . The prediction model becomes:

(9.14) $w^{\exp }=w^{\text {rea }}+e^{\exp }$

(9.15) $w^{\text {rea }}=w^{-d}+e^{\text {var }}$

Both error terms have the expected value 0 , their variances are respectively $\sigma_{\exp }^{2}$ and $\sigma_{\operatorname{var}}^{2}$, and they are mutually independent, while $e^{\exp } \mathrm{s}$ independent of $w^{\text {rea }}$ and $e^{\text {var }}$ of $w^{-d}$.

Thus, in this interpretation, the student can dispose of two expectations. A specific expectation $w^{\text {exp }}$ with an interpretation error, but without an information error, and an abstract expectation, the current wage $\boldsymbol{w}^{-d}$ which only has an information error and no interpretation error. The availability of different expectations should be interpreted carefully. Of course, a student forms only one prediction. The two expectations, the specific and the abstract, and their combinations, represent, however, other possible expectations the student could have used. This construction makes explicit the set of expectations available to the student and can therefore restrict the capabilities of the student to forecast: the rational expectation is not available in this set. It is easy to extend this extreme model conform (9.1)-(9.4) to a model in which both expectations contain both types of errors. For the main results this simplification does, however, not matter.

According to (7.22) it is optimal for a student to mix both expectations, to form his prediction:

(9.16) $w^{\text {pre }}=\lambda w^{-d}+(1-\lambda) w^{\exp }$

with

$$
\lambda=\frac{\sigma_{\exp }^{2}}{\sigma_{v a r}^{2}+\sigma_{\text {exp }}^{2}}
$$


This optimal behaviour will equal the cobweb behaviour if $\sigma_{\exp }^{2}=\infty$ or if $\sigma_{\text {var }}^{2}=0$. Thus, the model explains a cobweb behaviour if the student is completely unable to predict the future wage, or if the current wage equals the rational expectation. ${ }^{3}$

The advantage of this interpretation of the cobweb model is that it explains why the current wage is used as prediction. Given the forecast capacities a student has, according to the model (expressed by $\sigma_{\text {exp }}^{2}$ ) it is not possible to improve his behaviour. This interpretation of the cobweb model therefore meets Lucas's criterion about economic modelling.

The assumptions under which the cobveb behaviour comes about are very strong. As soon as a student has some capacity to forecast the future wage, i.e. as soon as $a_{\exp }^{2}$ becomes finite, the optimal prediction does not equal the cobweb prediction anymore. If $\sigma_{\exp }^{2}$ is large, the optimal prediction is, however, very close to the current wage. This is in accordance with the way the cobweb theory has been interpreted by the originators of the cobweb theory. "The cobweb behaviour has not been treated as an absolute law, but merely as a useful approximation of people's behaviour. Furthermore, if $\sigma_{\exp }^{2}$ is finite, an optimal prediction will come about which equals Theil's formulation, based on empirical evidence of direct measurement of expectations. The model provides an interpretation of Theil's parameter $\theta .{ }^{s}$ Students have two types of expectations to their disposal. The specific expectation contains an interpretation error. The lower the variance of this error $\left(\sigma_{e \varphi q}^{2}\right)$ the better predictable the future wage is. The use of the present wage as an expectation for the future wage contains an information error. The MSE of this error $\left(\sigma_{\operatorname{var}}^{2}\right)$ is large if the wage is very fluctuative or variable in time. Therefore, the optimal combination of the two expectations depends on the variability and the predictability of the wage. The variability depends on external characteristics of the labour market, while the predictability represents a personal characteristic of the student, his ability to forecast the future wage.

\subsection{Econometric Implications}

The model of the second interpretation of the cobweb theory explains the prediction of students to be a mixture of the not perfectly interpreted rational expectation and the cobweb expectation. For certain values of

5 See section 6.3. Chapter 10 provides a more extensive analysis of Theil's underestimation of changes. 
the variability and the predictability the optimal behaviour of students can become very close to the rational expectations behaviour and for other values it comes close to the cobweb behaviour. In this section it is investigated under what conditions the rational expectations hypothesis will be accepted although the model of section 9.4 is the true model. ${ }^{6}$

Suppose the following equation is tested on rationality:

(9.18) $S=C_{s}+\beta_{s} w^{\text {pre }}$

The variance of the prediction error equals (see (7.23)):

$$
\begin{aligned}
\sigma_{\text {pre }}^{2} & =\lambda^{2} \sigma_{\text {var }}^{2}+(1-\lambda)^{2} \sigma_{\text {exp }}^{2} \\
& =\lambda \sigma_{\text {var }}^{2} \\
& =(1-\lambda) \sigma_{\exp }^{2}
\end{aligned}
$$

This prediction error consists of a systematic error, which can be explained by $w^{-d}$, and an unsystematic component, which is caused by $\epsilon_{\exp }$ and is therefore independent of other variables.

$$
\begin{aligned}
& \sigma_{s y s}^{2}=\lambda^{2} \sigma_{v a r}^{2}=\left(\frac{\sigma_{\text {exp }}^{2}}{\sigma_{v a r}^{2}+\sigma_{\text {exp }}^{2}}\right)^{2} \sigma_{v a r}^{2} \\
& \sigma_{\text {unsys }}^{2}=(1-\lambda)^{2} \sigma_{\text {exp }}^{2}=\left(\frac{\sigma_{v a r}^{2}}{\sigma_{v a r}^{2}+\sigma_{\exp }^{2}}\right)^{2} \sigma_{\text {exp }}^{2}
\end{aligned}
$$

The rational expectations hypothesis states that $\sigma_{\exp }^{2}=0$, which implies that $\lambda=0$ and that $\sigma_{\text {pre }}^{2}=0$. It implies that both the systematic and the unsysteriatic component equal zero. Usually, however, only the hypothesis that the systematic component is zero is tested. There are two reasons for this restriction. Firstly, it is easier to test for a systematic error in the behaviour. Secondly, for most theories based on rational expectations ali results also hold in the case of unsystematic deviations from rational expectations. According to the proposition of Muth, Sargent, and Wallace the theory of rational expectations allows for this type of independent deviations. In section 7.4 it was shown, however, that this proposition is not as innocent as it appears.

6 Mankiw and Zeldes (1990) show that the consumption of stockholders fits better into the rational expectations framework than the consumption of non-stockholders. This is a typical example of a situation in which the rational expectation hypothesis is not rejected in specific situations. 
In a finite sample, tests are always based on the estimated level of a certain test-statistic. If a test is performed based on the systematic error or on the unsystematic error, the hypothesis will be rejected if this error exceeds a certain level. Figure 9.1 provides an isoquant of both tests. If the values of the variability and the predictability are above the relevant isoquant the rational expectations hypothesis will be rejected. If the sample gets larger, the critical value of the test will decrease and the isoquant will come closer to the axes. The figure clearly shows that a test based on a systematic error $(a)$ is almost completely used to reject cases with low predictabilities $\left(\sigma_{\exp }^{2}\right.$ is high) almost independently of the variability. For a test based on an unsystematic error $(b$, sometimes called excess volatility) the opposite is the case. Rational expectations are rejected in case of a high variability.

Based on this figure four cases can be distinguished. If both the value of $\sigma_{\operatorname{axp}}^{2}$ and $\mathbf{o}_{\text {var }}^{2}$ are low (1) the rational expectations hypothesis will always be accepted. If both values are high (4) the hypothesis will be rejected by both tests. If, however, the variability is high while $\sigma_{\exp }^{2}$ is low (3) only a test based on an unsystematic error will reject the rational expectations hypothesis, while in the reversed situation (2) only the test based on a systematic error will lead to a rejection.

FIGURE 9.1: A TEST ON SYSTEMATIC $(a)$ AND UNSYSTEMATIC (b) DEVIATIONS FROM THE RATIONAL EXPECTATION.

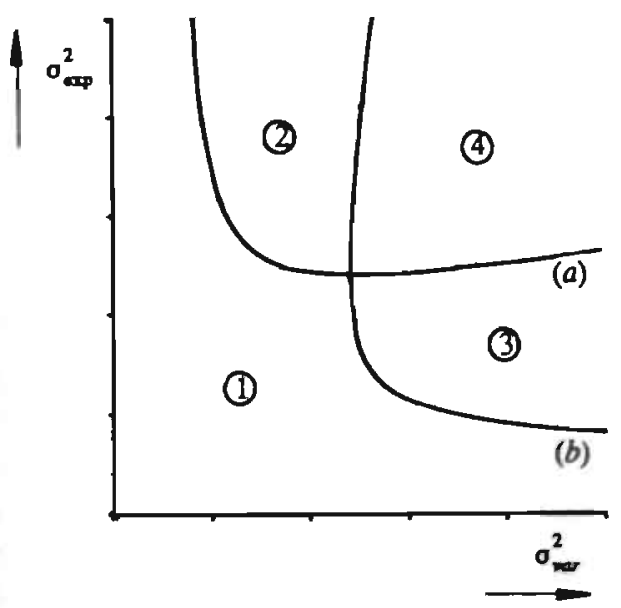

Since most tests are based on the systematic error, it can be explained 
why for consumption models the rational expectations hypothesis is often rejected, while for asset models the hypothesis is often accepted. Consumption depends on economic variables with a low variability, but the consumption decision is made by laymen in the field of investments. Assets are often very variable, but the trade is carried out by specialists who are bound to have a high degree of predictability and thus a low value of $a_{\exp }^{2}$.

\subsection{Expectations Manipulating Policies}

The variability-predictability model of section 9.4 has some interesting consequences for possible economic policies. In section 9.7 the consequences for the provision of labour market information will be investigated. The provision of information aims at improving students' expectations. The way people form expectations can however also be used to worsen the expectations. Some economic policy instruments (e.g. the Keynesian expenditure policy) may be based on a manipulation of expectations. Some economic instruments are chosen in such a way that a gap between people's expectations and the realisation of a variable will occur, which is optimal from the government's point of view. Under rational expectations such policies are not possible. Based on this, a rejection of the rational expectations hypothesis is sometimes treated as an acceptance of the possibility of the expectations manipulating policy. For example Campbell and Mankiw (1989, p. 210) state after an empirical rejection of the permanent income hypothesis that 'our findings are suggestive regarding the effects of policies. [...] The old-fashioned Keynesian consumption function may therefore provide a better benchmark for analyzing fiscal policy than does the model with infinitely-lived consumers.' These models, however, mostly do not satisfy Lucas's criterion. Contrary to Muth's rational expectations, the Lucas critique is not an empirical claim, but a fundamental prerequisite for the possibility to model agents' responses to policies.

This section provides a simple example which satisfies Lucas's criterion, which 'asserts that agents' responses become predictable to outside observers only when there can be some confidence that agents and observers share a common view of the nature of the shocks which must be forecast by both' (Lucas, 1976, p. 41), but in which the rational expectations hypothesis does not hold. The effects of expectations manipulating policies are investigated and it is shown that even after a rejection of the rational expectations hypothesis this type of policies is possible only to a limited extent. 
Consider again a situation in which an agent's behaviour depends on his expectation $w^{\exp }$ of the future variable $w^{\text {rea }}$. The rational expectations hypothesis states that it is possible to write $\boldsymbol{w}^{\text {red }}$ as a summation of two components: $w^{r e a}=w^{r e}+e^{r e}$ in which $w^{r e}$ is completely predictable, while $e^{r e}$ is completely unpredictable given the information set $\boldsymbol{I}_{\boldsymbol{t}-\boldsymbol{d}}$ available at the moment of choice. The rational expectation hypothesis is that people predict the predictable component correctly with $\boldsymbol{w}^{\mathrm{r}}$, while they do not predict the unpredictable component $e^{r e}$ (or predict it to be 0 ). The rational expectation of $w^{\text {rea }}$ is therefore $w^{\text {re }}$. Agents' expectations will in genera! contain an error $\Delta \bar{w}=w^{\text {pre }}-w^{\text {rea }}$. From the rational expectations point of view, this error can be split up in two parts. Firstly, there is a difference between the realisation of a variable and its rational expectation: $e^{r e}=w^{r e}-w^{r e a}$. Secondly, expectations may differ from the rational expectation (i.e. the rational expectations hypothesis is rejected): $e^{\text {pre }}=\boldsymbol{w}^{\text {pre }}-\boldsymbol{w}^{r e}$.

An expectations manipulating policy (EMP) is based on the possibility to influence economic variables in such a way that the expected (by the policy maker) expectation error (of the agent) will be at some non-zero level, $E\left\{e^{r e}+e^{p r e} \mid E M P\right\}=L \neq 0$ and this policy will be more accurate if $V A R\left\{e^{r e}+e^{p r e}-L \mid E M P\right\}$ is low.

It is not possible to carry out such a policy with respect to the rational expectation error $e^{r e}$, since also for the policy maker $e^{r e}$ is unpredictable. Expectations manipulating policy is therefore only possible if the rational expectations hypothesis, $e^{\text {pre }} \equiv 0$, is not true. Therefore it suffices to consider model $(9.14)-(9.15)$, in which $\boldsymbol{\epsilon}^{r \boldsymbol{c}} \equiv 0$, as an example. Therefore, $w^{r e a}=w^{r e}$. If $e^{\text {pre }}$ is written as $e^{p r e} \equiv f\left(I_{i-d}\right)+\epsilon$, in which $f$ is a function of all information known at time $t-d\left(I_{t-d}\right)$ and $\epsilon$ does not depend on any variable in $I_{t-d}$, with $E\{\varepsilon\}=0$, rejections of the rational expectations hypothesis can be divided up into two types. Firstly, it may be shown that $f\left(I_{t-d}\right) * 0$ statistically significant. Secondly, it may be shown that $\epsilon \neq 0$. It is in general very easy to find rejections of the rational expectations hypothesis. For example the situation in which two agents with the same information set $I_{t-d}$ have a different expectation provides such a rejection. This rejection may be caused, however, by both types, $f\left(I_{t-d}\right) \neq 0$, and $\epsilon \neq 0$. But, as mentioned in section 7.3 , since the second type of expectations errors can not be used for a manipulation policy they are not regarded as relevant for the theory (Sargent and Wallace, 1976, p. 180, call $\epsilon$ the 'mother-in-law' term). From their point of view only rejections which provide a relation $f\left(I_{t-d}\right) \neq 0$ are economically interesting. 
According to $(9.14)$ it is assumed that the agent indeed possesses a prediction for $w^{\text {rea }}$ which equals $w^{\exp }=w^{\text {rea }}+e^{\exp }$, the prediction equals the rational expectation plus a (possibly very large) random term (random with respect to the information set $\left.\boldsymbol{I}_{t-d}\right) . \boldsymbol{E}\left\{\boldsymbol{e}^{\exp \}}=\mathbf{0}\right.$ and the variance of $e^{\exp }$ is denoted by $a_{\text {exp }}^{2}$. Furthermore it is assumed that the agent also possesses an abstract expectation $g\left(I_{t-d}\right)$ for which conform (9.15) $\quad g\left(I_{t-d}\right)=w^{-d}$, which may contain a systematic error. $\left.\mathbf{\sigma}_{\text {var }}^{2}=E\left(w^{-d}-w^{r e a}\right)^{2}\right\}$ measures the MSE of $w^{-d}$ as a prediction of $w^{\text {rea }}$. In order to minimise the mean square error of his prediction error, according to $(9.17)$, it is optimal for an agent to mix his two sources of information. The optimal prediction ( $w^{\text {pre }}$ ) is therefore: $w^{\text {pre }}=\lambda w^{-d}+(1-\lambda) w^{\exp }$, in which $\lambda=\sigma_{\text {exp }}^{2} /\left(\sigma_{\text {var }}^{2}+\sigma_{\text {exp }}^{2}\right)$ minimises the mean square prediction error. This implies that the optimal prediction has an error $e^{p r e}=\lambda w^{-d}-\lambda w^{r e a}+(1-\lambda) e^{\exp }$, which contains a predictable component $\lambda\left(w^{-d}-w^{r e d}\right)$.

The mean squared error of $w^{\text {pre }}$ is $\sigma_{\text {pre }}^{2}=\lambda \sigma_{\text {ver }}^{2}=(1-\lambda) \sigma_{2}^{2}$, which can be split up into a systematic component $\sigma_{s y s}{ }^{2}=\lambda^{2} \sigma_{\text {var }}^{2}$ and an unsystematic component $\sigma_{\text {unsys }}^{2}=(1-\lambda)^{2} \sigma_{\text {exp }}^{2}$. Thus, a violation of the rational expectations hypothesis of the second type (a nonsystematic error) makes it optimal for agents to also introduce a systematic error to keep total prediction error minimal. There is a trade off between the error connected with the rational expectation and the bias of the abstract expectation. The possibility of an unbiased prediction, which seems to be a necessary assumption regarding Lucas's critique, does not imply its optimality.

The main question of this section is whether a rejection of the rational expectations hypothesis indeed makes it possible for a policy-maker to use expectations manipulating policies. The answer is that these possibilities wili occur, but limited to a certain extent. Assuming that $\sigma_{\text {exp }}^{2}$ and $g\left(I_{p}\right)$ do not change, due to the introduction of an expectations manipulating policy

$$
L^{2}=\sigma_{s y s}^{2}=\lambda^{2} \sigma_{v a r}^{2}=\left(\frac{\sigma_{\exp }^{2}}{\sigma_{v a r}^{2}+\sigma_{\exp }^{2}}\right)^{2} \sigma_{v a r}^{2}
$$

(see figure 9.2). This equation links the unpredictable behaviour of the policy-maker $\left(\sigma_{\text {var }}^{2}\right)$ to the systematic error $L$ of the agent. $\sigma_{s y s}^{2}$ reaches a maximum of $1 / 4 \sigma_{\text {exp }}^{2}$ for $\sigma_{\text {var }}^{2}=\sigma_{\text {exp }}^{2}$, and $\lim _{\sigma_{\text {sat }}^{2}-\infty} \sigma_{s s}^{2}=0$. At the maximum $\sigma_{\text {ungys }}^{2}=\sigma_{s y s}^{2}$, so $\sigma_{\text {pre }}^{2}=1 / 2 \sigma_{\text {exp }}^{2}$. 
FIGURE 9.2: EFFECTS OF EXPECTATIONS MANIPULATING POLICIES ON SYSTEMATIC AND UNSYSTEMATIC PREDICTION ERROR.

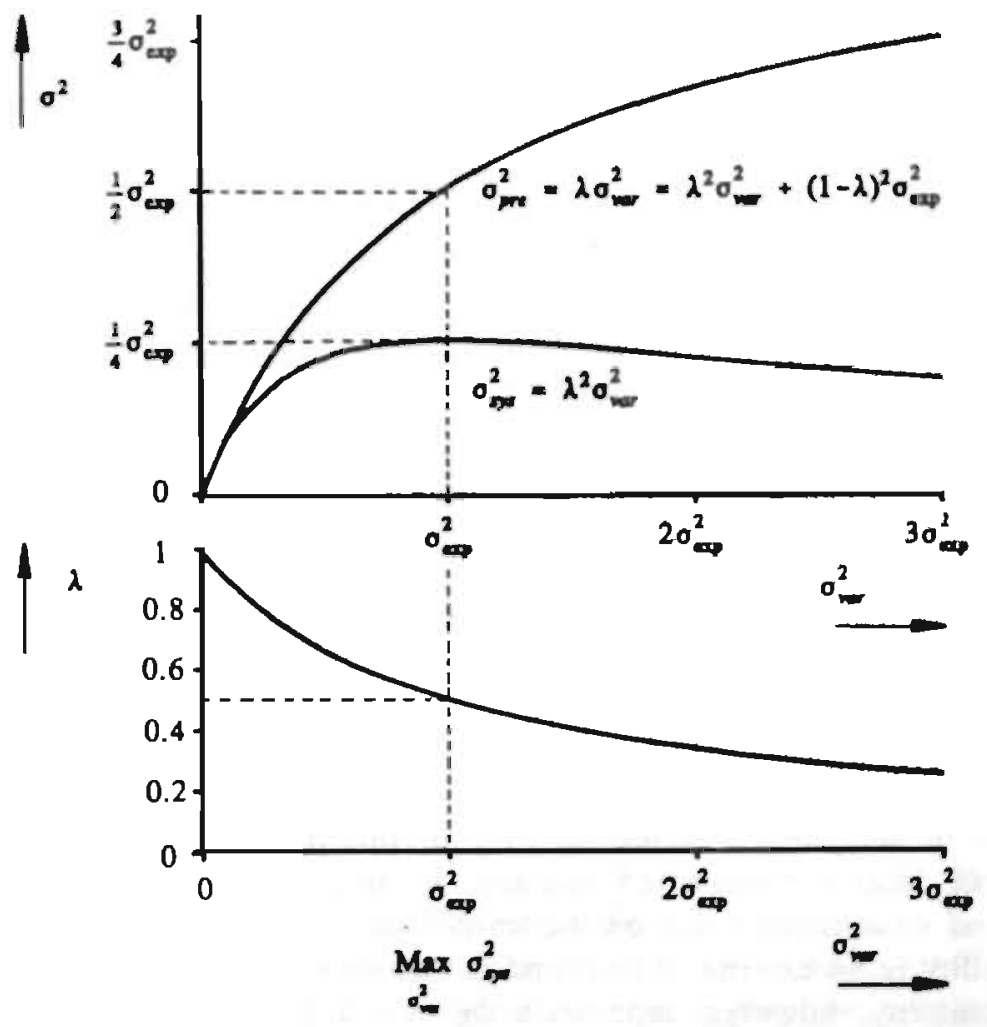

If $\sigma_{\exp }^{2}$ or the use of $w^{-d}$ as abstract forecast of $w^{\text {rea }}$ do change due to the manipulating policy, it seems reasonable to expect that this will be adjustments to the new situation, which even limit the possibilities for an expectations manipulating policy.

This limitation of the possibility of expectations manipulating policy is due to the endogenous character of $\lambda$. If $\sigma_{\text {var }}^{2}$ rises the abstract expectation will become less valuable as a predictor and therefore $\lambda=\sigma_{\text {exp }}^{2} f\left(\sigma_{\exp }^{2}+\sigma_{\text {var }}^{2}\right)$ will fall, i.e. the agent will make less use of this abstract expectation. Two main conclusions may be drawn from this example. Firstly, it is not fruitful to separate systematic and unsystematic deviations from the rational expectations as two completely different things, since there may be an optimal trade off between the systematic and the unsystematic forecast errors. 
Secondly, a rejection of the rational expectations hypothesis does not immediately imply that expectations manipulating policies will be possible to every extent.

\subsection{The Provision of Public Information}

The central problem of this study is the question how public labour market information may influence the labour market predictions of individual students, and therefore the functioning of the labour market. In chapter 4 it was shown that students do face large difficulties in adequately forecasting the future labour market situation. Rational expectations assumes, with its typical states of the world uncertainty, that the only prediction error students are faced with is due to unforecastable future events. Regarding the large difficulties in making forecasts, especially for the unexperienced students, the reduction of uncertainty to states of the world uncertainty is rather unrealistic. Section 9.4 provides a model in which prediction errors can be caused both by states of the world uncertainty and errors in the predictions themselves. There exists a trade off between abstract expectations and specific expectations. The first is liable to an information error, while the latter may face an interpretation error.

The mode! of section 9.4 makes it easy to interpret the meaning of provision of labour market information. In this model the optimal prediction of students depends on the variability and the predictability. The variability is an external factor, and is therefore treated as constant. The predictability, however, represents the capacities of the student to form expectations about the future labour market. The aim of providing labour market information is to assist the student in making this expectation. By publishing public labour market information the insight of professional forecasters about the functioning of the labour market becomes available to students. The provision of additional labour market information, therefore, can be modelled as a decrease of $\boldsymbol{\sigma}_{\exp }^{2}$. The future wage becomes better predictable for the student. The larger the insight in the model, the lower $\sigma_{\exp }^{2}$ becomes. The prediction error of a student consists of two components, the systematic error and the unsystematic error: 
(9.23) $\sigma_{s y s}^{2}=\left(\frac{\sigma_{\text {exp }}^{2}}{\sigma_{v a r}^{2}+\sigma_{\text {exp }}^{2}}\right)^{2} \sigma_{\text {var }}^{2}$

(9.24)

$$
\sigma_{\text {unsys }}^{2}=\left(\frac{\sigma_{v a r}^{2}}{\sigma_{v a r}^{2}+\sigma_{\text {exp }}^{2}}\right)^{2} \sigma_{\text {exp }}^{2}
$$

(9.25)

$$
\sigma_{p r e}^{2}=\frac{\sigma_{v a r}^{2} \sigma_{\exp }^{2}}{\sigma_{v a r}^{2}+\sigma_{\exp }^{2}}
$$

The derivatives with respect to $\sigma_{\exp }^{2}$ equal:

(9.26) $\frac{d \sigma_{s \mathrm{gr}}^{2}}{d \sigma_{\exp }^{2}}=(1-2 \lambda)(1-\lambda)^{2}$

(9.27) $\frac{\mathrm{d \sigma}_{\text {unsys }}^{2}}{\mathrm{d \sigma _{ \operatorname {exp } } ^ { 2 }}}=2 \lambda(1-\lambda)^{2}$

(9.28) $\frac{\mathrm{do} \sigma_{p r e}^{2}}{\mathrm{do}_{\exp }^{2}}=(1-\lambda)^{2}$

A decrease of $\sigma_{\exp }^{2}$ will lead to a decrease of $\lambda$, because the predictability increases and therefore the naive expectation becomes less valuable. This will lead to a decrease of the systematic error since both $\lambda$ and $\sigma_{\exp }^{2}$ decrease. The unsystematic error might, however, increase. $\sigma_{\exp }^{2}$ decreases, but $(1-\lambda)$ increases, since students are going to use the specific expectation to a larger extent. If $\lambda>1 / 2$, i.e. as long as the naive, abstract expectation is better than the real specific expectation, the net effect will be negative and the unsystematic error will increase. On the total prediction error, however, the effect of a decrease of $\sigma_{\text {exp }}^{2}$ is always negative.

The derivative is very small if $\lambda$ is close to 1 . In that case students' predictions depend almost completely on the current wage, because the real expectation has a very bad quality. A marginal increase of this quality will have almost no effect since students do not use the real expectation. To influence the prediction quality in such a case the improvement of the quality of the forecast should be substantial. Such a large decrease of $\sigma_{\text {exp }}^{2}$ will make the students start to use this real expectation ( $\lambda$ decreases) and therefore this real expectation gets influence upon the quality of the prediction. 
Figure 9.3 shows the relation between $\sigma_{\text {exp }}^{2}$ and the two components and the total prediction error. ${ }^{7}$

FIGURE 9.3: THE RELATION BETWEEN $\sigma_{\text {exp }}^{2}$ AND THE SYSTEMATIC AND UNSYSTEMATIC PREDICTION ERROR.

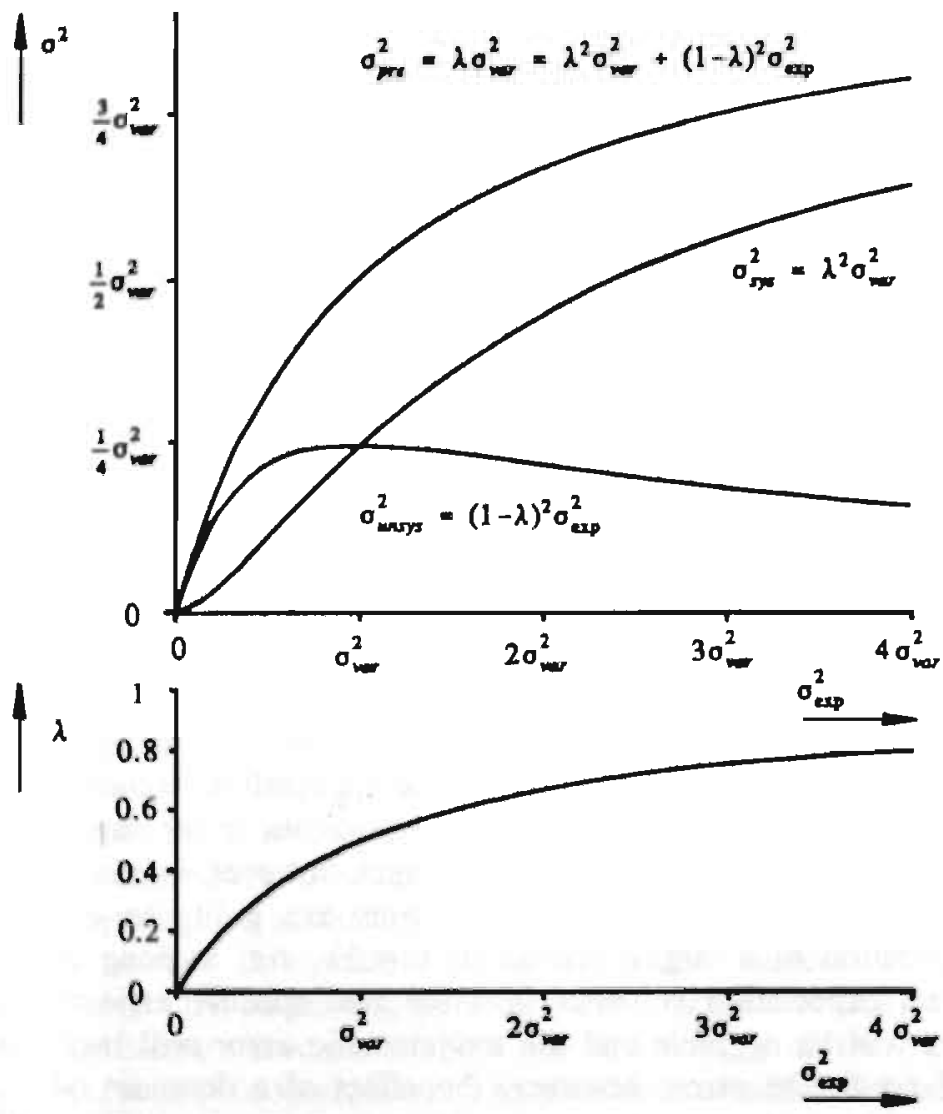

7 The improvement of students' expectations in these analysis arises due to an improved interpretation of information which is already available $\left(I_{t-1}\right)$. If new, relevant, data comes at the disposal of students (i.e. if $I_{t-d}$ increases) expectations may of course also improve, similar to the effects of additional information in the rational expectations model (see equation (9.10)). If this information is easy interpretable, the information error of both the abstract and the specific expectation will decrease and the prediction error will decrease with this amount. If the additional information is only used in the specific expectation the reduction of the prediction error will be proportional to the extent to which this specific expectation is used $(1-\lambda)$. 


\subsection{Conclusions}

In this chapter the question has been considered how to interpret expectation formation that deviates from rational expectations. Lucas's criterium for economic modelling requires that agent's behaviour is always optimal within the context of the model. It therefore makes no sense to explain cobweb-behaviour as the behaviour of people who are assumed to think that the cobweb-expectation is the best (as in interpretation 1, section 9.3). In interpretation 2 (section 9.4) it is shown that cobweb-behaviour can be explained as an extreme example of agents with a very low capability to forecast, for who it is optimal to stick to the simple cobweb-forecast, instead of some other more specific forecasting model. The agents realise that this is a bad forecast, but also know that every attempt to improve it will introduce an interpretation error which is not compensated for by the decrease in the information error.

The extent to which cobweb-like behaviour (i.e. systematic errors) occur depends on the predictability and the variability of the economic variable which has to be forcasted. In a context of low experienced forecasters and a variable with a low variability, systematic errors will be relatively large, while in the opposite case, with professional forecasters and high variability, most part of the forecast error will be unsystematic. Often, however, the prediction error is the largest in the second case, with unsystematic errors.

If policy wants to use the systematic expectation errors, however, it has to increase the variability, what leads to a reduction of these systematic errors. There are, in this model, therefore only limited possibilities for expectation manipulating policies.

On the other hand, the model offers a way to explain the effects of the provision of public information. Since systematic errors result from a kind of optimising behaviour, not every public forecast will have an immediate impact upon students' expectations. Only if the quality of such forecast is good enough, compared to students' predictions, it will significantly improve students" forecasts. It does not suffice to make students aware of the fact that a cobweb model is 'too naive', but it is needed to offer them an adequate alternative. 



\section{THE UNDERESTIMATION OF CHANGES}

In most economic studies the expectations formed by agents are observed only indirectly. While the enrolment decision theoretically depends on students' predictions, only the enrolment and the realisations of these predictions are observed. To investigate the link between decision and expectation, some additional assumptions have to be made about the way expectations are formed. Sometimes, as mentioned in section 6.3, however, it has been possible to investigate expectation formation based on direct measurement of the expectations, by means of surveys. Theil (1958, p. 154) concludes that "we observed that the predicted changes analysed there show a bias in relation to the corresponding actual changes in the sense that they are on average smaller. This phenomenon, which amounts to an underestimation of the level of the variable to be predicted in times of rises and to an overestimation of this level in times of falls, is not entirely unknown; but its general occurrence is not sufficiently realised.' This underestimation of changes can be expressed with the following equation:

$$
\left(w^{\text {pre }}-w^{-d}\right)=\theta\left(w^{\text {rea }}-w^{-d}\right)+\epsilon
$$

with $0<\theta<1$

with $\varepsilon$ orthogonal to $w^{\text {rea }}-w^{-d} .{ }^{1}$ The difference between the predicted wage ( $w^{\text {pre }}$ ) and the current wage, at the moment the decision is made $\left(w^{-d}\right)$, is only a fraction of the difference between the ex post realised wage $\left(w^{\text {rea }}\right)$ and the current wage. This relation is based on Theil's empirical observations of expectations. Two important consequences can be deduced from (10.1). Firstly, the predicted wage is not only related to the future wage, but also to the current wage: $w^{\text {pre }}=\theta w^{\text {rea }}+(1-\theta) w^{-d}+\epsilon$. To obtain an unbiased predictor of the realised wage the prediction, therefore, has to be extrapolated:

$$
\text { (10.2) } \hat{w}^{\text {rea }}=w^{-d}+\frac{1}{\theta}\left(w^{\text {pre }}-w^{-d}\right)
$$

Secondly, (10.1) makes it possible to explain Theil's observation that the prediction will, compared to the current wage, fluctuate less than the realisation. ${ }^{2}$ If $\sigma_{e}^{2}$ is relatively small compared to the underestimation of change - as Theil observes (p. 82) - the variation of the prediction is indeed lower than the variation of the realisation.

2 Theil (1958, p. 82) calls this "unequal variation". 


$$
\text { (10.3) VAR }\left\{w^{\text {pre }}-w^{-d}\right\}=\theta^{2} \boldsymbol{V A R}\left\{w^{r e a}-w^{-d}\right\}+\sigma_{e}^{2}<\boldsymbol{V A R}\left\{w^{\text {rea }}-w^{-d}\right\}
$$

Since enrolment is related to the prediction, this means that the volatility of the behaviour decreases if the underestimation increases. A low $\theta$ implies a passive anticipating behaviour. Theil uses mainly psychological arguments to explain this phenomenon and proposes to multiply the survey expectations with $1 / \theta$ to obtain a good predictor. Muth (1961), however, claims that his rational expectations theory explains this phenomenon in a rational way. Based on the errors in forecasts model of chapter 9 it is also possible to explain the underestimation phenomenon. In this chapter both Muth's explanation and the errors in forecasts model are investigated with respect to the underestimation of changes. The examples in this chapter show the important link between the assumption regarding expectation formation and the econometric treatment of the supply function. The investigation is based on the data about US lawyers. Furthermore, the underestimation of changes throws light on the volatility of the enrolment behaviour predicted by the different models.

\subsection{The US Lawyers}

Siow (1984) investigates the enrolment decision for US lawyers. The training to become a lawyer takes 3 years. It is therefore relevant for the students not to base their decision on the current wages, but to anticipate the wages three years in advance. Therefore, the student has to make a prediction. Siow assumes the expectations to be rational. The analysis is based on three time series: the enrolment, the average wages for lawyers, and the average alternative wages. In Siow's model the students are modelled by a representative agent. Such a representative agent does not fit in the framework used in this study. Therefore, in this chapter the data of Siow (1984) are used, but a supply function is assumed, according to (3.8):

(10.4) $S=\beta_{s} w$

in which $w$ is defined as the quotient of the average wages of lawyers and the average alternative wages. The constant $C_{s}$ is omitted because the data used are centred. Incorporating Theil's expectation formula (10.1) in the supply function it becomes:

$$
\text { (10.5) } \begin{aligned}
S & =\beta_{s}(1-\theta) w^{-d}+\beta_{s} \theta w^{\text {rea }} \\
& =\alpha_{1} w^{-d}+\alpha_{2} w^{\text {rea }}
\end{aligned}
$$

This relation is estimated with OLS. Table 10.1 provides the results. 
These results show that indeed both $w^{\text {rea }}$ and $w^{-d}$ are significantly related to the enrolment of students at the law school. The estimation implies $\theta=0.51$. In the next sections some alternative explanations of this phenomenon are presented.

TABLE 10.1: ESTIMATION RESULTS OF (10.5).

\begin{tabular}{l|c}
\hline \hline & $\begin{array}{l}\text { estimated } \\
\text { coefficient (with } t \text { - } \\
\text { value) }\end{array}$ \\
\hline$\alpha_{1}$ & $\begin{array}{c}30222.71 \\
(8.07)\end{array}$ \\
$\alpha_{2}$ & 31190.81 \\
& $(8.82)$ \\
$R^{2}$ & 0.90 \\
\hline
\end{tabular}

\subsection{Rational Expectations}

Theil's explanation for the underestimation of change is largely psychological. Muth (1961, p. 316) claims, however, that his rational expectations also explain the phenomenon. He remarks that 'two major conclusions from studies of expectations data are the following:

1. Averages of expectations in an industry are more accurate than naive models and as accurate as elaborate systems, although there are considerable cross-sectional differences of opinion.

2. Reported expectations generally underestimate the extent of changes that actually take place.

In order to explain these phenomena, I should like to suggest that expectations, since they are informed predictions of future events, are essentially the same as the predictions of the relevant economic theory.'

Consider the following model.

(10.6) $S=\beta_{s} w^{r e}$

(10.7) $w^{r e a}=w^{r e}+\epsilon^{r e}$

(10.8) $w^{r e}=\zeta w^{-d}+e^{i n s}$

The rational expectation $w^{r e}$ is an prediction which is optimal in the sense that the resulting prediction error $e^{r e}$ is minimal given the information available at the moment the expectation was formed. This implies that the prediction error does not correlate with any variable known at the moment of choice, so $\epsilon^{r e}$ does not correlate with $w^{-d}$ or 
with $w^{\text {re }}$. The rational expectation is, typically, assumed to be calculated based on current and past data, so $w^{\text {re }}$ may, and will in general, depend on, for example, $w^{-d}$. As will be shown later, such a relation between available information at the moment of choice and the rational expectation is useful for the estimation of the enrolment relation (10.6). $w^{-d}$ functions as an instrumental variable, according to McCalium (1976). Since the instrument $w^{-d}$ does, generally, not completely explain the rational expectation, there is an additional error $e^{\text {inst }}$, which is not correlated with $w^{-d}$.

Based on (10.6)-(10.8) it is possible to relate both $S$ and $w^{\text {rea }}$ to the instrument $\boldsymbol{w}^{-d}$ and the error variables.

(10.9) $S=\beta_{S} \zeta w^{-d}+\beta_{S} e^{i n g t}$

(10.10) $w^{r e a}=\zeta w^{-d}+e^{i n s t}+e^{r e}$

The covariances of $S, w^{r e a}$, and $w^{-d}$ equal:

(10.11) $\sigma_{s}^{2}=\beta_{s}^{2} \zeta^{2} \sigma_{-d}^{2}+\beta_{s}^{2} \sigma_{i n s}^{2}$

(10.12) $\sigma_{\text {sea }}=\beta_{s} \zeta^{2} \sigma_{-d}^{2}+\beta_{s} \sigma_{\text {inst }}^{2}$

(10.13) $\sigma_{S_{v}-d}=\beta_{S} \zeta \sigma_{-d}^{2}$

(10.14) $\sigma_{\text {rea }}^{2}=\zeta^{2} \sigma_{-d}^{2}+\sigma_{\text {inst }}^{2}+\sigma_{r e}^{2}$

(10.15) $\sigma_{r e a,-d}=\zeta \sigma_{-d}^{2}$

Table 10.2 gives the estimations of these moments based on centred data of Siow (1984). The model is overidentified. There are five equations for four unknown variables. A direct OLS regression of $S=\beta_{s} w_{2}^{\text {rea }}$ will provide a biased estimation due to the variance of the error, $\sigma_{r e}^{2}$ in the variable $w^{\text {rea }}$. One way to estimate the model consistently is by the instrumental variable method of McCallum (1976). With (10.15) $\zeta$ can be solved, and (10.13) provides, based on the estimation of $\zeta$ an estimation of $\beta_{s}$. This method is equivalent to a two step OLS estimation, with $w^{-d}$ as the instrument. Firstly, $\zeta$ is estimated by a OLS regression of the equation $w^{\text {rea }}=\zeta w^{-d}$, and secondly, the predictions of this regression are used in the OLS regression of $S=\beta_{s}\left(\zeta w^{-d}\right)$.

The alternative way to estimate the model is to use the fact that $\sigma_{S}^{2}=\beta_{S} \sigma_{S, r e a}$. This is equivalent to an OLS estimation of $w^{\text {rea }}=1 / \beta_{s} S$. This reversion of realised wages and the enrolment is typical for rational expectations. The realised wages do not cause the enrolment, because they are partially unknown at the monnent of choice, 
but the enrolment 'causes' the realised wages. A change in enrolment indicates a change in the predicted wages, and thus a change in the objective probability distribution of the realised wages. ${ }^{3}$

TABLE 10.2: Estimation OF MOMENTS BASED ON DATA OF SIOW (1984).

\begin{tabular}{l|c}
\hline \hline moment & estimation \\
\hline$\sigma_{S}^{2}$ & $43.953710^{6}$ \\
$\sigma_{S, \text { rea }}$ & 680.994 \\
$\sigma_{S,-d}$ & 609.911 \\
$\sigma_{\text {rea }}^{2}$ & 0.01756 \\
$\sigma_{\text {rea, -d }}$ & 0.00442 \\
$\sigma_{-d}^{2}$ & 0.01562 \\
\hline
\end{tabular}

The results in table 10.1 can be easily explained by the rational expectations model. The OLS regression of $S=\alpha_{1} w^{-d}+\alpha_{2} w^{\text {rea }}$ gives:

16) $\alpha_{1}=\frac{\sigma_{r e a}^{2} \sigma_{S,-d}-\sigma_{r e a,-d} \sigma_{S, r e a}}{\sigma_{r e a}^{2} \sigma_{-d}^{2}-\sigma_{r e a,-d} \sigma_{r e a}-d}=\beta_{s} \zeta\left(\frac{\sigma_{r e}^{2}}{\sigma_{r e}^{2}+\sigma_{i n s}^{2}}\right)$

(10.17) $\quad \alpha_{2}=\frac{\sigma_{s, r e a} \sigma_{-d}^{2}-\sigma_{\text {rea, }, d} \sigma_{S,-d}}{\sigma_{r e a}^{2} \sigma_{-d}^{2}-\sigma_{\text {rea },-d} \sigma_{\text {rea },-d}}=\beta_{S}\left(\frac{\sigma_{\text {inst }}^{2}}{\sigma_{r e}^{2} \div \sigma_{\text {inst }}^{2}}\right)$

The estimation results of table 10.1 can be seen as a weighted average of the instrumental variable $\zeta w^{-d}$ and the realised wages. $S$ theoretically depends on $w^{\text {pre }}$. The instrument and the realised wage both measure these predicted wage with an error. The instrument contains an error with $\sigma_{i n s}^{2}$ and the realised wages contain an error with $\sigma_{r e}^{2}$. These errors are independent. The optimal estimation weights these two errors such that the total error is minimised, i.e. they provide the best approximation of the predicted wage. The estimation is unbiased and equal to the instrumental variable estimator, although the $t$-values are larger, due to the use of additional information available in $\boldsymbol{w}^{\text {rea }}$.

3 E.g. Campbell (1987, p. 1249) uses the "ignored implication of the permanent income hypothesis", that "it follows that saving should be at least as good a predictor of declines in labor income as any other forecast that can be constructed from publicly available information'. 
This result also explains why the regression $S=\beta_{S} w^{\text {rea }}$ provides a biased estimation. In this regression the instrument $w^{-d}$ is replaced by a trivial instrument 0 . With 0 as an instrument the variance of the error of the instrumental variable becomes $\zeta^{2} \sigma_{-d}^{2}+\sigma_{i n s s}^{2}$. The estimated coefficient therefore equals $\beta_{s}\left(\sigma_{i n s t}^{2}+\zeta^{2} \sigma_{-d}^{2}\right) /\left(\sigma_{i n s t}^{2}+\zeta^{2} \sigma_{-d}^{2}+\sigma_{r e}^{2}\right)(=0.281$ $\times 138144.4=38791.65)$, which is less then $\beta_{s}$. The other part of the coefficient $\beta_{S}(0.719 \times 138144.4=99352.75)$ is not observable, because it is multiplied by 0 .

Table 10.3 provides the estimation results of the three estimation methods. The first column provides the estimates of the instrumental variable method, while in the second column the estimates are based on the reversed equation $w^{\text {rea }}=1 / \beta_{S} S$. The two correct estimation methods do not provide the same results. The basic difference is that the first method gives a smaller estimate for $\sigma_{\text {ins }}^{2}$ than the second method. In the instrumental variable estimation this $\sigma_{i n s t}^{2}$ is based on the unexplained residuals in $\sigma_{s}^{2}$. In similar studies about financial topics $\mathbf{\sigma}_{\text {lins }}^{2}$ is usually estimated to be 100 large by the instrumental variable method. This is the so-called excess volatility. It is remarkable how much the estimates for $\beta_{s}$ differ. For reference also the (incorrect) direct OLS estimates of $S=\beta_{s} w^{\text {rea }}$ are added. This method also gives completely different results, indicating the enourmous sensitivity of estimations for specification and method of estimation of a model. Estimated elasticities of supply and demand therefore should always be handled with great care.

\section{TABLE 10.3: THREE Estimations OF THE RATIONAL} EXPECTATIONS MODEL (WITH $t$-VALUE).

\begin{tabular}{l|ccc}
\hline \hline & $\begin{array}{c}\text { instrumental } \\
\text { variable }\end{array}$ & $w^{\text {rec }}=\frac{1}{\beta_{S}} S$ & $\begin{array}{c}S=\beta_{S} w^{\text {rea }} \\
\text { (not } \\
\text { consistent) }\end{array}$ \\
\hline$\zeta$ & 0.28258 & - & - \\
$\beta_{S}$ & $(1.30)$ & & \\
$\sigma_{\text {inus }}^{2}$ & 138144.4 & 72065.71 & 38791.65 \\
$\mathbf{\sigma}_{n e}^{2}$ & $(1.66)$ & $(5.10)$ & $(5.76)$ \\
& 0.00106 & 0.00368 & - \\
\hline
\end{tabular}

Muth (1961) claims that rational expectations theory is able to explain the underestimations of changes. The rational expectations model indeed 
predicts the phenomenon (10.3):

(10.18) $V A R\left\{w^{\text {pre }}-w^{-d}\right\}=V A R\left\{w^{\text {rea }}-w^{-d}\right\}-a_{r e}^{2}<\operatorname{VAR}\left\{w^{\text {rea }}-w^{-d}\right\}$

Rational expectations theory is, however, not able to explain the other form of the underestimation of change (10.2). In rational expectations

(10.19) $w^{\text {rea }}=w^{\text {pre }}+e^{\text {re }}$

so $\theta=1$. Rational expectations explain the smaller fluctuations of the prediction compared to the realisation but this small variance is not equal to real underestimation of changes. Bossons and Modigliani (1966) show that the explanation of the role of $w^{-d}$ in the rational expectations specification is purely statistical (i.e. $\boldsymbol{w}^{-d}$ is an instrumental variable), while the surveys indicate a real underestimation of changes. They therefore reject the rational expectations model. ${ }^{4}$

\subsection{Errors in Forecasts}

In the rational expectation theory expectation errors are always caused by uncertainties in the future state of the world. Given these uncertainties the expectations are perfect. In this section it is shown that the errors in forecasts model is also able to explain the results of table 10.1, and that this model does explain both the lower variance (10.3) property and the underestimation property (10.2). In this section an extreme variant of the model is presented. Section 10.4 and 10.5 relax the assumptions.

The basic assumption of the errors in forecasts model is that students are only able to make a forecast of future realised wages with an error. Furthermore, conform section 7.4, they can use other forecasts which are less specific, but which also contain a smaller error. The assumption is made that the rational expectation equals the realised wage, and that the alternative expectation equals the current wage.

(10.20) $S=\beta_{s} w^{\text {pre }}$

(10.21) $w^{\text {pre }}=\lambda w^{-d}+(1-\lambda) w^{\text {exp }}$

(10.22) $w^{\text {exp }}=w^{\text {rea }}+e^{\exp }$

(10.23) $w^{\text {rea }}=\zeta w^{-d}+e^{i n s t}$

Equation (10.23) is the instrumental variable relation conform (10.8).

4 Theil (1958, p. 73) already recognised that 'the danger exists, therefore, that the underestimation of changes is a spurious effect produced by the regression technique, so that we should ask the question whether the effect still manifests itself if we accept the second approach. The answer is affirmative." 
This equation is not necessary in this model, but is only used to facilitate a comparison with the rational expectations model.

Students will choose $\lambda$ such that the prediction error is minimised:

$$
\text { (10.24) } \lambda=\frac{\sigma_{\exp }^{2}}{\sigma_{\exp }^{2}+\sigma_{\mathrm{wr}}^{2}}
$$

in which $\sigma_{v a r}^{2}$ is the $M S E$ of the current wages as a forecast for the realised wages:

$$
\text { (10.25) } \boldsymbol{\sigma}_{\text {var }}^{2}=\boldsymbol{E}\left\{\left(w^{-d}-w^{r e a}\right)^{2}\right\}=(1-\zeta)^{2} \sigma_{-d}^{2}+\sigma_{\text {inst }}^{2}
$$

The comparison of (10.24) with (10.16) and (10.17) is interesting. In (10.6)-(10.8) the researcher does not know $w^{\text {re }}$ and therefore uses a combination of $w^{\text {rea }}$ and $\zeta w^{-d}$, which both contain an error, to approximate the rational expectation. In (10.24) the student does not know $w^{\text {re }}=w^{\text {rea }}$ and therefore combines $w^{\text {exp }}$ and $w^{-d}$ to approximate the rational expectation.

The model based on errors in forecasts is able to explain the underestimation of changes. (10.21) directly gives (10.2) with $\theta=1-\lambda$, and the variance of the prediction equals

(10.26) VAR $\left\{w^{\text {pre }}-w^{-d}\right\}=(1-\lambda)^{2} V A R\left\{w^{\text {rea }}-w^{-d}\right\}$

This implies (10.3).

Similar to (10.9) and (10.10) $S$ and $w^{\text {rea }}$ can be expressed in $w^{-d}$.

$$
\begin{aligned}
& \text { (10.27) } S=\left(\beta_{s} \lambda+\zeta \beta_{s}(1-\lambda)\right) w^{-d}+\beta_{s}(1-\lambda) e^{\exp }+\beta_{s}(1-\lambda) e^{i n s} \\
& (10.28) \quad w^{\text {rea }}=\zeta w^{-d}+e^{i n s t}
\end{aligned}
$$

The covariances are:

$$
\begin{aligned}
& (10.29) \quad \sigma_{s}^{2}=\left(\beta_{s} \lambda+\zeta \beta_{s}(1-\lambda)\right)^{2} \sigma_{-d}^{2}+\beta_{s}^{2}(1-\lambda)^{2}\left(\sigma_{\text {exp }}^{2}+\sigma_{\text {inss }}^{2}\right) \\
& \text { (10.30) } \sigma_{s_{s} \text { rea }}=\left(\beta_{s} \lambda+\zeta \beta_{s}(1-\lambda)\right) \zeta \sigma_{-d}^{2}+\beta_{s}(1-\lambda) \sigma_{\text {inst }}^{2} \\
& (10.31) \quad \sigma_{s,-d}=\left(\beta_{s} \lambda+\zeta \beta_{s}(1-\lambda)\right) \sigma_{-d}^{2} \\
& (10.32) \quad \sigma_{\text {rea }}^{2}=\zeta^{2} \sigma_{-d}^{2}+\sigma_{\text {inst }}^{2} \\
& \text { (10.33) } \sigma_{\text {rea, }-d}=\zeta \sigma_{-d}^{2}
\end{aligned}
$$

The model appears to be identified exactly, but (10.24) is a parameter restriction on the model, which makes it overidentified. OLS estimation 
of $S=\alpha_{1} w^{-d}+\alpha_{2} w^{\text {rea }}$ gives:

(10.34) $\alpha_{1}=\lambda \beta_{S}$

(10.35) $\alpha_{2}=(1-\lambda) \beta_{s}$

from which $\lambda$ and $\beta_{S}$ can be solved easily.

Table 10.4 provides the estimation results. $\sigma_{\text {exp }}^{2}$ is calculated from the residue in (10.29). The overidentifying restriction (10.24) makes it possible to calculate an alternative estimation of $\lambda$ based on $\sigma_{v a r}^{2}$ and $\sigma_{\exp }^{2}$ or reversely, based on $\sigma_{v a r}^{2}$ and $\lambda$ an alternative $\sigma_{\exp }^{2}$ can be calculated. These alternative values are presented in the second column of table 10.4. Again, the variance of the residual actually measured $(0.00440)$ is smaller than the value which is expected on theoretical grounds $(0.02359)$. Therefore, also this model explains more volatility than actually measured. For final conclusions about the significance of the gap between predicted and measured volatility a test-statistic is needed. Because of the non-linear character of the relationships, this statistic is omitted. Due to the small size of the data set such a test would most probably not lead to a rejection of the model.

TABLE 10.4: ESTIMATION RESULTS OF ERRORS IN FORECASTS MODEL (WITH IVALUES).

\begin{tabular}{l|cc}
\hline \hline & estimation & $\begin{array}{c}\text { over- } \\
\text { identifying } \\
\text { restriction }\end{array}$ \\
\hline$\lambda$ & $\begin{array}{c}0.49212 \\
(10.42)\end{array}$ & 0.15302 \\
$\beta_{S}$ & 61413.52 & \\
& $(13.92)$ & \\
$\sigma_{e D}^{2}$ & 0.00440 & 0.02359 \\
\hline
\end{tabular}

\subsection{A Combined Model}

In the errors in forecasts model of the previous section the assumption has been made that $w^{r e}=w^{r e a}$, i.e. that $\sigma_{r e}^{2}=0$. A model which relaxes this assumption may in general solve the violation of the parameter restrictions due to the overidentification of both the rational expectations and the errors in expectations model. If the rational expectations model generates excess volatility in the enrolment and the errors in expectations model generates too few volatility, this 
combination may equalise observed and theoretical expected volatility. The extra parameter $\sigma_{r e}^{2}$ reduces the overidentification to an identification. In this section this combined model is introduced. But since in the data-set used, both models have too small volatility, the combination does not give empirically satisfactory results. Some variances become negative to explain the volatility. For that reason only the analytical model is provided in this section, while estimation results are omitted.

The model of section 10.3 becomes:

(10.36) $S=\beta_{s} w^{\text {pre }}$

(10.37) $w^{\text {pre }} \equiv \lambda w^{-d}+(1-\lambda) w^{\exp }$

(10.38) $w^{\text {exp }}=w^{r e}+\epsilon^{\exp }$

(10.39) $w^{\text {rea }}=w^{r e}+e^{r e}$

(10.40) $w^{r e}=\zeta w^{-d}+e^{i n s t}$

This leads to:

(10.41) $S=\beta_{s}(\lambda+(1-\lambda) \zeta) w^{-d}+\beta_{s}(1-\lambda) \epsilon^{i n \Delta t}+\beta_{s}(1-\lambda) \epsilon^{\exp }$

(10.42) $w^{\text {rea }}=\zeta w^{-d}+\epsilon^{i n s}+\epsilon^{r e}$

The covariances are:

(10.43) $\sigma_{S}^{2}=\beta_{S}^{2}(\lambda+\zeta(1-\lambda))^{2} \sigma_{-d}^{2}+\beta_{S}^{2}(1-\lambda)^{2}\left(\sigma_{\text {exp }}^{2}+\sigma_{\text {ins }}^{2}\right)$

(10.44) $\sigma_{s, \text { rea }}=\beta_{s}(\lambda+\zeta(1-\lambda)) \zeta \sigma_{-d}^{2}+\beta_{s}(1-\lambda) \sigma_{\text {inst }}^{2}$

(10.45) $\sigma_{s,-d}=\beta_{s}(\lambda+\zeta(1-\lambda)) \sigma_{-d}^{2}$

(10.46) $\sigma_{\text {rea }}^{2}=\zeta^{2} \sigma_{-d}^{2}+\sigma_{\text {inst }}^{2}+\sigma_{\text {re }}^{2}$

(10.47) $\sigma_{r e a,-d}=\zeta \sigma_{-d}^{2}$

These covariances are almost equal to (10.29)-(10.33). The difference is the appearance of $a^{2}$ in equation $(10.46)$. The model has 5 equations with $\zeta, \sigma_{i n s}^{2}, \sigma_{r e}^{2}, \sigma_{\text {exp }}^{2} \lambda$, and $\beta_{s}$ as 6 unknown variables, but due to

(10.48) $\lambda=\frac{\sigma_{\exp }^{2}}{\sigma_{\text {exp }}^{2}+\sigma_{\text {var }}^{2}}$

in which

(10.49) $\sigma_{\text {var }}^{2}=(1-\zeta)^{2} \sigma_{-d}^{2}+\sigma_{\text {inst }}^{2}$

the model is exactly identified. 
The equations (10.43)-(10.47) can be solved by initially putting $\lambda$ equal to a constant. All other variables can then be solved easily. Based on these values of the other variables the value of $\lambda$ should be:

(10.50) $\lambda=\frac{\frac{\sigma_{s}^{2}}{\beta_{s}^{2}}-\frac{\sigma_{s, r e a}}{\beta_{s}}}{(1-\zeta) \sigma_{-d}^{2}}$

Therefore the system can be solved by searching a fixed point for $\lambda$.

If $\sigma_{r e}^{2}$ equals 0 the combined model is identical to the errors in forecasts model. As noted in section 10.3, in this case the measured variance of the residual is too small. Introducing a higher value of $\sigma_{r e}^{2}$ may explain this result. An increase of $\sigma_{r e}^{2}$ lowers the estimated value of $\lambda$ until $\lambda=0$ and the combined model equals the rational expectations model. In this example, however, in that case the value of the residuals, is still too small, while a further increase of $\sigma_{r e}^{2}$ is not possible anymore. Such an increase would lead to a negative value of $\sigma_{i n s t}^{2}$, which is of course impossible. The estimations of this model therefore make no sense and for that reason they are not provided.

\subsection{Endogenous Market Reactions}

The combined model of section 10.4 is not able to explain the low variance of the enrolment figures. The realised wages seem to fluctuate too much compared to these enrolment figures. The realised wages, have been treated, however, as endogenous, whi!e according to (3.14) they should be related to the prediction error. If too high wages are predicted the realised wages will drop, while if the predictions are too low, the realised wages become higher than the equilibrium wages.

(10.51) $w^{\text {rea }}=w^{e q}-\frac{\beta_{S}}{-\beta_{D}}\left(w^{\text {pre }}-w^{e q}\right)$

Thus, to predict $w^{\text {pre }}$, students have to predict the equilibrium wage, plus an additional term, which depends on the prediction error $\left(w^{\text {pre }}-w^{e q}\right)$. The prediction error consists of a systematic component and an unsystematic component. The assumption is made that students can not predict their own unsystematic prediction errors. Therefore, this part of the realised wages is assumed to be a random shock to them, which can be taken into account by the rational expectations model. For the other part of the realised wages, i.e. $w^{\ell q}$ plus the systematic part of the prediction error, the errors in forecast model is used. Thus it is 
assumed that students are able to forecast this part completely, but only with an error. This error generates the unsystematic prediction. error, and therefore the rational expectation error becomes endogenous.

(10.52) $S=\beta_{S} w^{\text {pre }}$

(10.53) $w^{\text {pre }}=\lambda w^{-d}+(1-\lambda) w^{\exp }$

(10.54) $w^{\text {exp }}=w^{\text {ec }}+e^{\text {exp }}$

(10.55) $w^{\text {re }}=w^{\text {eq }}-\Psi \Delta w^{\exp }$

(10.56) $w^{\text {rea }}=w^{e q}-\Psi \Delta w$

in which

(10.57) $\Psi=\frac{\beta_{S}}{-\beta_{D}}$

and $\Delta w^{\exp }$ is the predictable part of the prediction error:

(10.58) $\Delta w^{\text {exp }}=\lambda\left(w^{d d}-w^{r e}\right)$

After some manipulation of the equations it follows that

(10.59) $w^{r e}=\frac{w^{e q}-\Psi \lambda w^{-d}}{1-\Psi \lambda}$

and

$(10.60) \quad w^{r e}=w^{r e a}+\frac{\Psi(1-\lambda)}{1-\Psi} e^{\text {exp }}$

Therefore (10.53) can be rewritten as:

(10.61) $w^{\text {pre }}=\lambda w^{-d}+(1-\lambda) w^{r e a}+\left(\frac{1-\lambda}{1-\Psi} \Psi\right) e^{\exp }+(1-\lambda) \varepsilon^{\exp }$

$$
=\lambda w^{-d}+(1-\lambda) w^{r e a}+\left(\frac{1-\lambda}{1-\Psi}\right) \varepsilon^{\exp }
$$

The model, therefore, is equal to the errors in forecasts model of section 10.3 , except for the $\left(\frac{1-\lambda}{1-\varphi}\right)$ factor by which $e^{\exp }$ is multiplied.

Estimation results therefore also equal the results of section 10.2. The difference between the estimation of $\sigma_{\exp }^{2}$ based on residuals and the estimation based on equation (10.24) makes it possible to identify $\beta_{D}$ in this model. Their quotient $0.00440 / 0.02359=0.018652$ equals $1 /(1-\Psi)^{2}$. Therefore, $\Psi=8.32$. $\beta_{D}$ therefore equals in this estimation -7381.43 . 
Table 10.5 presents the estimations of $\beta_{S}$ and $\beta_{D}$ in this chapter recalculated to elasticities in the last year of the sample (with 40190 enrolments).

TABLE 10.5: THE ELASTICITIES OF SUPPLY AND DEMAND.

\begin{tabular}{l|cc}
\hline \hline & supply & demand \\
\hline rational expectations & 1.79 to 3.44 & \\
errors in forecasts & 1.53 & -0.18 \\
\hline
\end{tabular}

The elasticities of supply correspond very well to the elasticities mentioned in section 4.2. The elasticities of demand in section 4.2 were divided into a group of large negative and a group of small negative elasticities. The elasticity calculated in this chapter corresponds best to the lower elasticities, implying a low reaction of demand to wages.

\subsection{Conclusions}

The examples in this chapter show the consequences for estimation of different assumptions regarding expectation formation. Different assumptions about the non-observed prediction of students leads to completely different estimation results, and different assumptions make different estimation techniques necessary. There is a close link between the expectation formation theory and the way the model can be estimated.

The results of this chapter show that the errors in forecast model developed in chapter 7 and 9 , contrary to the rational expectations model, is able to explain the underestimation of change, which has been observed by Theil (1958), and more recently by Lovell (1986). Rational expectations explain the low volatility of expectations, but do not explain the real underestimation phenomenon.

Finally, the results of section 10.5 show that it is important to incorporate the market reactions to changes in the supply in the model to explain adequately the expectation formation of students. 



\section{THE COBWEB THEOREM: A RATIONAL INTERPRETATION}

From a rational expectations point of view, which departs from the existence of a true model of the world, naive behaviour like assumed in the cobweb theory is irrational. From this point of view, people voluntarily waste available information which has value for thenn. In chapter 7 it was shown that if the assumption of a given model is dropped, and the assumption is made that people can not know the true structure of the economy with certainty, but have to produce their own interpretation of the economic relationships, it may become optimal to exchange the theoretical specific expectations for more naive, abstract expectations. The interpretation error of the specific expectation, may exceed the information error of the abstract expectation.

Based on this insight, chapter 9 explained the cobweb behaviour of students is the observation that the current wage may serve as such an abstract expectation. If the developments at a certain segment of the labour market are rather stable, the variability is low, and the use of the current wage as predictor of the future situation may be valuable. This is mainly the case if it is difficult for students to theoretically predict the future situation, i.e. if the predictability is low.

The calculations in chapter 9 are, however, based on the assumption that the variability of the market is an exogenous constant. This assumption serves to keep the analysis simple. The assumption is, however, in conflict with the original cobweb thought. In cobweb theory an error in the expectations causes mismatch at the future labour market, but also this mismatch or disequilibrium generates new errors in the expectation formation of students. Therefore, the extent to which students use the current wage as abstract expectation, the more the current wage will move away from the equilibrium situation, and therefore the worse will be its value as predictor for the future situation. The variability therefore is, in cobweb theory, an endogenous factor.

The implementation of such a feedback mechanism in the expectations model is possible but makes the model rather complex. The aim of this chapter is to show that the model of chapter 9 can indeed be used to explain the real cobweb, and to draw some conclusions about the stabilisation properties of this model. Because of its complexity the analysis in further chapters are, however, based on the more simple model of chapter 9. 


\subsection{The Equilibrium Concept of Wages}

In a dynamic context the current wage serves two ends in the expectation model. Firstly, as in chapter 9 it can be used as an abstract forecast of the future wage. If one does not possess an adequate theory, the current wage gives at least a rough indication of the level at which the future wage may be expected to be. Secondly, however, the current wage itself is the realisation of the expected wage some years ago. And since the former expectations will not have been perfect, the current wage is affected by these past prediction errors. It is therefore important to realise that the current wage may deviate from the equilibrium, and if the prediction errors in the past have been large, these deviations will also be large.

If the labour market has some long lasting structural characteristics, it seems reasonable to view the current equilibrium wage as an abstract forecast of the future equilibrium wage. Contrary to the current equilibrium wage, there is no reason to expect that these deviations from equilibrium are also a good predictor of the future deviations from equilibrium. In this chapter, therefore the assumption is made that the current deviation from equilibrium has no informational contents about the future wage, and that the future deviation from equilibrium is unpredictable. The natural link between the current situation and the future is that the current equilibrium wage serves as an abstract forecast of the future equilibrium wage.

$$
w^{e q}=w_{-d}^{e q}+\epsilon^{\text {varl }} \text { with } \sigma_{\text {varl }}^{2}=E\left\{e^{\text {warl } l^{2}}\right\}
$$

This equilibrium wage itself is, however, not observed. The only thing that is observed directly, is the current (realised) wage. Again, if a student has no specific theory about the extent of this disequilibrium deviation, the current wage may be seen as an abstract forecast of the current equilibrium wage.

$$
w^{-d}=w_{-d}^{e q}+\epsilon^{\Delta} \text { with } \boldsymbol{\sigma}_{\Delta}^{2}=\boldsymbol{E}\left\{\epsilon^{\left.\Delta^{2}\right\}}\right.
$$

Indirectly the current wage again serves as an abstract forecast of the future wage, but contrary to the model in chapter 9 this relation is based on two steps. By the use of more specific theories or insights in the situation students can improve the quality of their forecast. This improvement may be based on both steps of the relation. Students may have additional insight into the current disequilibrium situation, and they may have insight into the future changes in the wage. Therefore, it is assumed that they possess two specific forecasts. One forecast of the 
current equilibrium wage $\left(w_{-d}^{\text {expeq }}\right)$ and one forecast of the future wage $\left(w^{\exp }\right)$.

(11.3) $w_{-d}^{\text {expeq }}=w_{-d}^{\text {eq }}+\varepsilon^{\exp I}$ with $\boldsymbol{E}\left\{e^{\exp I\}}=0\right.$ and or $_{\exp I}^{2}=\boldsymbol{V A} \boldsymbol{R}\left\{e^{\exp I\}}\right.$

(11.4) $w^{\exp }=w^{e q}+e^{\text {var2 }}$ with $\boldsymbol{E}\left\{\epsilon^{\exp 2}\right\}=0$ and $\sigma_{\exp 2}^{2}=\operatorname{VAA} \boldsymbol{R}\left\{e^{\exp 2}\right\}$

The covariances between all error terms again are 0 (see section 7.4). These concrete forecasts are again not without an error. Therefore the forecasts include zero-mean forecast errors, $e^{\exp i}$ and $e^{\exp 2}$, with variances $\sigma_{\exp 1}^{2}$ and $\sigma_{\exp 2}^{2}$, which denote the forecast quality. Departing from these sources of information, the 'natural' proxies (11.1) and (11.2) and the forecasts (11.3) and (11.4), which all contain an error, it is possible to derive the optimal anticipations. Firstly, students have to estimate the current equilibrium wage. These can be based on the current wage, which is in a disequilibrium situation not exactly equal to the equilibrium price, or they can use their forecast, which is not completely correct. Conform (7.22), depending on the quality of both sources of information again a certain mix:

(11.5) $w_{-d}^{\text {preeq }}=\lambda_{1} w^{-d}+\left(1-\lambda_{1}\right) w^{\text {expeq }}$

between them is optimal (i.e. minimises the MSE) when:

(11.6) $\lambda_{1}=\frac{\sigma_{\exp 1}^{2}}{\sigma_{\Delta}^{2}+\sigma_{\exp 1}^{2}}$

The MSE of this predicted current equilibrium equals:

(11.7) $a_{\text {preeq }}^{2}=\lambda_{1} \sigma_{\Delta}^{2}$

so, if this predicted equilibrium price is used as a proxy for the future equilibrium wage the $M S E$ of the error is:

(11.8) $\sigma_{\text {var }}^{2}=\sigma_{\text {varl }}^{2}+\lambda_{1} \sigma_{\Delta}^{2}$

A similar dilemma exists for the anticipation of the future wage. Students can use the (predicted) current equilibrium wage, representing the current value of the subject, which will not be totally equal to the future value, or use their forecast which also contains an error. A similar optimisation of: 
(11.9) $w^{\text {pre }}=\lambda_{2} w_{-d}^{\text {preeq }}+\left(1-\lambda_{2}\right) w^{\text {exp }}$

leads to:

(11.10) $\lambda_{2}=\frac{\sigma_{\exp 2}^{2}}{\sigma_{v a r}^{2}+\sigma_{\exp 2}^{2}}$

The use of $w^{\text {pre }}$ as an anticipation of future wage leads to the minimal error, given the forecast qualities $\left(\sigma_{p r e}^{2}\right)$ :

(11.11) $\sigma_{\text {pre }}^{2}=\lambda_{2} \sigma_{\text {var }}^{2}=\lambda_{2}\left(\sigma_{\text {varl }}^{2}+\lambda_{1} \sigma_{\Delta}^{2}\right)$

On a market with a usual linear demand and supply curve ( 3.2 and 3.8 ) an underestimation of the wage leads to a realised wage above the equilibrium and an overestimation leads to a realised wage below the equilibrium wage (see $(3.15)$ ):

$$
w^{r e a}=w^{e q}-\left(\frac{\beta_{s}}{-\beta_{D}}\right)\left(w^{p r e}-w^{e q}\right)
$$

and therefore:

(11.13) $\sigma_{\Delta}^{2}=\left(\frac{\beta_{S}}{-\beta_{D}}\right)^{2} \sigma_{\text {pre }}^{2}$

Note that by relating the aggregated market disequilibrium to the forecast errors of individuals, it is implicitly assumed that forecast errors are not dispersed. A high forecast of one person does not compensate for a low forecast of another.

Under the assumption that $\sigma_{\Delta}^{2}$ is constant through time it follows from (11.11) and (11.13) that:

$$
\text { (11.14) } \sigma_{\Delta}^{2}=\sigma_{\text {varl }}^{2} \frac{\lambda_{1} \lambda_{2}\left(\frac{\beta_{S}}{-\beta_{D}}\right)^{2}}{1-\lambda_{1} \lambda_{2}\left(\frac{\beta_{S}}{-\beta_{D}}\right)^{2}}
$$

The system of equations (11.6), (11.10), (11.8) and (11.14) determines a unique solution for $\lambda_{1}, \lambda_{2}, a_{\operatorname{var} 1}^{2}$, and $a_{\Delta}^{2}$, due to the monotony of the functions.

In this interpretation of the cobweb model, students try to anticipate the future wage, but they understand they have limited capacities to do this. 
As their forecast errors (with MSE $\sigma_{\exp 1}^{2}$ and $\sigma_{\exp 2}^{2}$ ) increase they use the current wage as an indication of current and future value of the equilibrium wage to a larger extent (equation (11.6) and (11.10)). But on the other hand, the use of this abstract expectation increases the systematic error, which makes the current wage less valuable as a proxy for the future wage (equation (11.8) and (11.14)). This decrease of the 'equilibrium revealing' character of the current wage has the opposite effect: students use the current wage to a smaller extent. Somewhere inbetween the total use of current wages and no use of current wage there is an optimum, in which a certain mix between the use of current wage and the expectations about the future wage minimises the $M S E\left(\sigma_{p r e}^{2}\right)$. Schultz (1930) draws this situation (see figure 7.1): 'The real process will more likely look like the dashed lines $a b^{\prime}, b^{\prime} c^{\prime}$ etc'. In this equilibrium a systematic error in the behaviour occurs, but it is reasonable for students not to correct this error since this biased error in their anticipation, in the case students understand they do not forecast perfectly, is smaller than the unbiased error in the case "he has no doubts of their accuracy' (Hart, 1937b, p. 277).

\subsection{Implications}

Figure 11.1 illustrates the model in a simplified case in which students are not able to correct the current wage for the fact that it may not be the equilibrium wage: $\sigma_{\operatorname{expl}}^{2}=\infty$ and therefore $\lambda_{1}=1$. In that case the model can be reduced to two equations:

(11.15) $\lambda_{2}=\lambda_{2}\left(\sigma_{v a r}^{2}\right)=\frac{\sigma_{\exp 2}^{2}}{\sigma_{v a r}^{2}+\sigma_{\exp 2}^{2}}$

and

(11.16) $\sigma_{\text {var }}^{2}=\sigma_{\text {var }}^{2}\left(\lambda_{2}\right)=\sigma_{\text {varl }}^{2}+\sigma_{\text {varl }}^{2} \frac{\lambda_{2}\left(\frac{\beta_{S}}{-\beta_{D}}\right)^{2}}{1-\lambda_{2}\left(\frac{\beta_{B}}{-\beta_{D}}\right)^{2}}$

The figure shows an example of the equilibrium between the use of the forecast and the 'myopic' cobweb behaviour. ${ }^{2}$ (11.16) states that the

1 Schultz (1930), p. 35. 'Der wirkliche Vorgang ăhnelt eher den gestrichenen Linien $a b$ '; b'c' usw'.

2 The figures in this chapter are based on $\beta_{S} / \beta_{D}=3 / 2, \sigma_{\operatorname{mat} 1}^{2}=10$, and $\sigma_{\cos 2}^{2}=10$. 
quality of the current wage as a proxy' for the future wage decreases as it is used to a larger extent. If $\lambda_{2}=1$ students totally rely on the current wage as prediction for the future wage. In the case illustrated in the figure this would lead to diverging wages, i.e. $\sigma_{\text {var }}^{2}$ would become infinitely large. According to (11.15) people make less use of the current wage, as a proxy for the future wage, if its forecast quality decreases ( $\sigma_{v a r}$ increases). At the intersection there is a point at which the optimal use of the abstract expectation corresponds to the variability caused by it.

FIGURE 11.1: THE OPTIMAL TRADE OFF BETWEEN A SYSTEMATIC (COBWEB) ERROR AND A FORECAST ERROR.

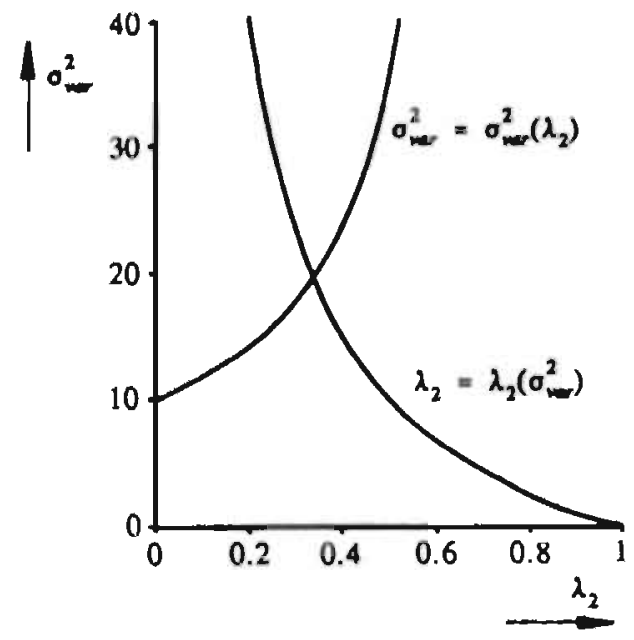

Figure 11.2 shows what happens when the ability to forecast increases (i.e. $\sigma_{\exp 2}^{2}$ decreases). (11.15) shifts to the left, since for a certain value of $\sigma_{\text {var }}^{2}$ students make more tise of their (improved) forecast. Initially this leads to shift a from the use of the myopic expectation to the use of the forecast. But due to this the error of the current wage as proxy of the future wage $\left(\mathrm{o}_{\mathrm{var}}^{2}\right)$ decreases. To reestablish the equilibrium, students again use the current wage to a greater extent (shift $b$ ). 
quality of the current wage as a proxy for the future wage decreases as it is used to a larger extent. If $\lambda_{2}=1$ students totally rely on the current wage as prediction for the future wage. In the case illustrated in the figure this would lead to diverging wages, i.e. $\sigma_{\text {var }}^{2}$ would become infinitely large. According to (11.15) people make less use of the current wage, as a proxy for the future wage, if its forecast quality decreases ( $\sigma_{v a r}^{2}$ increases). At the intersection there is a point at which the optimal use of the abstract expectation corresponds to the variability caused by it.

FIGURE 11.1: THE OPTIMAL TRADE OFF BETWEEN A SYSTEMATIC (COBWEB) ERROR AND A. FORECAST ERROR.

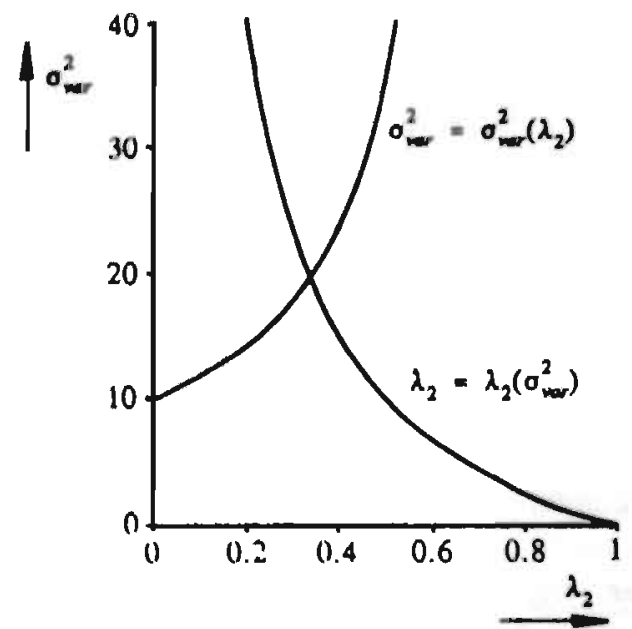

Figure 11.2 shows what happens when the ability to forecast increases (i.e. $\sigma_{2}^{2}$ exp decreases). (11.15) shifts to the left, since for a certain value of $\sigma_{\text {mar }}^{2}$ students make more use of their (improved) forecast. Initially this leads to shift $a$ from the use of the myopic expectation to the use of the forecast. But due to this the error of the current wage as proxy of the future wage $\left(a_{v a r}^{2}\right)$ decreases. To reestablish the equilibrium, students again use the current wage to a greater extent (shift $b$ ). 
destabilising effect of the use of the current wage as a proxy for the future wage decreases, given the extent to which it is used $\left(\lambda_{2}\right)$ (shift a). Again the decrease of $\sigma_{\text {varl }}^{2}$ is compensated by the fact that students use the myopic forecast to a larger extent (shift $b$ ). In the new equilibrium the use of the current wage is larger than initially, but also the systematic error $\left(\sigma_{v a r}^{2}\right)$ decreases.

Figure 11.4: Changes in the optimal trade ofF CAUSED BY INCREASES IN THE ABILITY TO CORRECT THE CURRENT WAGE FOR. ITS DISEQUILIBRIUM CHARACTER.

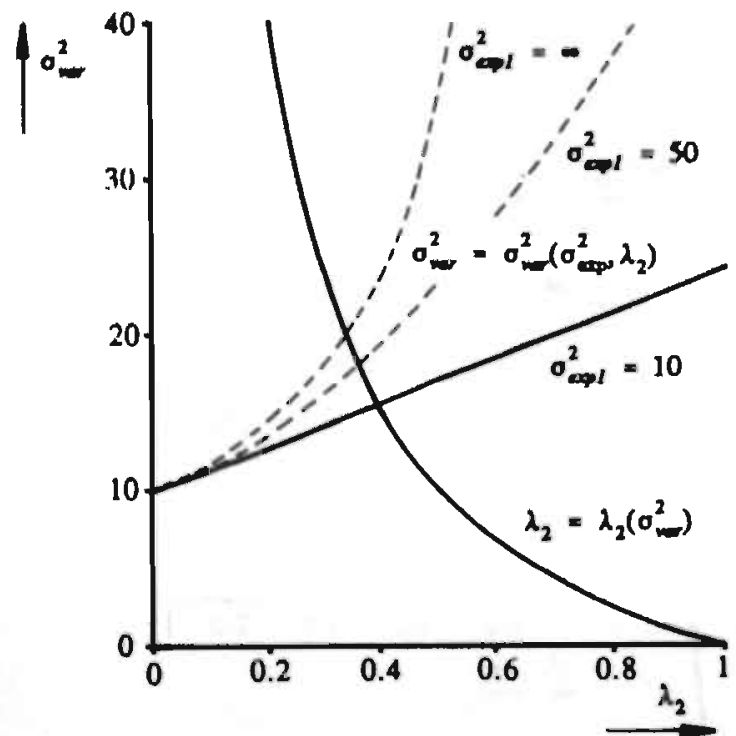

Finally, in figure 11.4 the assumption that the current equilibrium is unpredictable $\left(\sigma_{\text {expl }}^{2}=\infty, \lambda_{1}=1\right)$ is released. The picture allows for the fact that students are able to correct the current wage for its disequilibrium character, to some extent. If students are more able to correct for disequilibrium situations (11.16) also depends on $\lambda_{1}$ (see equation (11.14)):

(11.17) $\sigma_{v a r}^{2}=\sigma_{v a r l}^{2}+\sigma_{v a r l}^{2} \frac{\lambda_{1} \lambda_{2}\left(\frac{\beta_{s}}{-\beta_{D}}\right)^{2}}{1-\lambda_{1} \lambda_{2}\left(\frac{\beta_{S}}{-\beta_{D}}\right)^{2}}$ 
and this function becomes less steep if $\sigma_{\exp l}^{2}$ decreases. Therefore, the market stabilises and students make more use of current wage as indicator of future wage.

The model introduced in this chapter gives an interpretation of the cobweb theory developed in the thirties by economists like Tinbergen and Schultz. An attempt has been made to illustrate the dilemma which characterises their expectations theory. On the one hand, inspired by Walras and Pareto, wages were seen as indicators of value and people were assumed to use this information and to 'take prices given'. On the other hand, these equilibrium wages could (in a dynamic context) only be the result of people's economic behaviour. The model in this chapter shows that it is possible to give 'myopic' expectations a rational or reasonable interpretation. The cobweb-expectations which are biased may be preferred by people since this systematic error may be smaller than the unsystematic error of the alternative, an expectation which is not biased. This naive behaviour has, however, a feed back influence upon the quality of the current wage as forecast of the future wage what limits its possible use.

\subsection{Conclusions}

The cobweb model is typified by its cycle. In chapter 9 cobweb behaviour was explained, but its dynamic character was left out of the analysis. If people use the current wage a an abstract forecast for the future wage, there may occur an endogenous relationships. The quality of the prediction determines how far the wage will be out of equilibrium, while a wage out of equilibrium may decrease the quality of the forecast based on it.

In this chapter these endogenous relationships are investigated. It is shown that an equilibrium variability of the market will come about, which consists of the variability of the equilibrium wage plus an additional component determined by the prediction errors. Comparative statics show the relationship between the variability and predictability of the wage and the endogenous market fluctuations. 



\section{THE MARKET FOR PRIMARY SCHOOL TEACHERS}

In the Netherlands one of the most famous examples of vocational training which has to contend alternately with shortages and surpluses is the school for primary school teachers. While recently there was a large surplus, at present the Forecast Committee for Primary Education predicts shortages in the near future. ${ }^{1}$ Mostly, these mismatches are explained by certain incidents, such as changes in payment, an educational reorganisation or e.g. the introduction of mathematics as an entry-requirement. Furthermore, the problems on this market are often explained by the cobweb phenomenon. These explanations have, however, never been systematically investigated.

The aim of this chapter is to investigate the market for primary school teachers and to estimate to what extent several sources of uncertainty contribute to the mismatch problem, based on the theoretical model of chapter 9. As mentioned before, two types of models are used in literature to explain markets for certain occupations: the cobweb model and the rational expectations model. Sections 12.1 and 12.2 will provide an overview of the implications of these theories with respect to the market for teachers. Both theories provide a completely opposite characterisation of this market. While from the point of view of the cobweb theory the market for teachers is expected to be very problematic, from a rational expectations point of view it is expected to function rather well. Both theories, as remarked in chapter 9, fail to take into account one particular factor which seems to be crucial in anticipating behaviour. This is the capability to forecast. In section 12.3 the model of section 9.4 on the trade off between variability and predictability is considered as a framework to explain the Dutch market for primary school teachers. The basic assumption is that the future labour market situation ideally is predictable but that students' limited capabilities to make adequate forecasts cause deviations from the equilibrium.

In section 12.4 the market for primary school teachers will be introduced by providing some general statistics with respect to the theory of section 12.3. In sections 12.5 and 12.6 two models will be estimated which explain the enrolment at the teacher colleges. The estimation is based on the results of section 10.3. In the first model, policy behaviour is treated exogenous while in the second model policy is seen as, partially, endogenous. For both models the consequences of 
these estimates with respect to the causes of mismatches are calculated. It turns out that replacement demand and policy infuences upon demand are indeed difficult to forecast for students. Demographic changes, on the other hand, are more easily forecast. Finally, section 12.7 will provide some policy implications.

\subsection{Cobweb Theory}

The mismatches, frequently observed on the Dutch market for teachers, seem to fit very well into the cobweb model. The extent of the cobweb phenomenon depends on some characteristics of the labour market segment involved. Factors which, in the cobweb model, are positively influencing the mismatches are:

- the length of the curriculum,

- a low potential mobility to other occupations,

- an inelastic demand, and

- a strong reaction of students to the labour market situation.

The Dutch market for teachers shows at least three of these four characteristics. Firstly, the curriculum takes four years. Secondly, a qualification from the teachers' training college does not provide many job opportunities outside the teacher market. De Grip, Heijke, and Dekker (1989) measure the flexibility of educational groups with respect to occupation, by using the Gini-Hirschman-index. ${ }^{2}$ The group to which primary school teachers belong, have a flexibility 0.37 at a scale between 0 (no flexibility) and 1 (total flexibility). This result is very low. Only four out of the 53 educational groups show less flexibility. Thirdly, the demand for teachers is rather inelastic since demand is determined by policy decisions and not by free market forces.

For these reasons the market for primary school teachers is a typical example of a market on which, due to low mobility opportunities, the responsiveness to changing market connditions is relatively high, while the responsiveness of demand is low due to its institutional character $\left(\beta_{s} /\left(-\beta_{D}\right)\right.$ is large). In such a case the cobweb theory predicts that disturbances are preserved for a long, time, and that the cobweb cycle might even diverge.

2 The Gini-Hirschman-index is defined as $G H=\left(1-\sum_{p}^{2}\right) \neq n$ (n is the number of occupations) in which $p_{1}$ is the fraction of students with a certain education who have a certain occupation $i$. If people with this education are spread uniform over the occupations $\left(p_{1}=\frac{1}{a}\right.$ for every $\left.i\right)$ the index equals 1 . If all people with this education are concentrated in one occupation the index becomes 0 . 


\subsection{Rational Expectations Theory}

A completely different vision with respect to the market for teachers is provided by the rational expectations theory. In contrast with the assumptions of the cobweb theory, e.g. Siow (1984) and Zarkin (1983, 1985) suggest that students base their choice between different courses on rational expectations about the future labour market, and therefore the only reason which explains a mismatch between supply and demand is a change which was totally unpredictable at the moment the choice was made.

For a characterisation of the market for teachers this change in view has enormous consequences. In a cobweb model the market for teachers is a prototype of a market with mismatch problems, due to the length of the curriculum, the low potential mobility and the inelastic demand. The rational expectations theory claims, on the other hand, that there will be large matching problems only if the future labour market is largely unpredictable. But as Zarkin (1985, p. 410) states about the market for teachers, 'this market has an obvious special feature. The primary driving variable is the number of children enroled in school, which is essentially deterministic once people are born. This feature makes the task of forecasting future demand conditions much easier.' According to Zarkin the market for teachers must be one of the best predictable markets, since the number of children determines the demand for teachers. Therefore, from a rational expectations point of view, one may expect few mismatch problems with respect to teachers.

This conclusion seems to contradict the Dutch experience that the market for teachers often shows quite large mismatches. This observation either indicates that rational expectations theory does not provide a good explanation for educational choices, or that the presumption that the future market for teachers is largely predictable does not hold. Furthermore, the empirical justification of the rational expectations hypothesis in the theory of educational choice is difficult. Zarkin (1983) tries to compare the cobweb model with his rational expectations model, but does not provide a real test between both hypotheses. On the other hand, he observes 'that perhaps the most striking feature is that overall the cobweb model fits the data about as well as the forward looking, i.e. rational expectations model' (p. 9i).

\subsection{Predictability and Variability}

In the case of the market for teachers, two different theoretical points of view lead to very opposite characterisations. The cobweb theory 
predicts the market for teachers to be sensitive to mismatch problems, while rational expectation theory predicts few problems. The Dutch experience would therefore suggest the cobweb model to be the most appropriate.

As mentioned in chapter 9, there is, however, besides the testing problems, a theoretical problem with this cobweb explanation. If it is concluded that the market is cobweb-like, this does not explain why it is cobweb-like. In fact, cobweb theory assumes that independently of the situation of the market, students do not anticipate future changes. But in a market with many matching problems it is hard to believe students do not take these problems into account. If the cobweb theory is right, the most appropriate policy would be to inform students about the danger to base their decisions on the present labour market situation and to tell them they should anticipate the future. If this is the only thing needed to overcome the mismatch problems, one could wonder why it had not already happened.

It is clear that the situation is much more complicated. Not only the notion that one has to anticipate the future labour market, but also the ability to do this is a relevant factor. Agents' impotence to calculate the rational expectation is one of the major points of criticism of the rational expectations hypothesis (e.g. Spear, 1989). In fact Zarkin (1985, p. 440) inclicates the problem with rational expectations by the statement: 'This market has the special feature that future demand conditions can be readily forecast.' This is, from a rational expectations point of view, no argument to expect proper anticipations. The rational expectations argument for few mismatch problems would be the special feature that future demand conditions can be largely forecast. The dictionary defines 'readily' as 'without difficulty', which is not an argument in the rational expectations thought. Rational expectations theory only distinguishes between a predictable and an unpredictable part. The prediction is accurate if the predictable part is relatively large ('largely' is defined as 'to a great or preponderating extent').

In this chapter the Dutch market for primary school teachers is investigated, based on the model of section 9.4. The assumption is made that the future labour market situation is predictable (i.e. there is no states of the world uncertainty), but that students' capability to make forecasts limits the quality of the prediction. This model will put new light on the contradiction between cobweb and rational expectations at the market for teachers. 


\subsection{The Market For Primary School Teachers}

In this section the Dutch market for primary school teachers will be investigated within the framework of the model of chapter 9. Students' decision to go to a teacher training depends on their predictions about the future labour market situation. Over the years teacher training in the Netherlands has passed through several changes. Until 1967 the regular course took four years, but there were possibilities to enter the program after the first or second year for students with a higher preliminary education. The extent to which these side-entrances were used changed slowly throughout the years. Furthermore, it was possible to extend the study with an additional fifth year, to get an additional qualification. In the empirical analysis only the students who followed the entire program (four years) are taken into account. Furthermore, the assumption is made that all students intend to leave the school after four years. In 1968 the program became three years without further possibilities for side-entrance or extension of the curriculum. Therefore, the time-lag between the choice for the teacher training and the entrance at the labour market has been set on three years from 1968 till 1983.

In fact, not only the situation of the market at the moment one enters the market is important, but also the situation during the whole teaching career. Since the Dutch tenure system protects employed teachers against teachers entering the market, this facet is not taken into account. Therefore supply will depend on the prediction about the future labour market $d(d=3,4)$ years in advance:

(12.1) $C_{-d}=f\left(x^{p r e}\right)$

in which $x$ represents the relevant factors affecting students' choices, such as wages, probability to get a job and working conditions. Because on the one hand, not every student will enter the labour market (e.g. school drop-outs) and on the other hand other students might enter, e.g. those who followed a shorter program, the supply, $d$ years after the choice is assumed to be a factor $A_{t}$ of the enrolment.

(12.2) $S=\frac{C_{-d}}{A_{t}}$

Since it is difficult to determine which factors are relevant, and since there are no adequate data on possible factors, $x$ is taken into account only implicitly. As stated in the introduction of this chapter, $x$ will be affected by the demand for teachers. By treating the demand for labour as exogenous every $D$ can be associated with a $x$ which clears the 
market $(i . e . S=D)$.

(12.3) $x=g(D)$

A combination of (12.1) and (12.3) leads to

(12.4) $C_{-d}=f\left(g\left(D^{\text {pre }}\right)\right)$

If expected demand is substituted by realised demand this equation equals the market clearing condition $S=D$. Taking into account the factor between enrolment and supply at the market (12.2) gives:

\section{(12.5) $C_{-d}=A D^{p r e}$}

In formula (12.11) the enrolment decision depends on the prediction of the future demand for teachers. The demand for teachers is depicted in figure $12.1 .^{3}$ In the statistics used as a source for these data, replacement demand ${ }^{4}$ has been distinguished from expansion demand. Furthermore, it is possible to split up the expansion demand into a demographic component and a policy component.

FIGURE 12.1: TOTAL DEMAND.

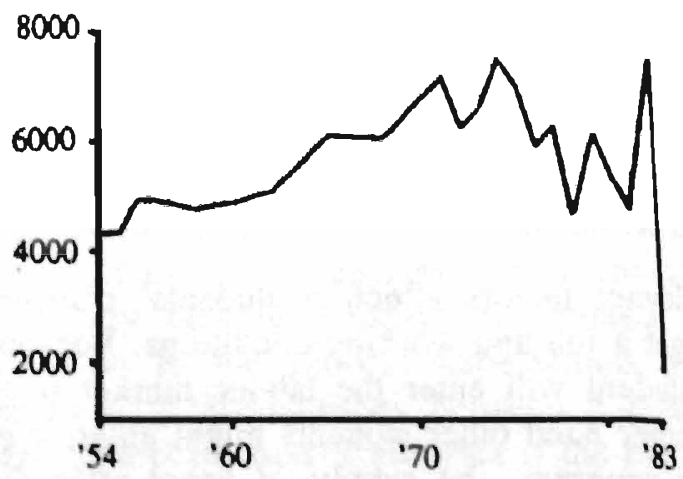

3 The data used for estimation has been taken from Statistiek van het basisonderwijs; leerlingen en scholen, Sratistiek van het basisonderwijs; instroom, doorstroom en uitstroom van hoofden en onderwijzers, and Staristiek van het beroepsonderwijs: opleidingsscholen voor kleuterleidsters, pedagogische academies and their predecessors of the Centraal Bureau voor de Statistiek. For an extended description of the data see Borghans (1991a).

4 Replacement demand is defined as "the number of teachers needed to replace teachers who left. |...। Replacement demand therefore refers to a, regarding its size, completely constant teaching staff (d.i. het benodigd aantal leerkrachten ter vervanging van vertrokkenen. [... De vervangingsvraag heeft dus betrekking op een wat omvang betreft, volkomen constant onderwijzerscorps"), CBS (1953), p. 5. From 1958 till 1971 replacement demand was not measured every year. In the estimates in the next two sections these missing values have been replaced by interpolations. 
The demographic component is constructed by imposing the studentteacher ratio from year $t$ upon the change in the number of children at primary school between year $t$ and year $t+1$. This figure indicates the demand for teachers that would be created due to a growth in the number of children under the assumption that the average clas size does not change. The remaining part of the expansion demand is called the policy component, because it is caused by (intended or unintended) changes in student/teacher ratio. The changes may be caused by explicit governmental decisions about the class size, but may also occur due to the flexibility of the system which allows schools to employ a number of teachers within certain limits. This kind of changes is also classified in the policy component. Although the decision to change the ratio between teachers and pupils in this case is not directly taken by the government, they indirectly did so by allowing for a certain flexibility of the system.

The demand for teachers can therefore be split up into:

$$
D=R e p l+D e m+P o l
$$

These data make it possible to calculate the variability of the three components. To adjust for the changing scale the variability of the components of demand, is defined as:

$$
\begin{aligned}
& \text { (12.7) } \sigma_{\text {var, Repl }}^{2}=E\left\{\left(\frac{R e p l_{t}-\text { Repl }_{t-1}}{D_{t}}\right)^{2}\right\} \\
& \text { (12.8) } \sigma_{\text {var,Dem }}^{2}=E\left\{\left(\frac{D e m_{t}-D_{e m}}{D_{t-1}}\right)^{2}\right\} \\
& \text { (12.9) } \sigma_{\text {var, Pol }}^{2}=E\left\{\left(\frac{P o l_{t}-P o l_{t-1}}{D_{t}}\right)^{2}\right\}
\end{aligned}
$$

In table 12.1 this variability is indicated for a period in the fifties, a period in the seventies and the total period. In the fifties demographic changes were the most important cause of variation. In the course of time the importance of this cause has diminished considerably, while the variability of the two other components, the replacement demand and the policy component has grown. For the period as a whole the policy component is the most important factor, with replacement demand very close to it. The demographic component is much less important.

This is an important objection against Zarkin's hypothesis. The idea that the demand for teachers is largely determined by these demographic 
changes is, at least for the Netherlands, not true. The two other components, replacement and the policy component, appear to be much. more important.

The table does not provide a measure of the variability of supply. This is the case because supply is modelled as a reaction to demand. But there also may be changes in supply that change the equilibrium situation. Firstly, the preferences of students may change. Secondly, it is possible that some students anticipate the forecast errors of others. Thirdly, due to mismatches a stock of unemployed teachers may exist, which is large after years of excess supply and which is small if supply has been too small.

TABLE 12.1: VARIABILITY OF THE DEMAND FOR TEACHERS. ${ }^{5}$

\begin{tabular}{l|ccc}
\hline & $' 50-' 60$ & $70-' 80$ & $' 50-' 80$ \\
\hline replacement & 0.006 & 0.080 & 0.042 \\
demographic & 0.032 & 0.005 & 0.017 \\
policy & 0.006 & 0.027 & 0.057 \\
\hline
\end{tabular}

These three supply side factors are not taken into account, because there is no data about them. For changes in preferences it can be argued that they are not very important since they are very slow changes and in the analyses only unexpected changes matter. Forecasts of other students' forecast errors may also be seen as unrealistic. The stock of unemployed teachers may, however, be a rather important factor at the market for teachers. This might make the estimates less reliable but it has no influence upon the assignment of the causes of mismatches to the three components, since changes in the stock of unemployed are ultimately caused by the unexpected changes in demand.

In the next section the expectation model of chapter 9, explaining the enrolment of students at the teacher training is estimated. Indirectly, the results provide information about the predictability of the several components of demand. These components have been treated as exogenous variables. It is, however, possible that policy changes are not random, but are to some extent reactions to shortages and surpluses at the market. The institutions will for example be flexible to a certain

5 For replacement demand the fifties measurement of the variability is based on the period 1951-1958 while for the demographic and policy component the period 1954-1961 has been used. The seventies measure is based on the period 1971-1981. 
extent which might lead to an adjustment of the demand to the market situation. In section 12.6 this is investigated: the policy component will be viewed as endogenous. On the other hand, it is also possible that a substantial part of replacement demand is, alternately, caused by policy changes. New policies may make the job of a teacher less or more attractive, resulting in a decrease or increase of the outflow of teachers. An example of this is the introduction of early retirement. With the data used in this paper it is, not possible to measure such links. Replacement demand will therefore be treated as exogenous.

\subsection{Enrolment with Exogenous Policy}

The aim of this section is to explain, departing from this expectations framework, students' enrolment at the teacher training. A combination of the enrolment function (12.5) and the demand-function (12.6) gives:

$$
C_{-d}=A_{t}\left(\text { Repl } l^{\text {pre }}+\text { Dem }^{\text {pre }}+\text { Pol }^{\text {pre }}\right)
$$

The predictions can be modelled conform section 9.4 as:

(12.11) Repl Rre $^{\text {pre }} \lambda_{R} \operatorname{Repl}_{-d}+\left(1-\lambda_{R}\right) R e p l^{\text {exp }}$

(12.12) Dem $^{\text {pre }}=\lambda_{D}$ Dem $_{-d}+\left(1-\lambda_{D}\right)$ Dem $^{\exp }$

(12.13) Pol $^{\text {pre }}=\lambda_{P} P_{o l}+\left(1-\lambda_{P}\right) P o l^{\text {exp }}$

Furthermore, a specific form for $A_{T}$ has to be taken:

(12.14) $A_{t}=\alpha_{0}+\alpha_{1} t+\alpha_{2} t^{2}$ with $t=1$ in 1946

Since the forecast errors do not correlate with the realised demand, e.g. $R e p l_{t+d}$, these realisations can be used as approximates for the expectations of these realisations, as is shown in section 10.3.

It takes three or four years before wrong predictions are falsified by realisations. Therefore errors might persist some years which cause autocorrelation in the errors. Therefore an AR(1) error-term has been added, indicated by a parameter $\rho$.

To adjust for changes in scale and to make the results comparable with the variability measure of section 12.4 , equation $(12.10)$ is estimated by least squares, with the observations weighted with total demand. The results are shown in table 12.2 .

Equation (9.17) gives the link between $\lambda$, the variability and the predictability. This can be rewritten as: 
(12.15) $\sigma_{\exp }^{2}=\frac{\lambda}{1-\lambda} \sigma_{v a r}^{2}$

Therefore, the predictability of the components of the future demand can be calculated. In the common literature, estimates of the predictability largely depend on the forecasting rule that has been adopted. In the approach followed here, the results depend on the correctness of the enrolment function (equation (12.10)). In the next section a slightly different model will give slightly different results. Furthermore, the calculation of $\sigma_{\exp }^{2}$ may have a bias since it is a nonlinear function of $\lambda$ and $\sigma_{\text {var }}^{2}$.

TABLE 12.2: ESTIMATION RESULTS OF EQUATION (12.10).

\begin{tabular}{l|ccc}
\hline$R^{2}$ & 0.510 & \\
$D W$ & 1.876 & \\
\hline & parameter & $t$-statistic & \\
\hline$\rho$ & 0.36 & 1.13 & \\
$\alpha_{0}$ & 0.6540 & 0.61 & \\
$\alpha_{1}$ & 0.0257 & 0.22 & $t$ of $1-\lambda$ \\
$\boldsymbol{\alpha}_{2}$ & -0.0001 & 0.05 & 0.15 \\
& parameter & $t$ of $\lambda$ & 0.59 \\
\hline$\lambda_{R}$ & 0.93 & 1.90 & 0.46 \\
$\lambda_{D}$ & 0.69 & 1.32 & \\
$\lambda_{P}$ & 0.85 & 2.68 & \\
\hline
\end{tabular}

Table 12.3 shows the variability and predictability of the three components of demand.

TABLE 12.3: VARIABILITY AND PREDICTABILITY.

\begin{tabular}{l|cc}
\hline & variability $\left(\sigma_{\text {mer }}^{2}\right)$ & predictability $\left(\sigma_{\text {sre }}^{2}\right)$ \\
\hline replacement & 0.042 & 0.558 \\
demographic & 0.017 & 0.038 \\
policy & 0.057 & 0.323 \\
\hline
\end{tabular}

Relatively speaking not only the variability of the demographic 
component is low, but also its predictability is very good. Replacement demand and the policy component therefore not only are larger sources of fluctuations on the market, but it is, for the students, also more difficult to predict these changes. This result rejects Zarkin's (1985) hypothesis that the demographic component is the only important factor on the market for teachers.

It is remarkable that the policy component appears to be better predictable than replacement demand. This result may be explained by the endogenous character of policy changes. If policy reacts on supply surpluses or shortages, there is a link between enrolment and policy changes, but the causation is alternately. In the next section a model will be examined in which this possibility is taken into account.

According to (9.19) the optimal prediction satisfies:

(12.16) $\sigma_{p r e}^{2}=\lambda \sigma_{v a r}^{2}$

FIGURE 12.2 : THE SYSTEMATIC ERROR.

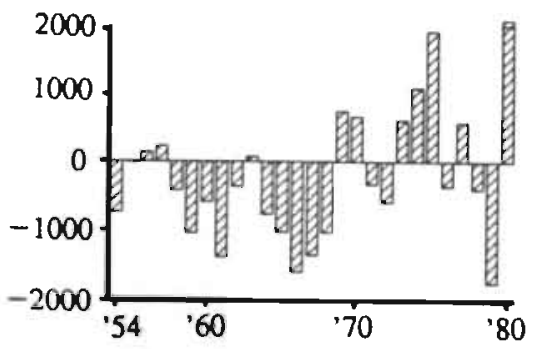

FIGURE 12.4: THE SYSTEMATIC ERROR IN THE DEMOGRAPHIC COMPONENT.

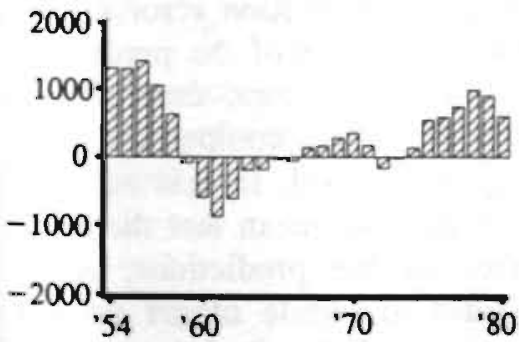

FIGURE 12.3: THE SYSTEMATIC ERROR IN THE REPLACEMENT DEMAND.

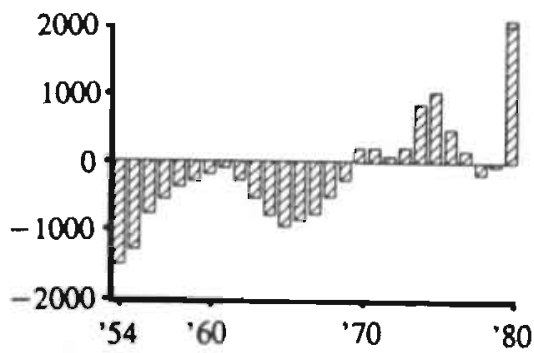

FIGURE 12.5: THE SYSTEMATIC ERROR IN THE POLICY COMPONENT.

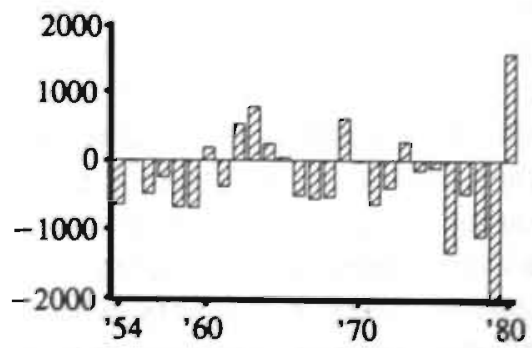


This is the variance of the prediction errors which remain after students have adjusted their expectations because of inaccuracy. This variance of the prediction error can also be written as

$$
\text { (12.17) } \sigma_{\text {pre }}^{2}=\lambda^{2} \sigma_{\text {var }}^{2}+(1-\lambda)^{2} \sigma_{\text {exp }}^{2}
$$

by using the calculation rules for the variance. Equation (12.23) shows that the prediction error consists of a systematic part $\left(\lambda^{2} \sigma_{v a r}^{2}\right)$ and an unsystematic part $\left((1-\lambda)^{2} \alpha_{\text {exp }}^{2}\right)$. The systematic part is a fraction of the difference between demand at the moment the choice was made and the moment of entering the labour market. Figure 12.2 gives the realisations of this part of the prediction error. It provides the predicted surpluses of students who enter the market for teachers yearly. Figure $12.3,12.4$ and 12.5 provide the same data with respect to replacement demand, the demographic component and the policy component. It is important to note that the total prediction error exceeds the error illustrated. The graphs only provide this systematic component of the error, which is only a $\lambda$-fraction of the total variance. These figures are denoted in table 12.4 .

TABLE 12.4: THE PREDICTION ERROR AND THE SYSTEMATIC COMPONENT.

\begin{tabular}{l|cc}
\hline & $\sigma_{\text {rre }}^{2}=\lambda \sigma_{\text {arr }}^{2}$ & systematic part $\left(\lambda^{2} \sigma_{\text {arr }}^{2}\right)$ \\
\hline replacement & 0.039 & 0.036 \\
demographic & 0.012 & 0.008 \\
policy & 0.048 & 0.041 \\
\hline
\end{tabular}

The unsystematic part of the prediction error can not be measured directly. Figure 12.6 provides data about the residuals of the estimation. These may partly consist of these unsystematic errors, but also other kinds of specification errors are included in these figures.

The extent to which the unsystematic part of the prediction error affects these residuals depends on the correlation of this part of the prediction error with individuals. If everyone makes the same errors, they will be reflected completely in the residuals, but if the errors compensate each other, this leads to a zero error on the aggregate level. In that case the market is not influenced by this error. This does not mean that the error has no consequences. Due to differences in the predictions, some students become teachers who did not want to, while others do not become teachers although they had wanted to, if they had known the 
labour market situation. Although at aggregate level the match is perfect, at individual level regret exists and therefore a disequilibrium situation.

\section{FIGURE 12.6: THE RESIDUALS.}

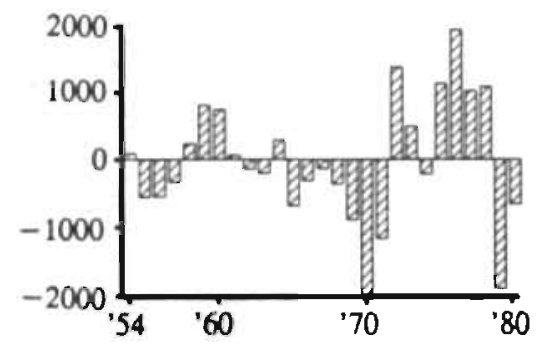

\subsection{Enrolment with Endogenous Policy}

The model of section 12.5 is based on the assumption that the three components of the demand for teachers are exogenous. Whether this assumption is true for the policy component is highly doubtful. Firstly, policy instruments may be used just to compensate for mismatches on the market. In a situation of shortages the government may decide for instance to increase the student/teacher ratio. Secondly, these adjustments of the policy component of demand may occur not because of an explicit policy decision but unintendedly, due to the flexibility of the system. Governmental rules with respect to the number of teachers a school is allowed to employ are not totally exact but may allow some flexibility.

In this section the model is adjusted to make such policy reactions to shortages and surpluses possible. Therefore the enrolment function (12.10) is changed into:

$$
C_{-d}=A_{t}\left(R e p l^{\text {pre }}+\text { Dem }{ }^{\text {pre }}+E x P o l^{\text {pre }}\right)
$$

The difference with $(12.10)$ is that supply does not anticipate the policy component of demand anymore, but only its exogenous part ExPol. The predictions are: 


$$
\begin{aligned}
& \text { (12.19) } \text { Repl }^{\text {pre }}=\lambda_{R} \operatorname{Repl}_{-d}+\left(1-\lambda_{R}\right) \text { Repl }^{\text {exp }} \\
& \text { (12.20) } \text { Dem }^{\text {pre }}=\lambda_{D} \text { Dem }_{-d}+\left(1-\lambda_{D}\right) \text { Dem }^{\text {exp }} \\
& \text { (12.21) } \text { ExPol }^{\text {pre }}=\left(\mu_{P} 0+\left(1-\mu_{P}\right) P_{0} l_{-d}\right)+0 . \text { ExPol }^{\text {exp }} \\
& =\left(1-\mu_{P}\right) \text { Pol }_{-d}
\end{aligned}
$$

The predictions for replacement demand and the demographic component are unchanged. It is assumed that the exogenous changes in the policy component of demand are totally unpredictable $\left(\sigma_{\exp }^{2}=\infty\right)$. Therefore this term is excluded $\left(\lambda_{P}=1\right)$. Furthermore, because the policy component is partly endogenous, it is not likely students will treat the present policy component as a prior for future policy demand. Therefore students' predictions consist of a mix between 0 , i.e. no future policy demand, and the present policy demand. The larger $\mu_{p}$, the more students expect present policy demand to be incidentally.

TABLE 12.5: ESTIMATION RESULTS OF EQUATION (12.18).

\begin{tabular}{l|ccc}
\hline \hline$R^{2}$ & 0.842 & & \\
$D W$ & 1.846 & & \\
\hline & parameter & $t$-statistic & \\
\hline$\rho$ & 0.71 & 6.48 & \\
$\alpha_{0}$ & 3.9037 & 2.37 & \\
$\alpha_{1}$ & -0.2979 & 1.97 & $t$ of $1-\lambda$ \\
$\alpha_{2}$ & 0.0079 & 2.32 & 0.30 \\
\hline$\lambda_{R}$ & parameter & $t$ of $\lambda$ & 3.74 \\
$\lambda_{D}$ & 0.98 & 18.11 & 0.63 \\
\hline$\mu_{P}$ & 0.33 & 1.83 & \\
\hline
\end{tabular}

Furthermore, it is possible to explain the policy component of demand as a reaction to shortages or surpluses in supply. The model provides two types of errors: the systematic error explained by the model and the residuals $\varepsilon$ of the estimation. The systematic error is called $E^{\mathbf{l}}$ and the unsystematic error is called $E^{2}$. By dividing them by $A_{t}$ they become comparable to the policy component of demand. 
(12.22) $\quad E^{1}=\lambda_{R}\left(R e p l-R_{e p l}^{-d}\right)+\lambda_{D}\left(\right.$ Dem - Dem $\left._{-d}\right)$

(12.23) $E^{2}=\frac{e}{A}$

The policy component of demand may depend on both these enrolment errors.

(12.24) $P$ ol $=$ Constant $+\gamma_{1} E_{-d}^{1}+\gamma_{2} E_{-d}^{2}$

Table 12.5 provides the estimation results of equation (12.18), while table 12.6 gives the results of the estimation of equation (12.24).

Table 12.5 shows that the estimates for the extent to which future demand is anticipated decrease in this alternative model. Furthermore, $\mu_{P}$ is almost 1 which implies that students expect policy to be incidental. Table 12.7 provides the calculations of the predictability, based on these estimates.

TABLE 12.6: ESTIMATION OF EQUATION (12.24).

\begin{tabular}{l|cc}
\hline$R^{2}$ & 0.051 & \\
\hline & parameter & $t$-stat \\
\hline $\mathrm{C}$ & 1211 & 4.35 \\
$\gamma_{1}$ & 0.18 & 0.85 \\
$\gamma_{2}$ & 0.26 & 0.73 \\
\hline
\end{tabular}

Table 12.6 shows that the attempt to explain policy demand as a function of surpluses and shortages is not very successful. The $R^{2}$ is very low and both parameters $\left(\gamma_{1}\right.$ and $\left.\gamma_{2}\right)$ are not significantly different from 0 .

The relative success of the model with endogenous policy is entirely due to equation (12.18). This is not caused by the endogenous character of the policy component of demand. It seems that the assumption that students view demand as transitory is correct.

The finding that the demographic component of demand is the best predictable component is confirmed. The predictability of replacement demand is rather low.

Table 12.8 shows that despite the low predictability of the replacement demand the variance of the prediction error is rather low. This is caused by the possibility for students to use present replacement as an 
approximation for future replacement. The variance of the prediction therefore never exceeds the variability of the component that is predicted.

TABLE 12.7: VARIABILITY AND PREDICTABILITY.

\begin{tabular}{l|cc}
\hline & variability & predictability \\
\hline replacement & 0.042 & 2.058 \\
demographic & 0.017 & 0.008 \\
policy & 0.057 & $\infty$ \\
\hline
\end{tabular}

TABLE 12.8: PREDICTION ERROR AND THE SYSTEMATIC COMPONENT.

\begin{tabular}{l|cc}
\hline & $\sigma_{p \pi r}^{2}=\lambda \sigma_{\text {arr }}^{2}$ & systematic part $\left(\lambda^{2} \sigma_{\text {nar }}^{2}\right)$ \\
\hline replacement & 0.041 & 0.040 \\
demographic & 0.006 & 0.002 \\
\hline
\end{tabular}

Figures 12.7-12.10 give the calculations for the systematic error $\left(E_{t}^{1}\right)$, the unsystematic error $\left(E_{t}^{2}\right)$, the systematic part of the error in the replacement demand and in the demographic component.

FIGURE 12.7: THE SYSTEMATIC ERROR $E^{\mathbf{l}}$.

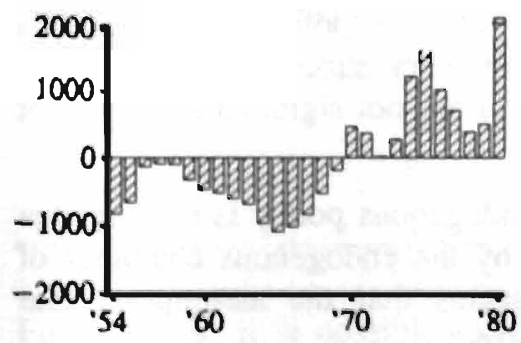

FIGURE 12.8: THE UNSYSTEMATIC ERROR $E^{2}$.

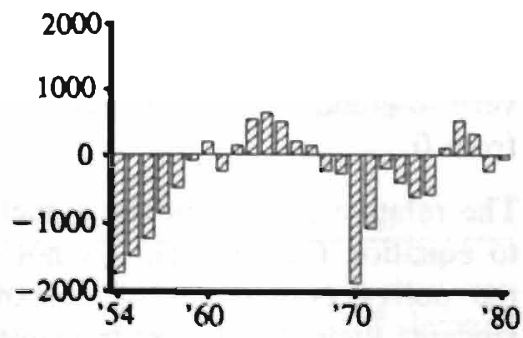


FIGURE 12.9: SYSTEMATIC ERROR OF THE REPLACEMENT DEMAND.

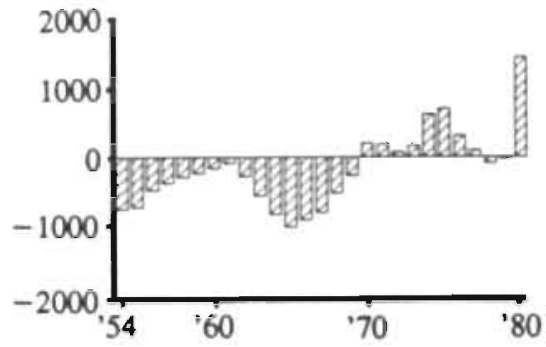

FIGURE 12.10: SYSTEMATIC ERROR OF THE DEMOGRAPHIC COMPONENT.

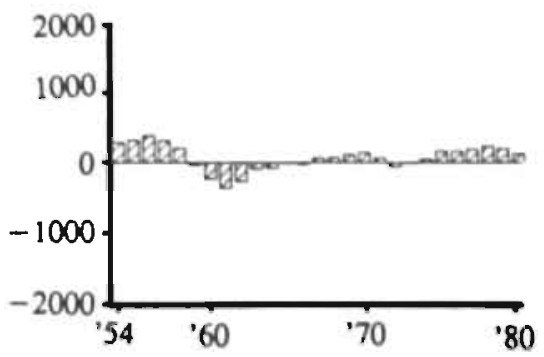

\subsection{Implications $^{6}$}

This chapter departed from the observation that cobweb and rational expectations theory, which are both used in research with respect to students' enrolment, provide completely different predictions with respect to the market for primary school teachers. The large mismatches on the Dutch market for primary school teachers would, at first sight, indicate the appropriateness of the cobweb model. However, this cobweb model does not explain why students do not use better predictions of the future labour market situation, from which they would profit.

In this chapter an attempt has been made to explain this behaviour by the use of the concepts of chapter 9 , variability and predictability. In rational expectations literature it is assumed that students dispose of the correct model to predict the future labour market situation. In the framework presented here this assumption has been abandoned, and it is assumed that students have a model which is not perfect and which will therefore generate a forecast error. If the predictability of this model is rather low, it may become useful to exchange the specific prediction of the model for the naive predictions of the cobweb model. Especially when the variability of the market involved is low the current situation is a good alternative for a bad prediction.

Both the model with exogenous policy (section 12.5) and the model with endogenous policy (section 12.6) provide a similar typification of the market for primary school teachers. The demographic component of the demand has a relatively low variability, but also a high predictability. Replacement demand and the policy component of demand have, 
however, a high variability and a low predictability.

Therefore, replacement demand and the policy component of demand seem to be the most important causes of the mismatch problem, while demographic changes seem to have little impact. The model provides two strategies to combat the mismatch problems: a reduction of the variability and an increase of the predictability of replacement demand and policy changes.

TABLE 12.9: IMPROVEMENT OF THE MATCH DUE TO IMPROVED FORECASTS.

\begin{tabular}{l|ccc}
\hline $\begin{array}{l}\text { improvements } \\
\text { forecast }\end{array}$ & $\begin{array}{c}\text { replacement } \\
\text { demand }\end{array}$ & demographic & policy \\
\hline $10 \%$ & 0.000301 & 0.000389 & 0.000794 \\
$20 \%$ & $(0.8 \%)$ & $(3.3 \%)$ & $(1.6 \%)$ \\
& 0.000671 & 0.000842 & 0.001751 \\
$50 \%$ & $(1.7 \%)$ & $(7.2 \%)$ & $(3.6 \%)$ \\
& 0.002555 & 0.002773 & 0.006319 \\
$80 \%$ & $(6.5 \%)$ & $(23.6 \%)$ & $(13.0 \%)$ \\
& 0.019597 & 0.009588 & 0.033106 \\
& $(21.9 \%)$ & $(55.3 \%)$ & $(37.5 \%)$ \\
\hline
\end{tabular}

Based on the estimation results of section 12.5, table 12.9 gives the effects on the prediction error for some imaginary scenarios. It has been calculated how much the prediction error will diminish, caused by a public labour market forecast. These effects are depicted in figure 9.3 for a theoretical situation. The quality of the forecast is in this example $10 \%, 20 \%, 50 \%$ and $80 \%$ better than those of the students themselves. In brackets the relative improvements of the match between the relevant component of supply and demand are provided. The figures show that an improvement of the labour market forecast leads to reduction of prediction errors which are relatively much lower. This is mainly the case for the minor improvements of $10 \%$. For the replacement demand this leads to only a $0.8 \%$ improvement of the prediction error. This is caused by the fact that, as indicated in table 12.2, with respect to replacement demand students almost totally rely on the current situation $(\lambda=0.93)$. The variability is very small compared to errors in the real forecast. Therefore, an improvement of the labour market forecast initially has only a small effect. Only if the quality of the forecast becomes comparable to the variability, the effect on the prediction error 
becomes substantial. This can also be shown by the fact that a decrease of the forecast error has, even absolutely, a larger effect upon the demographic component, which is much better predictable.

TABLE 12.10: IMPROVED MATCH DUE TO IMPROVED FORECAST AND DUE TO DECREASED VARIABILITY.

\begin{tabular}{l|cc}
\hline $\begin{array}{l}\text { improvement } \\
\text { variability/predictability }\end{array}$ & $\begin{array}{c}\text { effect for improvernent } \\
\text { predictability }\end{array}$ & $\begin{array}{c}\text { effect for decrease in } \\
\text { variability }\end{array}$ \\
\hline $10 \%$ & 0.000794 & 0.004180 \\
& $(1.6 \%)$ & $(8.6 \%)$ \\
$20 \%$ & 0.001751 & 0.008491 \\
$50 \%$ & $(3.6 \%)$ & $(17.5 \%)$ \\
& 0.006319 & 0.022260 \\
$80 \%$ & $(13.0 \%)$ & $(45.9 \%)$ \\
& 0.018168 & 0.037438 \\
& $(37.5 \%)$ & $(77.3 \%)$ \\
\hline
\end{tabular}

As indicated in section 9.7, in a situation in which students base their predictions largely on the current labour market situation (i.e. in a cobweb situation) a substantial improvement of the labour market forecast is necessary to induce a significant improvement of the match between education and labour market. To halve the prediction error due to replacement demand an improvement of $93.5 \%$ of the forecast is needed.

In general, it is not possible to change the variability instead of the predictability. In the case of the policy component of the expansion demand this is, however, possible. Government could try to maintain policies which have consequences for the demand for teachers as long as possible, or could introduce changes gradually. Table 12.10 compares the effects of a decrease of the variability of the policy component with an improvement of the predictability. Since also for the policy component students base their predictions mainly on the current situation $(\lambda=0.85)$ such a reduction of the variability immediately affects the prediction error, while the effect of an improved forecast initially only has a marginal effect. At least for small changes it seems to be the case that a reduction of policy changes has much more effect than an improved labour market forecast.

The other instrument to reduce mismatch problems, therefore, seems 
more appropriate. For replacement demand it may be possible to improve the quality of expectations by supporting students with professional forecasts of future replacement demand, based on detailed information about the age structure of the current teaching staff. The predictability of policy changes will not be improved by econometric investigations. For these policy changes, the only appropriate solution to increase the predictability and thereby to decrease the mismatches, may be to announce these changes at an early stage. In order to correctly anticipate, students should know these changes before they decide to enter teacher training.

\subsection{Conclusions}

The market for primary school teachers is an interesting case for this study. On the Dutch market there are large mismatch problems, which can be easily explained by the cobweb theory: the training is very job epocifio and demand io vory inflexiblo. Zarkin (1980, 1965), liuwever, mentions the market for teachers as an example in which few problems are to be expected. He argues that the demand for teachers will be largely determined by the demographic component (the number of children of a certain age) which is easily predictable.

The analysis of this chapter indicates that students have problems in predicting the future demand, but these problems are largely due to replacement demand and changes in public policy, while the demographic component both has a low variability and is easily predictable.

The results suggest that it would be important to provide better public forecasts about the replacement demand, and that it might be useful to reduce the amount of policy changes with respect to the demand for teachers. If a change is needed, mismatch problems could be avoided by an early announcement of this change. 




\section{WELFARE}



In the second part of this study, the errors students make in forecasting the future labour market situation were explicitly related to their ability to forecast. In this model the mismatch, which is caused by these errors in predictions, can be diminished by the provision of public labour market, forecasts. The idea behind this is that professional forecasters are better able to forecast the developments on the market. Their prediction errors therefore will be smaller. If students use these expert predictions they can improve their own predictions which will lead to a decrease in mismatch.

The evidence in chapter 4 shows that the extent of the misnnatch problem due to educational choices is rather large, suggesting the desirability of such public forecasts. The analytical results of the second part are, however, mainly restricted to individual students, while providing public labour market information at a large scale influences the functioning of the labour market as a whole. Public information will change students' behaviour which also has consequences at aggregate level. The positive effects at individual level may be accompanied by negative effects on the market level. To evaluate the welfare effects of the provision of public forecasts it is therefore necessary to compare individual welfare changes. This third part is devoted to such welfare analysis, based on the surplus concept. In this chapter, the medsurement of welfare and the use of partial equilibrium models are discussed. The other chapters are devoled to the welfare effects in the labour market model of chaptic 3 .

In section 8.4 about the junior secondary technical education a kind of welfare calculation was presented based on the calculation of the number of mismatches. Although this figure gives an interesting description of the matching problems at the vocational market studied in chapter 8 , this indicator has, as remarked, several disadvantages. Firstly, all mismatches are treated equally severe. There will, however, be students who have ex post a very small preference for the education which they have not chosen, but there may also be students for which this gap is rather large. A more adequate measure should therefore take these differences into account. Secondly, in section 8.4 the mismatch is compared to the realised labour market situation, which is in general not equal to the equilibrium. The provision of public labour market information changes students' behaviour and thus also changes the market realisations. In the idea! situation these realisations equal the equilibrium. It would therefore be better to compare the actual situation to the equilibrium situation. Thirdly, as already mentioned, the provision of additional information influences the labour market, which 
has, besides the allocational aspects, welfare implications for both sides of the market. Shifts in the wages due to changes in aggregate enrolment have welfare consequences for both supply and demand side of the market.

To overcome these shortcomings the surplus measure is used. This chapter will discuss the use of this measure. The use of surplus for wellfare measurement has been criticised very much, and there are many confusions with respect to this. Samuelson (1990) overviews all these criticisms against surplus measures. These criticisms and confusions are related to two aspects of the criterion. Firstly, the use of partial instead of general equilibrium models as point of reference has been attacked often. In section 13.1 and 13.2 the general equilibrium model and the partial equilibrium model are discussed, and the relevance of the usage of the second is set down in section 13.3 and 13.4. Secondly, the use of the surplus area as a measure for welfare is often refuted. In section 13.5 it is shown which problems are related to this index, but it is also shown that as long as one takes into account its limitations the surplus may, especially in the context of this study, be a very fruitful instrument for the analysis.

\subsection{General Equilibrium Analysis}

Samuelson (1990, p. 266) stresses the 'theoretical superiority of general equilibrium over partial equilibrium'. In this section, general equilibrium models and in the next section partial equilibrium models are discussed, and it is shown that the usefulness of both models depends on the problem which is investigated.

In a general equilibrium model a certain number of goods is distinguished. The initial endowments, the production possibilities, and the individual preferences constitute the context of the model. Furthermore, some assumptions are added about the way people exchange their endowments. If for simplicity the assumption is made that every good is only exchanged for money, then for every good a market institution has to be described which explains the outcome of the exchange process, and thereby the production, on every market. For all circumstances these market institutions describe the exchange of endowments of a certain good, with the accompanying exchange of money. Although at every single market only one good is exchanged for money, the exchange process may of course be influenced by the results and possibilities on other markets. The existence proof in a general equilibrium model shows under which conditions the whole system of interdependent markets has a solution (i.e. a fixed point). In the usual 
model the exchange outcome is assumed to be generated by price taking agents. This assumption is, however, not essential for general equilibrium analysis.

The strength of general equilibrium is that it takes into account that results for one market depend on the functioning of the economy as a whole. This advantage, however, sometimes turns out to be its weakness. While the interdependency of all markets is modelled in an elegant way, the results on a particular market become sensitive for the way other markets are modelled, and since it is impossible to build a model in which everything is perfectly modelled it is questionable whether simplifying assumptions about other markets provide an advantage or a disadvantage. Mostly it is assumed that these other markets have perfect competition, but it is evident that in reality many other market institutions exist.

\subsection{Partial Equilibrium Analysis}

In studies in which the interdependency of markets does not play a crucial role it may be useful to abstract from all other markets. This results in a partial equilibrium model. A challenge to partial equilibrium analysis is to carry out this abstraction in such a way that the results are as much as possible consistent with the general equilibrium framework.

Such a consistent construction is often regarded as theoretically impossible. It is indeed impossible to make one partial equilibrium model which is consistent with general equilibrium in all possible analysis, but the consistency may be obtained to a satisfactory degree if the partial equilibrium model is constructed with regard to the specific problem which has to be investigated.

A partial equilibrium model is usually constructed by the introduction of a supply and demand curve. General equilibrium does however not directly provide such curves which can be used in the partial model, and this causes the problem in the definition of an adequate partial model. In fact general equilibrium models provide (in case of uniqueness of the equilibrium) only one single point in the pricequantity space, namely the resulting equilibrium point after exchange. To define a supply curve it is needed to fill in what would have been the supply of the good under consideration if the price had been different from the equilibrium price. But such deviation is, from the general equilibrium point of view, logically impossible. As soon as the price on one market is chariged, the interdependency causes that the equilibrium conditions on other markets are not satisfied anymore. Therefore some 
hypothetical deviations from the equilibrium have to be introduced in the model.

To make such variations in the price on one market possible the system itself has to change or some error has to be assumed to exist in the behaviour of the agent. This error specifies the possibilities people expect to have on the other markets, given the price on the market under consideration. Such an error can result in the possibility that an agent 'announces' his supply in a situation which is in fact impossible. The remaining problem is that in order to operationalise a supply curve, the structure of the 'error' has to be modelled. This implies that for an exact derivation of a partial equilibrium model from a general equilibrium model a full description has to be made of the way people expect other markets to behave out of the equilibrium. The structure of this error determines the meaning of the supply or demand curve. The two best known concepts of supply and demand curve fill in this error structure in some specific way. In the Marshalian demand curve people expect constant prices on other markets and a constant income, while the price at the market under consideration varies. In the Hicksian demand curve people also expect the price on other markets to remain constant, but also expect their utility to be constant. The specific structure of the hypothetical error which people are assumed to make, together with the price taking behaviour of the people on other markets, makes it possible to define the supply and demand curve in a partial equilibrium model.

Many problems related to the use of partial equilibrium models are caused by the fact that the structure of the hypothetical error is not appropriate for the problem under investigation. Assume e.g. two occupations with a high degree of substitutability. In that case the introduction of a supply cuive for one of these occupations by the assumption that while the wage for one job changes the other wage remains constant is based on a very typical type of error, which will not be useful for most practical purposes. A certain type of error might lead to changes at all related markets. Therefore to each type of error a supply or demand curve on every market corresponds.

\subsection{The Supply and Demand Curve}

The model of chapter 3 , which presented a model of the supply and demand behaviour on a particular labour market, fits very naturally into the concept of partial equilibrium described above. The possibility that students make prediction errors generates a useful and obvious way to introduce an error into the general equilibrium, which makes possible 
the definition of the partial supply curve. The demand curve of chapter 3 is not based on errors made by employers, but is generated by changing circumstances. The prediction errors of students are the source of a variation in the total supply and the demand curve gives for every level of notional supply the resulting wage.

The supply curve (3.8) implicitly assumes (besides assumptions about the distribution of the reservation wages) a certain specification of the error made by students. The advantage of a partial equilibrium model is that it is not necessary to make this error explicit. Such an explicit description of the prediction error requires a theory about the way students perceive the economic reality, and it will generally be impossible to make such a description. The introduction of a supply curve per se makes it possible to allow for students making errors in their predictions, without stating explicitly its source.

Theoretically, there could be a problem with the introduction of such a supply curve which is not deduced from the general equilibrium model. Supply curve (3.8) has one given form. The specification of a supply curve based on a general equilibrium model may change, however, if the source of the error changes. If the analysis allows for unspecified, and therefore also possibly different errors, the uniqueness of the supply curve is not guaranteed anymore. A necessary approximation assumption to allow for the use of the partial equilibrium model is therefore that all types of prediction errors under consideration generate (approximately) the same supply curve. In the example of the model with two completely substitutable occupations this assumption is violated if it is sometimes thought that these wages will always move together, while in the same analysis in other cases assumed that one wage will remain constant while the other changes. The two supply curves generated by these two types of errors are too different.

\subsection{The Problem of Second Best}

According to the definition of chapter 2, the labour market model is in equilibrium if the students make a decision which is in accordance with their decision in the case of full information. This implies that the equilibrium equals the intersection of supply and demand curve. In a general equilibrium context it is however not necessary that this partial equilibrium situation is Pareto optimal.' Pareto optimality requires, as can be easily shown, an equality of the marginal price with the marginal 
utility or costs on all markets. This is called a first best situation. But as soon as on some market this requirement is not fulfilled, i.e. if there is a market distortion, the equality of marginal price and marginal costs at other markets is - even given the distortion as constraint - no guarantee anymore for Pareto optimality. This implies that, although on the labour market under consideration the requirement for a first best solution is fulfilled, it may be a Pareto improvement to deviate from this equilibrium point, because of some market distortion on another market. This is caused by the fact that the extent of market distortions are generally not constant. If the good on the distorted market is a complement for the good on the market under consideration, the welfare costs of the distortion are positively correlated with the amount of trade on the market in consideration. More trade, therefore has a negative external effect on the distorted market, and therefore it may be a Pareto improvement to increase the price in order to reduce the external effect, at the cost of a (smaller) distortion on the own market. A calculation of the optimal price which takes into account these external effects is called a second best solution. ${ }^{2}$ By the introduction of, e.g., taxes and subsidies a situation can be created which optimises welfare given the market distortion. ${ }^{3}$

Based on such tax system a corrected supply and demand curve can be derived. The optimal (second best) situation equals the equilibrium point of these new curves. In such situation the equality of marginal costs and marginal price (after tax) remains the optimal point. If these taxes are not introduced, the equalisation remains problematic, however.

$\mathrm{Ng}$ (1975) argues, however, that often the relation between the distortion and the market under consideration is too vague, making it impossible to calculate the second best solution. In such a case of informational poverty it is optimal to make the marginal price equal to the marginal costs. This is called a third best solution. A partial market model provides no information about the relationship with other markets. Therefore, the welfare analysis in a partial market model can never go beyond such a third best solution. In this study, therefore, the assumption is made that taxes and subsidies, or other market interventions, are such that the (constrained) Pareto optimum is reached if marginal costs or utility equal the marginal price, i.e. if supply equals 


\subsection{Surplus as a Measure of Welfare}

Figure 13.1 shows a supply and demand curve conform figure 3.1 . In this figure students' prediction of the wage (assumed to be equal for all students) is too high. Therefore too many enter the market and the wage falls. The welfare effect of this deviation from the equilibrium situation can be measured by the surplus. ${ }^{5}$

FIGURE 13.1: STUdENTS' (NEGATIVE) SURPLUS, DUE TO A HIGH PREDICTION OF THE WAGE.

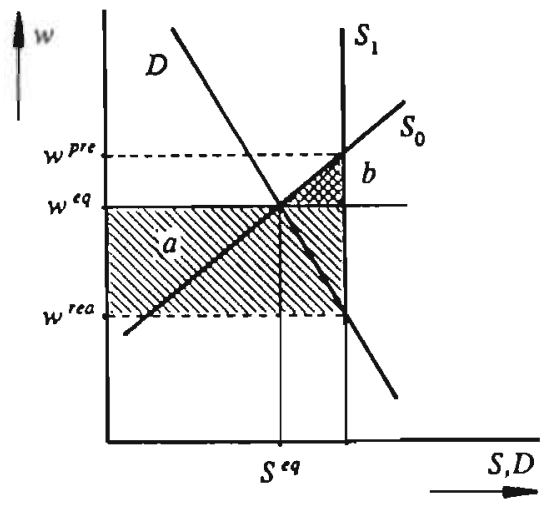

This surplus compares the welfare in the actual situation with a certain benchmark. In this study the equilibrium has been chosen as a benchmark. The benchmark should, of course, be feasible, and the equilibrium is a feasible situation in which no information problems occur, i.e. in which the cost of the information error is zero.

The (negative) surplus for students, compared to the equilibrium situation consists of two parts. Firstly, since the realised wage fell due to the large surplus, all students who enter the market earn less than the

4 Gunning and Keyzer (1993, p. 32) show that market distortions can, within the Negishi general equilibrium format, be viewed upon as additional notional agents who aim at the distortion. This implies that the welfare effects of the market distortion can be distinguished from the functioning of other markets.

5 The concept stems from Dupuit and Marshall (see Pfouts, 1953). 
equilibrium wage. The total loss due to this factor equals the rectangle area $a$. In this study this is called the stability component of the surplus. Secondly, there are some students who regret their enrolment decision. The wage for these students is lower than their reservation wage. The surplus loss they face therefore equals the difference between their reservation wage and the realised wage. Partly, this regret is caused by the relative low wage. This effect has already been counted in $a$. The remaining loss $b$, therefore equals the difference between the reservation wage and the equilibrium wage, for those whose reservation wage exceeds the equilibrium wage. These are the students who regret their decision, not only compared to the realised wage, but also compared to the equilibrium wage. In this study this is called the allocation component of the surplus. As remarked in section 13.2 there corresponds a supply curve at each market to a certain type of error. The surplus only measures the welfare costs at one market. Due to the interdependency between markets, additional information about wage on one market is also relevant information for the choice on other markets. Therefore, there might be welfare changes on all markets, each measured by the surplus on that market. In this study the analysis will, however, be restricted to welfare effects on one particular market.

The use of this surplus concept has been criticised very often. ${ }^{6}$ The two main arguments against the surplus measure are, firstly, that it assumes that the marginal utility of money is constant, and secondly, that it may be the case that students are not indifferent between getting the surplus paid in money, and a realisation of the equilibrium.

The first criticism is opposed by Harberger (1971, p. 788). 'The origin of this criticism is probably the thought that changes in consumer surplus ought directly to measure changes in utility. That this would be a fruitless pursuit should be obvious - among other things consumer surplus would not be invariant to monotonic transformations of the utility function.' Just like national income surplus does not aim at measuring "utils". Harberger shows that all criticism against surplus calculation also holds for national income calculation, although the latter is much more accepted.

Many attempts have been made to base welfare measures on compensation or equivalence schemes. In such schemes it is e.g. calculated how much a person is willing to pay, if a certain (positive) change is carried out, such that his utility stays constant. There are many ways to implement such a comparison. The critique on surplus 
measurement is that surplus can not be described as the answer to such a comparison question. This is true, but the question is whether this is problematic. The problem of compensations is that the transfer of money changes the problem under consideration. While initially only one disturbing factor is taken into account (in this case the wrong predictions of students) the compensation scheme introduces another disturbing factor, and the measures based on it add both welfare effects. Therefore, every compensation scheme may lead to another welfare measurement. The surplus measures a potential welfare change, under the condition that these changes are not disturbed, i.e. they are not compensated for these changes by side-payments. Therefore surplus is a theoretical but natural way to measure welfare changes. ${ }^{7}$ For a small gain in surplus it is always possible to reallocate money such that there is a Pareto improvement. Since these reallocations are not actually carried out this property does not necessarily hold for all changes, but in this study such pathological cases do not occur. In chapter 14 and 15 the welfare effects of the provision of information are investigated, based on this surplus welfare measure.

Finally, a remark has to be made about risk aversion. In the following chapters calculations are based on average welfare surpluses, based on probability distributions. The equalisation of a welfare effect by means of the distribution of welfare effects assumes risk neutrality, i.e. people are indifferent between two stochastic outcomes if the averages are equal, regardless the other aspects of the distribution. There are two reasons to abstract from such risk aversion due to a concave utility function. Firstly, it increases the value of information, and therefore the results without risk aversion serve as a lower bound for the welfare improvements due to the provision of public labour market information. Secondly, some recent studies question the validity of the expected utility framework as an explanation for risk aversion. ${ }^{8}$ Their results imply that the welfare effects due to the concavity of the utility function, may be very low. Most observed 'risk aversion' may be caused by other factors, of which mismatch possibilities, described in this study, are one possible explanation. 

In the model of chapter 7 , prediction errors were modelled as random variables. Since in this model uncertainty is not only caused by external random shocks, but there is also uncertainty in the production of forecasts, two forecasts based on the same data-information need not be the same. A prediction made by a person who has better capabilities to understand the functioning of the labour market may be an improvement to the prediction of less capable persons. This makes it possible to regard the provision of public labour market information as the publication of such an expert-made forecast. Even if a public forecast is not strictly better than the student's prediction, it may be useful, since it may contain insights which are not incorporated in the student's prediction. A combination of the public forecast with the student's forecast incorporates all information available.

In their famous paper, Grunberg and Modigliani (1954) have shown the possibility of a correct public forecast. Although a public forecast will change the expectations of future events of human beings, and will therefore change their actions, it still theoretically is possible to provide a public forecast that does not falsify itself. Grunberg and Modigliani base their existence proof on a fixed point argument, i.e. a correct public forecast has to be based on those presumed actions which will be chosen by the people, after they have received the public forecast. In the model of chapter 3 this means that as a public forecaster predicts the equilibrium wage, this prediction will not be self-denying.

The possibility of a correct public forecast does, however, not imply its desirability. In a situation in which a public forecast is available, people will react to this prediction which may influence their situation, but also other people's situation. Grunberg and Modigliani give an example of a situation in which the provision of a public forecast has such welfare effects. 'In the absence of public prediction, suppliers were found to act on the basis of unwarranted price expectations, so that they bring to the market a quantity which either falls short of or exceeds what can be sold at the expected price. Consequently, there is a misallocation of resources. If the market price is higher than the expected price, not enough resources have been allocated to this particular industry (and too much to other industries) and conversely. If, on the other hand, correct public prediction is made, suppliers will make their decisions on the basis of warranted price expectations, and no misallocation of the resources used in the industry occurs. By making available to the suppliers relevant information previously unknown to them, the public prediction causes an improved allocation of the resources used in the economy' (p. 476). 
In the seventies and in the early eighties some studies appeared which investigated these welfare effects of public price predictions by a calculation of changes in consumer and producer surplus. ${ }^{1}$ In most of this literature the welfare effects of public predictions have been related to the welfare effects of price stabilisation. ${ }^{2}$ Studies about the welfare effects of price stabilisation ${ }^{3}$ were based on the comparison between a situation of no public intervention in which demand or supply fluctuate in time and a situation in which the government intervenes, e.g. by introducing a kind of buffer stock, in a way such that supply and demand equal the long term equilibrium situation. Analogously, the study of the welfare effect of a public prediction may be based on a comparison between a situation in which supply or demand differ from equilibrium due to prediction errors and a situation in which supply and demand are 'constant' because of the availability of the correct public forecast. Variation in time is replaced by probabilistic variation due to forecast errors.

In the theory of price stabilisation new elements, like rational expectations and futures markets, have come to the attention, ${ }^{4}$ which pushed away the theory based on surplus calculations. However, for a study about the value of information of public labour market information the surplus model is still useful. Firstly, as shown in chapter 7 and 9 , it doed not seem reasonable to presume rational expectations in this context, since the reason for interest in public predictions is the notion that students are not able to form predictions that are sufficiently accurate. Students are no professionals in investment decisions. Secondly, on the labour market there is no such thing as a futures market. ${ }^{5}$ Although labour is also not storable, and thus the stabilisation model makes no sense on its own in the context of educational choices, the link between the value of public predictions and stabilisation policy remains (conceptually) valuable.

The aim of this chapter is to reconstruct the literature concerning the value of public predictions, with a special focus on the labour market. The existing literature on this subject is incomplete and contains some errors, so a reconstruction of the ideas and a recalculation of the

I See e.g. Freebairn (1976), Turnovsky (1978), Freebairn and Withers (1979), and Antonovitz and Roe (1986).

2 See e.g. Smyth (1973), Turnovsky (1974), and Devletoglou (1961).

3 See e.g. Waugh (1944), Oi (1961), Massel (1969), and Turnovsky (1978).

4 See e.g. Turnovsky (1979), Campbell and Turnovsky (1985), and Weller and Yano (1987).

5 Institutions like the internal labour market have a similar function, but they are not relevant for full-time students. 
formulas might remove several misunderstandings. Based on the model of chapter 3, the welfare costs are calculated, compared to a situation in which government completely stabilises wages and provides exact forecasts. The possibility for government to provide perfect information, is left out of the discussion. The equilibrium only serves as a hypothetical bench mark.

\subsection{Stabilisation}

The question whether government should stabilise prices has been a point of contention for a long time. Advocates of stabilisation policy stressed the fact that the market should be transparent in order to make optimal allocation decisions possible. Prices that vary too much will make many economic consequences very uncertain, and will cause people to make the wrong decisions. Opponents stressed the importance of free markets without any governmental intervention in order to get an optimal allocation process. In 1944 Waugh wrote a remarkable article in which he showed that consumers gained more from instable prices than from stable prices. In 1961 Oi demonstrated that producers gain from fluctuations in demand, and thus from price instability. Since high prices and high demand coincide, producers will gain more from a rise in prices than they lose in a situation of low demand and low prices.

A naive combination of Waugh's and Oi's results would lead to the conclusion that both consumers and producers gain from price instability. The incorrectness of this conclusion has been shown by Massel (1969). Waugh and Oi do not take into account the same type of price instability. While Waugh's price instability is caused by a changing supply function, Oi's instability is caused by changes in the demand function.

Massel takes into account both types of instability. Written in accordance with the basic model of chapter 3, this basic model of a partial equilibrium consists of the following equations:

(14.1) $S=C_{S}+X_{S}+\beta_{s} w$

(14.2) $D=C_{D}+X_{D}+\beta_{D} w$

(14.3) $S=D$

in which $\beta_{S} \geq 0, \beta_{D}<0$

Equation (14.1) is the supply function, which relates the supply of a certain type of labour $(S)$ to the wage $(w) . X_{S}$ is a random variable with expectation 0 and variance $\sigma_{s}^{2}$, which denotes the changes in the underlying utility functions that cause changes in the supply. Shifts in 
the supply function are only allowed to be parallel. It is also possible to allow for changes in the slope of the curve, but Massel $(1969)^{6}$ shows that this does not lead to qualitative different conclusions, while it does lead to more complex calculations. Equation (14.2) is the demandfunction for labour $(D)$. It also contains a random part, $X_{D}$, with expectation 0 and variance $\sigma_{D}^{2}$, which represents changes in the profit function, caused by, e.g., changes in prices on other markets or by technological innovation. The linearity of the supply and demand function reflects an implicit assumption about the distribution of preferences and production functions. This linearity is used to get analytical results. In comparison with the model of chapter 3 , in this model supply and demand are 'solved' simultaneously, without the timelag for supply, and the model contains the random components $X_{S}$ and $X_{D} . X_{S}$ and $X_{D}$ are assumed to be independent.

Solving the model gives an equilibrium wage and an equilibrium amount of labour:

$$
w^{e q}=\frac{C_{D}+X_{D}-C_{S}-X_{S}}{\beta_{S}-\beta_{D}}
$$

$$
S^{e q}=D^{e q}=\frac{\beta_{S}}{\beta_{S}-\beta_{D}}\left(C_{D}+X_{D}\right)+\frac{-\beta_{D}}{\beta_{S}-\beta_{D}}\left(C_{S}+X_{S}\right)
$$

and a random shift affects, compared to the situation in which $X_{S}=X_{D}=0$, the equilibrium wage and equilibrium amount of labour as:
(14.6) $\Delta w^{e q}=\frac{1}{\beta_{S}-\beta_{D}} X_{D}$
(14.7) $\Delta w^{e q}=\frac{-1}{\beta_{S}-\beta_{D}} X_{S}$
(14.8) $\Delta S^{e q}=\frac{\beta_{S}}{\beta_{S}-\beta_{D}} X_{D}$
(14.9) $\Delta S^{e q}=\frac{-\beta_{D}}{\beta_{S}-\beta_{D}} X_{S}$

Figure 14.1 shows the partial welfare effects of a shift in the demand function, using the surplus values as a measure of the welfare effect. Government may, by some imaginary kind of buffer stock policy

6 Massel (1969), note nr. 9. Newbery and Stiglitz (1981) dispute Massel's arguments. Nonlinearities and risk aversion might indeed influence the average wage or average utility, but this effect, which does not occur in the linear case, has nothing to do with the stabilisation and information issue that is the subject of this chapter. These effects of nonlinearities affect all suppliers and dernanders on a market, not only the 'marginal' who doubt whether they should enter or not. It is therefore more appropriate to separate these income-effects from the concept "value of information". 
(imaginary, because labour can not be stored) keep the wages equal to the normal level (i.e. the expected wage with $X_{S}=X_{D}=0$ ). If the wage is above the normal level, students will earn this higher wage, but also more students will enter. If the wage is below the normal level students will earn less, but also their number will decrease, making the loss in case of a price fall less than the gain of an equal price raise. Therefore the expected welfare effect of instability is positive. This difference in expected welfare, compared to the stabilised situation is called the welfare gain for students of demand instability:

$$
\text { (14.10) } \begin{aligned}
W_{S t}\left(0, \sigma_{D}^{2}\right) & =\int_{-\infty}^{\infty} \frac{1}{2} \Delta w^{e q}\left(S^{e q}+S^{e q}+\Delta S^{e q}\right) \mathrm{d} F_{D}\left(X_{D}\right) \\
& =\int_{-\infty}^{\infty}\left(\frac{1}{\beta_{S}-\beta_{D}} S^{e q} X_{D}+\frac{1}{2} \frac{\beta_{S}}{\left(\beta_{S}-\beta_{D}\right)^{2}} X_{D}^{2}\right) \mathrm{d} F_{D}\left(X_{D}\right) \\
& =\frac{1}{2} \frac{\beta_{S}}{\left(\beta_{S}-\beta_{D}\right)^{2}} a_{D}^{2}>0
\end{aligned}
$$

FIGURE 14.1: WELFARE EFFECTS DUE TO AN UPWARD (a) AND A DOWNWARD $(b)$ SHIFT IN DEMAND FOR STUDENTS?
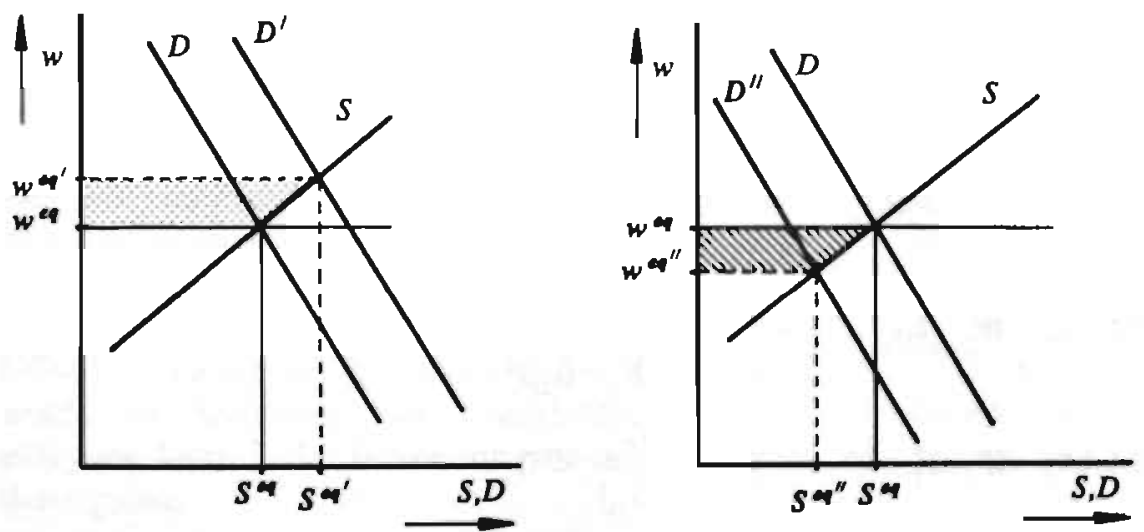

\section{Welfare gain Welfare loss}

The part of the equation in which $X_{D}$ appears in the first moment is equal to zero, because its expectation is equal to zero. This welfare gain 
is positive, so a public stabilisation will have the inverse, and therefore a negative effect on welfare. This is similar to the result of Oi (1961).

Similarly, the gains of an unstable supply function can be derived. Figure 14.2 illustrates this welfare effect. If the supply function moves to the right, students will, compared to the case in which the government keeps wages equal to the long-term equilibrium, lose a part of this equilibrium wage while many students enter the market. ${ }^{8}$ In the case of a shift to the left a small number of students gets a higher wage, so unstability makes students worse off:

$$
\text { (14.11) } \begin{aligned}
W_{S r}\left(\sigma_{S}^{2}, 0\right) & =\int_{-\infty}^{\infty} \frac{1}{2} \Delta w^{e q}\left(S^{e q}+\Delta S^{e q}+S^{e q}+X_{S}\right) \mathrm{d} F_{S}\left(X_{S}\right) \\
& =\int_{-\infty}^{\infty} \frac{1}{2} \frac{-1}{\beta_{S}-\beta_{D}}\left(2 S^{e q}+\left(\frac{-\beta_{D}}{\beta_{S}-\beta_{D}}+1\right) X_{S}\right) \mathrm{d} F_{S}\left(X_{S}\right) \\
& =\frac{1}{2} \frac{2 \beta_{D}-\beta_{S}}{\left(\beta_{S}-\beta_{D}\right)^{2}} \sigma_{S}^{2}<0
\end{aligned}
$$

In expectation the welfare gain from fluctuations in the supply function is negative.

Similar results can be derived for employers' welfare. Employers lose welfare due to shifts in the demand curve, but gain from shifts in the supply curve, which is the result of Waugh (1944). Adding up both sources of instability gives the total welfare costs of price instability:

$$
\begin{aligned}
& \text { (14.12) } W_{S t}\left(\sigma_{S}^{2}, \sigma_{D}^{2}\right)=\frac{\left(2 \beta_{D}-\beta_{S}\right) \sigma_{S}^{2}+\beta_{S} \sigma_{D}^{2}}{2\left(\beta_{S}-\beta_{D}\right)^{2}}<0 \\
& \text { (14.13) } W_{E m p}\left(\sigma_{S}^{2}, \sigma_{D}^{2}\right)=\frac{\left(\beta_{D}-2 \beta_{S}\right) \sigma_{D}^{2}-\beta_{D} \sigma_{S}^{2}}{2\left(\beta_{S}-\beta_{D}\right)^{2}}<0 \\
& \text { (14.14) } W_{T}\left(\sigma_{S}^{2}, \sigma_{D}^{2}\right)=-\frac{\sigma_{S}^{2}+\sigma_{D}^{2}}{2\left(\beta_{S}-\beta_{D}\right)}<0
\end{aligned}
$$

8 Note that in these calculations the welfare is compared to the situation in which students earn the average equilibrium wage, but in which their supply function remains constant, i.e. the welfare in the case of e.g. supply function $S^{\prime}$ and wage $w^{\prime q^{\prime}}$ is compared to the case of supply function $S^{\prime}$ and wage $w^{e t}$ ! The buffer policy only affects the earnings and not the preferences which determine the supply curve.

9 Massel (1969), p. 292. 
(14.15) $\sigma_{w}^{2}\left(\sigma_{S}^{2}, \sigma_{D}^{2}\right)=\frac{\sigma_{S}^{2}+\sigma_{D}^{2}}{\left(\beta_{S}-\beta_{D}\right)^{2}}$

FIGURE 14.2: WELFARE EFFECTS DUE TO AN UPWARD (a) AND A DOWNWARD (b) SHIFT IN SUPPLY FOR. STUDENTS. ${ }^{10}$

a

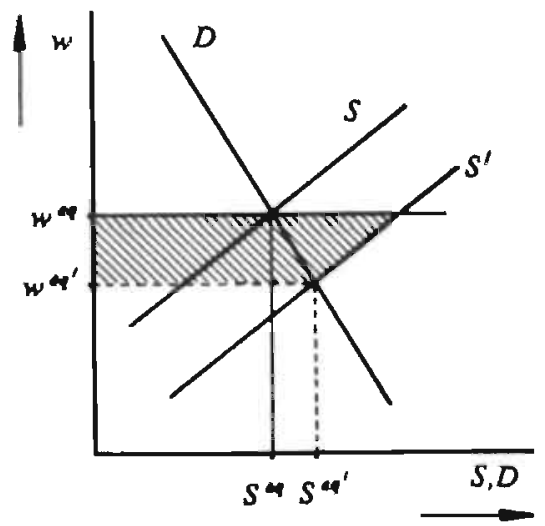

$b$

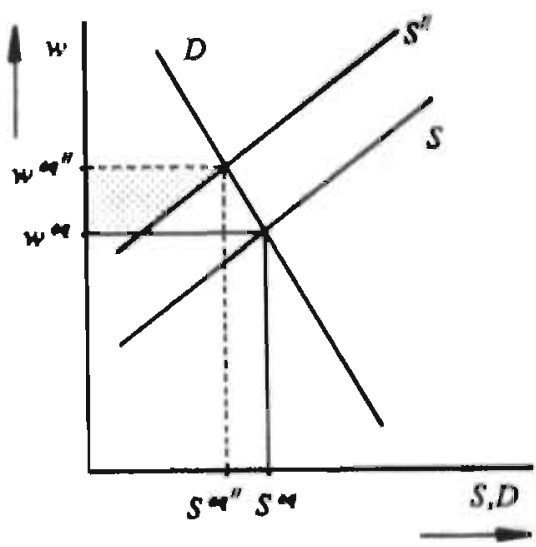

Welfare gain

Welfare loss

Equation (14.15) gives the wage variance that is related to the two sources of instability. While the welfare gains for students and employers may be both positive or negative, depending on the ratio of the two sources of instability and the parameters of the supply and demand function, in total (equation (14.14)) there is always a welfare loss due to instability. This completely agrees with Samuelson's (1972) intuition who, without giving proper arguments, criticises Waugh (1944), because of the impossibility of a Santa Claus. If instability would be desirable, extra instability could be introduced, making everyone better off. Samuelson stresses that somebody has to pay for these gains.

This theory of the welfare effects of price stabilisation has not been without critique. One of the main points against the theory is that if the government is able to keep a buffer in order to stabilise the market, entrepreneurs also are able to do so. Buffering, in fact is a technology which makes it possible to transform a product in a certain year into the 
same product in another year. Since this transformation is profitable, there is no need for the government to do so. The market system will, by arbitrage, stabilise the market itself. If, on the other hand, it is not possible to keep goods in buffer, as is the case with labour, this is impossible for the government. Keeping wages constant becomes a difficult and costly affair, of which the costs are not taken into account in the model.

A second objection against the model is that it does not incorporate one of the essential aspects which makes stabilising important. Stabilisation has been seen as desirable, because it makes the market more transparent. A stable price makes it more easy for people to predict the prices, which enables them to allocate more accurately. This, in fact, is an informational aspect, which does not appear in the model. The model contains no predictions.

In accordance with these two points of critique the theory of price stability has been extended with the study of futures markets. ${ }^{11}$ At futures markets the relation between the price of a certain product in different years is explicitly taken into account, and futures prices can be seen as mechanisms to optimise the accuracy of price predictions. For the study of the value of public information with regard to the relation between educational choice and the labour market, the simple welfare model has, however, not lost its appeal. Although labour is nonstorable, government may try to stabilise wages by the provision of wage forecasts. On the labour market there is no such a thing as a futures market, by which the need for information can be fulfilled.

Several studies have shown the link between public price stabilisation and public price forecasts. Unfortunately, they contain some errors, are incomplete or have not been expressed clearly. In next two sections the welfare effects of public forecasts are reexamined.

\subsection{The Value of Predictions: Stabilisation and Allocation}

Price instability in the last section is caused by stochastic changes in the supply and demand function. Another cause of price instability is the existence of forecast errors. In chapter 7 the stochastic character of prediction errors has been investigated. In this section the labour market model of chapter 3 is interpreted within the stabilisation framework. Similar models can be found in Freebairn (1976), Turnovsky (1978) and Freebairn and Withers (1979). 
Prediction errors can be compared to the equilibrium wage, i.e. the wage that would prevail if no information problem occurred (if prediction is equal to realisation), or to the realised wage. Here the first approach is chosen.

Figure 14.3 shows what happens in case of a prediction error. In figure $14.3 a$ the predicted wage is too high. Therefore, too many students choose this particular course and after several years too many students will enter this segment of the labour market. Since at this moment students can not switch anymore, the short term supply function $\left(S_{1}\right)$ is completely inelastic. The counterpart is illustrated in figure 14.3b. The prediction is too low, therefore too few students decide to enter, so the short term supply function shifts to the left.

FIGURE 14.3: WELFARE EFFECTS FOR STUDENTS IN CASE OF AN OVERPREDICTION (a) AND UNDERPREDICTION $(b)$.

$a$

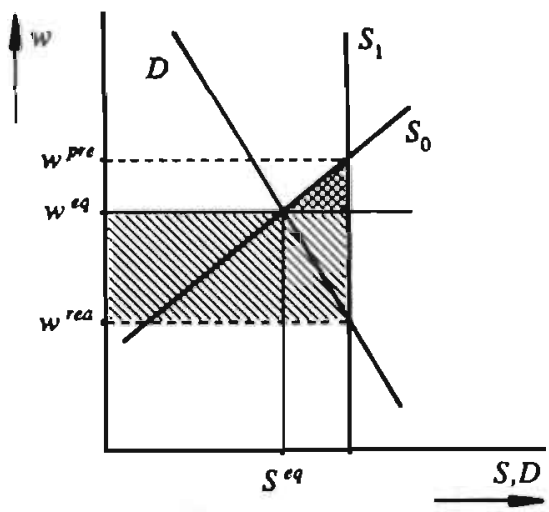

$b$

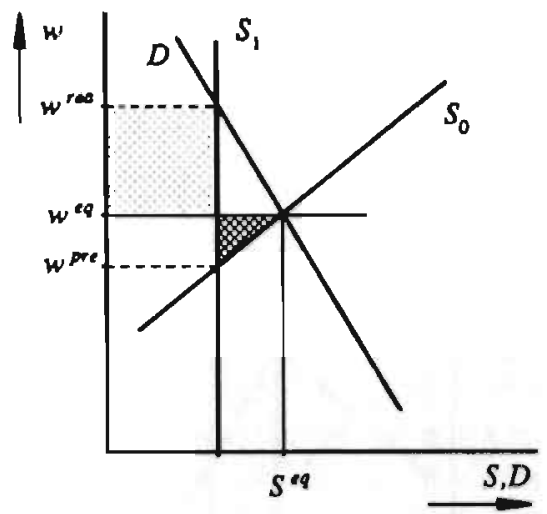

Welfare gain due to instability

Welfare loss due to instability

Welfare loss due to allocation problems

Due to the prediction error the short term supply function fluctuates around the equilibrium, analogous to the stability problem in the previous section. There is, however, a difference between the stability problem and the prediction error problem. In case of over-prediction, some students enter the market who would not even have entered if they had known they would receive the equilibrium wage. These students do not only lose money because the wage decreased, but also because their reservation wage is above the equilibrium wage. In case of underprediction, some students do not enter who would have entered if they had known the equilibrium wage. These cases are indicated in the figure 
with a checked triangle. If the prediction error disappears, not only the wage becomes equal to the equilibrium wage, but also some students will make a better match which induces an extra gain besides the stabilisation gain. Better predictions will thus provide welfare gains to students, due to stabilisation effects and due to allocation effects. Using the assumption that the prediction error $\Delta w$ has a zero expectation and variance $\sigma_{\text {pre }}^{2}$, the allocation welfare effect of forecast errors can be calculated as:

$$
\begin{aligned}
W_{S t}^{\text {all }}\left(\sigma_{\text {pre }}^{2}\right) & =\int_{-\infty}^{\infty}-\frac{1}{2} \Delta w^{p r e} \Delta S_{1}^{e q} \mathrm{~d} \Delta w \\
& =\int_{-\infty}^{\infty}-\frac{1}{2} \beta_{S} \Delta w^{p r e} \mathrm{~d}^{2} \Delta w \\
& =-\frac{1}{2} \beta_{S} \sigma_{\text {pre }}^{2}
\end{aligned}
$$

FIGURE 14.4: WELFARE EFFECTS FOR EMPLOYERS IN CASE OF AN OVERPREDICTION $(a)$ AND AN UNDER-PREDICTION $(b)$.

a

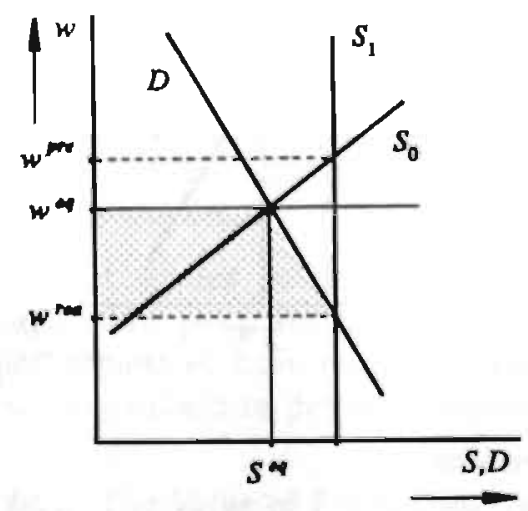

Welfare gain

Welfare loss $b$

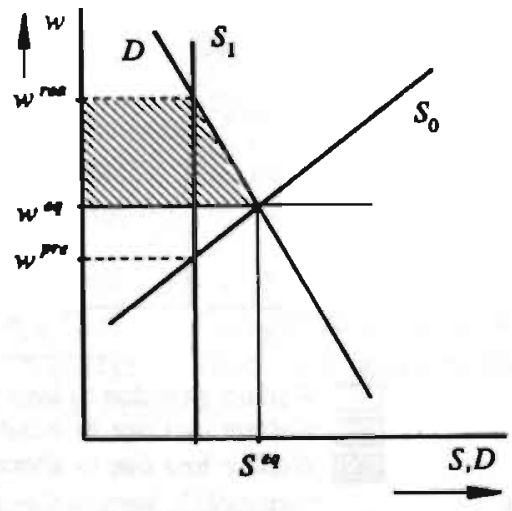

From the employers' point of view this allocation argument plays no role (figure 14.4). To them it does not matter whether a student enters the market mistakenly or not. Furthermore, in the model employers do not face any forecast problem. They can immediately adjust their demand to the situation without any costs. So, from the employers' point of view the situation is exactly the same as in the case of unstable 
supply and demand functions:

(14.17) $W_{\text {Emp }}^{\text {all }}\left(\sigma_{\text {pre }}^{2}\right)=0$

\subsection{Information versus Interpretation Forecast Errors}

In the previous section it has been shown that the welfare effect of a forecast error can be split up into the welfare effect of stabilisation and the allocation welfare effect. The allocation weifare effect has been calculated, but the precise relation between the prediction error problem and stabilisation problem has been omitted. In this section this stabilisation effect is fitted into the model of section 14.1. The nature of the prediction error determines the exact relation between the prediction error effect and the stabilisation welfare effect.

By incorporating stochastic elements in the model of chapter 3, the prediction error problem can be modelled as:

$$
S_{0}=C_{s}+X_{s}+\beta_{s} w_{0}^{\text {pre }}
$$

(14.19) $S_{1}=S_{0}$

(14.20) $D=C_{D}+X_{D}+\beta_{D} w^{\text {rea }}$

(14.21) $S_{1}=D$

The supply function is split up into a long term supply function (14.18), similar to (14.1), except for the fact that it depends on expected wage rather than the wage itself. The subscript 0 indicates the fact that the prediction has to be made before the market is cleared. (14.19) is the short term supply function, which is actual at the moment of marketclearance (moment 1). Short term supply is completely fixed. Students made their choice some years in advance and do not have the possibility to change to another market segment in the short term. Because the prediction error problem focuses on information problems, $X_{S}$ and $\boldsymbol{X}_{D}$ have a slightly different interpretation. In chapter 7 it is shown that if agents have non-rational expectations their prediction error can be divided into two parts. The first part of the prediction error, the information error, is caused by the fact that students do not use all relevant information. This may be the case because they do not possess this information (which is the case in rational expectations) or because they do not use it. The second part of the prediction error, the interpretation error, consists of the errors made in the processing of the information which is used. 
$X_{S}$ and $X_{D}$ represent the shifts in the supply function and the demand function which were not. predicted by students, i.e. they represent the information errors. Due to the well-known rational expectations argument they have a zero expectation. If expectations are non-rational students will also make an interpretation prediction error $\boldsymbol{e}$, with variance $\sigma_{e}^{2}$. This error can be interpreted as caused by incomplete insight in the functioning of the market. The labour market is very complex, and it is very likely students do not know 'the true model'. Therefore they will make interpretation errors. ${ }^{12}$

In the model of chapter 7 students have a whole range of expectations at their disposal, ranging from abstract, with a large information error and a small interpretation error, to very specific, with a small information error, but a large interpretation error. Out of this range of possible expectations students choose the optimal prediction. In this chapter this choice is considered as given and therefore only one prediction ( $\left.w^{\text {pre }}\right)$, i.e. the optimal prediction is regarded. In section 14.5 it is investigated how the welfare effects relate to possible changes in the optimal combination of an abstract and a specific expectation.

The hypothetical rational expectation is the expectation in which no interpretation errors are made, but in which the values $X_{S}$ and $X_{D}$ are unknown. Formula (14.22) and (14.23) give the supply and demand function determining the rational expectation wage:

(14.22) $S=C_{S}+\beta_{S} w_{0}^{r e}$
(14.23) $D=C_{D}+\beta_{D} w_{0}^{r e}$

The predicted wage equals this rational expectation plus the interpretation error:

$$
w^{\text {pre }}=\frac{C_{D}-C_{S}}{\beta_{S}-\beta_{D}}+\epsilon=w_{0}^{r e}+\epsilon=w^{e q}-\frac{X_{D}-X_{S}}{\beta_{S}-\beta_{D}}+\epsilon
$$

The predicted wage equals the equilibrium wage minus the unpredictable part $\left(X_{D}-X_{S}\right) /\left(\beta_{S}-\beta_{D}\right)$, together forming the rational

12 Most literature on this subject (e.g. Freebairn (1976), Turnovsky (1978), and Freebairn and Withers (1979)) only recognises this interpretation error and does not include the rational expectations type of prediction error. These two types of prediction error will, however lead to completely different results.

Antonovitz and Roe (1986) use the rational expectations error, but they only take total welfare into account and only provide empirical and no analytical results. 
expectations prediction $\left(w_{0}^{\text {re }}\right)$ plus the interpretation error $\epsilon$.

If students use the wrong prediction of (14.24) the supply and demand change into:

$$
\begin{aligned}
S_{1} & =C_{S}+X_{S}+\beta_{s} w_{0}^{\text {pre }} \\
& =C_{S}+X_{S}+\beta_{s}\left(w_{0}^{r e}+\epsilon\right) \\
& =C_{S}+X_{S}+\beta_{s} \varepsilon+\beta_{s} w_{0}^{r e}
\end{aligned}
$$

(14.26) $D=C_{D}+X_{D}+\beta_{D} w^{\text {rea }}$

In formula (14.25) $S_{1}$ is completely fixed, i.e. it does not depend on the wage $\left(w^{\text {rea }}\right)$.

The supply and demand curve as a function of the rational expectation prediction, makes clear that the prediction error model is, except for the allocation effect, a variant of the stability model of section 14.1 with:

$$
\begin{array}{ll}
\text { (14.27) } X_{S}^{\text {pre }}=X_{S}+\beta_{S} \epsilon & \text { with } \sigma_{S^{\text {ree }}}^{2}=\sigma_{S}^{2}+\beta_{S}^{2} \sigma_{e}^{2} \\
\text { (14.28) } X_{D}^{\text {pre }}=X_{D} & \text { with } \sigma_{D^{m e r}}^{2}=\sigma_{D}^{2}
\end{array}
$$

Three sources of prediction errors can be distinguished. Miscalculations of the expected (ex ante) equilibrium wage (type I) and unpredictable changes in the supply curve (type II) cause the welfare effects comparable to the stabilisation effects caused by a shift in the supply curve, while unpredictable changes in the demand curve cause effects similar to welfare effects of fluctuations in the demand curve (type III errors). Thus, type I errors consist of errors in interpretation, while type II errors consist of information errors with regard to the supply of labour (e.g. unexpected changes in students preferences), and type III errors refer to information errors with regard to demand (e.g. unknown changes in technology, new investments etc.).

It is more convenient to interpret prediction errors due to differences in the quantity as caused by predictions errors due to differences in the wage. Formulas (14.29), (14.30), and (14.31) relate the variance of supply or demand to the three types of prediction errors with respect to wage.
(14.29) $\sigma_{s_{I}}^{2}=\beta_{s}^{2} \sigma_{I}^{2}$
(14.30) $\sigma_{s_{I I}}^{2}=\left(\beta_{s}-\beta_{D}\right)^{2} \sigma_{I I}^{2}$
(14.31) $\sigma_{D_{m}}^{2}=\left(\beta_{S}-\beta_{D}\right)^{2} \sigma_{I I I}^{2}$ 
The reformulation of the prediction error problem into the stabilisation problem of section 14.1 makes it possible to use formulas (14.12)-(14.14) on the welfare effect of price stabilisation. In the case of interpretation errors (type I) this is straightforward. Table 14.1 presents the welfare costs of these interpretation errors.

TABLE 14.1: WelFARE EFFECTS OF TYPE I ERRORS: ${ }^{13}$ INTERPRETATION FORECAST ERRORS.

\begin{tabular}{l|ccc}
\hline & Stabilisation & Allocation & Sign \\
\hline Students & $-\frac{\beta_{S}^{2}}{-\beta_{D}} \sigma_{I}^{2}$ & $-\frac{1}{2} \beta_{S} \sigma_{I}^{2}$ & $<0$ \\
Employers & $+\frac{1}{2} \frac{\beta_{S}^{2}}{-\beta_{D}} \sigma_{I}^{2}$ & 0 & $>0$ \\
Total & $-\frac{1}{2} \frac{\beta_{S}^{2}}{-\beta_{D}} \sigma_{I}^{2}$ & $-\frac{1}{2} \beta_{S} \sigma_{I}^{2}$ & $<0$ \\
\hline
\end{tabular}

The prediction errors of type II and III are caused by unpredicted shifts in the supply or demand curve. As shown in section 14.1 shifts in the supply and demand curve cause, however, welfare effects even if they are perfectly predicted. To get a proper valuation of the prediction error a correction has to be made. Therefore, the welfare costs in the case $X_{S}$ or $X_{D}$ were known in advance $\left(W_{S t}^{0}\right.$ ) due to the shift of the supply or demand curve, are subtracted from the total welfare costs $\left(W_{S t}^{1}\right)$. This results in the stabilisation and the allocation component of the welfare effect of the prediction error:

(14.32) $W_{s t}^{1}-W_{S t}^{0}=W_{S t}^{s t a b}+W_{S t}^{\text {all }}$

Therefore the stabilisation effect e.g. for students of type II error equals:

13 Although they explicitly refer to stabilisation theory, Freebairn and Withers (1979) mistakenly assume the redistribution effects of stabilisation to be zero. Therefore their calculations are incorrect. In their formulas the welfare effect of prediction errors for employers is negative instead of positive, and these costs even exceed those for students. 


$$
\text { (14.33) } \begin{aligned}
W_{S t}^{\text {stab }} & =W_{S t}^{1}-W_{S t}^{0}-W_{S t}^{\text {all }} \\
& =\frac{2 \beta_{D}-0}{2\left(0-\beta_{D}\right)^{2}} \sigma_{S_{u}}^{2}-\frac{2 \beta_{D}-\beta_{S}}{2\left(\beta_{S}-\beta_{D}\right)^{2}} \sigma_{S_{u}}^{2}-\left(-\frac{1}{2} \beta_{S}\right) \sigma_{S_{u}}^{2} \\
& =-\frac{\left(\beta_{S}-\beta_{D}\right)^{2}}{-\beta_{D}} \sigma_{S_{u}}^{2}-\left(\beta_{D}-\frac{1}{2} \beta_{S}\right) \sigma_{S_{u}}^{2}-\left(-\frac{1}{2} \beta_{S}\right) \sigma_{S_{u}}^{2} \\
& =\left(-\frac{\beta_{S}^{2}}{-\beta_{D}}-\beta_{S}\right) \sigma_{S_{u l}}^{2}
\end{aligned}
$$

TABLE 14.2: WELFARE EFFECTS OF TYPE II ERRORS: INFORMATION FORECAST ERRORS WITH RESPECT TO SUPPLY.

\begin{tabular}{l|ccc}
\hline \hline & Stabilisation & Allocation & Sign \\
\hline Students & $\left(-\frac{\beta_{S}^{2}}{-\beta_{D}}-\beta_{s}\right) \sigma_{I I}^{2}$ & $-\frac{1}{2} \beta_{s} \sigma_{I I}^{2}$ & $<0$ \\
Employers & $\left(\frac{1}{2} \frac{\beta_{S}^{2}}{-\beta_{D}}+\beta_{s}\right) \sigma_{I I}^{2}$ & 0 & $>0$ \\
Total & $-\frac{1}{2} \frac{\beta_{S}^{2}}{-\beta_{D}} \sigma_{I I}^{2}$ & $-\frac{1}{2} \beta_{s} \sigma_{I I}^{2}$ & $<0$ \\
\hline
\end{tabular}

The welfare costs in the case of perfect foresight $\left(w_{S I}^{0}\right)$ are calculated by use of (14.12). For the welfare costs with anticipating supply decisions and therefore prediction errors $\left(w_{S t}^{1}\right)$, the same formula is used with the short term supply parameter $\beta_{s}=0 . \quad \sigma_{S_{u}}^{2}$ is converted into $\sigma_{n}^{2}$ by (14.30): $\sigma_{s_{n}}^{2}=\left(\beta_{s}-\beta_{D}\right)^{2} \sigma_{n}^{2}$. Similar calculations give the stabilisation components for employers and for errors of type III. Table 14.2 and 14.3 present the welfare costs of prediction errors of the information error types II and III.

The three sources of prediction errors do have the same consequences for the total welfare, but have completely different consequences for the distribution among students and employers of this welfare. Type I error in which a students' prediction error is caused by a miscalculation or misinterpretation, gives rise to a large welfare loss for the student (due to both stabilisation and allocation effects), but is a gain for the 
employer, since destabilisation of the supply side is advantageous at the demand side.

TABLE 14.3: WELFARE EFFECTS OF TYPE III ERRORS: INFORMATION FORECAST ERRORS WITH RESPECT TO DEMAND.

\begin{tabular}{l|ccc}
\hline & Stabilisation & Allocation & Sign \\
\hline Students & 0 & $-\frac{1}{2} \beta_{s} \sigma_{I I}^{2}$ & $<0$ \\
Employers & $-\frac{1}{2} \frac{\beta_{s}^{2}}{-\beta_{D}} \sigma_{I I}^{2}$ & 0 & $<0$ \\
& $-\frac{1}{2} \frac{\beta_{s}^{2}}{-\beta_{D}} \sigma_{I I}^{2}$ & $-\frac{1}{2} \beta_{s} \sigma_{I I}^{2}$ & $<0$ \\
Total & & & \\
\hline
\end{tabular}

Type III error, which is the information error, caused by insufficient data about the demand side, for students only leads to allocation welfare losses, but leads to stabilisation costs for the employer. Students do not have advantage in this case, like employers in the type I case, because their short run supply elasticity equals zero. They are not able to react to changes in the demand function ex post.

Type I errors make students react more than optimal to labour market changes, while in the case they do not have or use enough information (type III) their reactions are damped. Changes in the labour market situation are not noticed and therefore do not influence the behaviour. Crucial for the distribution of the welfare effect is the correlation between students' supply decision and the wage. For type III there is no correlation since the supply decision is fixed, while the wages vary. For type I errors there is some correlation, since wages fall as supply rises. For type II errors, which is an information error with respect to supply, the distribution effect is very unfavourable for students. In this case the correlation between supply and wage is very high. Wages will fall due to both the fact that supply itself rises and due to the fact that this fall is not anticipated.

These results would imply that there is a great difference between welfare effects due to an interpretation error, compared to the effects of an information error. Employers as a group have an interest in a reduction of the information error of the future labour market situation with respect to demand, but have an opposite interest with respect to the 
interpretation error. Students, on the other hand have an interest in both types of information in order to gain from the allocation effect but for the stabilisation effect they only have an interest in a reduction of the interpretation error and in information about changes of the supply curve. Information and interpretation, however, are related according to chapter 7. In section 14.5 it was shown that the provision of public labour market information has a rather complex influence upon the welfare. The provision of information can be interpreted, according to section 9.7 , as a decrease of $\mathrm{o}_{\text {exp }}^{2}$. Such a decrease of $\mathrm{o}_{\text {exp }}^{2}$, however, not only affects the total prediction error, but also a shift from information to interpretation errors may be introduced. Since interpretation errors have worse welfare effects for students than information errors, this leads to a complicated relation between students' welfare and the provision of information.

\subsection{Two Empirical Examples}

In the previous section formulas were derived that express the welfare cost of prediction errors. Reversely, these costs express possible gains from public forecasts. If government provides a public forecast that reduces the prediction error of the students, there is a gain equal to the difference between the cost with public forecast and without public forecast. If the forecast is perfect this gain is equal to minus the welfare effect in the situation without public forecast. Several welfare effects are distinguished. A distinction can be made between interpretation forecast errors (type I), information forecasts errors with respect to the supply side (type II), and information forecast errors with respect to the demand side (type III). Furthermore, the costs are split into stabilisation effect and allocation effect and into students' part and employers' part.

In order to get an impression of the extent of the forecast error problem and the relative importance of the distinguished parts, two empirical examples are presented in this section. Freebairn and Withers (1979) have used two studies of Freeman to calculate the welfare costs of prediction errors. They have used data and econometric results from Freeman (1975) about the market for US lawyers and Freeman (1971) about the market for US engineers. Because the calculations of Freebairn and Withers have a more restricted scope and contain some 
errors, ${ }^{14}$ their figures have been recalculated with the formulas of section 14.3.

Freeman's estimations of supply and demand functions are based on the cobweb model. In this model it is assumed that students expect that future wages will be equal to the present wages.

Based on the cobweb assumption Freeman is able to estimate the demand and supply parameters and the variance of the wage forecast error (table 14.4a). These figures can be used to calculate the welfare effects of these prediction errors. Although the estimated figures in fact represent a specific type of error, it is interesting, for reason of comparison, to calculate the welfare effects for all types of forecast errors of the same extent. These results are presented in table 14.4b- $d$.

It should be stressed that these empirical results have to be interpreted with care. Their construction is based upon strong assumptions about the way students form their expectations. Especially the variance of the prediction error may be influenced by this assumption. Therefore, the relative magnitude of the several effects is more important than their absolute values. As shown in table 4.6 estimates of the elasticity of demand vary quite largely. Freeman's estimates are very large, and therefore allocation effects are in his analysis more important than stabilisation effects. In a market in which demand does not so easily adjust itself to changes in supply, these stabilisation costs will be much larger.

Freebairn and Withers calculate their welfare measure for a great deal of hypothetical situations with respect to interest rate, experience premium salary growth rate and distinguish a non-substitution and a substitution case. The welfare effects of these different variants all provide the same picture about the welfare effects of prediction errors. Their differences can completely be explained by the different assumptions. ${ }^{15}$ For that reason in table 14.4 only one case is reported. It gives the welfare effects for engineers and lawyers, with respect to their salaries of the first 10 years after graduation, under the assumption

14 Firsily, they only take type ! errors into account. Secondly, as indicated in note nr. 13, their formula about the distribution of welfare between students and employers is incorrect. These implausible results are masked, because the columns representing employers and students" welfare have been exchanged.

15 Except for the difference between substitution and non-substitution. Freebairn and Withers report higher welfare losses in the substitution case, while intuition would predict a reverse result. 
that graduates are no substitutes for experienced workers, an interest rate of 0 , no experience premium.

TABLE 14.4: TWO EMPIRICAL EXAMPLES (WELFARE EFFECTS IN DOLLARS 1967 PER PERSON).

\begin{tabular}{l|c|c}
\hline \hline$a$ parameters & engineers & lawyers \\
\hline$\beta_{S} \frac{\text { income }}{\mathrm{N}}$ & 3.00 & 2.25 \\
$\beta_{D} \frac{\text { income }}{\mathrm{N}}$ & -10.00 & -10.00 \\
income (10 years) & $\$ 69,795$ & \\
$\frac{\sigma_{\mathrm{w}}^{2}}{\text { income }}$ & 1338 & $\$ 64,709$ \\
\hline
\end{tabular}

\begin{tabular}{l|rrr|rrr}
\hline \hline$b$ & \multicolumn{3}{|c|}{ engineers } & \multicolumn{3}{c}{ lawyers } \\
type I error & stab & alloc & total & stab & alloc & total \\
\hline Students & -1204 & -2007 & -3211 & -408 & -907 & -1315 \\
Employers & +602 & 0 & +602 & +204 & 0 & +204 \\
Total & -602 & -2007 & -2609 & -204 & -907 & -1111 \\
\hline
\end{tabular}

\begin{tabular}{l|rrr|rrr}
\hline \hline$c$ & \multicolumn{3}{|c|}{ engineers } & \multicolumn{3}{c}{ lawyers } \\
type II error & stab & alloc & total & stab & alloc & total \\
\hline Students & -5218 & -2007 & -7225 & -2222 & -907 & -3129 \\
Employers & +4616 & 0 & +4616 & +2018 & 0 & +2018 \\
Total & -602 & -2007 & -2609 & -204 & -907 & -1111 \\
\hline
\end{tabular}

\begin{tabular}{l|rrr|rrr}
\hline \hline$d$ & \multicolumn{3}{|c|}{ engineers } & \multicolumn{3}{c}{ lawyers } \\
type III error & stab & alloc & total & stab & alloc & total \\
\hline Students & 0 & -2007 & -2007 & 0 & -907 & -907 \\
Employers & -602 & 0 & -602 & -204 & 0 & -204 \\
Total & -602 & -2007 & -2609 & -204 & -907 & -1111 \\
\hline
\end{tabular}


In case of a type I error (interpretation error) roughly $66 \%$ of students costs are due to allocation effects. Employers have a small gain in case of this type of forecast error. In case of a type II error (an information error due to changing supply), this gain increases enormously, while students face very large costs. For engineers these costs are more than $10 \%$ of their income, while for lawyers these costs are almost $5 \%$. In case of type III errors (an information error due to changing demand) students do not face stabilisation costs and the gain for employers turns into a loss. Allocation effects are the same for all types of errors.

\subsection{The Provision of Information}

As stated in section 9.7 the prediction used by students can be interpreted as an optimal trade off between a specific forecast which contains an interpretation error $\left(\sigma_{\text {exp }}^{2}\right)$, and an abstract forecast containing an information error $\left(\sigma_{\text {var }}^{2}\right)$. If it is - due to the complexity of the labour market - difficult to make an adequate forecast, the optimal mix is close to the abstract forecast. The provision of public labour market information can be interpreted as an improved predictability, i.e. a decrease of $a_{\text {exp }}^{2}$. If the quality of the specific expectation changes, the optimal mix between the two also changes. Therefore, a decrease of $o_{\exp }^{2}$ leads to both a change in the unsystematic (interpretation) error, and to a change in the systematic (information) error. These effects are provided by (9.23)-(9.25). The systematic error always decreases due to the provision of information, but the unsystematic error also may increase.

Information errors are, depending on the source of uncertainty, errors of type II or III, while the interpretation error corresponds to an error of type I. If public forecasts improve students' predictions a substitution may occur from information to interpretation errors and therefore from type II or III errors to type I errors.

Since the weifare effects of both types of errors are not equal, regarding its distributional properties, this has implications for the value of information for the two groups distinguished: students and employers. In this section the results of section 9.7 about the effects of the provision of information are related to the welfare calculations of this chapter. Assuming that uncertainty is caused by changes in the demand for labour this relation leads to: 
(14.34)

$$
\begin{aligned}
& W_{S t}=\left(\frac{\sigma_{v a r}^{2}}{\sigma_{v a r}^{2}+\sigma_{\exp }^{2}}\right)^{2} \sigma_{\exp }^{2}\left(-\frac{\beta_{S}^{2}}{-\beta_{D}}\right)+\frac{\sigma_{\text {var }}^{2} \sigma_{\exp }^{2}}{\sigma_{v a r}^{2}+\sigma_{\exp }^{2}}\left(-\frac{1}{2} \beta_{S}\right) \\
& W_{E m p}=\left(\frac{\sigma_{\exp }^{2}}{\sigma_{v a r}^{2}+\sigma_{\exp }^{2}}\right)^{2} \sigma_{v a r}^{2} \frac{1}{2} \frac{\beta_{S}^{2}}{-\beta_{D}}+\left(\frac{\sigma_{v a r}^{2}}{\sigma_{v a r}^{2}+\sigma_{\exp }^{2}}\right)^{2} \sigma_{\exp }^{2}\left(-\frac{1}{2} \frac{\beta_{S}^{2}}{-\beta_{D}}\right) \\
& W_{T}=\frac{\sigma_{v a r}^{2} \sigma_{\exp }^{2}}{\sigma_{v a r}^{2}+\sigma_{\exp }^{2}}\left(-\frac{1}{2} \frac{\beta_{S}^{2}}{-\beta_{D}}-\frac{1}{2} \beta_{S}\right)
\end{aligned}
$$

For a fixed variability and fixed elasticities of supply and demand these formulas provide the relation between welfare and predictability. Figure 14.5 gives an example in which $\sigma_{\text {var }}^{2}=100, \beta_{S}=3$, and $\beta_{D}=-1$. The welfare of students, employers, and total welfare are at the vertical axis. At the horizontal axis is the predictability. An improvement of the predictability corresponds to a shift to the left of $\sigma_{\text {exp }}^{2}$. The figure has two remarkable aspects. Firstly, the welfare of students does not always increase if $\sigma_{\exp }^{2}$ decreases. For large values of the predictability (low values of $\mathrm{o}_{\text {exp }}^{2}$ ) the marginal effect of public labour market is, for the students, negative. Secondly, the welfare effect for employers becomes positive (compared to full information) for low values of $\sigma_{\text {exp }}^{2}$. Total welfare, however, always increases as $o_{\text {exp }}^{2}$ decreases.

If public predictions are provided (in the case in which uncertainty is due to changes in the demand) $\sigma_{\exp }^{2}$ decreases, which is advantageous for students. The improvement of the predictability, however, also causes a shift from a more abstract prediction to a more specific prediction. Therefore, information errors are partly replaced by interpretation errors. The welfare effect of these interpretation errors is, for students, worse than the welfare effect of information errors. This is so because in the case of information errors, students do not react to signals of the market. Their enrolment behaviour is therefore relatively stable. In the case of interpretation errors students do, however, react incorrectly to these signals. Therefore their enrolment behaviour becomes more fluctuative than the market conditions themselves. While for information errors the realisation moves around the prediction (states of the world uncertainty, section 7.2), for interpretation errors the prediction moves around the realisation (errors in forecasts, section 7.3). For interpretation errors a correlation exists between the number of students and the realised wage. If too many students enrol the wage will be low, while if too few enrol the wage will be above equilibrium. 
The gain of the small number does not compensate the loss of the large group. By becoming more responsive to future labour market situations, students as a group become more vulnerable to these problems. This is, however, only a matter of distribution. The total welfare always improves due to public information. The loss of students therefore is compensated by an extra gain for employers.

FIGURE 14.5: WELFARE EFFECT OF THE PROVISION OF LABOUR MARKET INFORMATION.

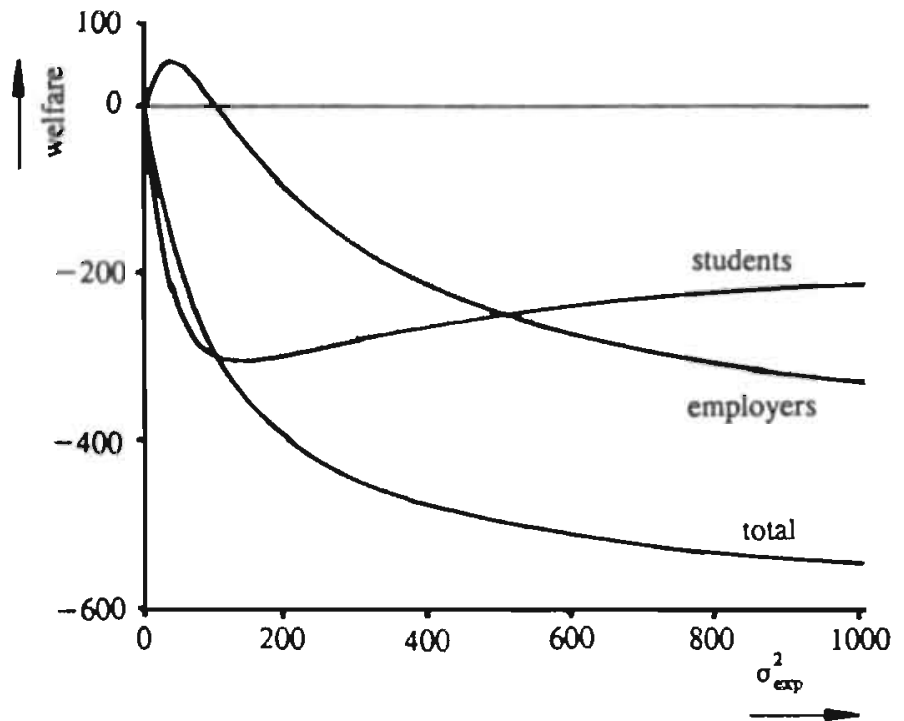

The problem of a negative marginal effect of the provision of information upon students" welfare only occurs under specific circumstances. The derivative of students' welfare with respect to $\sigma_{\text {exp }}^{2}$ must be positive for certain values of the predictability:

$$
(1-2 \lambda)(1-\lambda)^{2}\left(-\frac{\beta_{S}^{2}}{-\beta_{D}}\right)+(1-\lambda)^{2}\left(-\frac{1}{2} \beta_{S}\right)>0
$$

This leads to the condition 
(14.38) $\frac{\beta_{s}}{-\beta_{D}}>\frac{1}{2}$

If this condition is fulfilled the marginal value of public information is, for students, negative for large values of $\lambda$, or $\sigma_{\text {exp }}^{2}$. The minimum is reached if

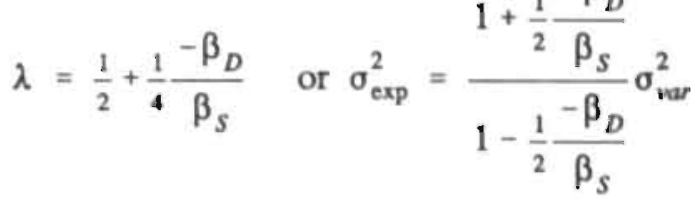

In the example in figure 14.5 this is the case if $\lambda=7 / 12$, and thus $\sigma_{\operatorname{axp}}^{2}=140$. The welfare of students exceeds the level of welfare in the case all errors are information errors $\left(\sigma_{\exp }^{2}=\infty\right.$ or $\left.\lambda=1\right)$ not until $\lambda=-\beta_{D} /\left(2 \beta_{s}\right)$. If uncertainty is caused by possible changes in supply this inversion problem does not occur since the welfare costs of information errors exceed the interpretation costs.

In table 4.6 , in which elasticities are reported of studies which estimate both a supply and a demand function, most results do not fulfil the condition $\beta_{S} /\left(-\beta_{D}\right)>1 / 2$. In these cases $\beta_{D}$ is largely negative, making impossible the inverse welfare effect for students. Hansen et al (1980) and Huffman and Orazem (1983), however, report very low elasticity values for $-\beta_{D}$. The first estimates of Huffman and Orazem (1985) imply $\beta_{S} /\left(-\beta_{D_{2}}\right)=0.66$. In this case the minimum welfare for students is reached if $\sigma_{\text {exp }}=7.19 \sigma_{v a r}^{2}$, while the welfare of students compared to a complete naive prediction $\left(\sigma_{\exp }^{2}=\infty\right)$ is better if $\sigma_{\exp }^{2}<3.10 \sigma_{\text {var }}^{2}$. The values of the predictability for which problems may occur are rather high, although in table 12.2 two of three estimates of the predictability exceed the $\lambda=-\beta_{D} /\left(2 \beta_{s}\right)=0.76$ at which the welfare for students equals the welfare of a completely naive prediction.

If students' prediction errors mainly consist of interpretation errors the welfare of employers may become positive, compared to the situation of full information. This is the case if $\lambda<1 / 2$, or $\sigma_{\text {exp }}^{2}=\sigma_{\text {var }}^{2}$. The maximum welfare is reached if $\lambda=1 / 4$, or $\sigma_{\text {exp }}^{2}=1 / 3 \sigma_{\text {var }}^{2}$.

It is difficult to see whether the negative effect on students' welfare due to the provision of information is a robust result, i.e. whether it still occurs if assumptions are slightly changed. As an example it shows, however, that the provision of labour market information may have 
negative welfare effects for a specific group. In total the provision of information is, however, always a gain.

\subsection{Conclusions}

In this chapter it is shown that the provision of public information has welfare effects which are comparable to the effects of price stabilisation. Besides these stabilisation effects, allocation effects have to be distinguished, because prediction errors not only cause changes in the wage, but also cause people to make educational choices which they regret.

The distribution of the welfare costs of prediction errors heavily depends on the type of prediction erior made by students. Interpretation errors are unfavourable to students compared to information errors with respect to changes in demand (while information errors with respect to changes in supply are the most unfavourable for them). In chapter 9 it was shown, however, that the provision of public labour market information causes a substitution from information errors to interpretation errors. It might therefore be the case - for certain values of the parameters of the model - that public information decreases students' welfare. Total welfare will, however, always improve. 


\section{THE CASE OF DISPERSED PREDICTIONS}

In chapter 14 the value of information was calculated based on a model in which students make their educational choice with forecasts which contain a certain prediction error. A simplification of this calculation, which is implicit in much literature on expectations, is the assumption that the predictions of the future labour market are equal for every student. This assumption is made by all similar studies about the value of public information. 'All these papers relate the problem of forecast errors to stabilisation theory. Their main argument is that if students decrease their prediction error by use of a public forecast, the supply of labour will become more stable and this leads to a welfare gain similar to gains from stabilisation in studies like Massel (1969). Due to this simplification there is no aggregation problem. Individual prediction errors can be directly related to phenomena at aggregate level such as the stability of the market. But more important, this assumption excludes a negative aspect of public forecasts. The prediction error of one individual student does not influence the market stability and an overprediction of some students may compensate for the underprediction of others. A prediction error in a public forecast is more dangerous. It influences everybody in the same direction and may therefore destabilise the market.

Under the assumption that students' predictions are dispersed a public forecast has an additional effect of reducing the dispersion. Students' predictions become more correlated and therefore may disturb the market equilibrium more easily. The purpose of this chapter is to calculate the effects of labour market information in a context of dispersed predictions.

\subsection{An Example with Dispersed Predictions}

Before starting the theoretical analysis of dispersed prediction in this section an extreme example is given about the consequences the introduction of dispersion might have. Consider the following special case of the labour market model of chapter 3 :

1 See e.g. Hayami and Peterson (1972). Freebairn (1976). Bradford and Kelejian (1977), Turnovsky (1978) and Antonovitz and Roe (1986) in another context, while Freebairn and Withers (1979) focuses on the value of public labour market information. 
(15.1) $S_{0}=w^{\text {pre }}$

(15.2) $S_{1}=S_{0}$

(15.3) $D=200-w^{\text {rea }}$

(15.4) $D=S_{1}$

In this example with $\beta_{S}=1, C_{S}=0, \beta_{D}=-1$, and $C_{D}=200$, the equilibrium wage equals 100 , and the equilibrium supply also equals 100 .

Now, suppose that the students are divided up randomly into two equally large groups I and II both forming their own prediction, with $w_{I}^{\text {pre }}=140$ and $w_{I I}^{\text {pre }}=60$. Since the probability to be in group I equals the probability to be in group II, the expected forecast error equals 0 , conform requirement (7.5). Table 15.1 shows that the oversupply of group I compensates the undersupply of group II. Therefore, total supply equals the equilibrium supply.

TABLE 15.1: SUPPLY WITHOUT AND WITH PUBLIC FORECAST.

\begin{tabular}{l|rr|cr|cr}
\hline & $w_{i}^{\text {exp }}$ & $\mathrm{S}$ & $\mathrm{N}=120$ & $\mathrm{~S}$ & $\mathrm{~N}=80$ & $\mathrm{~S}$ \\
\hline group I & 140 & 70 & 120 & 60 & 80 & 40 \\
group II & 60 & 30 & 120 & 60 & 80 & 40 \\
supply & & 100 & & 120 & & 80 \\
wage & & 100 & & 80 & & 120 \\
\hline
\end{tabular}

Now a public forecast $(N)$ is published which has a better quality (measured with an MSE loss function) than the students' predictions. Again the expected prediction error has to equal 0 , therefore, it is assumed that with probability 0.5 the public forecast is $\mathrm{N}=120$ and with probability 0.5 the forecast is $N=80$. Thus the probability that the public forecaster overestimates the future wage equals the probability that it underestimates this wage. If the assumption is made that students completely adopt this public prediction, supply becomes 120 with a realised wage 80 , or supply becomes 80 with a realised wage 120 . The public prediction therefore caused the total supply to deviate from the equilibrium value. Such effects can only occur in case of dispersed predictions. In this chapter it is shown, however, that these results do not immediately imply that public predictions might have a negative impact on the functioning of the labour market. Firstly, it is argued that it is unlikely that students completely adopt the public forecast. Since students will realise that also a public prediction is not 
perfect, it is optimal for them to combine their own prediction with the public prediction. Secondly, table 15.1 only presents aggregate consequences, while the provision of public labour market information also influences individual welfare: In the case without public information there are 20 students in group I who erroneously enter the market, while in group II 20 students erroneously do not enter. The public forecast reduces this allocation effect from 40 to 20 .

\subsection{General and Individual Predictions}

In the welfare calculations of the previous chapter the realised wage depends on the equilibrium wage and on the predicted wage. The prediction, however, does not need to be the same for every student. Surveys indicate a considerable dispersion of students' expectations. ${ }^{2}$ Students will have different information relevant for predicting the future situation, but most important, students will have different interpretations on the information. Every student has his own 'theory' of how the labour market develops. Therefore, their predictions are dispersed. On the other hand, students may use similar insights, and they will discuss their opinions, which leads to a correlation between their prediction errors.

According to chapter 3 the individual predictions can be split up into a general and an individual component.

$$
w_{i}^{\text {pre }}=G+I_{i}
$$

In this section the model of chapter 3 is extended with some assumptions about the distribution of the predictions. For every individual prediction it is assumed that:

$$
E\left\{w_{i}^{\text {pre }} \mid w^{e q}\right\}=w^{e q}
$$

This assumption implies that all errors made by the students are interpretation errors. Since dispersion of predictions is likely to be mainly caused by different interpretations and not by different sets of information, the analysis in this chapter is mainly restricted to interpretation errors. This restriction, furthermore, has the advantage that it keeps the calculations manageable.

Furthermore the assumption is made that $w^{e q}-w^{\text {rea }}$ is unpredictable for students. Since predictions are not assumed to be equal for every 
student one student may be able to predict the prediction errors of others. But it is assumed that students are not able to predict the forecasts errors of others. This component of the prediction error, which is equal for every student is an information error. Therefore, their prediction of $w^{\text {eq }}$ in (15.6) can also be seen as a prediction of $w^{\text {rea. }}$.

For simplicity the assumption is made that every student predicts the future wage with the same precision.

(15.7) $\left.V A R\left|w_{i}^{\text {pre }}\right| w^{e q}\right\}=\sigma_{\text {pre }}^{2} \quad \forall i$ or

(15.8) $\left.V A R\left|w_{i}^{\text {pre }}\right| w^{\text {rea }}\right\}=\sigma_{\text {pre }}^{2} \quad \forall i$

The assumption is made that the individual part of the prediction error does not correlate with the general prediction error or with the individual part of others:

(15.9) $\left.\boldsymbol{E}\left\langle U_{i}\right| I_{p}, G\right\}=0 \quad \forall i \neq j$

Consequently, because of (15.5) and (15.6),

(15.10) $E\left\{G \mid w^{e q}\right\}=w^{e q}$

and by calling

$$
\text { (15.11) } \operatorname{VAR}\left\{I_{i} \mid w^{e q}\right\}=\sigma_{I}^{2} \quad \forall i
$$

it follows that

(15.12) $\operatorname{VAR}\left\{G \mid w^{e q}\right\}=\sigma_{G}^{2}=\sigma_{p r e}^{2}-\sigma_{I}^{2}$

Finally, an additional labour market prediction $N$ exists, which is independent of the individual components but which may be correlated with the general prediction.

(15.13) $E\left\{N \mid w^{e q}\right\}=w^{e q}$ with $\operatorname{VAR}\left\{N \mid w^{e q}\right\}=\sigma_{N}^{2}$

with

(15.14) $\operatorname{CoV}\left\{N, G \mid w^{e q}\right\}=\sigma_{N G}$

(15.15) $\operatorname{COV}\left\{, I_{i} \mid w^{e q}\right\}=0$

This additional prediction represents the information of the government or an institution, published with the purpose to improve the match between schooling and work. 
Table 15.2 summarises the covariances between the general prediction, the predictions of two students ( 1 and 2 ) and the additional prediction.

\section{TABLE 15.2: THE COVARIANCES. BETWEEN THE}

LABOUR MARKET PREDICTIONS (CONDITIONAL ON $w^{e q}$ ).

\begin{tabular}{c|cccc}
\hline & $G$ & $w_{1}^{\text {pre }}$ & $w_{2}^{\text {pre }}$ & $N$ \\
\hline$G$ & $\sigma_{G}^{2}$ & $\sigma_{G}^{2}$ & $\sigma_{G}^{2}$ & $\sigma_{N G}$ \\
$w_{1}^{\text {pre }}$ & & $\sigma_{G}^{2}+\sigma_{I}^{2}$ & $\sigma_{G}^{2}$ & $\sigma_{N G}$ \\
$w_{2}^{\text {pre }}$ & & & $\sigma_{G}^{2}+\alpha_{I}^{2}$ & $\sigma_{N G}$ \\
$N$ & & & & $\sigma_{N}^{2}$ \\
\hline
\end{tabular}

All moments defined above refer to the relation between the predictions and the equilibrium or the realisation of the wage and indicate the 'prediction quality'. To indicate the stability of the market $\left(\sigma_{\bar{w}}^{2}\right.$, the variance of the difference between equilibrium and realisation is used:

$$
\sigma_{\bar{w}}^{2}=E\left\{\left(w^{\text {rea }}-w^{\text {eq }}\right)^{2}\right\}=E\left\{\left(\frac{\beta_{S}}{-\beta_{D}}\left(G-w^{e q}\right)\right)^{2}\right\}
$$

\subsection{Individual Predictions}

In chapter 14 the welfare effects of interpretation errors have been calculated in the case that the prediction is equal for every student. These welfare losses are not the only costs students face. Due to the fact that predictions are dispersed some students will make a better prediction than the general prediction while others make a worse prediction. The costs of a worse prediction are not fully compensated by the gain of a better prediction.

The individual prediction error is distributed in two ways. Firstly, there is a distribution over the students such that for the aggregate enrolment the individual prediction errors do not matter (see equation (3.9)). Therefore the individual prediction error does not influence the realisation of the wage. Secondly, the individual prediction errors are 
the realisations of a stochastic variable, with a certain distribution (see section 7.1). To calculate the expected welfare costs of the individual prediction error $\left(\boldsymbol{W}_{S t}\left(\sigma_{l}^{2}\right)\right)$ the costs of prediction errors have to be integrated over all possible errors and over all individuals: $\iint_{1} L_{I} \operatorname{Loss}_{i}\left(w_{i}^{\text {res }}, I_{i}\right) \mathrm{d} F_{I}\left(I_{i}\right) \mathrm{d} F_{\text {res }}\left(w_{i}^{\text {res }}\right)$. On the assumption that the individual prediction error is independent of the reservation wage the integrals can be exchanged, i.e.

$$
\begin{aligned}
W_{S t}\left(\sigma_{I}^{2}\right) & =\int_{I} \int_{i} \operatorname{Loss}_{i}\left(w_{i}^{\text {res }}, I\right) \mathrm{d} F_{\text {res }}\left(w_{i}^{\text {res }}\right) \mathrm{d} F_{I}(I) \\
& =\int_{-\infty}^{\infty} \frac{1}{2} I\left(S\left(w^{\text {eq }}\right)-S\left(w^{\text {pred }}\right)\right) \mathrm{d} F_{N}(I) \\
& =\int_{-\infty}^{\infty}-\frac{1}{2} \beta_{S} I^{2} \mathrm{~d} F_{I}(I) \\
& =-\frac{1}{2} \beta_{S} \sigma_{I}^{2}
\end{aligned}
$$

Therefore, the welfare costs can be calculated as if every student makes the same prediction error $I$, but such that the realised wage is not affected by this prediction error. This is illustrated in figure 15.1.

These welfare costs equal the allocation part of students' welfare costs of a general prediction error. Because an individual prediction error does not influence the realised wage, the stability component does not play a part in this calculation. For employers the individual dispersion has no consequences. For them only the total supply is relevant, and it does not matter to them whether students entered correctly or not. In this model employers do not have to base their decision on expectations since they do not face adjustment costs. Therefore they experience no uncertainty, only fluctuations in the market wage.

To evaluate the effects of public information it is possible to use the welfare costs of students, employers and the total welfare costs. Table 15.3 summarises these results of section 14.3 (table 14.1) and this section. A student who has to decide which prediction he should use will, however, not base his decision on welfare arguments of the group he belongs to, but tries to maximise his own individual welfare.

Therefore, according to section 7.1, it seems appropriate to assume students will minimise the $M S E$ of the prediction error itself, and not a weighted sum of individual and general prediction error. Furthermore, 
the prediction error that is relevant for students is the prediction error with respect to the realisation of the wage and not with respect to equilibrium. One individual student has no influence upon the realisations.

$$
\begin{aligned}
M S E=\sigma_{\bar{p} \bar{e}}^{2} & =\boldsymbol{E}\left\{\left(w_{i}^{\text {pre }}-w^{\text {rea }}\right)^{2}\right\} \\
& =\boldsymbol{E}\left\{\left(G-w^{\text {rea }}+I_{i}\right)^{2}\right\} \\
& =\boldsymbol{E}\left\{\left(\left(\frac{\beta_{S}}{-\beta_{D}}+1\right)\left(G-w^{\text {eq }}\right)+I_{i}\right)^{2}\right\} \\
& =\left(\frac{\beta_{S}}{-\beta_{D}}+1\right)^{2} \sigma_{G}^{2}+\sigma_{l}^{2} \\
& =(\Psi+1)^{2} \sigma_{G}^{2}+\sigma_{I}^{2}
\end{aligned}
$$

For convenience $\beta_{s} /\left(-\beta_{D}\right)$ will be abbreviated by $\boldsymbol{\Psi} \boldsymbol{\Psi}>0$.

FIGURE 15.1: STUDENTS' WELFARE IN CASE GF AN INDIVIDUAL PREDICTION ERROR.

$a$

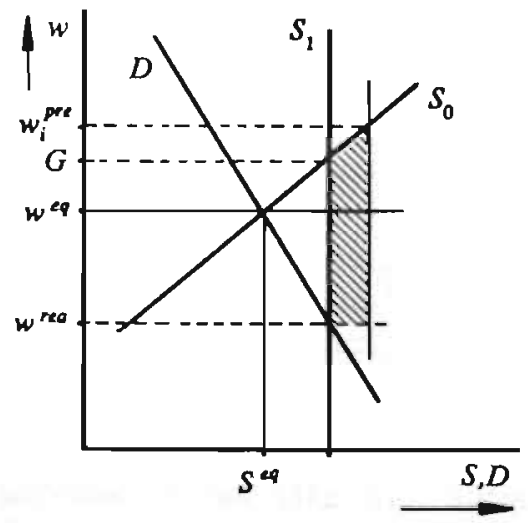

$b$

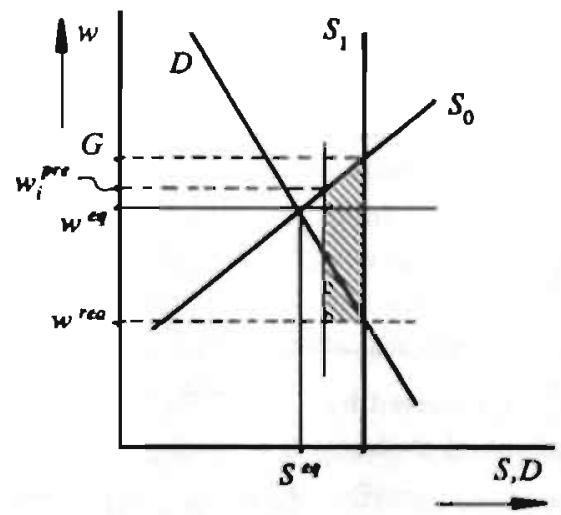

Finally, table 15.3 contains the stability of the market. In practice public forecasts are mostly evaluated based on aggregate level. ${ }^{3}$ They do not take into account individual prediction errors, or the individual mismatch. The stability of the market represents this market level evaluation criterium. 
The use of public information has two consequences, as mentioned in the introduction. Firstly, it decreases the variance of the prediction error of each student $a_{\text {pre. Secondly, it decreases the individual component }}^{2}$ and increases the general component of the prediction error. Since only the general prediction error influences the market both types of errors can not be seen as equal. Both types of errors lead to different welfare costs as shown in table 15.3. To choose an optimal use of the public information it is necessary to balance the advantages of a decrease of the prediction error and the disadvantages of a decrease of the dispersion. The third column of table 15.3 gives, for students, employers and the total, the relative welfare costs of general prediction errors compared to individual prediction errors.

TABLE 15.3: AN OVERVIEW OF THE WELFARE EFFECTS OF PREDICTION ERRORS AND THE STABILITY OF THE MARKET.

\begin{tabular}{l|ccc}
\hline & $\begin{array}{c}\text { general prediction } \\
\text { error }\end{array}$ & $\begin{array}{c}\text { individual } \\
\text { prediction error }\end{array}$ & $\begin{array}{c}\text { ratio general- } \\
\text { individual } \\
\text { prediction } \\
\text { error }\end{array}$ \\
\hline Welfare effects: & $-\left(\frac{\beta_{S}^{2}}{-\beta_{D}}+\frac{1}{2} \beta_{S}\right) \sigma_{G}^{2}$ & $-\frac{1}{2} \beta_{S} \sigma_{I}^{2}$ & $2 \Psi+1$ \\
students & $\frac{1}{2} \frac{\beta_{S}^{2}}{-\beta_{D}} \sigma_{G}^{2}$ & 0 & - \\
employers & $-\frac{1}{2}\left(\frac{\beta_{S}^{2}}{-\beta_{D}}+\beta_{S}\right) \sigma_{G}^{2}$ & $-\frac{1}{2} \beta_{S} \sigma_{I}^{2}$ & $\Psi+1$ \\
\hline total & $-\left(\frac{\beta_{S}}{-\beta_{D}}+1\right)^{2} \sigma_{G}^{2}$ & $-\sigma_{I}^{2}$ & $\Psi^{2}+2 \psi+1$ \\
\hline $\begin{array}{l}\sigma_{p \bar{p}}^{2} \text { (perceived by } \\
\text { individual students) }\end{array}$ & $-\left(\frac{\beta_{S}}{-\beta_{D}}\right)^{2} \sigma_{G}^{2}$ & 0 & - \\
stability of market & & & \\
\hline
\end{tabular}

The ratio between the importance of general and individual prediction errors from the point of view of individual students, does not equal the ratios of the three welfare measures. This indicates that there are some external effects which the student does not take into account. Firstly, by weighing up the consequences of individual and general prediction 
errors students do not take into account the (very small) effects their choice has upon other students. On aggregate level these small effects are, however, substantial. This results in a transfer of (negative) welfare from students to other students. Secondly, by minimising their prediction error students also cause redistribution between themselves and employers, since employers gain from prediction errors. Thirdly, students will overvaluate the importance of general prediction errors, because for individual students the difference between their prediction and the realisation is important. They do not take into account that an improvement of the prediction with respect to the equilibrium wage will also lead to a decrease of the gap between equilibrium and realisation.

\subsection{The Use of Information}

Last section was addressed to the measurement of the costs of prediction errors. An important conclusion is that individual students relatively overestimate the importance of general prediction errors. In this section it is derived to what extent students will use additional labour market information in order to minimise their risk.

Departure of this calculation is the possibility for students to choose to what extent they use the public information. Mostly, it is assumed that students completely adopt the public prediction and give up their own prediction. ${ }^{4}$ This would be very unrealistic and inefficient. Unrealistic, because it is hard to imagine students completely changing their mind due to public information. In accordance with studies about expectation formation public information will only partially influence students. Since public forecasts will never be infallible it is also rational not to use public information completely. The public forecast contains an error, so other information, like students' own predictions, still has some value. Providing public information may be seen as adding new elements into students' discussion, which generates their expectations.

Students will, however, by deciding the extent of using of public information not take into account the three external effects of their decision upon the stability of the market (see section 15.3), since individual students have no influence on the aggregate market situation. As noticed in the previous section students will not avoid using public information because this would cause destabilisation, but they use public information to a less extent because it appears less reliable. The

4 Or alternatively, that some students completely adopt the public prediction, while others stick completely to their own prediction, e.g. because they did not receive the public information (Turnovsky, 1978). 
disadvantages of using public information have to be transformed into a decrease of its quality (measured with respect to the realised wage) before it will influence students' behaviour.

The provision of an additional labour market prediction, published by a (governmental) forecasting bureau, gives students the possibility to adjust their expectations about the labour market, on which they base their decisions which school to attend. As said before, since also this additional prediction is not perfect they can, comparable to the optimal mix between abstract and specific expectations, form a new prediction by mixing their prediction with the additional prediction. Indicating this new, mixed, prediction with a circle $\left(^{\circ}\right)$ this leads to:

(15.19) $\dot{w}_{i}^{\text {pre }}=\lambda w_{i}^{\text {pre }}+(1-\lambda) N$

Although the decision about this mix is made at an individual level, $\lambda$ does not contain a subscript $i$. Since the variances of the prediction errors are the same for every student all individual $\lambda$ 's will be equal. Therefore the subscript $i$ can be omitted.

The variance of $\dot{w}_{i}^{\text {pre }}$ can again be split up in a general part and an individual part $\left(\sigma_{\vec{G}}^{2}, \sigma_{l}^{2}\right)$, both depending on the mixing coefficient $\lambda$ and the variances of $G, I_{i}$, and $N$. Students are, according to the results of the last section, not interested in minimising the welfare costs of $\sigma_{\text {pre }}^{2}$. Individual students do want to minimise the $M S E$ of the prediction error, as defined in last section. Minimising this prediction error is equivalent to minimising the variance of the difference between the prediction $\dot{w}_{i}^{\text {pre }}$ and the realised wage (not the equilibrium wage). Students choose weight $\lambda$ such that the resulting prediction error is minimal. This $\lambda$, from a students point of view, is thus a function of the prediction errors of the two initial sources, and of their covariance with respect to the realised wage.

The variance of this difference between prediction and realisation depends, however, on the extent to which the several sources of information are used. If an information source is used to a greater extent, its influence on the realised wage will be bigger and this will influence the reliability of all sources, e.g. because $w^{\text {rea }}=w^{\text {eq }}-\Psi\left(\lambda G+(1-\lambda) N-w^{\text {eq }}\right)$ : 
(15.20)

$$
\begin{aligned}
\sigma_{\bar{N}}^{2} & =E\left\{\left(N-w^{r e q}\right)^{2}\right\} \\
& =E\left\{\left(N-w^{e q}+\Psi\left(\lambda G+(1-\lambda) N-w^{e q}\right)\right)^{2}\right\} \\
& =E\left\{\left((1+(1-\lambda) \Psi)\left(N-w^{e q}\right)+\lambda \Psi\left(G-w^{e q}\right)\right)^{2}\right\} \\
& =\lambda^{2} \psi^{2} \sigma_{G}^{2}+(1+(1-\lambda) \psi)^{2} \sigma_{N}^{2}+2\left(1+(1-\lambda \psi) \lambda \Psi \sigma_{N G}\right.
\end{aligned}
$$

Similar calculations for $\sigma_{\bar{G}}^{2}$ and $\sigma_{\bar{N} \bar{G}}$ lead to:

(15.21)

$$
\left(\begin{array}{c}
\sigma_{\bar{G}}^{2} \\
\sigma_{\overline{\mathcal{G}}}^{2} \\
\sigma_{\bar{N} \bar{\sigma}}^{2}
\end{array}\right)=\left(\begin{array}{ccc}
(1+\lambda \psi)^{2} & (1-\lambda)^{2} \psi^{2} & 2(1+\lambda \psi)(1-\lambda) \psi \\
\lambda^{2} \psi^{2} & (1+(1-\lambda) \psi)^{2} & 2(1+(1-\lambda) \psi) \lambda \psi \\
(1+\lambda \psi) \lambda \psi & (1+(1-\lambda) \psi)(1-\lambda) \psi & (1+\lambda \psi)(1+(1-\lambda) \psi)+\lambda(1-\lambda) \psi^{2}
\end{array}\right)\left(\begin{array}{c}
\sigma_{G}^{2} \\
\sigma_{1 \psi}^{2} \\
\sigma_{W O}
\end{array}\right)
$$

The implication of these formulas is that the usage of both $N$ and $w_{i}^{\text {pre }}=G+I_{i}$ affects the reliability of the predictions. Since students use the predictions depending on their reliability, a simultaneous dependency occurs between the reliability of $N$ and $G$ and its usage.

The decision to use the additional labour market information is taken at an individual level. On this level the extent to which the additional prediction is used does not affect its reliability, since the decision of only one person does not have any effects on aggregate level. A student, thus, does not take these effects into account as he optimises the extent of usage. He will take the reliability of both his own prediction and the additional prediction as given.

In formula (15.22) the prediction error that is minimised by the students is calculated. Because a student takes the variances of the predictions as given, he does not take the relation between the prediction qualities of $G$ and $N$ and $\lambda$ into account. The $\lambda$ 's that are treated as constants by the students have been indicated by a tilde $(\tilde{\lambda})$. (15.22) will be minimised with respect to $\lambda$ without tilde only.

(15.22) $\sigma_{m=}^{2}=E\left(w_{1}^{m+n}-w^{m o n}\right)^{n}$

$$
=\left(\lambda^{2},(1-\lambda)^{2}, 2 \lambda(1-\lambda)\right)\left(\begin{array}{c}
\sigma_{\bar{G}}^{2}(\bar{\lambda}) \\
\sigma_{\bar{\mu}}^{2}(\bar{\lambda}) \\
\sigma_{\bar{N} \sigma}(\bar{\lambda})
\end{array}\right)+\lambda^{2} \sigma_{l}^{2}
$$

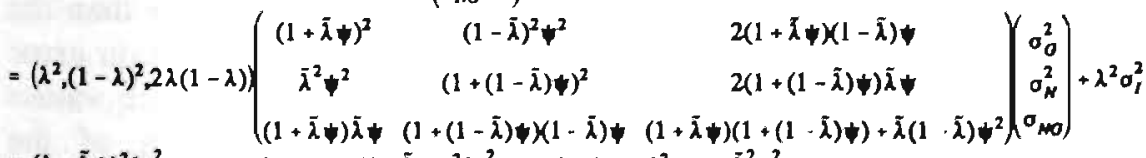

$=(\lambda+\tilde{\lambda} \psi)^{2}\left(\sigma_{\sigma}^{2}-\sigma_{M O}\right)+((1-\lambda)+(1-\tilde{\lambda}) \psi)^{2}\left(\sigma_{N}^{2}-\sigma_{M O}\right)+(1+\phi)^{2} \sigma_{M O}+\tilde{\lambda}^{2} \sigma_{I}^{2}$

Students minimise this equation under the assumption that 


$$
\text { (15.23) } \frac{\mathrm{d} \bar{\lambda}}{\mathrm{d} \lambda}=0
$$

Correct minimisation of $\sigma_{\overline{p r e}}^{2}$ by use of the additional public information would require taking this external effect into account:

$$
\text { (15.24) } \frac{\mathrm{d} \bar{\lambda}}{\mathrm{d} \lambda}=1
$$

The first order condition for the minimum of the prediction error is:

$$
\text { (15.25) } \begin{aligned}
& \frac{\partial \sigma_{\overline{N i}}^{2}\left(\lambda, \sigma_{G}^{2}, \sigma_{N}^{2}, \sigma_{M G}, \sigma_{l}^{2}\right)}{\partial \lambda} \\
& =2 \lambda(1+\psi)\left(1+\frac{\mathrm{d} \bar{\lambda}}{\mathrm{d} \lambda} \psi\right)\left(\sigma_{G}^{2}-\sigma_{N O}\right)-2(1-\lambda)(1+\psi)\left(1+\frac{\mathrm{d} \bar{\lambda}}{\mathrm{d} \lambda} \psi\right)\left(\sigma_{N}^{2}-\sigma_{M Q}\right)+2 \lambda, \sigma_{l}^{2}=0
\end{aligned}
$$

Solving for $\lambda$ gives the equilibrium $\lambda^{\bullet}$ :

$$
\lambda^{*}=\frac{\sigma_{N}^{2}-\sigma_{N G}}{\sigma_{G}^{2}-\sigma_{N G}+\sigma_{N}^{2}-\sigma_{N G}+\frac{\sigma_{I}^{2}}{(1+\psi)\left(1+\frac{d \tilde{\lambda}_{1}}{d \lambda_{1}} \psi\right)}}
$$

Since $\psi>0$ it follows immediately that students' $\lambda^{*}$ (with $\frac{d \bar{\lambda}}{d \lambda}=0$ ) is less or equal to the prediction error minimising $\lambda$ (using $\frac{d \bar{\lambda}}{d \lambda} \stackrel{d \lambda}{=} 1$ ).

Figure 15.2 shows the variance of the prediction error, depending on the variance of the additional, public information according to the optimal use by individual students, without considering the destabilisation effect $\left(\frac{d \bar{\lambda}}{d \lambda}=0\right)$ and according to an optimisation in which the external effects are taken into account $\left(\frac{d \bar{\lambda}}{d \lambda}=1\right)$. For reference, the straight line indicates the prediction error in the case no public information is provided. The figure shows that the prediction error may exceed the prediction error in the case that additional public information is not available.

A certain value of $\sigma_{N}^{2}$ leads to a choice of $\lambda^{*}$ which is smaller than the prediction error minimising $\lambda, i . e$. aiming at a minimal prediction error the public information is used to a 'too large' extent. For certain values of the parameters a decrease of $\sigma_{N}^{2}$ leads to an increase of the prediction error, until $\sigma_{N}^{2}$ has reached a certain level at which the quality of the public information compared to the general prediction error without public information is high enough to cause the overusage to improve the prediction error. 


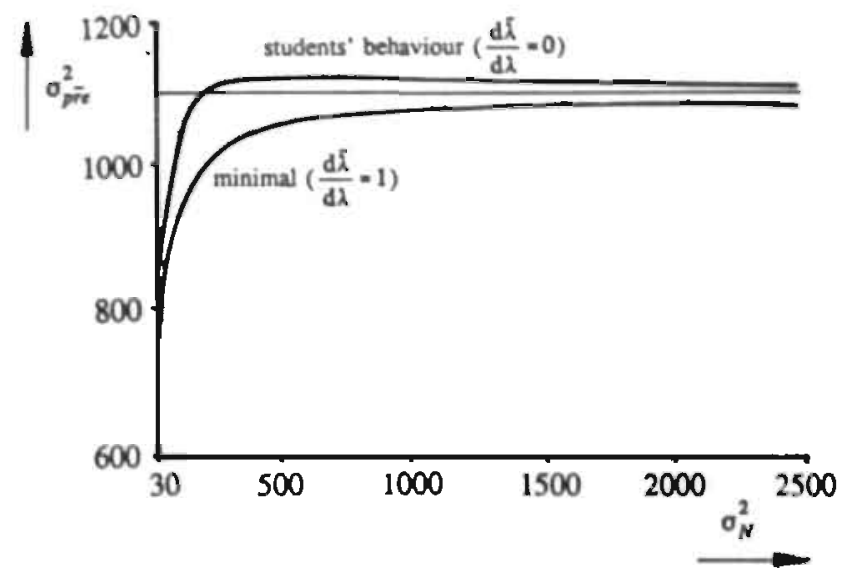

As noticed before, the stability of the market only depends on the general prediction error, since only the general prediction error affects the aggregated supply, and thereby the realised wage. The graph in figure 15.2 depicts the total prediction error, which consists of both individual and general prediction error. In figure 15.3 the general prediction error is depicted. Multiplying this general prediction error by gives the stability of the market. The straight line again provides ${ }^{+*}$ reference for the prediction error in case of no public information.

For the stability of the market the inverse effect of a public prediction will be even larger since it does not include $\sigma_{l}^{2}$. The individual prediction error always decreases as the public prediction improves.

From this example it can be concluded that providing the additional labour market information does not always make the market more stable. Conditions for which additional information increases the stability of the market are deduced later.

5 In numerical examples the following figures are used:

$$
\begin{aligned}
& \sigma_{T}^{2}=300 \\
& \sigma_{G}^{2}=50 \\
& \sigma_{M G}=30 \\
& \beta_{S}=2 \\
& \beta_{D}=-2 / 3 \\
& \text { so } \psi=3
\end{aligned}
$$

The figures are chosen in such a way that effects of public information include all possible negative aspects. 
Taking the partial derivatives of the equilibrium $\lambda^{*}$ with respect to $\sigma_{N}^{2}$ and $\boldsymbol{\sigma}_{N G}$ leads to:

(15.27) $\frac{\partial \lambda^{*}}{\partial \sigma_{N}^{2}}=\frac{\lambda^{*}\left(1-\lambda^{*}\right)}{\sigma_{N}^{2}-\sigma_{N G}}>0$

(15.28) $\frac{\partial \lambda^{*}}{\partial \sigma_{N G}}=\frac{\lambda^{*}\left(2 \lambda^{*}-1\right)}{\sigma_{N}^{2}-\sigma_{N G}}\left\{\begin{array}{l}>0 \text { if } \lambda^{*}>1 / 2 \\ \leq 0 \text { if } \lambda^{*} \leq 1 / 2\end{array}\right.$

The implications of these formulas are obvious. An increase of the variance of the public prediction decreases its use and an increase of the covariance between the general prediction and the public prediction makes the use of information more extreme, i.e. if own information was used more than public, the use of public information further decreases, while if public information was used to a greater extent its usage increases. If the covariance increases the advantage of mixing the two sources diminishes.

FIGURE 15.3: THE GENERAL PREDICTION ERROR, I.E. THE STABILITY OF THE MARKET.

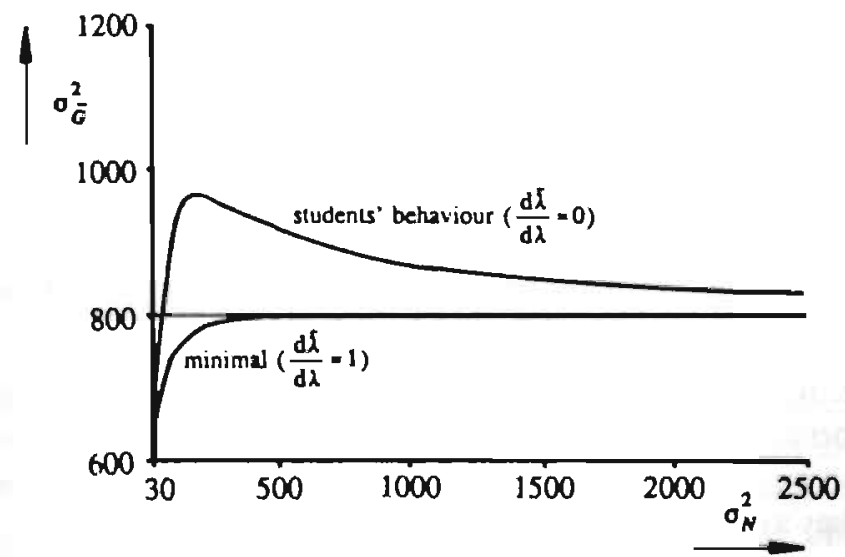

\subsection{Welfare Effects of Additional Labour Market Information}

After these calculations about the usage of additional labour market information we come to the main question of this chapter: What are the welfare effects of additional information? This question can be solved by substituting the formula for the usage of additional information (15.26) into the three cost functions of table 15.3. 
Before solving these substitutions the reverse question will be answered: If students do not minimise their cost function and if they do not take external effects into account, what function do they minimise? This question can be solved rather easily. In section 15.3 it is derived that students minimise

$$
\begin{aligned}
\sigma_{p \bar{p} e}^{2}= & (\lambda+\tilde{\lambda} \psi)^{2}\left(\sigma_{G}^{2}-\sigma_{N G}\right)+(1-\lambda+(1-\tilde{\lambda}) \psi)^{2}\left(\sigma_{N}^{2}-\sigma_{N G}\right) \\
& +(1+\psi)^{2} \sigma_{N G}+\lambda^{2} \sigma_{I}^{2}
\end{aligned}
$$

(equation (15.22)) with respect to $\lambda$, under the (false) assumption that $\frac{\mathrm{d} \lambda}{\mathrm{d} \lambda}=0$. This leads to:

$$
\begin{aligned}
\frac{\partial \sigma_{\bar{p} \bar{r} e}^{2}(\ldots)}{\partial \lambda}= & 2 \lambda(1+\psi)\left(\sigma_{G}^{2}-\sigma_{N G}\right) \\
& -2(1-\lambda)(1+\psi)\left(\sigma_{N}^{2}-\sigma_{N G}\right)+2 \lambda \sigma_{I}^{2}
\end{aligned}
$$

\section{(see equation (15.25))}

This equation gives the derivatives of the prediction error from the point of view of one individual student. At every value of $\lambda$ the equilibrium condition $\tilde{\lambda}=\lambda$ is imposed. Integrating this derivative gives a function $A I$ with the property that students behave as if they minimise this equation:

$$
\text { (15.31) } \begin{aligned}
A I & =\int\left[\frac{\partial \sigma_{\bar{p} \overline{r e}}^{2}}{\partial \lambda}\right]_{\bar{\lambda}=\lambda} \mathrm{d} \lambda \\
& =(1+\Psi)\left(\lambda^{2} \sigma_{G}^{2}+\left(1-\lambda^{2}\right) \sigma_{N}^{2}+2 \lambda_{1}(1-\lambda) \sigma_{N G}\right)+\lambda^{2} \sigma_{I}^{2}+\text { constant } \\
& =(1+\Psi) \sigma_{\hat{G}}^{2}+\sigma_{I}^{2}+\text { constant }
\end{aligned}
$$

This is, apart from a constant $-1 / 2 \beta_{s}$, the total cost function from a welfare economic point of view (table 15.3). Thus, students behave as if they minimise total costs, i.e. the sum of students' and employers' costs, of the use of information. This is a remarkable result. Firstly, students do not take into account the destabilising effect of their use of public information. They base their decision on the usage of public information on the observed quality of the two sources of information. The quality of the sources itself is influenced by their usages.

Apparently, the observed quality of information (with respect to the realisation, thus including the destabilisation effect) transforms the information about the disadvantages of general prediction errors in such 
a way that students choose a mix $\lambda^{\circ}$, which maximises total welfare.

Since the unpredictability of the gap between equilibrium wage and realised wage influences both students and public prediction, this does not influence students' decision. Furthermore, students do not take into account the redistribution of welfare from themselves to other students and to employers. Redistribution does, however, not influence total welfare what may explain the result.

In general, this mix does not minimise other criteria which have been distinguished before. In table 15.4 five criteria have been summed up: (1) students' welfare, (2) employers' welfare, (3) total welfare, (4) the prediction error, and (5) the stability of the market. The first column gives the value of $\lambda$ for which these criteria are optimised. These $\lambda$ 's are always ordered like:

(15.32) $\lambda^{*}=\lambda^{\text {total }} \leq \lambda^{\text {stud }} \leq \lambda^{\text {pred }} \leq \lambda^{\text {stab }}$

This means that for the criteria of students' welfare, the prediction error and the stability of the market the additional public information is always used to a too great extent. For employers' welfare is optimised if the prediction error is at its maximum. This means that their optimal $\lambda^{\text {emp }}$ equals 0 if the public prediction is better than the students' prediction, and $\lambda^{e m p}=1$ otherwise. The second column of table 15.4 gives the intervals for $\lambda$ in which the value of the public additional information is non-negative, compared with the situation in which no additional information is used. The lower bounds of these intervals are ordered the same way as the optimal $\lambda$ 's.

The third column of the table gives conditions for the value of information to be positive, i.e. it gives conditions for the cases in which the optimal $\lambda$ with respect to total welfare, which will be chosen, is in this interval.

The implications of the results in table 15.4 are the following. Although the mix of own predictions and public prediction is not optimal with regard to students' welfare, for students this mix never results in a negative value of information. An important condition for this result is that the equilibrium mix is actually used. The results depend on the assumption that students know the quality of their own prediction and the public prediction. Therefore students need to have a correct estimation of the prediction error of both sources of information. In the next section this assumption is relaxed, by investigating the effects of an overestimation of the reliability of the public prediction. 
TABLE 15.4: OPTIMAL $\lambda$, NON-NEGATIVE INTERVALS, AND CONDITIONS FOR THE VALUB OF INFORMATION TO BE NON-NEGATIVE.

\begin{tabular}{|c|c|c|c|}
\hline criterion & optimal $\lambda$ & non-negative interval & condition \\
\hline \multirow{3}{*}{ Student } & $\sigma_{N}^{2}-\sigma_{N G}$ & \multirow{2}{*}{$\sigma_{N}^{2}-\sigma_{G}^{2}-\frac{\sigma_{I}^{2}}{1+2 \psi}$} & \multirow{3}{*}{ always 6} \\
\hline & \multirow{2}{*}{$\sigma_{N}^{2}+\sigma_{G}^{2}-2 \sigma_{N G}+\frac{\sigma_{I}^{2}}{1+2 \psi}$} & & \\
\hline & & $\sigma_{N}^{2}+\sigma_{G}^{2}-2 \sigma_{N Q}+\frac{\sigma_{l}}{1+2 \psi}$ & \\
\hline Employer & 0 if $\sigma_{N}^{2} \geq \sigma_{G}^{2}$ & {$\left[0, \frac{\sigma_{N}^{2}-\sigma_{G}^{2}}{0}\right]$} & $\begin{array}{l}\text { if not } \\
(15.33)\end{array}$ \\
\hline & 1 if $\sigma_{N}<\sigma_{G}$ & {$\left[\sigma_{N}^{2}+\sigma_{G}^{2}-\sigma_{N G}\right]$} & \\
\hline \multirow{3}{*}{ Total } & $\sigma_{N}^{2}-\sigma_{N G}$ & $\sigma_{N}^{2}-\sigma_{G}^{2}-\frac{\sigma_{l}^{2}}{-}$ & \multirow{3}{*}{ always } \\
\hline & $\alpha^{2}+\alpha^{2}-2 \alpha+\sigma_{t}^{2}$ & ${ }^{N} \quad 1+\psi$ & \\
\hline & $0{ }^{N}+0_{G}-20_{N G} \overline{1+\psi}$ & $\sigma_{N}^{2}+\sigma_{G}^{2}-2 \sigma_{N G}+\frac{\sigma_{i}^{2}}{1+\psi}$ & \\
\hline \multirow{3}{*}{$\begin{array}{l}\text { Prediction } \\
\text { error }\end{array}$} & $\sigma_{N}^{2}-\sigma_{N G}$ & $\sigma_{N}^{2}-\sigma_{G}^{2}-\frac{\sigma_{I}^{2}}{2}$ & \multirow{3}{*}{ ? } \\
\hline & $\sigma^{2}+\sigma^{2}-2 \sigma+\frac{\sigma_{I}^{2}}{2}$ & $N{ }^{-}(1+\Psi)^{2}$ & \\
\hline & $\sigma_{N}+\sigma_{G}-20_{N G} \overline{(1+\psi)^{2}}$ & $\sigma_{N}^{2}+\sigma_{G}^{2}-2 \sigma_{N G}+\frac{\sigma_{I}^{2}}{(1+\psi)^{2}}$ & \\
\hline \multirow[t]{2}{*}{ Stability } & $\frac{\sigma_{N}^{2}-o_{N C}}{2}$ & {$\left[\sigma_{N}^{2}-\sigma_{0}^{2}, 1\right]$} & \multirow[t]{2}{*}{ (15.33) } \\
\hline & $\sigma_{N}^{2}+\sigma_{G}^{2}-2 \sigma_{N G}$ & $\sigma_{N}^{2}+\sigma_{G}^{2}-2 \sigma_{N G}, 1$ & \\
\hline
\end{tabular}

Conditions for increase of the stability of the market:

$$
\left\{\begin{array}{l}
\sigma_{I}^{2}<(1+\psi)\left(\sigma_{G}^{2}-\sigma_{N G}\right) \quad \text { or } \\
\sigma_{N}^{2}-\sigma_{N G}<\frac{\sigma_{I}^{2}+(1+\psi)\left(\sigma_{G}^{2}-\sigma_{N G}\right)}{\sigma_{I}^{2}-(1+\psi)\left(\sigma_{G}^{2}-\sigma_{N G}\right)}\left(\sigma_{G}^{2}-\sigma_{N G}\right)
\end{array}\right.
$$

The value of information with respect to the total welfare will of course also be positive, because this is what is actually optimised. Employers' welfare, on the other hand, may be negative. This is the case in situations in which additional information increases the stability of the

6 Proof in appendix 15.A.

7 The conditions for which additional information decreases the prediction error are cumbersome and do not have an interesting interpretation. Therefore they have been omitted.

8 Proof in appendix 15.B. 
market. This can be explained by the observation of table 14.1 that employers' welfare increases as the instability of the market increases.

Formula (15.33) in table 15.4 gives the condition necessary and sufficient for the market to become more stable as a result of additional labour market information. This stabilisation is assured if (1) the individual component of the prediction error is smaller than the general component, or if (2) the additional information has a prediction error below a certain level. If the public prediction error is smaller than the general component this stability condition will be fulfilled.

In figure 15.4 the value of information depending on its variance is depicted. The value of information is a relative concept. The straight lines indicate the welfare costs in the case no public information is provided. The value of information equals the difference betvveen the welfare costs after some public forecast is provided and the costs before the provision. In fact the relation between the variance of the public forecast and the costs is indirect. The variance influences $\lambda^{*}$, the extent of usage, and together with this $\lambda^{*}$ it influences the costs.

FIGURE 15.4: THE VALUE OF INFORMATION.

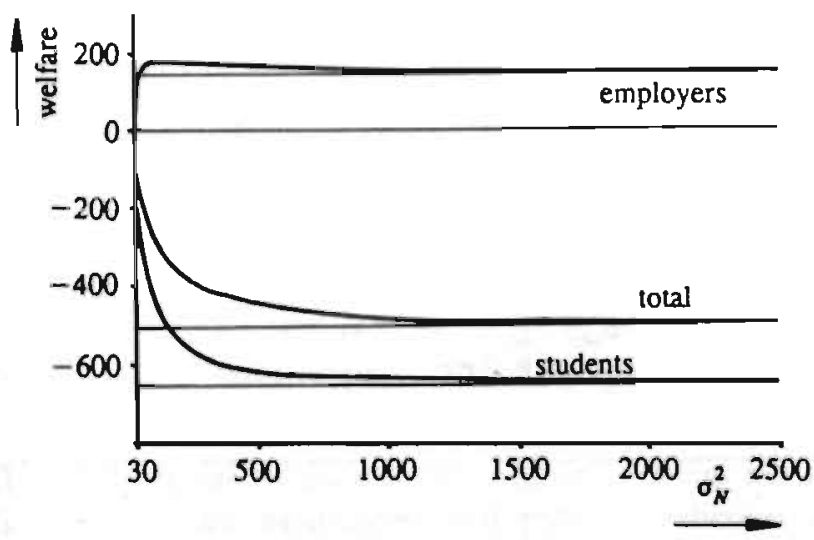

\subsection{The Example Reconsidered}

In section 15.1 an example illustrated the questions related to dispersed predictions. In this example the aggregate supply of students equals exactly the demand, although individual students made errors in their predictions. Due to the introduction of a public prediction this aggregate 
equilibrium is disturbed. In section 15.5 it is shown, however, that the provision of public information leads to optimal improvements in welfare. This is illustrated in table 15.5.

Contrary to table 15.1 , in the calculations of this table the assumption is made that students optimally use the public information. According to 15.3 this means that students take $\lambda^{*}=1 / 5$. Therefore the destabilising effect is less severe than in table 15.1. Furthermore, the table shows that although there is a destabilising effect, the welfare advantages are in total positive. The stabilisation component of students' welfare decreases but this loss is compensated by an increase in welfare in the allocation component. The number of students who receive wages for which they would have decided not to enter that segment decreases. Finally, employers gain from the destabilisation of the market.

The results of the previous section and this example show that it is not justified to evaluate, as has generally been done, the effects of public forecasts only with measurements at the aggregate level. The match between total supply and total demand is only one aspect of the relation between education and the labour market, the importance of which can be easily dominated by mismatches at the individual level.

TABLE 15.5: WELFARE EFFECTS OF THE PREDICTION ERROR IN THE EXAMPLE.

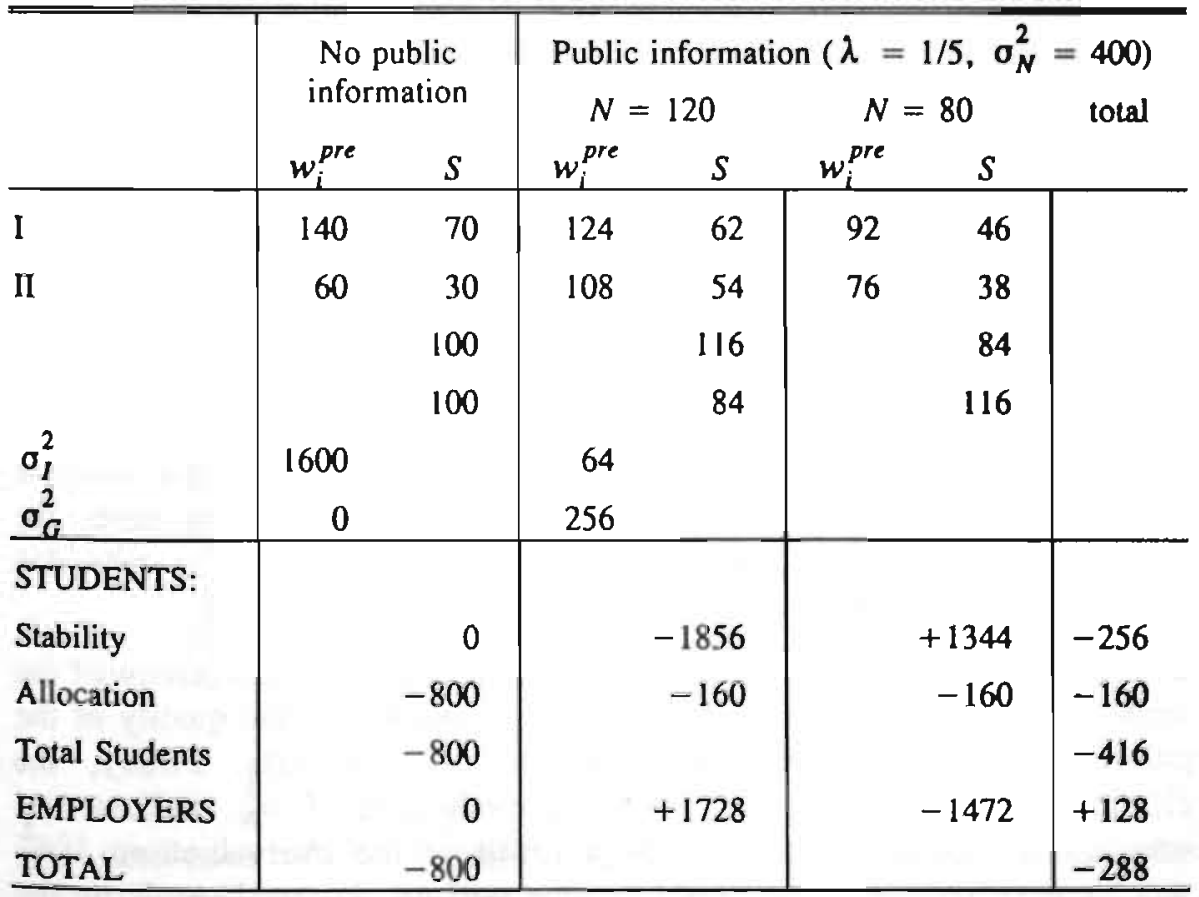




\subsection{Overvaluation of the Public Prediction}

All results presented in previous sections depart from the assumption that students know (or correctly estimate) the quality of the public prediction, i.e. they know its variance and its correlation with their own prediction. It is very doubtful whether this is a realistic assumption. In figure 15.5 the results of the welfare calculations in the case students have a wrong perception of these figures, have been depicted. (In this example they estimate the variance to be half the real variance and they think the covariance to be 0 instead of its real value 30 ).

FIGURE 15.5: CONSEQUENCES FOR THE WELFARE EFFECTS, DUE TO A MISPERCEPTION OF THE QUALITY OF THE PUBLIC PREDICTIONS.

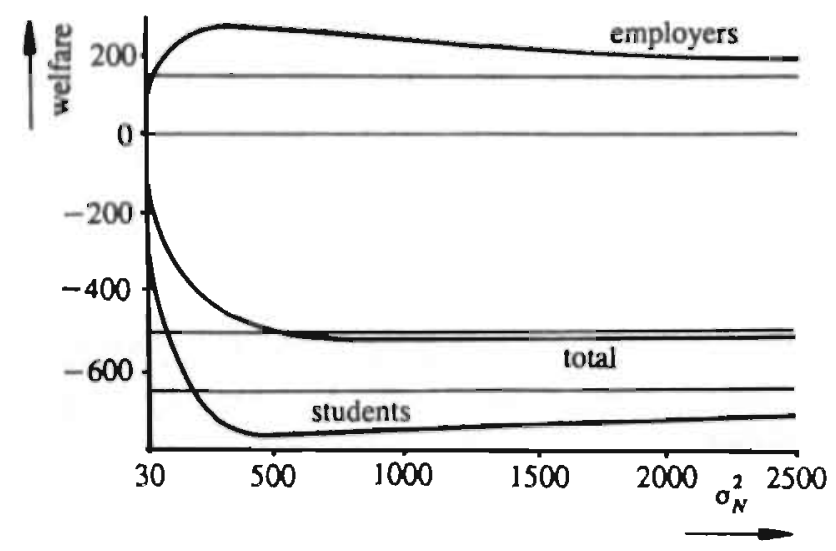

The figure immediately makes clear that the effects of such an overestimation of the reliability of the public prediction may be rather bad. Due to the overestimation of the public prediction students make too much use of this additional information. Therefore the negative welfare effect of the decrease of dispersion overwhelms the positive effect of a decrease of the prediction error: the welfare costs for students are lower than the costs in case no information is provided (indicated by the straight line).

In this section an indicator is developed to measure the sensitivity of the welfare results of section 15.4 to an overestimation of the quality of the public forecast. This indicator consists of two parts. Firstly, the elasticity of $\lambda^{*}$ with respect to an overvaluation of $\sigma_{N}^{2}$, indicates to what extent behaviour changes as a resuit of the overvaluation. If $\sigma_{N}^{2}$ will be perceived incorrectly, the $\lambda$ that will be chosen depends on the 
perceived $\sigma_{N}^{2}$ instead of the real $\sigma_{N}^{2}$. The elasticity indicates the sensitivity of $\lambda$ for a slight misperception of $\sigma_{N}^{2}$.

Secondly, table 15.4 gives the interval of $\lambda$ 's for which the total welfare effect is positive. The ratio between the break-even $\lambda$ at which the welfare effect is exactly 0 , and the optimal $\lambda^{*}$ provides an indication of the maximum relative change in $\lambda$ (due to misperception) for which the welfare effect remains positive.

In section 15.4 (equation (15.27)) the partial derivative of $\lambda$ with respect to $\sigma_{N}^{2}$ has been calculated. Rewriting this derivative as an elasticity gives:

(15.34)

$$
\frac{\left(\frac{\partial \lambda^{*}}{\partial \sigma_{N}^{2}}\right)}{\left(\frac{\lambda^{*}}{\sigma_{N}^{2}-\sigma_{N G}}\right)}=1-\lambda^{*}
$$

With the use of the non-negativity interval of table 15.3 the ratio between the $\lambda$ for which total welfare is exactly zero and $\lambda^{*}$, which optimises total welfare can be calculated:

(15.35) $\frac{\lambda^{\text {b.e. }}}{\lambda^{*}}=\frac{\sigma_{N}^{2}-\sigma_{G}^{2}-\frac{\sigma_{I}^{2}}{1+\Psi}}{\sigma_{N}^{2}-\sigma_{N G}}=2-\frac{1}{\lambda^{*}}$

FIGURE 15.6: THE DERIVATIVE OF $\lambda$ WITH RESPECT TO $\sigma_{N}^{2}$.

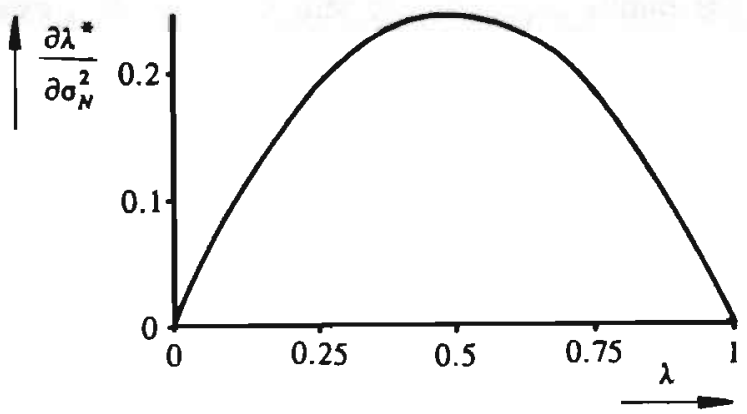

The derivative of $\lambda^{*}$ (equation (15.27)) and the ratio between the break-even $\lambda$ and the optimal $\lambda$ are graphed in figure 15.6 and 15.7. 
Figure 15.7 shows that if $\lambda^{\circ}<1 / 2$ total welfare can not be negative as a result of a misperception. The risk of a misperception will be large if the derivative is high, i.e. a small misperception leads to a relative large change in $\lambda$, and will be large if the gap between optimal and breakeven $\lambda$ is smali, i.e. if the ratio in (15.35) is large. The risk-indicator, i.e. the product of the elasticity and the break-even-ratio is:

(15.36) RISK $=\left(1-\lambda^{*}\right)\left(2-\frac{1}{\lambda^{*}}\right)$

FIGURE 15.7: THE BREAK-EVEN RATIO.

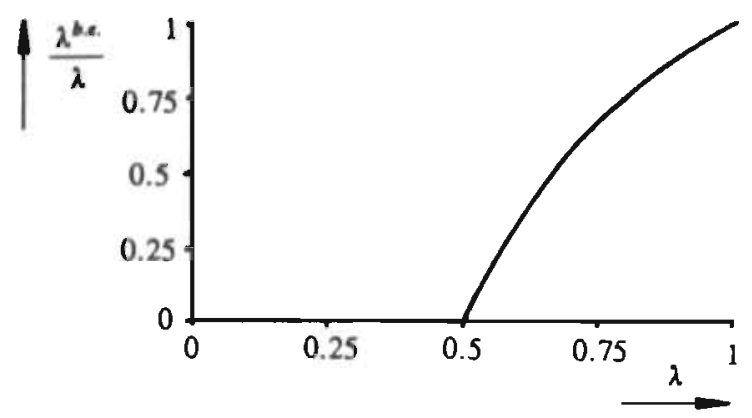

Figure 15.8 shows this 'risk'. Its maximum is reached at $\lambda^{*}=\sqrt{2} \approx 0.707$.

The risk of a negative value of public information due to a misperception of its quality is relatively high if the variance of the public information is slightly less than the variance of individual students. In this situation the public forecasts are still substantially, used while its reliability is relatively low. Such a low quality forecast may be very useful, but only if it is used in the right way. If its quality further diminishes its use also decrease, which decreases its risk.

This risk-measure indicates that it is very important to report is quality together with a public prediction. Since it is not unlikely that many public predictions do not really dominate individual predictions by variance, most part of their value comes from the combination of individual and public prediction which makes necessarily a correct valuation of both sources. 
FIGURE 15.8: THE 'RISK OF MISPERCEPTION'.

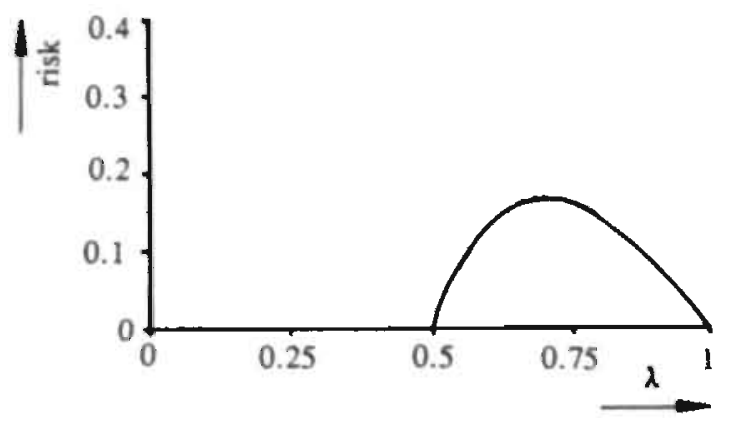

\subsection{Conclusions}

In this chapter it has been shown that the possibility of dispersion in students' prediction complicates the relation between public information and aggregate market outcomes. Since the value of public information not only stems from stabilisation but also from allocation improvements as shown in chapter 14 , there may be - due to the dispersion situations in which aggregate supply is close to the equilibrium supply, although many students are misallocated. Public information may improve welfare in such a case even at the costs of destabilisation, by improving this allocation.

An important conclusion is therefore that it is not sufficient to evaluate the effects of public labour market information at aggregate level, but that indiviual gains have to be taken into account.

Furthermore, it is shown that public information always improves welfare if the condition is fulfilled that students know the relative quality of the public forecast. This indicates that it is very important to give students - together with the public labour market forecasts --- an indication of its reliability. 
Appendix 15.A

Proof of the non-negativity of the value of information with respect. to students welfare:

$$
\begin{aligned}
\lambda \cdot= & \frac{\sigma_{N}^{2}-\sigma_{N G}}{\sigma_{N}^{2}+\sigma_{G}^{2}-2 \sigma_{N G}+\frac{\sigma_{l}^{2}}{1+\Psi}} \\
& \geq \frac{\sigma_{N}^{2}-\sigma_{N G}-\frac{\sigma_{I}^{2}}{1+2 \Psi}}{\sigma_{N}^{2}+\sigma_{G}^{2}-2 \sigma_{N G}+\frac{\sigma_{l}^{2}}{1+\Psi}-\frac{\sigma_{I}^{2}}{1+2 \Psi}} \\
& \geq \frac{\sigma_{N}^{2}-\sigma_{N G}-\frac{\sigma_{I}^{2}}{1+2 \Psi}}{\sigma_{N}^{2}+\sigma_{G}^{2}-2 \sigma_{N G}+\frac{2 \sigma_{I}^{2}}{1+2 \Psi}-\frac{\sigma_{I}^{2}}{1+2 \Psi}} \\
& \geq \frac{\sigma_{I}^{2}}{\sigma_{N}^{2}-\sigma_{G}^{2}-\frac{\sigma_{I}^{2}}{1+2 \Psi}}
\end{aligned}
$$

what is the lower-bound of the interval (table 1.5.4) for which the value of information with respect to students' welfare is non-negative $\square$. 
Appendix 15.B

Proof of condition (15.33) for which additional information increases the stability of the market:

$$
\begin{aligned}
& \frac{\sigma_{N}^{2}-\sigma_{N G}}{\sigma_{N}^{2}+\sigma_{G}^{2}-2 \sigma_{N G}+\frac{\sigma_{I}^{2}}{1+\Psi}}>\frac{\sigma_{N}^{2}-\sigma_{G}^{2}}{\sigma_{N}^{2}+\sigma_{G}^{2}-2 \sigma_{N G}}- \\
& \left(\sigma_{N}^{2}-\sigma_{N G}\right)^{2}+\left(\sigma_{N}^{2}-\sigma_{N G}\right)\left(\sigma_{G}^{2}-\sigma_{N G}\right) \\
& >\left(\sigma_{N}^{2}-\sigma_{N G}\right)^{2}+\left(\sigma_{N}^{2}-\sigma_{N G}\right)\left(\sigma_{G}^{2}-\sigma_{N G}\right)+\frac{\left(\sigma_{N}^{2}-\sigma_{N G}\right) \sigma_{I}^{2}}{1+\Psi} \\
& \quad-\left(\sigma_{N}^{2}-\sigma_{N G}\right)\left(\sigma_{G}^{2}-\sigma_{N G}\right)-\left(\sigma_{G}^{2}-\sigma_{N G}\right)^{2}-\frac{\left(\sigma_{G}^{2}-\sigma_{N G}\right) \sigma_{I}^{2}}{1+\Psi}- \\
& \left(\sigma_{N}^{2}-\sigma_{N G}\right) \sigma_{I}^{2}-\frac{\left(\sigma_{G}^{2}-\sigma_{N G}\right) \sigma_{I}^{2}}{1+\Psi}-\left(\sigma_{N}^{2}-\sigma_{N G}\right)\left(\sigma_{G}^{2}-\sigma_{N G}\right)-\left(\sigma_{G}^{2}-\sigma_{N G}\right)^{2}<0
\end{aligned}
$$



The educational choice is often an important but difficult choice. The choice between different types of education can have long-term consequences on the labour market. Especially at the moment a student enters the labour market after he has finished school it may have farreaching consequences what type of education he has had. Therefore it would be very relevant for students to know at the moment the educational choice has to be made, the labour market prospects for different types of education at the moment they finish school, which is often four to six years in advance. Empirical evidence in chapter 4 showed that labour market prospects may change rather drastically within some years, and that students have great difficulties in anticipating these changes, but at the same time indeed are interested in better information about the labour market prospects.

Many students regret their educational choice afterwards. This empirical evidence shows that students are not fully capable of making adequate labour market forecasts which they need for their educational choice. Based on this notion the aim of this study is to investigate the possibilities for the provision of public labour market forecasts which may assist students in their educational choice.

The investigation of these possibilities requires both theoretical and practical considerations. An analysis of the standard economic theory about economic policy shows that this theory does not allow for influencing people's expectations. The standard economic theory starts from the assumption that there exists a true model of the economy. Although it is admitted that it is difficult (or even impossible) to know the data generating process in practice, all analyses start (implicitly) from the assumption that the data generating process is known. Therefore some simplified model is assumed to be the real economic model. In this framework economic decisions can always, theoretically, be compared to this real model.

The assumption of such a real economic model makes it difficult to incorporate the provision of public forecasts into the model. Within this context students' expectations are, by definition correct or incorrect. If the expectations are already correct there is no need for public information, and if they are incorrect the model is unable to explain why they use these incorrect expectations, and therefore simply has to assume that they do. The theory can not provide a reason to deviate from the optimal expectation, and consequently can not predict how students' expectations will change if public information is provided.

Lucas (1976) introduces an important criterium for economic theories, 
which states that economic models always have to explain why people behave the way they do: All behaviour of the agents in the model has to be deduced from optimality criteria. For policy analysis this is a very important criterium. But, within the context of a theory in which the true economic model is assumed to be given, this necessarily leads to rational expectations. In rational expectations students' expectations are perfect in the sense that all prediction errors they make are not caused by inadequate analysis made by themselves, but are caused by exogenous random shocks. In rational expectations the only way students can be assisted in their choice is by the collection and provision of new data. Students themselves can draw the right conclusions from these data.

This conclusion of rational expectations is obviously in contradiction with the real live observations that students do have difficulties in forecasting future labour market, that the choice of the right expectations is not obvious, and that some doubt will always persist.

To make an adequate theory about the effects of the provision of labour market information it is therefore required that a theory is constructed which on the one hand holds on to Lucas's criterium that an economic theory should explain why people behave the way they do, and on the other hand incorporates the real life notion that students do face difficulties in predicting the future labour market situation. Adequateness means above all that the intuitive notions about difficulties students face are included in the theory. In this study an errors in forecasts model is developed which makes it possible to incorporate the provision of public forecasts which has non-trivial consequences. This model has both theoretical and practical implications, which are discussed in section 16.1 and 16.2 , respectively. Finally, in section 16.3 possibilities for future research are suggested.

\subsection{Implications for Economic Theory}

The basic property of existing models about expectations is that they (implicitly) depart from the assumption that the real model of the economy is at hand. Expectation formation is modelled within this context of a knowable data generating process. Departing from such a model the only expectations which are optimal are rational expectations, which are perfect expectations besides possible exogenous sources of uncertainty. For rational expectations, making expectations is therefore without difficulty and uncertainty. The uncertainty always lies outside the student and the production of a forecast generates no uncertainty itself. 
The model developed in this study does not start from the assumption of a model of reality which is at hand, but starts from the observation that people do have the capability to make (more or less adequate) forecasts. A forecast will generally involve a forecast error. Essential for a forecast is that the person who makes the forecast can not predict himself what value this forecast error will have. If, as is the case in this model, there is no background of the real model, it is impossible to distinguish in a sensible way between ex ante and ex post forecast errors, i.e. it is not possible to state that at a certain moment of time, given the information available at that time, it was not possible to make a better forecast than has been made. It is always possible that there is a theory which would have been able to predict the events that actually happened.

For that reason an equilibrium situation is defined, according to Hayek, as a situation in which all people have actually taken the same decision as they would have done in the case they had known the future developments with certainty. In a situation of equilibrium there is no need for extra information. If the actual choices people make, differ from this equilibrium, some people will, once they know the true developments, regret their choice. Such a deviation of equilibrium is called mismatch, i.e. a situation which would not have occurred if all relevant information had been known in time.

A student who has to forecast the future labour market situation therefore has to make his own model of reality, which of course may contain errors. If a theory is relatively abstract, the theory itself may be rather adequate, but many important factors are left out of the model, leading to additional exogenous random shocks (i.e. stochastic innovations). In such a case the forecast contains only a small interpretation error, but has a large information error. On the other hand if the model used by a student is relatively specific, and more factors are incorporated in the model, the importance of the exogenous random shocks diminishes (i.e. the information error diminishes), but due to the complexity of the forecast more interpretation errors are included. There exists therefore a trade off between the robustness of the abstract forecast and the precision of the specific forecast.

From this point of view it is easy to explain cobweb behaviour. People use the very simple cobweb expectation, that future wages will equal current wages, not because they really are naive, but because the interpretation errors which will occur if they make their forecasts more specific are not compensated by the gains of a more specific forecast. It is optimal for them only to use simple rules-of-thumb. 
In the errors in forecasts model the optimal prediction depends on two factors. Firstly, the predictability indicates student's capability to make specific forecasts. Secondly, the variability indicates to what extent the market is subject to changes, i.e. to what extent it is necessary to use better models than e.g. the simple cobweb expectation. If the predictability is low and the variability is low, 'naive' expectations are optimal, while if predictability is high and variability is high it becomes optimal to use more complex models of reality.

This relationship is able to explain the fact that in certain circumstances it is difficult to reject the rational expectations hypothesis, while in other circumstances it is easy. In a context in which professional forecasters have to make predictions about a very fluctuative variable, (e.g. at financial markets) the optimal expectations will be very specific. The only prediction errors which are made in such a case are unsystematic deviations. Usually, these independent random deviations are not treated as evidence against the rational expectations hypothesis. In the reversed situation, when variability is low and predictability is low (e.g. the decision of consumers to save) the same model leads to significant deviations from the rational expectation.

Another important implication of the model is that if some systematic deviation from optimal expectations is observed, it is only possible to a limited extent to manipulate these expectations, for example for a Keynesian policy. The fact that people use such a naive expectation scheme is caused by circumstances and as soon as these circumstances change in order to 'misuse' these expectations, the optimal way to form expectations will adjust to the new situation.

The aim of the study is to investigate the effects of the provision of public forecasts to students. Within the developed model it is easy to interpret this provision of information. A public forecast functions as a way to improve the quality of the specific forecasts of students, and therefore improves the predictability. An improvement of the predictability has two effects. Firstly, it will change the optimum between the abstract and the specific forecast. Students' forecasts will therefore become less naive. Secondly, the prediction error of this optimal prediction will diminish. This second effect will however be larger if the optimal use of forecasts lies nearer to the specific forecast. If students mainly use the naive, abstract expectation, a small improvement of the specific expectation will not have much influence upon the quality of the prediction actually used. Before significant changes will occur the improved specific expectation, i.e. the increased predictability, first has to shift the optimal mix of the abstract and 
specific prediction.

\subsection{Implications for Manpower Forecasting}

The errors in forecasts model developed in this study makes it possible to investigate the effects of providing public forecasts to students. These effects can be investigated at the individual level, but since changes in individual behaviour will on aggregate level influence the functioning of the market as a whole, more importantly, the welfare effects at market level have to be taken into account. These investigations provide some insights which may be useful for manpower forecasting and its evaluation in practice.

At the individual level it is important to notice that the model explains that the way students will form their expectations, rather naive or not, depends on both the variability and the predictability of the market. This implies that the observation of naive anticipating behaviour not necessarily indicates the need for correction of the forecasts made by students. It may very well be the case that the naive behaviour is due to the low variability of the market, and therefore the need for more appropriate forecasts is very low. A case in which both the variability is high and the predictability is low, students' predictions may appear to be more advanced, but this does not imply that the mismatch problem is less severe. An appropriate measurement for the need for public forecasts is therefore not the fact whether or not students make systematic prediction errors (as is the case in the cobweb behaviour). An adequate indicator measures the size of the prediction error itself.

If, however, students' behaviour is observed to be rather naive it is not possible to assist their choice only with a small improvement of the specific forecast. To influence the behaviour, firstly, a shift from the abstract to the specific expectation is needed. In the case in which expectations are more specific but nevertheless their error is large, a small improvement of the forecast will have an immediate favourable impact on the mismatch.

At the aggregate, market, level two welfare effects have to be distinguished. Firstly, uncertainty causes changes in supply (i.e. deviations from the equilibrium supply) and this will cause changes in the realised wage. These fluctuations in the wage cause welfare effects: the stabilisation effect. These welfare effects are for a large part only distributional effects. If the wage is low employers gain and students loose while if the wage is high students gain and employers loose. The stability effect has, however, also consequences for the total welfare, 
because the gains do not fully compensate the losses. If the fluctuations in the wage are caused by errors in students' predictions, students will bear a welfare loss while employers gain from this situation. This is caused by the fact that students' enrolment correlates negatively with the wage. If many students enter the wage will fali, while if few enter the wage will rise. This effect will in particular be large for the prediction errors which relate to the prediction of labour supply. If only students' welfare is taken into account the improvement of predictions regarding supply is therefore very important.

Besides the stability effect there is an allocation effect. Wrong expectations will cause students' to make wrong decisions and therefore they will get a job which they do not prefer given the wages. This type of effect only affects students. The welfare loss involved in it may, however, be rather large.

If students are ignorant regarding the future labour market situation, i.e. if they use the abstract expectation, the stability effect does not occur. In such a case students' enrolment can be viewed upon as a constant and therefore there is no correlation with the wage. The loss in case of low wages is compensated by the gain in case of high wages. The provision of public information will reduce the naivety of students' predictions. There are circumstances in which the provision of information reduces the total welfare costs, but in which due to the fact that expectations become less naive, the welfare effect for students are negative. In general, labour market problems become larger if the ratio of the elasticities of supply and demand is larger, i.e. if there are relatively small quantity adjustments at demand side of the market.

If the assumption is dropped that every student has the same prediction (i.e. if dispersed predictions are introduced) a reduction of the forecast error not necessarily leads to stabilisation anymore. Although the provision of information may lead to destabilisation of the market, it still has, under certain assumptions, positive welfare effects. The possible negative effect of destabilisation is compensated by positive allocation effects. The match between supply and demand at aggregate level may get worse, but more students will be allocated in the job they actually prefer.

An important assumption for this result is that students correctly estimate the quality of the public prediction. If students overestimate this quality the welfare gain becomes lower than possible, and the gain may even turn into a loss. This indicates that not only public forecasts themselves, but also an indication about their quality has value. 
The case of dispersed predictions has two important consequences for manpower forecasting. Firstly, in the evaluation of the effects of public forecasts not only their effects at aggregate level should be taken into account, but also their effects upon the individual allocation of students, which can be measured by the amount of students who regret their educational choice afterwards. Secondly, public forecasts should always be accompanied by an indication about the quality of the forecast.

Summarising, if students have a correct perception of the quality of a public forecast, regardless its quality the provision of public labour market information theoretically always improves welfare, although it might lead to a redistribution of welfare between employers and students.

\subsection{Future Research}

Every study has its limitations and therefore leaves behind theoretical questions and possibilities for future research. In this final section some of these possibilities for future research are sketched in order to provide insight into the limitations and prospects of the theory developed in this study.

Economic theory, very often, is split into two approaches. The first approach focusses on empirical justification. A theory is empirically adequate if it fits into the economic data, thus if it is sufficiently able to predict economic events. The other approach focusses on plausibility. The behaviour of economic agents should be explained, i.e. it has to be shown that the economic behaviour results from agents' optimising behaviour.

Unfortunately, it very often seems not possible to bridge the gap between these two approaches. The existence of this gap often leads to the rejection of one of both approaches. The right conclusion to draw is, however, that the theory is still uncomplete. As long as theories based on agents' optimising behaviour lead to other results than theories suited to predict economic data, unexplained aspects are left. Such a situation justifies the existence of both types of theories, but also requires attempts to overcome the contradiction.

The coexistence of rational expectations and ad hoc expectation theories, as the cobweb theory, is an example of a theoretical gap between empirical justification and plausibility. This study is an attempt to bridge the gap between both approaches to expectations. It shows the possibility to overcome this discrepancy between models which explain expectations from optimising behaviour and models which better fit in 
the experience that human behaviour is far from perfect. It might be possible to extend this type of analysis to other areas of economic theory in which similar gaps between optimising behaviour and observed behaviour seem to exist. An important example of this is the theory of unemployment, in which on the one hand the real business cycle theory explains unemployment, based on the optimising behaviour of agents, but in a way which is clearly in contradiction with empirical observations, while on the other hand many ad hoc theories on unemployment are able to provide an empirical satisfactory description of unemployment by the introduction of assumptions which, however, contradict the optimising behaviour of agents.

Furthermore, the model developed in this study has several shortcomings itself. It is based on some rather strong assumptions about the relationship between education and the labour market. These assumptions are made to reduce the complexity of the analyses, but of course the assumptions are made in the conviction that the simplified model which has been considered reveals some interesting aspects about expectations formation and the relevance of information which still hold in a more realistic model.

Two important abstractions have to be mentioned. Firstly, the welfare analysis of the third part does not incorporate unemployement situations. Unemployment is of course a very important characteristic of the labour market nowadays, and many manpower forecasting activities are directed towards the reduction of unemployment. The theory about unemployment does, as mentioned above, not provide enough grip to analyse the relationship between the provision of public information and the level of unemployment.

Secondly, the model in this study assumes a fixed relationship between education and occupation. In practice there is, however, substitution between different types of education. It would be of great interest to analyse the role of specialised versus more general types of education. From the point of view of this study it may be possible to explain the existence of general education as a way to adjust the educational system to a situation of uncertainty.

More generally, it will be interesting to extend the development of models in which on the one hand the true economic model is not given to the agents anymore, but on the other hand people still behave optimally within the context of the uncertainty they are faced with. This might further increase the insight in theories in which deviations from Pareto-optimality are not imposed by restricting assumptions, but can be 
explained by people's optimising behaviour. Such explanations of nonoptimalities are important both for welfare analyses and for predictions about the effects of policy changes. 



\section{LITERATURE}

Allais, M. (1949), 'Rendement Social et Productivité Sociale'. Metronomica 1, pp. 122-125.

Allais, M. (1973), 'La Théorie Générale des Surplus et l'Apport Fondamental de Vilfredo Pareto'. Revue d'Economie Politique 6, pp. 1044-1096.

Antonovitz, F., and T. Roe (1986), 'A Theoretical and Empirical Approach to the Value of Information in Risky Markets'. Review of Economics and Statistics 68 , pp. $105-114$.

Arrow, K.J. (1951), 'Alternative Approaches to the Theory of Choice in RiskTaking Situations'. Econometrica 19, pp. 404-437.

Arrow, K.J., and L. Hurwicz (1958), 'On the Stability of the Competetive Equilibrium'. Econometrica 26, pp. 522-552.

Arrow, K.J., and M. Nerlove (1958), 'A Note on Expectations and Stability'. Econometrica 26, pp. 297-305.

Becker, H.A., and G. Dewulf (Ed.) (1989), Terugkijken op toekomstonderzoek. Utrecht.

Benassy, J-P. (1991), 'Incomplete Markets and the Suboptimality of Rational Expectations'. Economics Letters 36, pp. 343-346.

Bentolila, S., and J.J. Dolado (1991), 'Mismateh and Internal Migration in Spain, 1962-86'. In Padoa Schioppa (1991a), pp. 182-234.

Berger, L.A. (1989), 'Economics and Hermeneutics'. Economics and Philosophy 5, pp. 209-233.

Blanchard, O.J., and P. Diamond (1989), 'The Beveridge Curve'. Brookings Papers on Economic Activity, pp. 1-60.

Blanchard, O.J., and S. Fisher (1989), Lectures on Macroeconomics. Cambridge (Mass.).

Blaug, M. (1967), 'Approaches to Educational Planning'. Economic Journal 76, pp. 262-287.

BLS (1984), Occupational Outlook Handbook. 1984-85 edition, US Department of Labor, Bulletin 2205, Washington D.C.

Borghans, L. (1991a), 'Occupational Choice: The Market for Primary School Teachers'. ROA-RM-1991/3E, Maastricht.

Borghans, L. (199lb), 'De arbeidsmarkt en de invloed van voorspellingen'. Economische Statistische Berichten 76, pp. 1113-1116.

Borghans, L. (1992a), 'A Histo-Topographic Map of the Dutch University Studies'. ROA-W-1992/5E, Maastricht.

Borghans, L. (1992b), 'The Productivity of the Dutch Labour Market in Matching Unemployment and Vacancies: A Comment'. De Economist 140, pp. 258-266.

Borghans, L. (1993), 'Errors in Rational Expectations Matter'. Forthcoming in Economics Letters.

Bossons, J., and F. Modigliani (1966), 'Statistical vs. Structural Explanations of Understatement and Regressivity in "Rational" Expectations'. Econometrica 34 , pp. $347-353$.

Bouman, A. (1989), 'Varkenscycli op de arbeidsmarkt'. Economische Statistische Berichten 74, pp. 816-819, 833. 
Bradford, D.F., and H.H. Kelejian (1977), 'The Value of Information for Crop Forecasting in a Market System: Some Theoretical Issues'. Review of Economic Studies 59. pp. 519-531.

Bray, M. (1982), 'Learning, Estimation, and the Stability of Rational Expectations'. Joumal of Economic Theory 26, pp. 318-339.

Buchanan, N.S. (1939), 'A Reconsideration of the Cobweb Theorem'. Joumal of Political Economy 47, pp. 67-81.

Burns, M.E. (1973), 'A Note on the Concept and Measure of Consumer's Surplus'. American Economic Review 63, pp. 335-344.

Cagan, P. (1956), 'The Monetary Dynamics of Hyperinflation'. In M. Friedman (Ed.), Studies in the Quantity Theory of Money. Cambridge (Mass.), pp. 25-117.

Campbell, R.B., and S.J. Turnovsky (1985), 'An Analysis of the Stabilizing and Welfare Effects of Intervention in Spot and Futures Markets'. Journal of

Public Economics 28, pp. 165-209.

Campbell, J.Y. (1987), 'Does Saving Anticipate Declining Labor Income? An Alternative Test of the Permanent Income Hypothesis'. Econometrica 55, pp. 1249-1273.

Campbell, J.Y., and N.G. Mankiw (1989), 'Consumption, Income, and Interest Rates: Reinterpreting the Time Series Evidence'. In: O.J. Blanchard, and S. Fisher, NBER Macroeconomic Annual 1989, Cambridge (Mass.), pp. 185-216.

CBS (1953), De voorziening in de behoefte aan onderwijzers bij het lager onderwijs in 1952. Utrecht.

Coase, R.H., and R.F. Fowler (1935), 'Bacon Production and the Pig-Cycle in Great Britain'. Economica 2, pp. 142-167.

Coase, R.H., and R.F. Fowler (1937), 'The Pig-Cycle in Great Britain: An Explanation'. Economica 4, pp. 55-82.

Cohen, R., and J.D. Barker (1935), 'The Pig Cycle: A Reply'. Economica 2, pp. 408-428.

Commissie Prognose Primair Onderwijs (1989), Vraag en aanbod in het primair onderwijs 1988-1993. Publicatie 15, Den Haag.

Connelly, R. (1989), 'Occupational Choice under Uncertainty when Experience is a Determinant of Earnings'. Econometrica 57, pp. 1215-1219.

Corlett, W.J., and D.C. Hague (1953), 'Complementarity and the Excess Burden of Taxation'. Review of Economic Studies 21, pp. 21-30.

Cumby, R.E., J. Huizinga, and M. Obstfeld (1983), 'Two-Step Two-Stage Least Squares Estimation in Models with Rational Expectations'. Joumal of Econometrics 21, pp. 333-355.

Cyert, R.M., and M.H. DeGroot (1987), Bayesian Anlysis and Uncertainty in Economic Theory. Totowa.

Davidson, P. (1991), 'Is Probability Theory Relevant for Uncertainty? A Post Keynesian Perspective'. Journal of Economic Perspectives 5, pp. 129-143.

Debreu, G. (1959), Theory of Value. New Haven.

De Grip, A. (1988), Onderwijs en arbeidsmark: scholingsdiscrepanties. 
Dissertation, Amsterdam.

De Grip, A., J.A.M. Heijke, and R.J.P. Dekker (1989), The Labour Market by

Education and Occupation in 1992. ROA-R-1989/8E, Maastricht.

Devletoglou, E.A. (1961) , 'Correct Public Prediction and the Stability of Equilibrium'. Journal of Political Economy 69, pp. 142-161.

Dewulf, G. (1992), Limits to Forecasting: Towards a Theory of Forecast Errors. Amsterdam.

Dobbs, I.M. (1991), 'A Bayesian Approach to Decision-Making under Ambiguity". Econometrica 58, pp. 417-440.

Ellsberg, D. (1961), 'Risk, Ambiguity, and the Savage Axioms'. Quarterly Joumal of Economics 75, pp. 643-669.

Enthoven, A.C., and K.J. Arrow (1956), 'A Theorem on Expectations and the Stability of Equilibrium'. Econometrica 24, pp. 288-293.

Ezekiel, M. (1928), 'Statistical Analysis and the "Laws" of Price'. Quarterly Journal of Economics 42, pp. 199-227.

Ezekiel, M. (1938), 'The Cobweb Theorem'. Quarterly Journal of Economics 52, pp. 255-280.

Fisher, G.R., and M. McAleer (1981), 'Alternative Procedures and Associated Tests of Significance for Non-Nested Hypotheses'. Journal of Econometrics 16 , pp. 103-119.

Fiorito, J., and R.C. Dauffenbach (1982), 'Market and Nonmarket Influences on Curriculem Choice by College Students'. Industrial and Labor Relations Review 36, pp. 88-101.

Freebairn, J.W. (1976), 'The Value and Distribution of the Benefits of Commodity Price Outlook Information'. Economic Record 52, pp. 199-212.

Freebairn, J.W., and G.A. Withers (1979), 'Welfare Effects of Salary Forecasts Error in Professional Labour Markets'. Review of Economics and Statistics 61, pp. 234-241.

Freeman, R.B. (1971), The Market for College-Trained Manpower; A Study in the Economics of Career Choice. Cambridge (Mass.).

Freeman, R.B. (1975a), "Legal "Cobwebs": A Recursive Model of the Market for New Lawyers'. Review of Economics and Statistics 57, pp. 171-179.

Freeman, R.B. (1975b), 'Supply and Salary Adjustements to the Changing Science Manpower Market: Physics, 1948-1973'. American Economic Review 65, pp. 27-39.

Freeman, R.B. (1980), 'Employment Opportunities in the Doctorate Manpower Market'. Industrial and Labor Relations Review 33, pp. 185-197.

Freeman, R.B. (1986), 'Demand for Education'. In O. Ashenfelter, and R. Layard (Ed.), 1986, Handbook of Labor Economics, Volume I, Amsterdam, pp. 357-386.

Freeman, R.B. (1987), 'Supply Elasticities for Educated Labor'. In Psacharopoulos (1987), pp. 244-248.

Freeman, R.B. (1989), Labour Markets in Action; Essays in Empirical Economics. New York.

Frisch, R. (1934), Statistical Confluence Analysis by Means of Complete 
Regression Systems: Oslo.

Fuhrer, J.C. (1987), 'Information Gathering and Expectation Formation under Model Uncertainty'. Southern Economic Joumal, pp. 685-701.

Grunberg, E., and F. Modigliani (1954), 'The Predictability of Social Events'. Joumal of Political Economy 62, pp. 465-478.

Gunning, J.W., and M.A. Keyzer (1993), 'Applied General Equilibrium Models for Policy Analysis'. SOW-VU RM-93-05, Amsterdam.

Haanstra, F, J.K. Koppen, and J.D. Costwoud Wijdenes (1987), De samenhang onderwijs-beroepspraktijk in de sector van de beeldende kunsten. Beleidsgerichte Studies Hoger Onderwijs en Wetenschappelijk onderzoek, $\mathrm{SCO}_{n}$ A msterdam.

Haas, G.C., and M. Ezekiel (1926), Factors Affecting the Price of Hogs. United States Department of Agriculture, Department Bulletin 1440, Washington D.C.

Haavelmo, T. (1944), 'The Probability Approach in Econometrics'. Econometrica 12, Supplement.

Haavelmo, T. (1958), "The Role of the Econometrician in the Advancement of Economic Theory'. Econometrica 26, pp. 351-357.

Hanau, A. (1927), Die Prognose der Schweinepreise. Vierteljahrshefte zur Konjunkturforschung, Sonderheft 2, Berlin.

Hanau, A. (1929), Bestimmungsgründe der Preise für Schlachtrinder. Vierteljahrshefte zur Konjunkturforschung, Sonderheft 13, Berlin.

Hanau, A. (1930), Die Prognose der Schweinepreise. Vierteljahrshefte zur Konjunkturforschung, Sonderheft 18, Berlin.

Hansen, W.L., H.B. Newburger, F.J. Schroeder, D.C. Stapleton, and D.J. YoungDay (1980), 'Forecasting the Market for New Ph.D. Economists'. American Economic Review 70, pp. 49-63.

Harberger, A.C. (1971), 'Three Basic Postulates for Applied Welfare Economics: An Interpretive Essay'. Journal of Economic Literature 9, pp. 785-797.

Hart, A.G. (1937a), 'Failure and Fulfillment of Expectations in Business Fluctuations'. Review of Economics and Statistics 19, pp. 69-78.

Hart, A.G. (1937b), 'Anticipations, Business Planning. and the Cycle'. Quarterly Joumal of Economics 51, pp. 273-297.

Hayami, Y., and W. Peterson (1972), 'Social Retums to Public Information Cervices: Statistical Reporting of U.S. Farm Commodities'. American Econamic Review 52. pp 119-130.

Hayek, F, A. (1937). 'Economics and Knowledge'. Economica NS IV, pp. 33-54.

Hayek, F.A. (1945), 'The Use of Knowledge in Society'. American Economic Review 35, pp. 519-530.

Hayek, F.A. (1990), 'Economic Freedom and Representative Government'. In Littlechild (1990a), pp. 439-454.

Heijke, J.A.M. (1986), The Research Centre for Education and Labour Market. ROA-R-1986/1E, Maastricht.

Heijke, J.A.M., and A. de Grip (1991), 'The Information System on Education and the Labour Market Developed by ROA'. ROA-W-1991/2E, Maastricht. 
Hellwig, M. (1989), 'Asymmetric Information, Financial Markets, and Financial Institutions. Where Are We Currently Going?'. European Economic Review 33 , pp. $277-285$.

Hicks, J.R. (1935), 'Gleichgewicht und Konjunktur'. Zeitschrift für Nationalokonomie IV, pp. 441-455.

Hinchliffe, K. (1987), 'Forecasting Manpower Requirements'. In Psacharopoulos (1987), pp. 315-323.

Huijsman, R., T. Kloek, D.A. Kodde, and J.M.M. Ritzen (1986), 'An Empirical Analysis of College Enrollment in the Netherlands". De Economist 134, pp. 181-190.

Huffman, W.E., and P. Orazem (1985), 'An Econometric Model of the Market for New Ph.D.s in Agricultural Economics in the United States'. American Journal of Agricultural Economics 67, pp. 1207-1214.

Hughes, G. (1991), Manpower Forecasting. A Review of Methods \& Practice in Some OECD Countries. The Economic and Social Research Institute, Dublin.

IAB (1990), 'Arbeitslandschaft bis 2010'. Mitteillungen aus der Arbeitsmarks und Berufsforschung (MittAB) 111990.

Jackman, R., R. Layard, and C. Pissarides (1989), 'On Vacancies'. Oxford Bulletin of Economics and Statistics 51, pp. 377-394.

Kaldor, N. (1934), 'A Classificatory Note on the Determinateness of Equilibrium'. Review of Economic Studies 1, pp. 122-136.

Katona, G. (1958), 'Business Expectations in the Framework of Psychological Economics (Towards a Theory of Expectations)'. In: Bowman, M.J. (Ed.), Expectations, Uncertainty, and Business Behaviour, New York.

Keuzenkamp, H.A. (1989), 'The Prehistory of Rational Expectations'. Center Discussion Paper no. 8931, Tilburg.

Keynes, J.M. (1937), 'The General Theory of Employment'. Quarterly Joumal of Economics 51, pp. 209-223.

Kirzner, I.M. (1978), 'Economics and Error'. In J.M. Spadaro (Ed.), 1978, New Directions in Austrian Economics. San Fransisco, pp. 57-76.

Klaassen, L.H., and J.A.M. Heijke (1977), 'A Social Labour Market Indicator'. Papers of the Regional Science Association 38, pp. 113-121.

Klamer, A. (1984), The New Classical Macroeconomics; Conversations with the New Classical Economists and their Opponents. Brighton.

Klein, L.R. (1954), 'Applications of Survey Methods and Data to the Analysis of Economic Fluctuations'. In Klein, L.R. (Ed.), Contributions of Survey Methods to Economic Fluctuations, New York.

Knight, F. (1921), Risk, Uncertainty, and Profit. New York.

Kodde, D.A. (1985), Microeconomic Analysis of Demand for Education. Dissertation Rotterdam.

Kramer, C., and M.L. Schreurs (1988), Beroepsperspectief van gezondheidswetenschappers. Rijksuniversiteit Limburg, Maastricht.

Lange, O. (1935), 'Formen der Angebotsanpassung und wirtschaftliches Gleichgewicht'. Zeitschrift für Nationalokonomie 4, pp. 358-365. 
Layard, R., S. Nickell, and R. Jackman (1991), Unemployment; Macroeconomic Performance and the Labour Market. Oxford.

Leffler, K.B., and C.M. Lindsay (1981), 'Markets for Medical Care and Medical Education: An Integrated Long-Run Structural Approach'. Joumal of Human Resourses 16 , pp. 20-40.

Leontief, W.W. (1934), "Verzögerte Angebotsanpassung und partielles Gleichgewicht'. Zeitschrift für Nationalokonomie 5, pp. 670-676.

Little, I.M.D. (1951), 'Direct versus Indirect Taxes'. Economic Joumal 61, pp. 577-584.

Littlechild, S.C. (Ed.) (1990a), Austrian Economics III. Aldershot.

Littlechild, S.C. (1990b), 'Equilibrium and the Market Process'. In Littlechild (1990a), pp. 50-65.

Lorr, M. (1983), Cluster Analysis for Social Scientists. San Fransisco.

Lovell, M.C. (1986), 'Test of Rational Expectations Hypothesis'. American Economic Review 76, pp. 110-124.

Lucas Jr., R.E. (1976), 'Econometric Policy Evaluation: A Critique'. CarnegieRochester Conference Series on Public Policy 1, pp. 19-46.

Lucas Jr., R.E. (1981), Studies in Business-Cycle Theory. Cambridge (Mass.).

Machina, M.J. (1987), 'Choice Under Uncertainty: Problems Solved and Unsolved'. Economic Perspectives 1, pp. 121-154.

Mankiw, N.G., and S.P. Zeldes (1990), 'The Consumption of Stockholders and Non-Stockholders'. NBER Working Paper No. 3402.

Margaritis, D. (1990), 'A Time-Varying Model of Rational Learning'. Economics Letters 33, pp. 309-314.

Massel, B.F. (1969), 'Price Stabilization and Welfare'. Quarterly Journal of Economics 83, pp. 284-298.

Matilla, J.P. (1982), 'Determinants of Male School Enrollments: A Time-Series Analysis'. Review of Economics and Statistics 64, pp. 242-251.

Maurice, G. (1991), 'Werkgelegenheid voor fysici'. Nederlands Tijdschrifi voor Nanurkunde 57, p. 15, 19.

McCallum, B.T. (1976), 'Rational Expectations and the Estimation of Econometric Models: An Alternative Procedure'. International Economic Review 17, pp. 484-490.

Metzler, L.A. (1945), 'The Nature and Stability of Inventory Cycles'. Review of Economic Statistics 23, pp. 113-129.

Ministerie van Onderwijs en Wetenschappen (1989), Richness of the Uncompleted; Challenges Facing the Dutch Education. Den Haag.

Modigliani, F., and O.W. Sauerlender (1955), 'Economic Expectations and Plans of Firms in Relation to Short-Term Forecasting'. In Short-Term Economic Forecasting, NBER Studies in Income and Wealth, no. 17, Princeton.

Moore, H.L. (1929), Synthetic Economics. New York.

Morgan, M.S. (1987), 'Statistics without Probability and Haavelmo's Revolution in Econometrics'. In: L. Krüger, G. Gigerenzer, and M.S. Morgan (Ed.), The Probabilistic Revolution: Volume 2, Ideas in the Sciences. Cambridge (Mass.), pp. 171-197. 
Morgan, M.S. (1990), The History of Econometric Ideas. Cambridge.

Morgenstern, O. (1935), 'Vollkommene Voraussicht und wirtschaftliches Gleichgewicht'. Zeitschrift für Nationalokonomie 6, pp. 337-357.

MTS-Roermond (1986), Samenvatting uitwerking van gehouden enquête. MTSRoermond, Roermond.

Muth, J.F. (1960), 'Optimal Properties of Exponentially Weighted Forecasts'. Journal of the American Statistical Association 55, pp. 299-306.

Muth, J.F, (1961), 'Rational Expectations and the Theory of Price Movements'. Econometrica 29, pp. 315-335.

Nerlove, M., and S. Wage (1964), 'On the Optimality of Adaptive Forecasting'. Management Science 10, pp. 207-224.

Newbery, D.M.G., and J.E. Stiglitz (1981), The Theory of Commodiry Price Stabilization. Oxford.

NILI-MPW (1989), De Wageningse Ir. in functie. Algemeen eindrappon loopbaanenquête 1989. NILI-MPW Onderzoek, Wageningen.

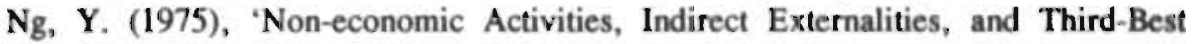
Policies". Kyklos 29, pp. 507-525.

$\mathrm{Ng}$, Y. (1983), Welfare Economics. Houndmills.

OECD (1983), Educational Planning; A Reappraisal. Paris.

Oi, W.Y. (1961), 'The Desirability of Price Instability under Perfect Competition'. Econometrica 29 , pp. 58-64.

Oostwoud Wijdenes, J.D. (1990), Arbeidsmarkt en curriculum letteren. SCOrapport 217, Amsterdam.

Padoa Schioppa, F. (Ed.) (1991a), Mismatch and Labour Mobility. Cambridge.

Padoa Schioppa, F. (1991b), 'A Cross-Country Comparison of Sectoral Mismatch in the 1980s'. In Padoa Schioppa (1991a), pp. 1-43.

Pater, L. (1987), Weg van school \& aan de studie. Marketing en mediabeleid and Perscombinatie, Amersfoort.

Paulsen, M.B., and T.F. Pogue (1988), 'Higher Education Enrollment: The Interaction of Labor Market Conditions, Curriculem, and Selectivity'. Economics of Education Review 7, pp. 275-290.

Pfouts, R.W. (1953), 'A Critique of Some Recent Contributions to the Theory of Consumers' Surplus'. Southern Economic Joumal 19, pp. 315-333.

Pikkemaat, G.F.W.M. (1969), Informatie, communicatie en economische organisatie. Dissertation Groningen.

Psacharopoulos, G. (1973), 'A Note on the Demand for Enrollment in Higher Education'. De Economist 121, pp. 521-525.

Psacharopoulos, G. (Ed.) (1987), Economics of Education Research and Studies. Oxford.

Ricci, U. (1930), 'Die "synthetische Ökonomie" von Henry Ludwell Moore'. Zeitschrift für Nationalokonomie 1, pp. 649-668.

Robbins, L. (1935), An Essay on the Nature and Significance of Economic Science. London.

Roos, E.J.J. (1989), Hollen of stilstaan. OSA-voorstudie nr. V 29, Den Haag.

Röpke, W. (1949), Die Lehre von der Wirtschaft. Erlenbach-Zürich. 
Rosen, S. (1987), 'Job Information and Education'. In Psacharopoulos (1987), pp. 179-182.

Runde, J. (1990), 'Keynesian Uncertainty and the Weight of Arguments'. Economics and Philosophy 6, pp. 275-292.

Samuelson, P.A. (1947), 'Foundations of Economic Analysis'. Cambridge (Mass.).

Samuelson, P.A. (1972), "The Consumer Does Benefit from Feasible Price Stability'. Quanerly Joumal of Economics 86, pp. 476-503.

Samuelson, P.A. (1990), 'Trimming Consumers' Surplus Down to Size'. In: J.D.

Hey and D. Winch (Ed.), A Century of Economics. Oxford, pp. 261-297.

Sargent, T.J., and N. Wallace (1976), 'Rational Expectations and the Theory of

Economic Policy'. Journal of Monetary Economics 2, pp. 169-183.

Sarle, C. (1925), 'Forecasting the Price of Hogs'. The American Economic Review 15, Suppl. 2.

Savage, L.J. (1954), The Foundations of Statistics. New York.

Schmitt, N., and R.L. Levine (1977), 'Statistical and Subjective Weights: Some Problems and Proposals'. Organizational Behavior and Human Performance 20, pp. $15-30$.

Schultz, H. (1930), Der Sinn der statistischen Nachfragekurven. Veröffentlichungen der Frankfurter Gesellschaft fur Konjunkturforschung, Heft 10, Bonn.

Scolt, C.E. (1979), 'The Market for Ph.D. Economists: The Academic Sector'. American Economic Review 69, pp. 137-142.

Selten, R. (1975), 'Reexamination of the Perfectness Concept for Equilibrium Points in Extensive Games'. International Journal of Game Theory 4, pp. 25-55.

SER (1986), Advies planning voortgezet onderwijs. Publication nr. 7, Den Haag.

Shackle, G.L.S. (1949), 'Probability and Uncertainty'. Metronomica 1, pp. 161-173.

Singh, H. (1988), 'Investigating the Compatibility of econometric Forecasts and Subjective Expectations: A Suggested Framework'. Joumal of Economic Psychology 9, pp. 233-249.

Siow, A. (1984), 'Occupational Choice under Uncertainty'. Econometrica 52, pp. 631-645.

Slutzky, E. (1937), 'The Summation of Random Causes as the Source of Cyclic Processes'. Econometrica 5, pp. 105-146.

Smith, B.B. (1925), 'Forecasting the Acreage of Cotton'. Joumal of the American Statistical Association 20, pp. 31-47.

SMO (1988), 'Technologische revolutie leidt tot ernstige knelpunten'. SMOberichten juni 1988, pp. 10, 15.

Smyth, D.J. (1973), 'Effect of Public Price Forecast on Market Price Variation: A Stochastic Cobweb Example'. American Joumal of Agricultural Economics 56, pp. 706-716.

Soumelis, C. (1983), 'An Overview'. In OECD (1983), pp. 12-51.

Spear, S.E. (1989), 'Learning Rational Expectations under Computability Constraints'. Econometrica 57, pp. 889-910.

Stapleton, D.C. (1989), 'Cohort Size and the Acadernic Labor Market'. The 
Journal of Human Resourses 24, pp. 221-252.

Stijnen, F.H.H.C., and M.H. Wieling (1988), Arbeidsmarktverwachtuing en arbeidsmarktpositie van LTS-ers. Rijksuniversiteit Limburg, ROA, Maastricht.

Theil, H., (1958), Economic Forecasts and Policy. Amsterdam.

Tijdelijke Adviescommissie Onderwijs en Arbeidsmarkt (1990), Ondenwijsarbeidsmarkt: naar een werkzaam traject. Alpen aan den Rijn.

Tinbergen, J. (1930), 'Bestimmung und Deutung von Angebotskurven: Ein Beispiel'. Zeitschrift für Nationalokonomie 1, pp. 669-679.

Tinbergen, J. (1931), 'Ein Problem der Dyamik'. Zeitschrift fïr Nationalokonomie III, pp. 169-184.

Tinbergen, J. (1933), 'The Notions of Horizons and Expectancy in Dynamic Economics'. Econometrica 2, pp. 247-264.

Tinbergen, J. (1939), Les Cycles Economiques aux Etats-Unis d'Amérique de 1919 à 1932. Geneva, League of Nations.

Tinbergen, J. (1952), On the Theory of Economic Policy. Amsterdam.

Tinbergen, J. (1956), Economic Policy. Amsterdam.

Tinbergen, J. (1974), 'Substitution of Graduates by other Labour', Kyklos 27, pp. 217-226.

Tinbergen, J., and G. Psacharopoulos (1983), 'Longe-Range Educational Policy Planning Perspectives in OECD Countries: A Review of Issues and Policy Proposals'. In OECD (1983), pp. 250-333.

Turnovsky, S.J. (1974), 'Price Expectations and the Welfare Gains from Price Stabilization'. American Joumal of Agricultural Economics 56, pp. 706-716. Turnovsky, S.J. (1978), 'Stabilization Rules and the Benefits from Price Stabilization'. Journal of Public Economics 12, pp. 87-95.

Turnovsky, S.J. (1979), 'Future Markets, Private Storage, and Price Stabilization'. Joumal of Public Economics 12, pp. 301-327.

Van Eijs, P. (1993), 'The Manpower Requirements Approach: Background and Methodology'. ROA-RM-1993/3E, Maastricht.

Van Ours J.C. (1991), 'The Efficiency of the Dutch Labour Market in Matching Unemployment and Vacancies'. De Economist 139, pp. 358-378.

Vercelli, A. (1991), Methodelogical Foundations of Macroeconomics: Keynes \& Lucas. Cambridge.

Wallace, H.A. (1920), Agricultural Prices. Des Moines, Iowa.

Waugh, F.V., (1944), 'Does the Consumer Benefit from Price Instability?' Quarterly Journal of Economics 63, pp. 602-614.

Weerdenburg, L.J.M. (1985), Studiekeuze en studievoorlichting; Een onderzoek onder 5e klas VWO-leerlingen in Oost-Nederland. Faculteit Bestuurskunde, Universiteit Twente.

Weerdenburg, L.J.M. (1987), 'Studiestakers en studievoorlichting'. Tijdschrifi voor Hoger Onderwijs 5, pp. 133-145.

Weller, P., and M. Yano (1987), 'Forward Exchange, Futures Trading, and Spot Price Variability: A General Equilibrium Approach’. Econometrica, 55. pp. 1433-1450. 
Wenthworth, E.N., T.U. Ellinger (1924), 'The Determination of Hog Prices at Public Markets'. Journal of Farm Economics 6, pp. 279-282.

Whitfield, K., and R.A. Wilson (1991), 'Staying on in Full-Time Education: The: Educational Participation Rate of 16-Year-Olds'. Economica 58, pp. 391-404.

Wilbrink, B. (1989). Arbeidsmarld en curriculum economie. SCO-rapport 198, Amsterdam.

Willes, R., and S. Rosen (1979), 'Education and Self-Selection'. Joumal of Political Economy 87, pp. 517-536.

Willig, R.D. (1976), 'Consumer's Surplus without Apology'. American Economic Review 66, pp. 589-597.

Wilson, R.A., et al. (1991), Review of the Economy and Employment; Occupational Assessment. Institute for Employment Research, Warwick.

Working, H. (1925), 'The Statistical Determination of Demand Curves'. Quarterly Journal of Economics 39, pp. 503-543.

Wright, S. (1925), Corn and Hog Correlations. United States Department of Agriculture, Department Bulletin 1300, Washington D.C.

Wright, S. (1929), Review of H. Schultz: 'Statistical Laws of Demand and Supply'. Journal of the American Statistical Association 24, pp. 207-215.

Zarkin, G.A. (1983), 'Cobweb versus Rational Expectations Models'. Economics Letters 13, pp. 87-95.

Zarkin, G.A. (1985), 'Occupational Choice: An Application to the Market for Public School Teachers'. Quarterly Journal of Economics 100, pp. 409-446. 
Wenthworth, E.N., T.U. Ellinger (1924), 'The Determination of Hog Prices at Public Markets'. Journal of Farm Economics 6, pp. 279-282.

Whitfield, K., and R.A. Wilson (1991), 'Staying on in Full-Time Education: The Educational Participation Rate of 16-Year-Olds'. Economica 58, pp. 391-404.

Wilbrink, B. (1989), Arbeidsmarka en curriculum economie. SCO-rapport 198, Amsterdam.

Willes, R., and S. Rosen (1979), 'Education and Self-Selection'. Journal of Political Economy 87, pp. 517-536.

Willig, R.D. (1976), 'Consumer's Surplus without Apology'. American Economic Review 66, pp. 589-597.

Wilson, R.A., et al. (1991), Review of the Economy and Employment; Occupational Assessment. Institute for Employment Research, Warwick.

Working, H. (1925), 'The Statistical Determination of Demand Curves'. Quarterly Journal of Economics 39, pp. 503-543.

Wright, S. (1925), Corn and Hog Correlations. United States Department of Agriculture, Department Bulletin 1300, Washington D.C.

Wright, S. (1929), Review of H. Schultz: 'Statistical Laws of Demand and Supply'. Journal of the American Statistical Association 24, pp. 207-215.

Zarkin, G.A. (1983), 'Cobweb versus Rational Expectations Models'. Economics Letters 13, pp. 87-95.

Zarkin, G.A. (1985), 'Occupational Choice: An Application to the Market for Public School Teachers'. Quarterly Journal of Economics 100, pp. 409-446. 
Allais, M. 193, xi

Antonovitz, F. 4, 196, 206, 219 xi

Arrow, K.J. 68, 80, xiii

Barker, J.D. 66 , xii

Becker, H.A. 225, xi

Benassy, J.-P. 80, xi

Bentolila, S. 19, xi

Berger, L.A. 86, xi

Blanchard, O.J. 19, 38, 39, xi, xii

Blaug, M. 1, xi

BLS 2, xi

Borghans, L. $36,37,39,166,177$, xi

Bossons, J. 72, 143, xi

Bouman, A. 74, xi

Bradford, D.F. 219, xii

Bray, M. 84, xii

Buchanan, N.C. 66 , xii

Burns, M.E. 193, xii

Cagan, 68, xii

Campbell, R.B. 128, 141, 196, xii

CBS 100,166 , xii

Coase, R.H. 66 , xii

Cohen, R. xii, 66

Commissie Prognose Primair

Onderwijs 161 , xii

Connelly, R. 4, xii

Corlett, W.J. 190, xii

Cumby, R.E. 105, xii

Cyert, R.M. 84, xii

Dauffenbach, R.C. 34, xiii

Davidson, P. 87, xii

Debreu, G. 80 , xii

De Grip, A. 2, 5, 74, 162, xii, xiii, xiv

DeGroot, M.H. 84, xii

Dekker, R.J.P. 2, 162, xiii

Devletoglou, E.A. 196, xiii

Dewulf, G. 225, xi

Diamond, P. 38, 39, xi

Dobbs, I.M. 84, xiii

Dolado, J.J. 19, xi

Dolpin, A.M. 34

Ellinger, T.U. 58, xx

Ellsberg, D. 87, xiii

Enthoven, A.C. 68, xiii

Ezekiel, M. 58, 61, 69, xiii, xiv
Fiorito, J. 34, xii

Fisher, S. 19, xi, xii

Fisher, G.R. 105, xiii

Fowler, R.F. 66, 78, xii

Freebairn, J.W. 4, 196, 202, 206, $208,211,212,219$, xiii

Freeman, R.B. 3, 4, 31, 34, 35, 73, $74,102,211,212$, xiii

Frisch, R. 70, xiii

Fuhrer, J.C. 87, xiv

Grunberg, E. 195, xiv

Gunning, J.W. 191, xiv

Haanstra, F. 33, xiv

Haavelmo, T. 7, 46, 47, 63, 66 , $69-71,75,118$, xiv, xvi

Hague, P.C. 190 , xii

Hanau, A. 58, 59, 74, xiv

Hansen, W.L. 34, 35, 217, xiv

Harberger, A.C. 192, xiv

Hart, A.G. 62, 155, xiv

Hayami, Y. 219, xiv

Hayek, F.A. 3, 18, 48, 49, 249, xiv

Heijke, J.A.M. 2, 5, 16, 162, xiii, xiv, $x v$

Hellwig, M. 19, xv

Hicks, J.R. 61, xv

Hinchliffe, K. 1, xv

Hughes, G. 1, xv

Huijsman, R. 34, xv

Huizinga, J. 105, xii

Hurwicz, L. 68, xi

Huffman, W.E. 35, 217, xv

IAB 3, xV

Jackman, R. 16, 38, 39, xv, xvi

Kaldor, N. 57, 60, 65, 68, xv

Katona, G. 66, xv

Kelejian, H.H. 219, xii

Keuzenkamp, H.A. 63, xv

Keynes, J.M. 83, 85, 87, 119, xiv

Keyzer, M.A. 191, xiv

Kirzner, I.M. 48, xv

Klaassen, L.H. 16, xv

Klamer, A. 18, xv

Klein, L.R. $66, \mathrm{xv}$

Kloek, T. xv

Knight, F. 85, 87, 119, xv

Kodde, D.A. 34, 35, 221, xv 
Koppen, J.K. 33, xiv

Kramer, C. 33, xv

Lange, $\mathrm{O}, 51,61,65, \mathrm{xv}$

Layard, R. 16, 38, 39, xiii, xv, xvi

Leontief, W.W. 66, xvi

Levine, R.L. 81, xviii

Leffler, K.B. 34, xvi

Lindsay, C.M. 34, xvi

Little, I.M.D. 190, xvi

Littlechild, S.C. 49, xiv, xvi

Lorr, M. 36, xvi

Lovell, M.C. 72, 149, xvi

Lucas, R.E. Jr. 18, 46-49, 5!, $117-123,125,128,130,135$, 247,248 , xvi, xix

Machina, M.J. 193, xvi

Mankiw, N.G. 126, 128, xii, xvi

Margaritis, D. 84, xvi

Marshall, A. 59, 191

Massel, B.F. 196-201, 219, xvi

Matilla, J.P. xvi

Maurice, G. 33, xvi

McAleer, M. 105, xiii

McCallum, B.T. 104, 140, xvi

Metzler, L.A. 67, xvi

Ministerie van Onderwijs en Wetenschappen 33, xvi

Modigliani, F. 66, 72, 143, 195, xi, xiv, xvi

Moore, H.L. 59, 60, xvi, xvii

Morgan, M.S. 59, 63, 69, xvi, xvii

Morgenstern, $0.61, x v i i$

MTS-Roermond 33, xvii

Muth, J.F. 68, 71-73, 90, 94, 95, 97. $119,126,128,138,139,142$. xvii

Negishi, T. 191

Nerlove, M. 68, xi

Newbery, D.M.G. 198, xwii

Newburger, H.B. xiv

$\mathrm{Ng}, \mathrm{Y}, 189,190$, xvii

Nickell, S. 16, xvi

NILI-MPW 33, xvii

Obstfeld, M. 105, xii

OECD 1, xv, xvii, xviii, xix

Oi, W.Y. 196, 197, 200, xvii

Oostwoud Wijdenes, J.D. 33, xiv, xvii
Orazem, P. 35, 217, xv

Padoa Schioppa, F. 16, 17, xi, xvii

Pareto, V. 59, 61, 159, 189, 190, $193,255, x i$

Pater, L. 33, xvii

Paulsen, M.B. 34, xvii

Peterson, W. 219, xiv

Pfouts, R.W. 191, xvii

Pikkemaat, G.F.W.M. 3, xvii

Pissarides, C. 34, 38, 39, xv

Pogue, T.F. 34, xvii

Psacharopoulos, G. 1, 34, xiii, xv, xvii, xviii, xix

Ricci, U. 57, 60, 65, xvii

Ritzen, J.M.M. xv

Robbins, L. 69, xvii

Roe, T. 4, 196, 206, 219, xi

Roos, E.J.J. 74, xvii

Röpke, W. 49, 50, xvii

Rosen, S. 4, 34, xviii, xx

Runde, J. 87, xviii

Samuelson, P.A. $186,190,192,201$, xviii

Sargent, T.J. $90,94,95,97,126$, 129, xviii

Sarle, C. 58, xviii

Sauerlender, O.W. 66, xvi

Savage, L.J. 81, xiii, xviii

Schmitt, N. 81, xviii

Schreurs, M.C. 33, xv

Schroeder, F.J. xiv

Schultz, H. 57-59, 65, 155, 159 , xviii, $x x$

Scott, C.E. 35, xviii

Selten, R. 73, xviii

SER 2, xviii

Shackle, G.L.S. 85-87, xviii

Singh, H. 81, xviii

Siow, A. 4, 21, 74, 103, 138, 140 , 141,163 , xviii

Slutzky, E. 69 , xviii

Smith, B.B. 58, xviii

SMO 33, xviii

Sinyth, D.J. 4, 196, xviii

Soumelis, C. 1, xviii

Spear, S.E. 164, xviii

Stapleton, D.C. 34 , xiv, xviii

Stiglitz, J.E. 198, xvii 
Stijnen, F.H.H.C. 33, xix

Theil, H. 8, 67, 72, 125, 137-139, 143,149 , xix

Tijdelijke Adviescommissie Onderwijs en Arbeidsmarkt 2, xix

Tinbergen, J. 1, 34, 45-48, 51, 57, $62-65,70,72,118,119,159$, xix

Turnovsky, S.J. 4, 196, 202, 206, 219, 227, xii, xix

Van Eijs, P. 1, xix

Van Ours, J.C. 38, xix

Vercelli, A. 119, xix

Von Mises, L. 48

Wage, S. 68, xvii

Wallace, H.A. $58,90,94,95,97$. 126,129 , xviii, xix

Walras, L. 59, 159

Waugh, F.V. 196, 197, 200, 201, xix

Weerdenburg, L.J.M. 30-32, xix

Weller, P. 196, xix

Wenthworth, E.N. $x x$

Whitfield, K. 34, xx

Wieling, M.H. 33, xix

Wilbrink, B. 33, xx

Willes, R. 34, $x x$

Willig, R.D. 193, xx

Wilson, R.A. 2, 34, xx

Withers, G.A. 4, 196, 202, 206, $208,211,212,219$, xiii

Working, H. 70, xx

Wright, S. 58, 59, xx

Yano, M. 196, xix

YoungDay, D.J. xiv

Zarkin, G.A. 4, 73, 103, 110, 163, $164,167,171,180, \mathrm{xx}$

Zeldes, S.P. 126, xvi 

ability to forecast $125,156,157,185$ abstract expectation $7,8,34,68,71$, $91-95,97,117,120,123,124$, $130,132-135,151,152,155$, $156,159,187,193,206,214$, $215,228,249.252$

adjustment $16,51,58,65,74,169$. 224

agricultural economists 35

agricultural engineering 33

allocation component 192, 204, 205, $207,208,211,221,237,252$

art 33,46

Austrian school 18, 49, 52

basic model $8,22,24,25,123,197$

Bayesian statistics 84-86, 89, 95, 96

benchmark $6,16,18,19,90,129$, 191

\section{BLS 2}

building industry $40,41,99,101$, $102,106-111,113,114$

cobweb $3,4,7,8,17,57-60,62$, $64-68,72-74,99,102,103$, 106-108, 110-113, 115-117, $121-123,125,126,136,151$, $154-156,159,161-164,177$, $179,180,212,249-251,253$

collective optimality 15

compartmentalisation 29, 36-39, 42

compensation schemes 192, 193

constant prices $22,23,41,42,61$, $63,65,100,106,107,109$, $133,138,147,151,154,166$, $188-190,192,196,200,202$, 233,252

contracts 19

coordination 19

data generating process $69,75,247$, 248

democratic principle $47,50,52$

demographic component (of expansion demand) $40,166,167,170-172$, $174-177,179,180$

direct measurement of expectations $66,72,125$

disequilibrium $8,18,119,120$, $151-154,158,173$ dispersed predictions 8, 24, 219, $220,236,252,253$

dynamic inconsistency 19

econometrics $45,47,72,117-119$. $126,138,180,211$

educational planning 1

elasticity of demand $35,5 !, 212$

elasticity of supply 34, 35, 51, 109

engineers $35,211-214$

equivalence (welfare) 192

errors in forecasts $4,7,8,52,62,75$, $77,80,86,88,89,92,93,97$, $119,123,138,143-145,147$. $149,215,248,250,251$

excess volatility $127,142,146$

existence proof 186,195

expansion demand $40,166,167,179$ expectations manipulating policy 128 , $129,131,132$

external effect $18,73-75,77,104$, $117,125,133,190,195,226$, $227,230,233$

extrapolative expectations 67 feasibility $15,19,191$

food and catering industry 41, 99, $102,106-109,111,114,116$

formalisation $7,72,74,77$

Freiburg school 49, 50, 53

frictional unemployment 15,16

full information $18,63,112,189$, $196,202,215,217$

general equilibrium $60,186-189,191$ general information 31

general prediction $23,24,26,27$, $222-224,226,227,230-233$

Gini-Hirschman-index 162

health sciences 33

hermeneutics 86

Hicksian demand curve 188

IAB 3

IER 2

income distribution 19

income risk 16

indeterminateness 65,68

individual optimality 15

individual prediction $24,219,221$, 223-226, 231 
information error 117, 120, 124, $125,133,135,136$

information error 77, 88-97, 151, 191, 205-207, 209-211, 214, $215,217,222,249$

informational poverty 190

instrument (policy) 1, 7, 19, 45, 5153

instrumental variable 140-142, 180, 186

interpretation error 117, 120,

$123-125,133,136$

interpretation error 77, 88-95, 97, $151,205-208,210,211,214$, $215,217,218,249$

irreversibility 22,24

job search 39

junior general secondary education 33

junior secondary technical education $7,33,99,115,185$

languages 33,37

lawyers $35,138,211-214$

learning models 86,88

linearity $23,24,22,23,198$

Lucas critique $47,117,118,120$, $122,123,129,131$

Lucas's criterion 121, 123, 125, 129 manpower forecasting $1-5,9,251$, 253,254

market clearing 22, 166

Marshalian demand curve 188 mean square error (MSE) 9. 71, 78$80,86,89,94,121,125,130$, 144, 153, 155, 220, 224, 228

measurement errors $70,71,94$ mechanics of the economic system 18 metal industry 40, 41, 99, 101, 102 . $106,107,109,113,114$ Ministerie van Onderwijs en

Wetenschappen 33

mismatch $6-8,15-19,29,30,32,33$, $36,39,42,57,99,112-114$, $116,151,161,163,164,178-$ $180,185,193,225,249,251$ misperception 238-241 model uncertainty $87,89,195$ monetary policy 5
MTS-Roermond 33

neo-liberal 7, 49, 50, 52

neutrality 120,193

objective probabilities: $83-87$ ', 88, 96 $122,123,141$

OECD 1

optimal prediction $7,9,19,20,88$, $89,95,96,117,125,130$. $133,171,206,250$

optimising behaviour $47,52,75$, $136,253-255$

overestimation $80,106,113,137$, $154,234,238$

Pareto optimality 189, 190, 254

partial equilibrium 185-189, 197

perfect competition 187

perfect expectation $89,90,93,94$, 248

permanent income hypothesis 128, 141

personal judgements $50,52,87,88$, 125

physics 33, 35

pig-cycle 59,66

plausibility 253

policy component of expansion demand 40, 166-169, 171-175, $177-179$

pre-university education 30,33

predictability $7,117,125-128,133$, $134,136,151,159,161,163$, $168-171,175-180,214-217$, 250,251

price mechanism 15

price stabilisation 196, 201, 202, 208, 218

principal-agent 19

prior knowledge 85

probability concepts 69

probability to get a job $15,22,35$, $39-42,99,101,105-107,109$, 115,165

professional forecasters $2,19,77$, $78,115,133,136,185,250$

proposition of Muth, Sargent, and Wallace $90,94,95,127$

provision of information $8,9,19$. $45,47,52,53,211,214$, 
$216-218,193,121,128,133$,

$136,218,237,252,254$

qualitative policy 45

quantitative policy 45

random shocks $46,71,75,77,195$, 248,249

rational expectations $3,4,7,8,21$, $34,47,50,63,67,71-75,77$,

$80,83,89,90,93,94,97,99$, $103-106,108-112,115$, $117-133,135,136,138-144$, $146-149,151,159,161,163$, $164,177,196,205-207,227$, $248,250,253$

real economic model 247

reasonable expectation 63

reform 45

regret $15,17,25-27,29,30,32,33$, $39,42,112,173,192,218$, $247,249,253$

replacement demand 40,162 , $166-169,171,172,174-180$

reservation wage $22,27,28,31$, $101,189,192,203,224$

risk 193,198

risk and uncertainty 87

ROA 2, 5

savings behaviour 5

search $16,37,39$

second best 189,190

segmentation 37

senior general secondary education 30,33

senior secondary technical education 33

SER 2

short-run 17

short term supply 203, 205, 209

similarity 36,37

stabilisation effect 192, 205, 208, $211,224,251$

stability of the market $4,219,223$, $225-227,231,232,234,235$, 243

states of the world $7,77,80-83$, $85-93,96,117,119,121,122$, $133,164,215$

statistical business research 58 stochastic process $7,68,69,71,75$

structural unemployment 15,16

subjective probabilities $71,81-84$, $83,84,88,96,122,123$

surplus $3,17,161,185,186$, $191-193,196,198$

systematic error $74,97,112$, $126-128,130,131,133,134$, $136,155,158,159,171,174$, $176,177,214$

teachers $8,39-41,73,161-169$, $171-173,177,179,180$

test-statistic $105,127,145$

textbooks 45,52

third best 190

transparent 197, 202

true (or reall economic) model 7, 47, $49,89,118,126,151,206$. 247

uncertainty $4,5,7,17,32,33,35$, $62,63,73,77-79,81-87,89$, $90,93,96,104,117,120-122$. $133,161,164,195,214,215$, $217,224,248,251,254$

underestimation of change 8,72 , $125,137-139,143,144,149$

unemployment $16,35,38,51,115$, 254

unequal variation 137

union power 16

university studies 36

unsystematic error 97, 127, 133, $134,136,159,172,174,176$, 214

vacancies $16,36-40$

value of information $3,4,9,31,46$, $78,79,81-84,94,96,101$, $114,115,121,127,128,147$, $153,155,156,193,195,196$, $198,202,214,217,219,230$, $233-236,240-242$

variability $7,40-42,117,125-128$, $133,136,151,156,159,161$, $163,167-170,176-180,215$, 250,251

welfare $4,8,27,16,82,83,99$, $112,185,186,190-193$, 195-219, 221, 223-228, 
232-242, 251-255 
Vanwege het grote economische belang van onderwijs voeren overheden veelal beleid om de ansluiting van het onderwijs op de arbeidsmarkt te verbeteren. Dit gebeurt met behulp van zogenaande 'manpower forecasting' of 'educational planning'. Er worden prognoses gemaakt van de toekomstige vraag naar arbeid met een bepaald type scholing, en het toekomstig aanbod per opleidingscategorie. De discrepanties tussen vraag en aanbod geven vervolgens aan waar het beleid in dient te grijpen. De manpower-forecasting-literatuur geeft echter doorgaans niet aan hoe er ingegrepen dient te worden. In de meeste vrije-markteconomieën is het immers de student zelf die zijn opleidingskeuze bepaalt en kan de overheid deze keuze niet volledig opleggen. In de context van een vrije-markt-economie ligt het dan ook voor de hand dat de prognoses met betrekking tot de toekomstige arbeidsmarkt niet direct gebruikt worden voor overheidsmaatregelen, maar dat deze voorspellingen gebruikt worden om studenten voor te lichten over de mogelijke consequenties van hun studiekeuze. Via het keuzegedrag van studenten zouden deze arbeidsmarktprognoses dan toch een verbetering van de aansluiting tussen onderwijs en arbeidsmarkt tot stand kunnen brengen. Het doel van deze studie is deze relatie tussen het verstrekken van arbeidsmarktinformatie aan studenten en het functioneren van de arbeidsmarkt te onderzoeken.

Het proefschrift bestaat uit drie delen. In het eerste deel Mismatch wordt een kader geschetst waarop de rest van het onderzoek is gebaseerd. Verder wordt in dit deel het begrippenkader zowel vanuit de empirische als vanuit de theoretische hoek nader bekeken. In het tweede deel Information wordt een model (het 'errors in forecasts'-model) ontwikkeld, waarin de problemen die studenten hebben om in hun studiekeuze op de arbeidsmarktontwikkelingen te anticiperen, een centrale plaats innemen. Dit model wordt gerelateerd aan twee in de literatuur belangrijke theorieën over verwachtingsvorming, de varkenscyclustheorie en de theorie van de rationele verwachtingen. Het errorsin-forecasts-model maakt het mogelijk, in tegenstelling tot deze twee theorieën, de invloed van publieke voorspellingen op het keuzegedrag van studenten te verklaren. In het derde deel Welfare wordt, op basis van het errors-in-forecasts-model, onderzocht welke welvaartsconsequenties het verstrekken van publieke voorspellingen heeft op geaggregeerd niveau, voor zowel de studenten/werknemers als de werkgevers.

Uitgangspunt van het onderzoek zijn de begrippen mismatch en evenwicht. Deze worden in hoofdstuk 2 geïntroduceerd. Studenten moeten een studie kiezen op een moment waarop ze nog niet alle 
consequenties voor het tijdstip waarop ze op de arbeidsmarkt komen kunnen overzien. Dit kan ertoe leiden dat tegen die tijd de arbeidsmarkt zich zo ontwikkeld heeft dat zij spijt hebben van hun keuze. Als zij destijds de arbeidsmarktsituatie precies gekend hadden, dan hadden zij een andere keuze gemaakt. Deze niet optimale allocatie heet mismatch en de optimale situatie, waarin niemand een keuze maakt waarvan hij later spijt heeft, is het evenwicht. In hoofdstuk 3 worden deze begrippen ondergebracht in een arbeidsmarktmodel dat als uitgangspunt voor de rest van het. onderzoek dient.

In hoofdstuk 4 wordt getoond dat de hierboven geschetste mismatchproblematiek empirisch relevant is. Ten eerste blijken veel studenten moeite te hebben met hun onderwijskeuze en heeft een substantieel gedeelte van hen achteraf spijt van de studiekeuze. Ten tweede blijken studenten in hun studiekeuze zeer duidelijk geleid te worden door arbeidsmarktfactoren. Ten derde is er op de arbeidsmarkt sprake van compartimentalisering, waardoor de gemaakte onderwijskeuze relevant lijkt te zijn voor de arbeidsmarktmogelijkheden. Tenslotte zijn de arbeidsmarktomstandigheden dermate veranderlijk dat vooruitlopen op deze veranderingen van belang is.

In hoofdstuk 5 wordt ingegaan op het verstrekken van publieke informatie als beleidsinstrument in de economische literatuur. Dit beleidsinstrument blijkt geen aandacht te krijgen in de literatuur. In de neo-klassieke theorie worden de verwachtingen van agenten gemodelleerd als een mechanische reactie op andere economische grootheden. Een extreme variant hiervan betreft de rationele verwachtingen. Hier zijn deze mechanische verwachtingen optimaal, zodat publieke informatie geen rol meer kan spelen. Het verstrekken van publieke informatie lijkt het best te passen binnen het neo-liberale gedachtengoed van de Freiburger school. Hier wordt namelijk veel accent gelegd op aan de noodzaak voor de overheid om het economische proces te ondersteunen, zonder het te ontdoen van haar flexibiliteit, bijvoorbeeld door de markt transparanter te maken.

In hoofdstuk 6 wordt ingegaan op de ontwikkeling van verwachtingen in de economische theorie. Als gevolg van de formalisering van de economische theorie, met name sinds Haavelmo, worden economische ontwikkelingen gezien als een kenbaar stochastisch proces. Uitgaande van een dergelijk waar model van de economie lijkt de introductie van rationele verwachtingen onvermijdelijk. Alle andere verwachtingen hebben namelijk, gezien vanuit dit ware model, een duidelijke aanwijsbare systematische fout en het is niet aannemelijk dat agenten zullen volharden in het maken van zulke systematische fouten. 
In hoofdstuk 7 wordt een alternatief model ontwikkeld, waarin de aanname van een kenbaar stochastisch proces wordt losgelaten. Bij rationele verwachtingen wordt alle onzekerheid veroorzaakt door exogene stochastische invloeden die niet kenbaar zijn op het moment dat een voorspelling gemaakt moet worden. Naast deze toestand-van-dewereld-onzekerheid wordt in het model ook onzekerheid geïntroduceerd die het gevolg is van de beperkte voorspelcapaciteiten van studenten (de 'errors in forecasts'-onzekerheid). Het blijkt dat een combinatie van deze twee soorten onzekerheid leidt tot een optimale trade-off, waarin studenten vanwege hun beperkte voorspelcapaciteiten overstappen op een abstracter model van de werkelijkheid. Dit abstracter model kent een grotere toestand-van-de-wereld onzekerheid, zodat deze vorm van onzekerheid niet langer gezien kan worden als een gevolg van nog onkenbare exogene invloeden. De voorspelfouten die hieruit voorkomen zijn een gevolg van een optimale, maar niet noodzakelijke versimpeling van het model van de werkelijkheid dat studenten hanteren.

In hoofdstuk 8 worden zowel de varkenscyclustheorie - waarin studenten verwachten dat de arbeidsmarktomstandigheden zich niet zullen wijzigen - en de rationele-verwachtingentheorie toegepast op de specialisatiekeuze van leerlingen op de LTS. Het blijkt dat het varkenscyclusmodel betere empirische resultaten geeft dan het rationeleverwachtingenmodel. Dit duidt erop dat studenten inderdaad systematische fouten maken in hun keuzegedrag.

In hoofdstuk 9 worden de implicaties van het errors-in-forecasts-model voor de gevolgen van het verstrekken van publieke informatie verder uitgewerkt. Uitgangspunt hierbij is Lucas' criterium dat het vooronderstelde gedrag van agenten altijd verklaarbaar moet zijn vanuit het model en niet door ad hoc aannames mag worden opgelegd. Het blijkt mogelijk om varkenscyclusachtig gedrag van studenten te verklaren op grond van hun lage capaciteiten goede voorspellingen over de toekomstige ontwikkelingen te maken. Gezien deze capaciteiten ('predictability') en gezien de veranderlijkheid van de arbeidsmarkt ('variability') is het optimaal voor studenten om af te zien van een verdergaande anticipatie van de ontwikkelingen. Door het verstrekken van publieke informatie neemt in feite deze capaciteit om te voorspellen toe en zullen de keuzen van studenten beter inspelen op toekomstige veranderingen.

Theil (1958) constateerde dat voorspellingen veranderingen neigen te onderschatten. Vanuit de theorie van de rationele verwachtingen is dit fenomeen moeilijk te verklaren. In hoofdstuk 10 wordt deze 'underestimation of changes' verklaard vanuit het errors-in-forecasts- 
model dat in hoofdstuk 7 en 9 ontwikkeld werd. Het verschil tussen beide modellen wordt verduidelijkt aan de hand van data van de instroom van juristen in de: Verenigde Staten.

Het klassieke varkenscyclusmodel wordt getypeerd door de golfbeweging in instroom en lonen die het genereert. In hoofdstuk 11 wordt dit golfpatroon onderzocht vanuit het errors-in-forecasts-model en worden de determinanten van de omvang van deze golven afgeleid. Het blijkt dat bij het errors-in-forecasts-model de voortgebrachte golf niet kan divergeren.

In hoofdstuk 12 wordt de Nederlandse markt. voor leerkrachten onderzocht aan de hand van het errors-in-forecasts-model. Het blijkt dat naast de vervangingsvraag, het overheidsbeleid een belangrijke factor is voor de onzekerheid en daardoor voor de grote aansluitingsproblemen op deze markt.

In het laatste deel van het proefschrift wordt. ingegaan op de welvaartsconsequenties van het verstrekken van prognoses over de toekomstige arbeidsmarkt. In hoofdstuk 13 wordt ingegaan op de gehanteerde methode om welvaart te meten. Er wordt, in het partiëlemarktmodel, gebruik gemaakt van het werkgevers- en werknemerssurplus.

In hoofdstuk 14 wordt een vergelijking gemaakt tussen de welvaartseffecten van prijsstabilisatie en de welvaartseffecten van het geven van publieke voorspellingen. Het blijkt dat naast de welvaartsvoordelen door stabilisatie, het verstrekken van publieke voorspellingen ook een positief effect heeft op de allocatie van studenten over de beroepen. Verder blijkt de aard van de voorspelfout in sterke mate te bepalen hoe de welvaartskosten verdeeld zijn over werkgevers en werknemers. Doordat het verstrekken van publieke voorspellingen een verschuiving van de aard van de voorspelfouten teweeg kan brengen, is het in bepaalde gevallen mogelijk dat deze voorlichting voor de studenten tot een welvaartsnadeel leidt. De studenten/werknemers en de werkgevers te zamen zullen echter altijd profiteren van publieke voorspellingen.

In hoofdstuk 15 wordt ingegaan op het geval waarin studenten onderling afwijkende prognoses van de arbeidsmarktontwikkelingen hebben. Doordat de voorspellingen onderling uiteenlopen kan op geaggregeerd niveau het effect van hun voorspelfouten klein zijn. In dat geval kan een publieke voorspelling, die immers voor iedereen gelijk is, voor meer instabiliteit zorgen en daardoor op geaggregeerd niveau de mismatch vergroten. Uit de analyses blijkt echter dat er toch altijd sprake is van 
een welvaartverbetering. De verhoogde instabiliteit leidt op zich wel tot een welvaartsverlies, maar daar staat tegenover dat op individueel niveau studenten minder snel een studiekeuze zullen maken waarvan zij achteraf spijt hebben. Deze verbetering van de allocatie weegt op tegen de grotere instabiliteit. Een belangrijke voorwaarde voor dit resultaat is dat studenten op een juiste wijze de kwaliteit van de publieke voorspelling weten in te schatten.

Op grond van dit onderzoek naar de arbeidsmarkteffecten van het verstrekken van publieke voorspellingen kunnen enkele belangrijke conclusies getrokken worden voor de praktijk van 'manpower forecasting'. Ten eerste blijken dergelijke voorspelilingen een duidelijke positieve invloed op de totale welvaart te hebben. Hoewel het welvaartseffect voor studenten meestal positief zal zijn, hoeft dit niet altijd het geval te zijn. Verder is het van groot belang dat naast de voorspellingen zelf, ook een indicatie gegeven wordt van de betrouwbaarheid van deze voorspellingen. Tenslotte moet bij het evalueren van de effecten van publieke voorspellingen niet alleen gekeken worden naar de gevolgen op geaggregeerd (markt-) niveau, maar zijn ook de gevolgen op individueel niveau van belang. 



\section{CURRICULUM VITAE}

Lex Borghans werd op 8 augustus 1964 geboren te Geleen. Van 1976 tot 1982 volgde hij het atheneum aan de RK scholengemeenschap St. Michiel en vervolgens studeerde hij econometrie en wijsbegeerte aan de Katholieke Universiteit Brabant. In 1988 studeerde hij af en ging werken als assistent in opleiding bij het Researchcentrum voor Onderwijs en Arbeidsmarkt (ROA) aan de Economische Faculteit van de Rijksuniversiteit Limburg. Sinds 1 augustus 1992 is hij onderzoeker bij het ROA. 
